\title{
Seasonal Spatial Ecology of juvenile Muskellunge and Northern Pike in upper St. Lawrence River Nursery Bays: Applied Perspectives
}

By

Sarah Elizabeth Walton

BSc in Biology with Specialization in Conservation Biology, Trent University, 2012

A thesis submitted to the Faculty of Graduate and Postdoctoral Affairs in partial fulfillment of the requirements for the degree of

Master of Science

In

Biology

Carleton University, Ottawa, Ontario

(C) 2018, Sarah. E. Walton 


\section{Dedication}

First and foremost, I dedicate this thesis to my husband, who has encouraged and supported me every step of the way. You pushed me to apply, despite knowing it would mean long-distance for two years because you knew it would it benefit our relationship in the long-run. You were a consistent source of inspiration, and an ear when I needed to vent, especially when I hit moments where I felt I was not good enough to continue. You found me such a wonderful little apartment, I do not want to leave its breathtaking view of Gatineau Park and its sunsets, but I cannot wait to snuggle you each night once again. You became my husband half way through graduate school, and while we have been apart for most of our first year of marriage, it has only made us stronger. I so look forward to the next chapters of our lives and the joys a young family will bring. Thank you for your constant belief and supporting my life pursuits. I hope I can make you proud.

To my parents, who inspired me as a young child to pursue my dreams, regardless of how untraditional they were. First, it was a meteorologist, one that chased tornadoes. I will admit, the idea of studying weather is still intriguing; however, it was our inaugural Algonquin Provincial Park camping trip where a unique interaction with a black bear started me down my path to work with wild animals. Moreover, your push for me to attend a Girl Guide canoe camp solidified my need to be outdoors, and an absolute love for canoe tripping. You empowered me to pursue an adventurous life, one in which every experience, and those with whom I established close friendships along the way, made me the woman I am today. 


\begin{abstract}
Nursery habitat requirements for age-0 Esox spp. in the upper St. Lawrence River are well understood; however, little is known about the influence of environmental variables (i.e., depth, temperature, habitat) on their spatiotemporal ecology during fall and winter periods. A hatchery study evaluated biologically relevant endpoints post-implantation of a mini-acoustic transmitter in age-0 Muskellunge. Neither tag expulsion nor mortality were observed, nor influence of tag presence on short-term growth rates. Applying this tool to evaluate their ecology, I captured and tagged age-0 Muskellunge (Esox masquinongy) and Northern Pike (Esox lucius) from August to October in natal bays. Detection data, modeled against environmental covariates, found deeper littoral regions were used by both species, and complex interactions between covariates influenced spatial trends during this critical period. With similar overwintering spatial ecology between these congeneric competitors, overwintering microhabitat use studies in association with water level management may confirm habitat overlap and inform wetland restoration efforts.
\end{abstract}




\section{Acknowledgements}

Thank you to Steven Cooke and John Farrell for providing me with this incredible opportunity to conduct aquatic research in the upper St. Lawrence River and Thousand Islands Biological Station. Thank you to Elodie Ledee for her down-to-earth attitude and continuous patience, educating me on data analysis and interpretation, and Jeremy Kerr for being a wonderful mentor.

Thank you to Fish Ecology and Conservation Physiology Laboratory (FECPL) lab mates Petra Szekeres, Jessica Taylor, Tanya Prystay, Clay Steel, and Lisa Kelly, SUNY College of Environmental Science and Forestry (SUNY ESF) lab mates John Paul Leblanc, Nathan Satre, Erica Augstyn, Julie Beck, Jessica Goretzke, US Fish and Wildlife Service taff, Carleton University and University of Ottawa undergraduate volunteers, and Clayton Dive Club members for all their assistance in riverine field work. Moreover, thank you to FECPL alumni and Beneath the Waves CEO Austin Gallagher for kicking starting this project in 2015. Thank you to FECPL lab mate Amanda Jeanson and Fleming College School of Environmental and Natural Resource Sciences staff (Mark Newell) and students (Xavier Tuson, Leroy Reynolds, Ian Wick, Hailey Ropertz and Kristopher Radzichowsky) for all their assistance in planning, designing, and conducting hatchery work, and in-kind care of nearly 100 young Muskellunge for four months.

Thank you to Best Buy Geek Squad employee, Nick. A split-second of angered frustration prior to completing my analysis could have had dire consequences. Nick's amazing customer service skills allowed me to keep my cool and enabled me to complete my work.

Thank you to the US Fish and Wildlife Service for funding this research, and additional funding from Muskies Canada Incorporated. 


\section{Co-Authorship}

Chapter 2. Evaluation of acoustic transmitter implantation on tag retention, healing, growth and behaviour of juvenile muskellunge. Sarah Walton, Mark Newell, Amanda Jeanson, Elodie Lédée, John Farrell, and Steven Cooke.

While this study is my own, the research was undertaken as part of a collaborative effort and each co-author played a role in its completion. The project was conceived by Walton. Data were extrapolated by Walton and Ledee. All figure construction and analyses were conducted by Walton. Data were interpreted by Walton and Ledee. All writing was conducted by Walton. All co-authors provided comments and feedback on the manuscript. This manuscript has been prepared as a management brief submission to the North American Journal of Fisheries Management.

Chapter 3. Spatiotemporal ecology of juvenile Muskellunge (Esox masquinongy) and Northern Pike (Esox lucius) in upper St. Lawrence River nursery bays over fall and winter seasons. Sarah Walton, Elodie Lédée, John Paul Leblanc, Petra Szekeres, Jon Midwood, Austin Gallagher, John Farrell, and Steven Cooke.

While this study is my own, the research was undertaken as part of a collaborative effort and each co-author played a role in its completion. The project was conceived by Farrell and Cooke. Data were collected by Walton, Leblanc, Szekers, and Gallagher. The figures were constructed by Walton with the assistance of Lédée and Graham Raby. Data interpretation and analysis were conducted by Walton with direction from Lédée. All writing was conducted by Walton. All co-authors provided comments and feedback on the manuscript. This manuscript has been prepared for submission to Ecology of Freshwater Fish. 


\section{Table of Contents}

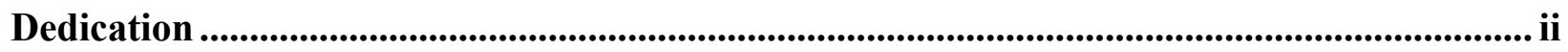

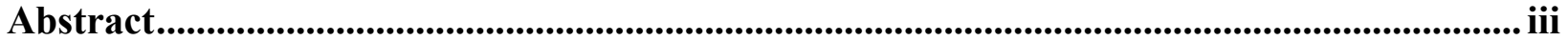

Acknowledgements ........................................................................................................................ iv

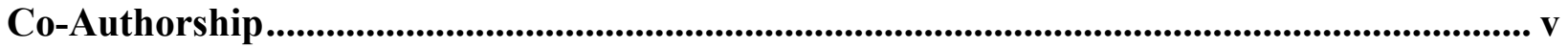

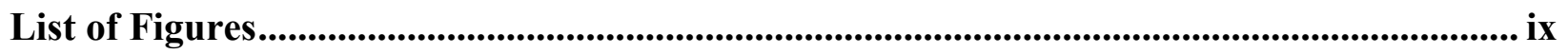

List of Tables ................................................................................................................................. xiv

CHAPTER 1: General Introduction .............................................................................. 1

1.1 Spatiotemporal Fish Ecology ........................................................................... 1

1.2 Rehabilitation Efforts for Early-Life Stages ................................................................... 2

$1.3 \quad$ Tracking Aquatic Creatures in the Field........................................................................ 2

1.4 Muskellunge and Northern Pike Ecology and Knowledge Gaps.................................... 4

1.5 Research Rationale and Objectives .............................................................................. 5

CHAPTER 2: Evaluation of acoustic transmitter implantation on tag retention, healing, growth and behaviour of juvenile muskellunge ............................................................................... 7

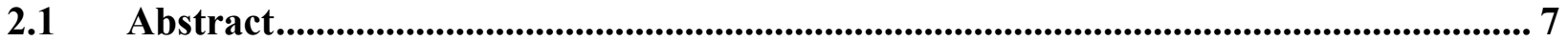

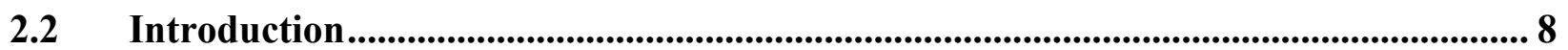

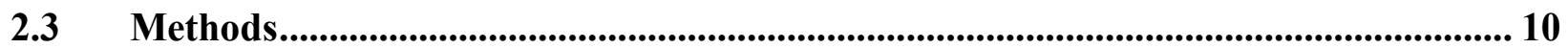

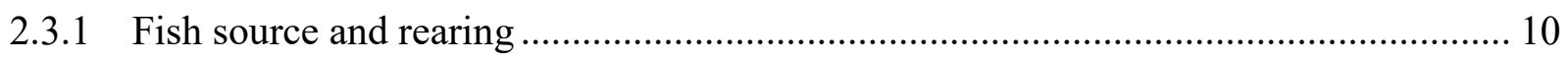

2.3.2 Environmental and physical fish measurements...................................................... 10

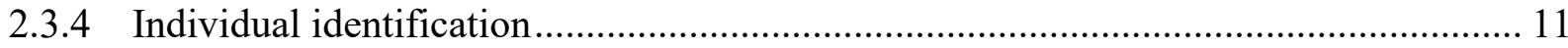

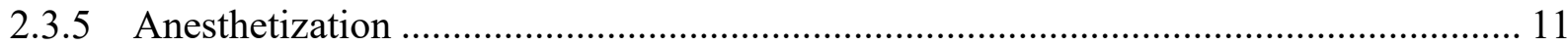

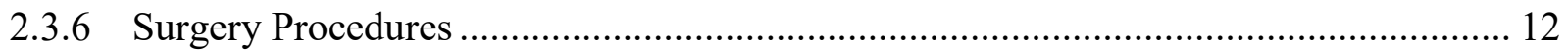

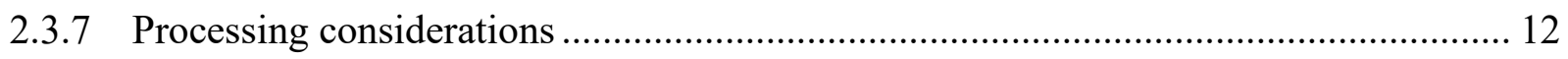

2.4 Statistical Analysis ........................................................................................................ 13

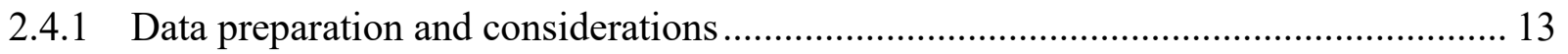

2.4.2 Survival, Internal Tag Assessment, Tag Retention, \& Tag Burden............................... 13

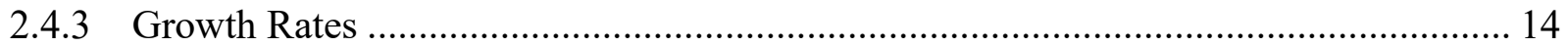

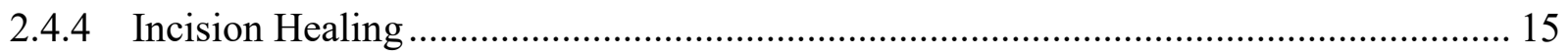

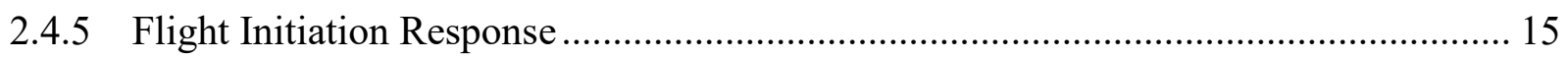

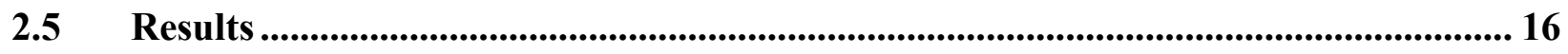

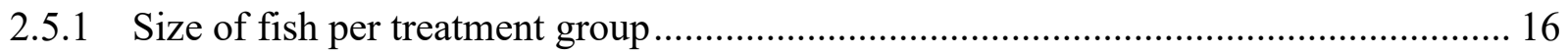

2.5.2 Surgery Procedures .............................................................................................. 17 
2.5.3 Survival, Internal Tag Assessment, Tag Retention \& Tag Burden........................... 17

2.5.4 Body Size \& Specific Growth Rates................................................................ 17

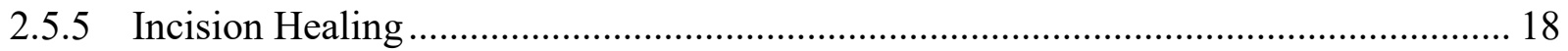

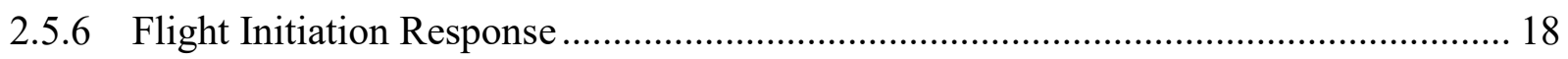

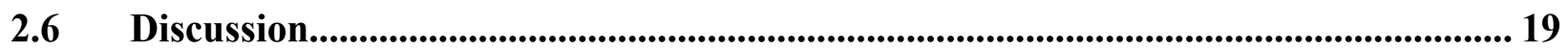

2.7 Supplementary .................................................................................................................. 32

Chapter 3 - Spatiotemporal ecology of juvenile Muskellunge (Esox masquinongy) and Northern Pike (Esox lucius) in upper St. Lawrence River nursery bays over fall and winter

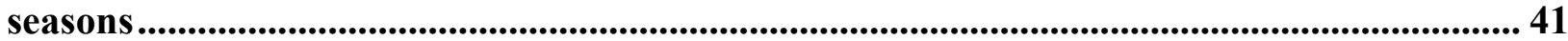

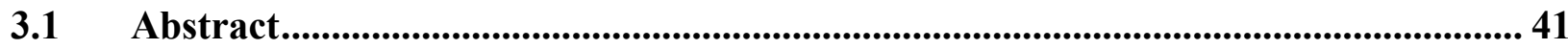

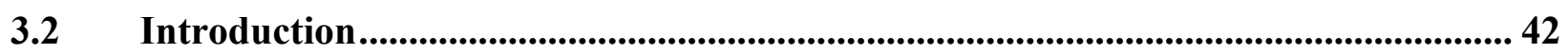

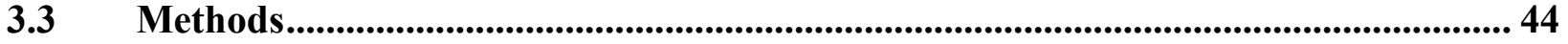

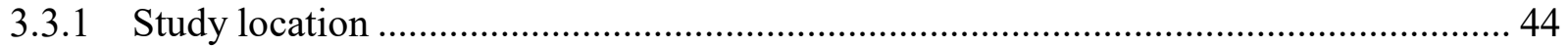

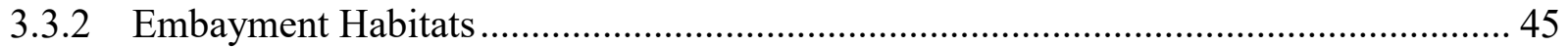

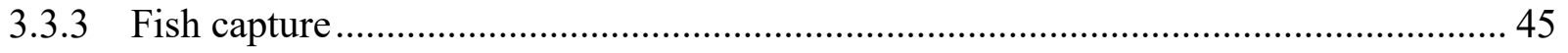

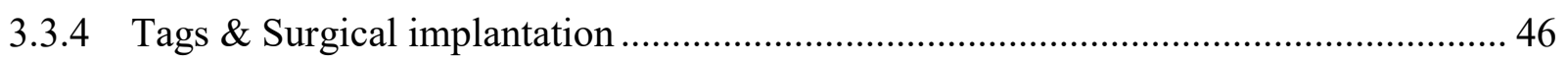

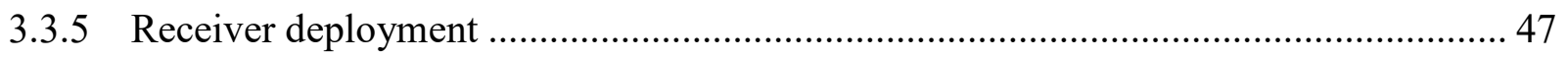

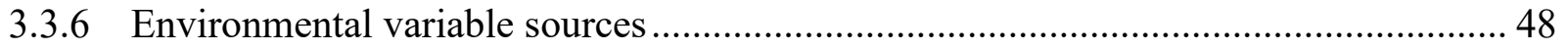

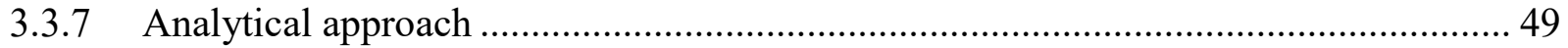

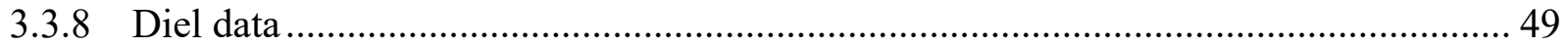

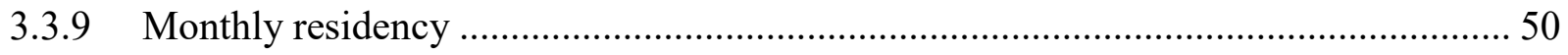

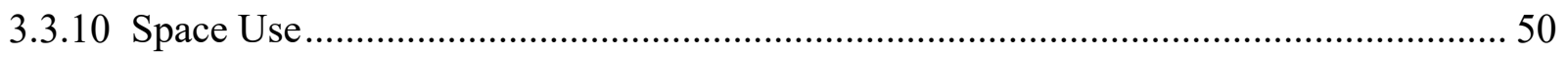

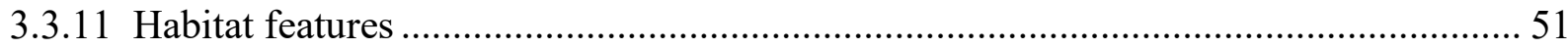

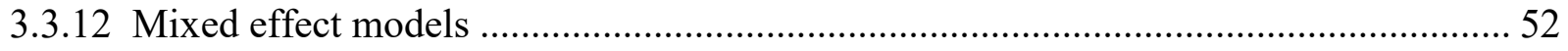

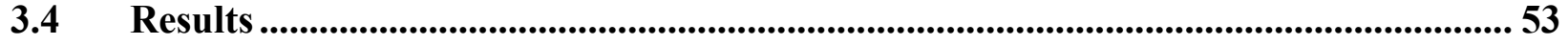

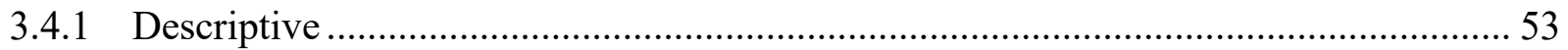

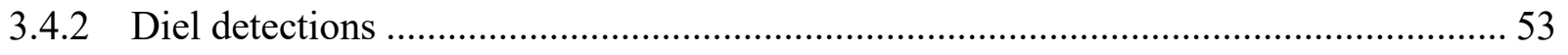

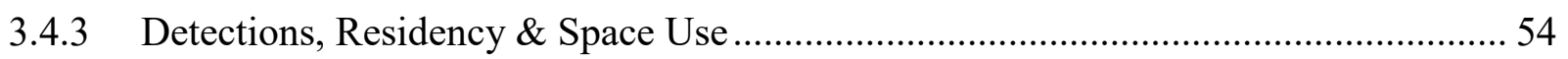

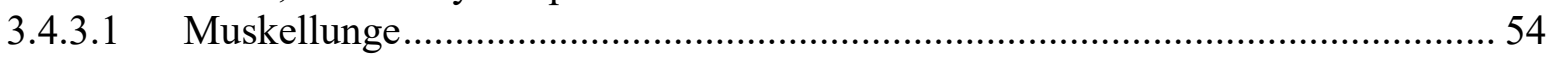

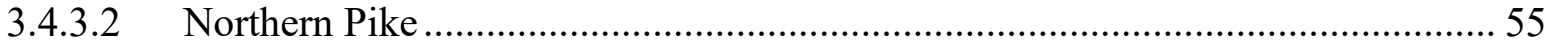

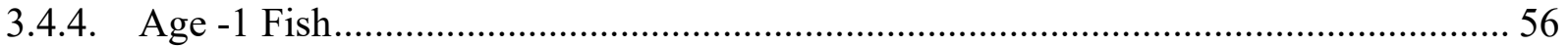

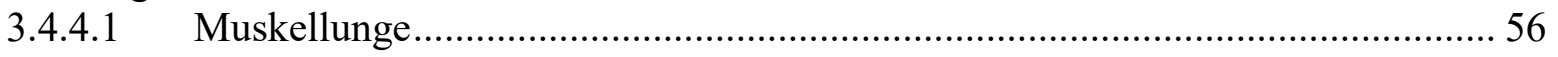

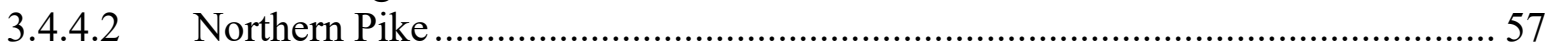

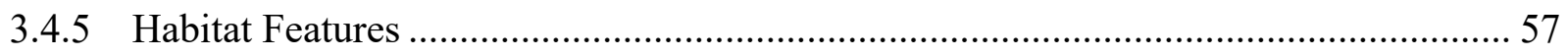

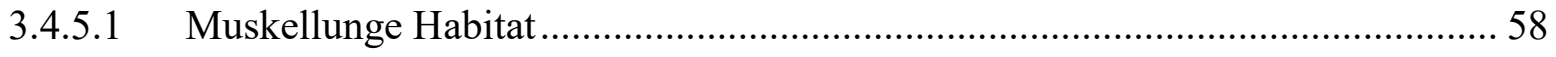


3.4.5.2 Northern Pike Habitat ....................................................................... 58

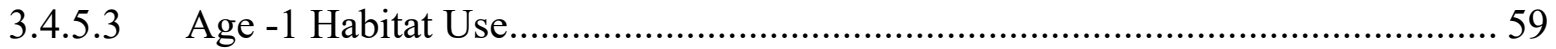

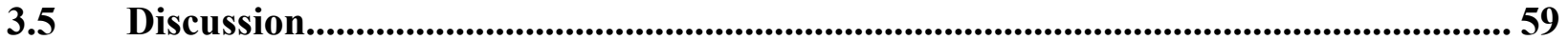

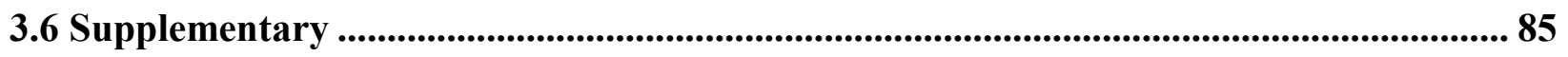

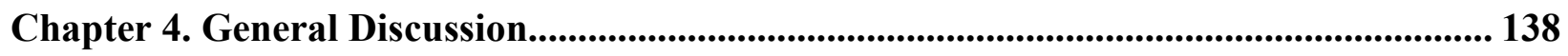

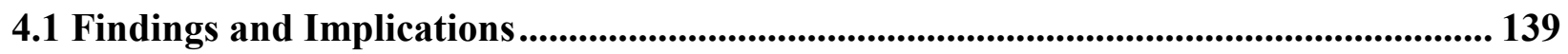

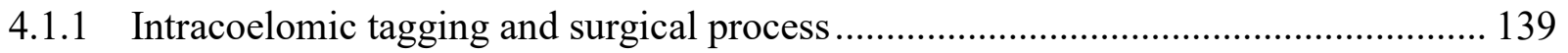

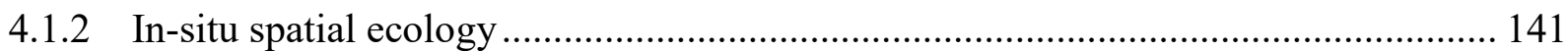

4.2: Future Research Opportunities.............................................................................. 143

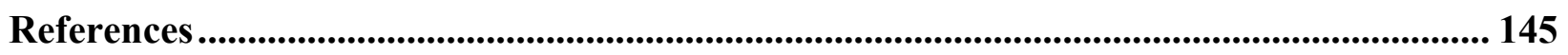




\section{List of Figures}

Figure 2.1. A diagram describing the order in which captive reared, age-0 Muskellunge were sampled and rotated through five 2.4 (1) x 1.2 (w) x 1.2 (h) m tanks at the Fleming College Muskellunge Hatchery. All fish were first sampled from Tank 2, and temporarily housed in Tank 1. Fish from Tank 3 were sampled (weighed, measured, and photographed) and moved to Tank 2. This process continued with Tank 4 fish moved to Tank 3 (post-sampling), and Tank 5 fish to Tank 4 . Once processing was complete after as specific sampling interval, all fish in Tank 1 were moved to Tank 2, as Tank 1 did not have the same dimensions as Tanks 2 through 5.

Figure 2.2. JSAT tag (white) location inside of a $250-\mathrm{mm}, 64.6$ gram (including tag) juvenile Muskellunge, 90-d post-implantation. This fish jumped from its tank and was found the morning of March 11, 2018. Necropsy was performed on March 16, 2018. The tag was found encapsulated between the stomach and the liver within the coelom, with no peritoneal infection.

Figure 2.3. Presence of mini-acoustic transmitters had no effect on growth of age-0 Muskellunge in a hatchery experiment. The average size as natural log total length $(\ln T L, \mathrm{~mm})$ of control, sham and tagged juvenile Muskellunge relative to treatment group 120-days post anesthesia, laparotomy, and surgical implantation of a mini acoustic tag (Treatment Group, a), and sampling interval in days (Time, b). Tagged fish were found to be significantly larger in average size at the start and end of the study, indicated by average length $(\ln T L)$ at the end of the study, relative to sham and control fish

Figure 2.4. Specific (or relative) growth rates by weight $\left(\mathrm{SGR}, \mathrm{g}^{-1} \mathrm{day}^{-1}\right.$ ) of control, sham, and tagged age-0 Muskellunge over five sampling intervals. Error bars represent the SEs of treatmentspecific means. Average water temperature for each sampling interval (horizontal dash line) is 
presented by the secondary Y axis. Sham fish had a significantly lower SGR between 7 and 30 days $(t=-5.67, p=<0.001)$, as did tagged fish between 60 and 90 days $(t=-2.37, p=<0.018)$. Control fish had significantly higher SGR between 7 and 30 days $(t=8.87, p=<0.001), 60$ and 90 days $(t$ $=9.07, p=<0.001)$ and 90 to 120 days $(t=2.73, p=<0.001)$.

Figure 2.5. Mosaic plots showing the number of fish (sham and tagged) per inflammation (a) and wound closure category (b) over four sampling periods and temperature ranges $\left(30-\mathrm{d} / 14.5^{\circ} \mathrm{C}, 60\right.$ $\mathrm{d} / 11.4^{\circ} \mathrm{C}, 90-\mathrm{d} / 16.4^{\circ} \mathrm{C}$, and $120-\mathrm{d} / 17.8^{\circ} \mathrm{C}$ ). The same number of observations were made between the two treatment levels (sham and tagged fish) and wound closure categories (1 and 2), as seen by its symmetrical design. A significant effect was found between the (a) sampling interval and inflammation interaction (LR $\left.\mathrm{x}^{2}=66.85, p=<0.001\right)$ where inflammation levels were not independent of time, and (b) sampling interval and wound closure interaction $\left(\mathrm{LR} \mathrm{x}^{2}=66.85, p=\right.$ $<0.001$ ), where level of dehiscence was not independent of temperature. Pink rectangles indicated significantly fewer fish scored per category and sampling interval, while blue rectangles indicated more fish. Significantly few fish exhibited low levels of inflammation at the start of the study (as wounds had not yet begun to heal), and significantly fewer sham fish showed high levels of inflammation or dehiscence after 90 -d at $16.4{ }^{\circ} \mathrm{C}$, relative to tagged fish, though differences were minimal. Significantly more tagged fish exhibited cases of dermal rupture after 60 -d when temperature dropped and inflammation after 120-d, relative to sham fish. Though few fish exhibited low levels of inflammation those first 30-d, significantly more sham fish exhibited high levels inflammation and dermal rupture during this period, relative to tagged fish.

Figure 2.6. Representative photographs of six different juvenile Muskellunge, illustrating ranges of inflammation and wound openness. The key on each panel designates scores for inflammation (I) and wound openness (O) from 0 to 1 , and days post-surgery (D). Score were based on six different percent categories (see Schoobyan et al. 2017). 
Figure 2.7. The average reaction post-exposure to the move object (movement relative to grid squares) by control (thick line), sham (dashed line) and tagged fish (thin line), post-recovery and seven days post-surgery. Tagged fish reacted significantly slower than sham or control fish postrecovery; their $95 \%$ confidence interval (with respect to their reaction score) did not cross zero. Moreover, tagged fish reacted significantly faster $\left(\mathrm{LR}^{2}=7.8387, d f=2, p=0.02\right)$ seven days after chemical anesthesia exposure compared to their initial reaction.

Figure 3.2. Map of the upper St. Lawrence River, and the study site, relative to Lake Ontario and the St. Lawrence River, where age-0 Muskellunge and Northern pike were captured, tagged, and tracked between 2015 and 2017. Embayment locations in which age-0 Muskellunge and Northern Pike were tagged and tracked are denoted by a dotted line indicating its location in the upper St. Lawrence River, with the associated letter. Embayments include A) Rose, B) Flynn, C) Buck and D) Grass Point Bays. The receivers deployed in 2015 are denoted by a grey circle with a black dot, and those from November 2016 to March 2017 by black stars. Colours denote the habitat features selected through the Iso unsupervised clustering analysis in ArcGIS. Deep zones are those $>3$ meters. Submerg/Exposed zones indicate regions with $25 \%$ or $50 \%$ exposed substrate. Submerge/Emerge zones include both SAV and emergent species in shallow waters, similarly to zones with both Floating and SAV. Exposed zones are exposed substrates in $>3$ meters of water, and Exposed_Sh are similar zones in shallow waters. Note that Typha is only present in Flynn, while the Plume is only observed in the nearshore of Rose.

Figure 3.2. Significant differences in residency and space use were noted for Muskellunge in Rose Bay in 2015 and 2016/17; a) residency increased with warmer water temperatures in fall months, while b) core space use decreased with increased water temperatures and c) higher water levels. In 2016/17, d) residency increased with water temperatures, e) core space use became variable with high water levels, and extent increased with higher water temperatures. 
Figure 3.3. Core space use $\left(\mathrm{km}^{2}-50 \% \mathrm{KUD}\right)$ by age-0 Muskellunge and Northern Pike in the upper St. Lawrence River in A) 2015 and B) 2016 and 2017. Darker circles denote areas heavily used by fish based on a monthly analysis for A) Rose (top), Flynn (middle) and Buck (bottom) and B) Rose (top), Flynn (middle) and Grass Point (bottom).

Figure 3.4. Significant differences in core use ( $\mathrm{km}^{2}-50 \%$ KUD) between muskellunge in Rose Bay, 2015 (top) and Northern pike in Flynn Bay, 2015 (bottom). Three muskellunge (BF60, D3B1 and DDF) had significantly larger core use areas, relative to conspecifics. Four Northern pike (49DA, D0E7, E0A8, and E528) had significantly smaller core use areas, relative to conspecifics. Total length did not influence core use size between fish. Fish with significant differences are denoted by a star, above or below their boxplot.

Figure 3.5. The significant effects of water levels and temperature on spatial ecology of age-0 Northern Pike in 2015; a) the proportion of age-0 Northern Pike relative to water levels managed by the IJC was significantly more variable below 74.5 meters, while b) the residency index of age0 Northern Pike in Flynn Bay in 2015 significantly increased as water levels increased above 74.5 meters. Core space use (c) and extent (d) Northern significantly increased with higher water temperatures in fall months (core space, $x^{2}=5.4234, p=0.020$; extent $x^{2}=9.3907, p=0.002$ ).

Figure 3.6. Boxplots indicating significant differences in proportional habitat use by age-0 Muskellunge in (a) Buck Bay in 2015 and (b) Grass Point Bay from 2016 to 2017), and for age-0 Northern Pike within (c) Flynn Bay in 2015 and (d) Flynn Bay from 2016 to 2017. Letters indicate how habitats are grouped with respect to their level of significance. Deeper regions were most used by Rose Muskellunge ( $>90 \%$ ) compared to Float, Sub. 
Figure 3.7. A) Boxplot indicating significant differences in proportional habitat use by age-1 Northern Pike from 2016 to 2017. Letters indicate how habitats are grouped with respect to their level of significance; B) Total length was found a significant predictor of proportional habitat use by age-1 Northern Pike; the lower the habitat use (e.g. deep zone, exposed with SAV), the larger the fish. 


\section{List of Tables}

Table 2.1. How juvenile Muskellunge were scored, post-anesthetic recovery. Individual fish were scored based on active movement during the five-minute acclimation interval in the aquarium, the flight initiation distance and reaction with respect to a moving object (aerator bubbler attached to a long rod), and the speed of the reaction response once the object was within two grid squares.

Table 2.2. Mean total length (TL) and weight (W) with standard deviations (SD) of juvenile Muskellunge by treatment group (Treat) over the six sampling intervals (Time), and the average water temperature between tanks over each sampling interval, and evaluation of the tag burden and effects of $0.2 \mathrm{~g} \mathrm{JSAT}$ acoustic tags on their growth (SGR) between November 2017 and March 2018 at the Fleming College Muskellunge hatchery. Significant values are bolded (e.g. SGR weight differences from sham and tagged fish relative to control fish) and starred (SGR of sham fish 7-30d, SGR of tagged fish 60-90-d; final total length of tagged fish relative to control fish).

Table 2.3. An evaluation of variation in specific growth rates of juvenile Muskellunge over the four major sampling intervals. T values from linear mixed effect model results and associated $p$ values show that sham fish grew significantly less during the 7- to 30-d sampling interval, as did tagged fish during the 60 - to 90 -d interval. All treatment groups indicated significant growth rates in correlation with changes in temperature via Tukey's test, which occurred during the 7- to 30-d, 7- to 60-d, 60- to 120-d, and 90- to 120-d sampling intervals (see Figure 4).

Table 2.4. Percent of juvenile Muskellunge from each treatment group that scored 4, 3, 2, or 1 (see Table 1) in response to a moving object in the behavioural experiment. The reactions of fish were scored immediately after their recovery from anesthesia (post-recovery), and seven-days after surgery. The number of fish (No. Fish) does not equal the original number assigned to each group $(n=32)$, as fish that did not have a matching score (post recovery or seven-days post-surgery) due 
to processing difficulties, or lack of video, were eliminated from the analysis. No significant differences were found between the percent of fish per reaction group over time.

Table 3.2. Detection and space use information for age- 0 Muskellunge monitored in the upper St. Lawrence River over two different years. Fish captured in 2015 were tracked between October and December, and those in September 2016 from October 2016 to March 2017. Core use ( \pm SE) and Extent $( \pm$ SE) represent the mean 50\% and 95\% KUDs for each bay. Residency Index was calculated using the consecutive number of days fish were detected by the number of days the array was active.

Table 3.3. Detection and biological data for individual age- 0 Muskellunge monitored in the upper St. Lawrence River from October to December 2015. The total number of detections are those of individual fish after filtering for double detections (receiver overlap) and removing detections within 5-minutes of each other. Residency Index (\%) was the cumulative days detected by the total number of days. Fish greyed out were not used in residency, space or habitat use analyses, as they were detected $<7$ days in October or November (or $<2$ days in December), or less than two consecutive months. Muskellunge 875E was captured in Flynn and released in Buck Bay.

Table 4.3. Detection and biological data for individual age-0 Northern pike monitored in the upper St. Lawrence River from November 2016 to March 2017. Total number of detections is the total number of detections collected from an individual fish, after filtering for double detections (receiver overlap) and removing detections within 5-minutes of each other. Fish grey out were not used in analyses (residency, space or habitat use) as they either died prior to tracking due to surgery 
or were detected $<7$ days in October or November (or $<2$ days in December), or less than two consecutive months. Fish 6944 and CD5B were detected solely in November.

Table 3.5. Detection and biological data for individual age- 0 Muskellunge tracked in their natal embayment. Total number of detections is the total number of detections collected from an individual fish, after filtering for double detections (receiver overlap) and removing detections within 5-minutes of each other. Fish grey out were not used in analyses (residency, space or habitat use) as they were detected $<7$ days per month, or less than two consecutive months. Muskellunge A76D was first tagged as 933D on September 9, 2016.

Table 3.5. Detection and biological data for individual age-0 Northern Pike tracked in their natal embayment. Number of detections is the total number of detections collected from an individual fish, after filtering for double detections (receiver overlap) and removing detections within 5minutes of each other. Fish grey out were not used in analyses (residency, space or habitat use) as they were detected $<7$ days per month, or less than two consecutive months. Muskellunge A76D was first tagged as 933D on September 9, 2016.

Table 3.6. Detection and biological data for individual age-1 Muskellunge monitored in Rose Bay. Number of detections is the total number after filtering for double detections (receiver overlap) and removing detections within 5-minutes of each other. Fish grey out were not used in analyses (residency, space or habitat use) as they were detected $<7$ days per month, or less than two consecutive months.

Table 3.7. Detection and biological data for individual age-1 Northern Pike monitored in Flynn Bay. Number of detections is the total number after filtering for double detections (receiver overlap) and removing detections within 5-minutes of each other. Fish grey out were not used in analyses (residency, space or habitat use) as they were detected $<7$ days per month, or less than two consecutive months. 


\section{CHAPTER 1: General Introduction}

Riverine fish are amongst the most threatened taxa due to persistent environmental stressors and anthropogenic pressures including shoreline development, migration barriers, habitat degradation, overfishing, pollutants, and climate change (Dudgeon et al. 2006, Cooke et al. 2012). Where and when riverine fish distribute themselves over time to reside, forage, avoid predation, and reproduce - their spatiotemporal ecology - is markedly influenced by such stressors and natural variability in physio-chemical characteristics of their environment, as are their interactions with other species. Insight into the spatiotemporal patterns of juvenile fish may elucidate how early life stages distribute themselves as environmental conditions fluctuate and the subsequent influence on source and sink population dynamics. Studying these patterns may illuminate factors that trigger variation in space use and dispersal patterns (e.g. emigration, transient movement) and elucidate how and why variation may exist (Chapman et al. 2012, Radinger and Wolter 2014). Such insight may aid in characterizing seasonal habitat use and inform in-situ habitat protection and management to promote recruitment and enable self-sustaining populations (Warfe and Barmuta 2004, Jewell et al. 2014) amongst such persistent stressors and anthropogenic pressures.

\subsection{Spatiotemporal Fish Ecology}

Understanding the mechanisms that influence distribution and subsequent habitat use, and the ability to predict changes in spatiotemporal patterns based on environmental fluctuations, using statistical analysis, is at the core of aquatic ecological studies (Planque et al. 2011). Measuring and modeling how environmental drivers may influence spatial distribution enables researchers to predict where organisms are likely to reside, interspecific interactions, and variability between stocked and native individuals (Cooke et al. 2016). Data may illustrate core habitat use areas at earlier-life stages (i.e. nursery rearing, foraging, winter residency), and elucidate ontogenetic shifts 
in habitat use (e.g. Cunjak 1996, Shuter et al. 2012, Huusko et al. 2007).

\subsection{Rehabilitation Efforts for Early-Life Stages}

Restoration, recovery or rehabilitation of habitats, as witnessed in projects throughout Areas of Concern in the Great Lakes - St. Lawrence River basin (Kelso and Hartig 1995, Brooks et al. 2017), exemplify the importance and success of in-situ initiatives to promote natural recruitment of self-sustaining fish populations. Success stories include reconnecting coastal wetlands in the upper St. Lawrence River, to encourage residency and population growth by aquatic biota and use of restored wetlands by juvenile fish like larval Northern Pike (Esox lucius; Augustyn et al. 2018). Several case studies throughout the Great Lakes basin focus on the need to determine seasonal fish-habitat associations for the purpose of habitat restoration within largeriverine systems like the St. Mary's, St. Clair, Detroit and Niagara Rivers (Brooks et al. 2017). Though these case studies focused on whether restoration and use of spawning habitats for native and invasive species had occurred, using acoustic telemetry to follow the fish in real-time, work and subsequent adjustments to habitat availability may have direct implications on juvenile fishes.

\subsection{Tracking Aquatic Creatures in the Field}

Telemetry is a well-recognized tool for addressing knowledge gaps associated with spatiotemporal distributions of aquatic and terrestrial organisms by investigating the relationship of individuals with their environment (Grimm 1999, Cooke et al. 2013, Hussey et al. 2015). Understanding how fish habitat associations and environmental drivers are correlated and influence spatiotemporal ecology are key research topics elucidated by acoustic telemetry, and the postulates from such applied science are used to inform fisheries managers (Donaldson et al. 2014). Indeed, the focus of data collection is often premised on informing in-situ conservation science plans for declining populations and at-risk species (e.g. Simpfendorfer et al. 2010). 
Individual movements are tracked, and collective patterns are analyzed to permit a better understanding of spatial occupancy and habitat requirements (Jackson et al. 2001, Cooke et al. 2004) of fish at various life-stages, which may advise habitat restoration and stock enhancement initiatives (Lucas and Baras 2000).

Development of smaller, efficient, coded acoustic transmitters (e.g. McMichael et al. 2010) have enabled researchers to tag and track smaller species and earlier life stages of large-bodied fish (Cooke et al. 2013). Within riverine environments, early life stage studies have focused on elucidating coarse and fine-scale movements of salmonids (e.g. Juanes et al. 2000). For instance, McMichael et al. (2010) tracked juvenile salmon (Oncorhynchus sp.) and steelhead using miniacoustic transmitters to examine migration and survival through multiple hydroelectric facilities on Canada's west coast, while Laurel et al. (2007) tracked juvenile Atlantic Salmon (Salmo salar) to examine whether age- or stage- habitat suitability and subsequent distribution may be relative to season and ontogeny. Use of mini-acoustic tag technology (e.g. JSAT tags) may therefore elucidate the spatiotemporal ecology of other recreationally valuable fish whose basic juvenile ecology remains unknown (Murry and Farrell 2007), such as esocids.

Telemetry studies often presume that the behaviour, condition, and fate of tagged fish are not influenced by transmitter presence or tagging process, suggesting that tagged fish are representative of untagged conspecifics (e.g. Skalski et al. 2001). Yet, the extent to which that presumption is correct has been questioned, particularly, when transmitters are implanted in the coelom (Brown et al. 2011). Therefore, validating tagging procedures to minimize welfare impacts on tagged fish is important to consider (Walsh et al. 2000), as well as the suitability of miniacoustic tags to collect spatiotemporal data for early-life stages in field studies. (e.g. and long-term physical consequences associated with the tag presence). Validation studies have shown that implanting passive integrated transponder (PIT) tags are suitable for age-0 fish (e.g. Acolas et al. 
2007, Richard et al. 2013, Tiffan et al. 2015), including esocids like Muskellunge (Wagner et al. 2007, Younk et al. 2010) and Northern Pike (Hühn et al. 2014), however, the influence of surgical implantation and presence of these new mini-acoustic tags on these cryptic and declining species must be evaluated.

\subsection{Muskellunge and Northern Pike Ecology and Knowledge Gaps}

Muskellunge (Esox masquinongy), the largest piscivorous fish in North America, are restricted to eastern waters of North America (Scott and Crossman 1998). This species, one of five in the Esox genus (Harvey 2009) derived from a single glacial refuge (Crossman 1986) and includes three major stocks: the upper Mississippi River, Ohio River, and Great Lakes (Koppelman and Phillip 1986). Within the Great Lakes and their connecting channels, Muskellunge live in sympatry with Northern Pike, an older relative and competitor which exhibits a circumpolar distribution (Scott and Crossman 1998). In their sympatric range, Northern Pike are likely more common than Muskellunge due to their spawning phenology and subsequent predation on young Muskellunge, and tolerance to varying temperature and oxygen ranges (Harvey 2009).

Bi-national management of these well-known sportfish in the St. Lawrence River has shifted from a harvest focus to catch-and-release, with objectives to conserve and sustain spawning and nursery habitat requirements in coastal embayments (Farrell et al. 2007). Juvenile and subadult ecology, however, remains poorly understood (Midwood et al. 2015). Much effort has been devoted to restoration of fish habitat in the upper St. Lawrence River system, due to hydroelectric operations and shoreline alteration, but there remain many questions about the effectiveness of past restoration efforts or basic understanding of esocid-environment relationships needed to inform future restoration activities.

Pragmatic research needs for Muskellunge include critical habitat identification and core ecology for juvenile Muskellunge (ages 0-5; Farrell et al. 2007); the ability to support early-life 
stages through habitat associations is imperative when population restoration is a key management goal (Farrell et al. 1999). Notably, fine-scale assessments of a small sample of stocked, sub-adult Muskellunge (age-1) and wild age-1 Northern Pike in the upper St. Lawrence River bay noted ecological separation observed in summer months (Farrell et al. 2014). Targeted research on the spatiotemporal ecology and habitat use of riverine age-0 Muskellunge and Northern Pike in summer months has further elucidated movement activities for stocked individuals at varying latitudes (Hanson and Margeneau 1992, Wagner and Wahl 2011), observed persistent use of nearshore regions with low water velocity, fine substrates, and habitat complexity (Murry and Farrell 2007) in addition to woody debris (DeBoom and Wahl 2012, Owensby et al. 2017), supported conservation of well-vegetated habitat which support abundant fusiform fish for strong year class formation (Kapincinski and Farrell 2014), and modeled how variation in water temperature and community dynamics may influence recruitment and survival (Eslinger et al. 2010). Given that many restoration and rehabilitation efforts have focused on early life stages, information on the spatiotemporal ecology of juvenile esocids in fall and winter months remains a significant research gap.

\subsection{Research Rationale and Objectives}

My thesis provides insight on an important life stage of esocids and the potential impacts of riverine conditions on their behaviour and survival. Indeed, the significant decline in selfsustaining Muskellunge and Northern Pike populations inhabiting the upper St. Lawrence River (Farrell et al. 2007) and no understanding of the role of winter phenology on juveniles prompted collection of real-time dispersal and residency data, using mini-acoustic tags, to identify spatiotemporal trends, core habitat feature use, and elucidate how environmental mechanisms (e.g. temperature, water levels) may drive spatiotemporal patterns during fall and winter periods. My thesis includes two data chapters (Chapters 2 and 3). 
Chapter two evaluated the effects of surgical procedures and tag implantation on captivereared age zero Muskellunge. Tag retention, survival, growth rates, rate of healing due to surgical wounds, and flight initiation behaviour associated with chemical anesthetic exposure using three treatment groups - tagged, sham, and control - were quantified, to assess whether rates differed significantly treatment groups, and how behaviour post-anesthetic exposure may influence vulnerabilities to predators, post release in field studies.

Chapter three characterized the spatiotemporal ecology of age- 0 and age-1 Muskellunge and Northern Pike in the upper St. Lawrence River, and compared their collective dispersal patterns, core winter residencies and habitat use to environmental covariates to elucidate overwintering habitat requirements for these early life stages, and how interspecific overlap with Northern Pike may influence survival of Muskellunge beyond their first winter. 


\section{CHAPTER 2: Evaluation of acoustic transmitter implantation on tag retention, healing, growth and behaviour of juvenile muskellunge}

\subsection{Abstract}

Acoustic telemetry is an increasingly common tool used in fisheries science. The development of small acoustic transmitters has enabled researchers to target earlier life stages and smaller fish species than was previously possible. The underlying assumptions of any telemetry study are minimal tag loss and negligible effects on the behaviour and survival of tagged individuals. To that end, tag retention, healing, survival, growth, and behaviour were evaluated in age-0 Muskellunge (Esox masquinongy) (205 $\pm 10 \mathrm{~mm}$ total length [TL]) implanted with one of the smallest commercially available acoustic transmitters (Pacific Northwest National Laboratory JSAT tag; $12.0 \times 5.3 \times 3.7 \mathrm{~mm}, 0.217-\mathrm{g}$ in air) in an overwinter hatchery experiment. Tagged fish were compared to untagged controls and sham fish (fish that had undergone surgery, but not transmitter implantation). MS-222 was used for anesthesia, the incisions were closed with a synthetic absorbable monofilament, and all surgeries were conducted by a single trained researcher. All tags were retained throughout the experiment; surgical wounds healed within 30 days, and $32 \%$ of sutures were retained 120 -d post-surgery. Growth was similar among the three groups (tagged, untagged and sham fish), and 98\% of fish survived the experiment. Minor behavioural differences were observed in the tagged fish hours after the tagging procedure as well as sham fish, relative to controls, seven days post chemical anesthesia. Results validate the utility of surgically implanted small acoustic transmitters in juvenile Muskellunge ( $>150 \mathrm{~mm})$ in future ecological studies. 


\subsection{Introduction}

Telemetry has become a mainstream tool for studying the spatial ecology and survival of fish (Donaldson et al. 2014, Hussey et al. 2015). Early telemetry studies focused on larger bodied fish species and adult life stages, but enhancements (e.g. smaller tag size, longer battery life) have enabled tracking and collection of real-time movement data for smaller life stages and species. In telemetry studies it is often presumed that the behaviour, condition, and fate of tagged fish are not influenced by transmitter presence or tagging process, suggesting that tagged fish are representative of untagged conspecifics (Skalski et al. 2001, Deriso et al. 2007). Yet, the extent to which that presumption is correct has been questioned, particularly, when transmitters are implanted in the coelom (Brown et al. 2011). Therefore, validating tagging procedures to identify methods that minimize welfare impacts on tagged fish is important to consider (Walsh et al. 2000). The ratio of tag size (the volume, shape, and mass) to fish body size seems to be particularly influential (e.g., on healing, retention, behavioral impairments, survival; Jepsen et al. 2004). Nonetheless, other aspects such as suture material, incision location, surgeon experience, and tag type (e.g. presence of antenna for radio tags, tag coating) are also important considerations (reviewed in Bridger and Booth 2003, Cooke et al. 2011, Thorstad et al. 2013). Clearly, there is a large degree of interspecific variation in responses, that are further mediated by environment (Cooke et al. 2011).

Researchers use telemetry tools to explore and assess recreational fishes' spatial behaviour in their natural environment (Lucas and Baras 2000), often to develop a mechanistic understanding of spatial patterning (e.g., Cooke et al. 2008). Researchers efforts are expanding to study the spatial ecology and survival of juvenile fish, including Muskellunge (e.g. Hanson and Margenau 1992, Farrell et al. 2014, Owensby et al. 2017), and Northern Pike (Hühn et al. 2014). Validating how telemetry tools may influence the welfare of fish, or limit data interpretation, is therefore 
imperative. Implanting passive integrated transponder (PIT) tags, for instance, was not found to impair the welfare or produce sublethal effects for age-0 fish (e.g. Acolas et al. 2007, Richard et al. 2013, Tiffan et al. 2015), including age-0 Muskellunge (Wagner et al. 2007, Younk et al. 2010), and Northern Pike (Hühn et al. 2014). However, these studies are limited in their capacity to capture fine-scale (e.g. daily) movements. Radio telemetry has been used to estimate mortality, dispersal, and habitat use of stocked age-0 Muskellunge (Hanson and Margenau 1992, Wagner and Wahl 2011, Owensby et al. 2017), though no validation studies were performed. Deters et al. (2010) evaluated implantation and retention associated with the smallest, commercially available, coded transmitter (e.g. Juvenile Acoustic Salmon Telemetry (JSAT) tag; McMichael et al. 2010) and found neither tag expulsion nor mortality associated with implanting tags in juvenile Chinook Salmon (Oncorhynchus tshawytscha; FL range $=96-121 \mathrm{~mm}$; tag $2-6 \%$ body weight). With acoustic telemetry growing in popularity as tool for research on juvenile life stages and small fish (Hussey et al. 2015), there is merit in studying effects of surgical implantation and presence of these new mini-acoustic tags on other species.

With research gaps related to the spatial ecology of juvenile Muskellunge (e.g., Crane et al. 2015), and no publications evaluating the influence of acoustic telemetry tools for this species, this paper focuses on the influence of surgical procedures, tag presence, and anesthesia on captive reared, age-0 Muskellunge. Fish implanted with JSAT transmitters were compared to untagged controls and sham fish (fish that have undergone surgery but not transmitter implantation) with 1) survival, 2) tag retention, 3) tag burden, 4) tag encapsulation, 5) incision healing, and 6) growth rates for each sampling interval (day 0-30, 30-60, 60-90, and 90-120 days post-tagging) and full experiment duration of 120-d (Hühn et al. 2014), as well as individual flight response postanesthetic recovery and seven days post-surgery as end points. 


\subsection{Methods}

\subsubsection{Fish source and rearing}

Muskellunge used in this study were reared at the Fleming College Muskellunge Hatchery (Lindsay, Ontario) in 2.4 (1) x $1.2(\mathrm{w})$ x 1.2 (h) m tanks with a normal operating volume of 3000 L with recirculated water. Eggs were collected as gametes from a native, wild stock in Gloucester Pool, Lake Huron (Wilson et al. 2016) and fertilized on April 27. Eggs were incubated between $15^{\circ} \mathrm{C}$ to $17^{\circ} \mathrm{C}$ in early rearing units. Fish were transferred to intermediate rearing units, six to seven weeks post-hatch, for eight to 10 -weeks, where rearing temperatures were $\sim 22^{\circ} \mathrm{C}$. Fish were fed a manufactured salmonid Skretting diet; Nutra ST $0.3 \mathrm{~mm}$ crumble feed (58\% protein, $18 \%$ lipid) as fry, Nutra RC NP $1.8 \mathrm{~mm}$ (50\% protein, 20\% lipid), and Europa $154.0 \mathrm{~mm}$ (55\% protein, $15 \%$ lipid) food pellets as juveniles grew. Muskellunge $(n=96)$ were processed in November 2017 over three days.

\subsubsection{Environmental and physical fish measurements}

Water temperature and dissolved oxygen levels were documented daily for each tank postprocessing. Every 30 days, body size (total length, nearest $1 \mathrm{~mm}$; weight, nearest $0.1 \mathrm{~g}$ ) was measured to estimate growth (Table S.2.1). Average temperatures (based on sampling intervals) declined after $60-\mathrm{d}\left(14.3\right.$, December; $11.4{ }^{\circ} \mathrm{C}$, January), then increase to $16.9^{\circ} \mathrm{C}$ in February $(90-$ d) and $18.1^{\circ} \mathrm{C}$ in March (120-d). Both the incision site and fins (caudal, dorsal, pelvic) were photographed for each fish. If a fish died, a necropsy was performed to assess if peritoneal infection (presence of viscous pale-pink fluid in a sack around the transmitter or in the body cavity) was present or absent (Walsh et al. 2000) and whether the tag was encapsulated or free-floating.

\subsubsection{Missing data}

Fish that were missing a measurement for one or more sampling intervals related to overall body size $(n=2)$, healing rate $(n=3)$, or activity response $(n=17)$ were omitted from their 
respective statistical analyses. Analyses were conducted in R Studio 3.4.1 (R Studio Team, 2016). Significance was identified if $\alpha \leq 0.05$.

\subsubsection{Individual identification}

All fish were handled with electrosedation gloves (TENS 3000 unit, DT3002 Roscoe Medical, low voltage setting; as per Ward et al. 2017) and implanted with two visible implant elastomer (VIE) tags for group and individual identification. Colors (red, orange, and green) were selected by recommendation of Northwest Marine Technology (Shaw Island, Washington). Tags

were administered with handheld $0.3-\mathrm{mL}$ tuberculin syringes (29-gauge needle) coupled with syringe holders. The elastomer and curing agent were mixed several minutes prior to injection. Ink was kept on ice to reduce coagulation during injections, and tag codes were implanted in a systematic order. Tags were injected in the transparent tissue where each fin (pectoral, pelvic, anal, caudal, and dorsal) met the body cavity, rather than the lower-jaw (Younk et al. 2010). All fish were weighed (nearest $0.1 \mathrm{~g}$ ) and measured (fork length; nearest $1 \mathrm{~mm}$ ) post VIE implantation. As natural body markings are known as an effective identification tool (e.g. Wilson et al. 2006, Brooks et al. 2010, Pablo Barriga et al. 2015), the dorsal, caudal, and pelvic fins were photographed as a form of secondary identification by spot pattern.

\subsubsection{Anesthetization}

A total of 96 Muskellunge were selected at random from their source tanks and were assigned to one of three treatment groups for a total of 32 per treatment group (Younk et al. 2010): tagged (anesthetized and implantation with acoustic tag), sham (anesthetized, no tag implantation), and control (no anesthetic or tag implantation, measurements only). Sham controls were used to isolate the effects of surgical procedure from the presence of the transmitter following Cooke et al. (2011). For control fish to be processed (that is, held in anesthetic and recovery bins) in the same fashion as sham and tagged fish, the average time sham and tagged fish underwent anesthesia 
and recovered was calculated and used to time control fish. To achieve this, all fish from each treatment were processed at the same time (e.g. all sham, all tagged, all control), rather than rotational order (sham, tagged, control), which is often used to remove biases associated with processing fish. Neither length (TL) nor weight (W) of fish processed at the start of the study were normally distributed ( $W=0.95985, P=0.005$ ), so both parameters were transformed to their $\log$ natural (lnTL and $\ln \mathrm{W})$ and met assumptions of normality (Gaussian distribution) and homoscedasticity, and to calculate specific (or relative) growth rates.

\subsubsection{Surgery Procedures}

Fish were not fasted prior to surgery to mimic in-situ field surgery conditions. Before implantation, sham and tagged fish were anesthetized $(70 \mathrm{mg} / \mathrm{L}$ solution of tricaine methanesulfonate (MS-222) in hatchery water) until opercular rates slowed and fish were unresponsive to touch (see Carter et al. 2011, Wagner et al. 2011, Wagner et al. 2014). Fish were placed supine on a surgery table in recirculating water and received a maintenance anesthetic dose (70 mg/L MS-222) by placing a small-diameter (size) silicone rubber tube from a pump (in the recirculating tank) inside the mouth so water gently flowed over the gills. A $\sim 5 \mathrm{~mm}$ lengthwise incision was made between the pelvic and pectoral fins and closed with one simple interrupted suture (PDS II, 3/0, Ethicon Inc.) following tag insertion. Tagged fish were implanted with a sterilized (Virkon), JSAT tag (Pacific Northwest National Laboratory; $12.0 \times 5.3 \times 3.7 \mathrm{~mm}, 0.20$ $\mathrm{g}$ in air) into their coelom. Surgical tools were sterilized in a diluted solution of Virkon between each surgery.

\subsubsection{Processing considerations}

Fish were tagged by the same researcher, to reduce surgeon bias on survival (Cooke et al. 2003, Richard et al. 2013, Tiffan et al. 2015). To compare healing rates, the ventral side of each fish that received surgery was photographed. Any abnormalities associated with fish and 
deviations from the tagging process were noted. Post-surgery, fish were held in a recovery cooler with aerated water. Surgically processed fish (both tagged fish and sham fish) were kept under sedation (knock out and laparotomy or surgery) between two to six minutes and recovered in two to three minutes. Individuals were systematically assigned to one of four replicate holding tanks, so as each tank contained eight fish per treatment group (Tiffan et al. 2015). Fish were removed from their tanks at specific sampling intervals (7, 30, 60, 90 and 120-d) to measure endpoints, and were rotated between tanks once processed to ensure individuals were not sampled twice (Fig. 1).

\subsection{Statistical Analysis}

\subsubsection{Data preparation and considerations}

To quantify how tag burden may influence growth (body size in length or specific growth rates in weight), tag weight (0.2 grams) was removed from the total weight of tagged fish measured each sampling interval. To determine whether final body size of fish after 120-d from each treatment group may have been biased by their initial size, total lengths of fish randomly picked for each group at the start of the study were compared using a one-way ANOVA. The potential effect of treatment group (sham, tagged and control) and time under anesthesia on recovery time was evaluated using an ANCOVA, with treatment the categorical variable, and time continuous.

\subsubsection{Survival, Internal Tag Assessment, Tag Retention, \& Tag Burden}

Fish health was monitored daily by hatchery staff to assess survival, and individuals that suffered mortality were frozen until a necropsy could identify the location of the transmitter and level of peritoneal infection due to the presence of the transmitter. Tanks were visually scanned for expelled tags during daily, routine cleaning, and the lone drain for all hatchery effluent was covered by a small-mesh net, to ensure expelled tags would be located, if not observed upon initial inspection. Survival and tag retention were calculated as a percentage (the total number of fish that survived and retained their tags, respectively, per treatment group; Gries and Letcher 2002). Tag 
burden, or body-to-weight ratio $(\%)$, was calculated as $100 \times(\operatorname{tag}$ weight $) / W$, where tag weight was 0.2 grams and $W$ was an individual fish weight when tagged (Wooton 1990) (Table S.2.2).

\subsubsection{Growth Rates}

Specific (or relative) growth rates (SGR) for individual fish were calculated as $100 \times(\operatorname{lnW} 2$ $-\ln \mathrm{W} 1) /(\mathrm{t} 2-\mathrm{t} 1)$, where W2 and W1 were body weights at sampling intervals $\mathrm{t} 2$ and $\mathrm{t} 1$ (Ricker 1975); SGR calculations were made between each sampling interval and the full experiment duration (Table S.2.2). The overall difference in body length (lnTL) between treatment groups 120-d post-processing and SGR's at each sampling interval were evaluated with linear mixed effect models (lme, R package 'nlme'; Pinherio et al. 2018). Collinearity between biological and temporal factors (time, treatment, $\operatorname{lnTL}, \ln \mathrm{W}$, temperature, and tank fish was housed over a specific sampling interval), were compared using Pearson correlation coefficients and variance inflation factors (vif, R package “car"; Fox and Weisburg 2011). Time and lnW had vif value $>3$, indicating time was collinear with temperature and $\ln W$ with $\ln T L$ (Table S.2.3). Despite the correlation of time with temperature, two nested linear mixed effect models were compared (Fig. S.2.4), and one model included time and temperature. Both models included a time:lnTL interaction to control for size over time. Temperature and lnTL (fixed variables) were centralized to simplify interpretation and facilitate comparison of their relative importance (Schielzeth, 2010).

Temporal autocorrelation was tested, confirmed, and accounted for in the repeated measures ANOVA for overall growth in body size, and SGR (Eq. S.1). The best fit SGR model was fit using the corARMA function, relative to corCARl and corARl functions (R package 'nlme'; Pinherio et al. 2018). The model included the average temperature across tanks for each respective sampling interval (TM), treatment group (TR), rearing tank at the specified sampling interval (TK), and the log natural total length of individual fish (lnTL) (Table S.2.4). 


\subsubsection{Incision Healing}

Macroscopic inflammation (redness) and wound closure (amount of open dermal tissue) was scored from 0 to 1 (see Schoonyan et al. 2017 Table 1 for rating system) by two researchers independently to account for variability. Due to the large variation in wound closure scores between each researcher for the 90-d and 120-d sampling interval, when sutures caused additional dehiscense (rupture), the more conservative scores were selected for analysis. Generalized linear mixed models ( $g l m$, R package 'nlme'; Pinherio et al. 2018) compared the number of Muskellunge scored for each wound type (openness and inflammation) over time, using a Poisson distribution and log link function. Two models for each wound type were compared using AICc to determine whether temperature or sampling interval were appropriate, as they were collinear; wound category and treatment group were included in all models as main effects and interaction terms.

Suture retention over time was assessed using the same generalized liner mixed effect model described for incision healing, but with a binomial distribution, log link function, a "bobyqa" optimizer, maxfun of 1e5, and an nAGQ value of seven. Time and treatment groups were fixed factors and fish ID the random factor. Interaction terms were removed, as none were significant. Multiple comparisons were tested using Tukey's (glht, R package 'multcomp'; Hothorn et al. 2017).

\subsubsection{Flight Initiation Response}

The sedation level of each fish was established by lightly touching the fish every 30 seconds to determine its response stage. Fish were no longer considered sedated when they became upright and displayed regular opercular and fin movement (Wagner et al. 2014). Activity and reaction time were recorded using a Hero 3 GoPro, mounted above a 40L aquarium (51 x 25 x 30$)$. A Styrofoam sheet with $2.54 \times 2.54 \mathrm{~cm}$ grid squares was placed under the aquarium, to quantify movement. Fish were placed in the aquarium once they reached Stage 1 anesthesia in their recovery 
cooler and were permitted to acclimatize for five minutes. Fish activity was recorded between five and 10-minutes. A moving object (76.5-cm plastic, hollow, hexagonal cross section control rod from a set of horizontal mini-blinds with a square, silicate aquarium air-stone attached by white electrical tape; total length of 79-cm or 31-in) was then immediately placed in the fish's line of sight, on the opposite end the aquarium from the fish, and was slowly moved towards the fish. Video recordings of activity responses post-anesthetic were randomly viewed and blindly scored, to avoid observer bias associated with treatment. Active movement and response to a moving object, including flight initiation distance, were scored based on movement during the acclimation period ( 1 or 2 ; fish crossed $<$ or $\geq 2$ grid squares in 5-minutes), flight initiation reaction ( 1 to 4 ; fish did not react, reacted $<$ or $\geq 2$ grid squares from object, or before object entered tank), and reaction post exposure (1 to 4; fast, moderate, slow or no reaction) were included as fixed factors.

A two-way repeated measures ordinal ANOVA $(\mathrm{clmm})$ was used to analyze the ordinal, dependent variable (reaction to moving object) for flight initiation response post-anesthesia, with time (repeated measurement) and treatment as fixed factors and activity and speed as independent, ordered factors. The proportional odds assumption was checked using the nominal_test function. Fish was a random factor to account for their selection from a randomly sampled population (i.e., Gloucester Bay), and temperature was centralized for both incision healing and flight response analyzes. The best models selected had the lowest AICc accounting for small sample size. Multiple comparisons were tested using (R package "lsmeans", Lenth 2016).

\section{$2.5 \quad$ Results}

\subsubsection{Size of fish per treatment group}

Fish selected for tagging had statistically significant larger body sizes than those selected for control at the study's start (Tukey's, $t=2.912, p=0.0124$ ) and post 120-d (Tukey's, $z=2.829$, $p=0.0114$; Fig. 2), but the actual mean difference was small (e.g., mean difference of TL, 7-mm 
(201 \pm 9.7-mm [mean $\pm \mathrm{SD}$ ], control; $206 \pm$ 10.3-mm, sham; $208 \pm 10-\mathrm{mm}$, tagged) and 3-grams body mass (29 $\pm 5.4-\mathrm{g}$, control; $32 \pm 5$-g, sham; $32 \pm 4.6-\mathrm{mm}$, tagged). Average overall size (TL) of Muskellunge at 120-d ranged from 261- to 264-mm (Table 2).

\subsubsection{Surgery Procedures}

Though this study aimed to process sham and tagged fish similarly, the amount of time under sedation between treatment groups (368 \pm 102 seconds, sham; $280 \pm 47$ seconds, tagged) differed significantly $(F=10.9313, d f=1, p=0.002)$. Recovery time ( $241 \pm 93$ seconds, sham; $183 \pm 44$ seconds, tagged $)$ post anesthetic exposure $(F=8.6589, d f=2, p=0.0005)$ was also significantly different between treatment groups.

\subsubsection{Survival, Internal Tag Assessment, Tag Retention \& Tag Burden}

All tagged fish retained their acoustic tags. Two tagged fish died as tank escapees, and no peritoneal infection was observed for either mortality. Tags were encapsulated in the serous membrane between the liver and stomach (Fig. 2). Tag burden was low, from initial processing day $(<0.8 \%)$ to the end of the study 120 -d post tagging (Table 2$)$.

\subsubsection{Body Size \& Specific Growth Rates}

Specific growth rates (SGR) ranged over time from an average of $0.08 \mathrm{~g}^{-1}$ day $^{-1}$ (30- to 60d) across treatment groups to $1.05 \mathrm{~g}^{-1} \mathrm{day}^{-1}$ by $120-\mathrm{d}$ (Table 2). Rates ranged from negative growth (weight loss of $-0.5 \mathrm{~g}^{-1}$ day $^{-1}$ ) during the first seven days to $2.93 \mathrm{~g}^{-1}$ day $^{-1}$ between the 60 - and 90d mark; both were control fish. SGRs for all treatment groups decreased in the first 60-d from 0.59 $\pm 0.31 \mathrm{~g}^{-1} \mathrm{day}^{-1}(30-\mathrm{d})$ to $0.10 \pm 0.14 \mathrm{~g}^{-1} \mathrm{day}^{-1}(60-\mathrm{d})$, considerably increased to $1.07 \pm 0.8 \mathrm{~g}^{-1} \mathrm{day}^{-1}$ at 90-d (likely due to the substantial increase in temperature and thus metabolism), then decreased to $0.81 \pm 0.34 \mathrm{~g}^{-1}$ day $^{-1}$ at 120 -d (Table 2, Fig. 3). Growth rates did not significantly differ between treatment groups over the full four-month study $\left(\mathrm{x}^{2}=3.4926, p=0.1744\right)$; however, control fish grew significantly longer and heavier the first 7-d $(t=8.40, p=<0.001)$, and between 60- and 90- 
$\mathrm{d}(t=2.40, p=<0.001)$. Sham fish $(t=-5.67, p=<0.001)$ grew significantly less between 7-d and 30-d (Fig. 2.4, Table S.2.5), as did SGR of tagged fish $(t=-2.37, p=<0.001)$ relative to control and sham between 60-d and 90-d (Fig. 2.4, Table S.2.5). Total length of all fish significantly increased over time $(t=3.25, p=<0.001)$, as anticipated; however, growth rates of all fish in tank 5 were significantly lower $(t=-3.25, p=<0.001)$, reiterating the challenges associated with controlling for all environmental variables (Table S.2.5).

\subsubsection{Incision Healing}

Wound dehiscense (dermal tearing or rupture) scores decreased throughout the study for both sham and tagged fish. Sham fish exhibited low levels of dehiscense (0-0.3\%); tagged fish ranged from $0-0.15 \%$ (categories 1 to 3; see Schooynan et al. 2017; Fig. 2.5). Level of inflammation ranged from $0-0.45 \%$ (category 1 to 4 ) for both treatment groups. Incisions healed by 60 -d; however, $32 \%$ ( $n=29$ fish) of sutures were retained by both groups 120 -d post-surgery. The rate at which sutures fell out significantly declined with each sampling interval, starting at 60$\mathrm{d}(z=-2.22, p=0.02 ; 90-\mathrm{d}[z=-3.08, p=0.002] ; 120-\mathrm{d}[z=-3.34, p=0.001])$.

The number of Muskellunge scored in each dehiscense (LR $\left.x^{2}=40.46, p=<0.001\right)$ and inflammation (LR $x^{2}=31.05, p=<0.001$ ) category was not independent of sampling interval (Fig. $2.5,2.6)$. Significantly fewer fish exhibited open wounds $(90-\mathrm{d}, z=-4.20, p=<0.001 ; 120-\mathrm{d}, z=$ 3.63, $p=<0.001)$, or inflammation later in the study $(90-\mathrm{d}, z=-5.00, p=<0.001 ; 120-\mathrm{d}, z=-5.23$, $p=<0.001)$. Sampling interval was a better predictor of when inflammation was noticeably reduced (interval, $\mathrm{AICc}=133.90$; temperature, $\mathrm{AICc}=149.05)$ while temperature influenced wound closure (interval, $\mathrm{AICc}=282.70$; temperature, $\mathrm{AICc}=113.70$ ).

\subsubsection{Flight Initiation Response}

Nearly $25 \%$ of fish responded immediately to the moving object post-processing (postsedation for sham and tagged fish). The reaction of sham fish post-object exposure (slow vs. 
moderate, scores 2 and 3) declined seven-days post sedation, while the reaction of tagged fish was significantly faster $\left(\mathrm{LR}_{\mathrm{x}}^{2}=7.8387, d f=2, p=0.01985\right.$ ) relative to that post-recovery (Fig. 2.7). No variation in behaviour was noted during the acclimation period or flight initiation distance test.

\subsection{Discussion}

The present study suggests mini acoustic transmitter implantation did not impair short-term growth (120-d) juvenile Muskellunge. Similarly, growth was not impaired for free-ranging, multitagged (external and internal) age- 0 Northern Pike, or conspecifics $>480-\mathrm{mm}$ TL implanted solely with radio transmitters (Hühn et al. 2014). Though the mean length of tagged age-0 Muskellunge was larger than control fish at the start in our study, reduced size and growth rates of tagged fish (an anticipated result of an invasive procedure) was not observed after four months (120-d).

Control fish grew significantly longer and heavier than sham and tagged fish the first week (Fig. 2.4) as groups which underwent laparotomy may have allocated more energy to initiate wound closure than to somatic growth. Declines in SGR between 30- and 60-d for all treatment groups is likely attributed to the decline in average water temperatures below preferred values $\left(\geq 12^{\circ} \mathrm{C}\right.$; Kerr and Lasenby 2011) during the first 60 -d of the study. By 120 -d, all fish were growing $0.8 \pm 0.04 \mathrm{~g}^{-1}$ day $^{-1}$ and by 60 - $\mathrm{d}$; comparable to the size of those of intensively reared age- 0 Muskellunge in Chautauqua hatchery ponds after 50-d (Colesante and Bubnack 1992).

Low burden $(<0.8 \%)$, high retention $(100 \%)$, and high survival $(98 \%)$ suggest micro acoustic tags are not harmful for juvenile Muskellunge studies. Burden was lower than most microacoustic and PIT tag implantation studies (1\% to 9\%; e.g. Winter 1983, Tiffan et al. 2015, Panther et al. 2018), and high retention rates mimic studies assessing PIT tag retention ( $>95 \%)$ previously reported for age-0 Muskellunge (Younk et al. 2010) and JSAT tag retention (>99\%) for juvenile Chinook Salmon (Wagner et al. 2014) and Bloater (Coregonus hoyi; Klinard et al. 2018). Moreover, no tagging-induced mortalities up to 325-d post-tagging and full tag retention was 
observed for multi-tagged (PIT, fin clip, external tag) age-0 Northern 195-325-d (Hühn et al. 2014). These age-0 Northern Pike suffered substantial overwintering mortality in this pond experiment, suggesting mesocosm studies may elucidate whether our high Muskellunge survival rates were due to a captive environment, consistent food supply, or elevated water temperatures.

Similar to Atlantic salmon (Salmo salar) tagged with dummy acoustic transmitters (Lacroix 2004), a lack of peritoneal inflammation or infection, along with a clearly encapsulated tag were observed in two age-0 Muskellunge, post-necropsy. Tags within the juvenile Atlantic Salmon became encapsulated in a thick membrane prior to expulsion 142 and 217-d post-surgery (Lacroix 2004). Protracted suture retention was observed in $25 \%$ of juvenile Muskellunge $120-\mathrm{d}$ post-surgery, possibly due to lower water temperatures $\left(<20^{\circ} \mathrm{C}\right.$; Deters et al. 2010). Despite increased vertical (dorsal to ventral) tearing of dermal tissue in the $\sim 25 \%$ of tagged Muskellunge (induced by protracted suture retention) 60 -d into the study, $>75 \%$ of incision wounds fully healed (fully closed, no suture, or erythema) within 120-d post-surgery. This suggests that expulsion poststocking into Gloucester Pool (wild source) is unlikely. Suture retention for juvenile Muskellunge did not vary between treatment groups, but significantly decreased at after 60 -d, similar to freeranging Walleye (Sander vitreus), of which 50\% healed approximately 60-d post-release (Schoonyan et al. 2017), and 100\% after 90-d.

This study used MS-222 concentrations within acceptable limits (60 - $100 \mathrm{mg} / \mathrm{L})$, and fish were induced and sedated within recommended timelines and manufacturer guidelines (see Wagner et al. 2011, Wagner et al. 2014); however, increased exposure to MS-222 (relative to tagged fish) may have influenced short-term (30-d) recovery for sham fish. Though no published studies indicate short-term growth impairment associated with MS-222 exposure on juvenile fish, alterations in physiology may reduce feed intake or nutrient uptake. A significant interaction was observed between decreased $\mathrm{Na}^{+}, \mathrm{Ca}^{2+}$, and $\mathrm{K}^{+}$blood levels in juvenile Chinook Salmon over a 
two-week period, after increased MS-222 exposure (Wagner et al. 2014), suggesting stress response patterns observed post-surgery may have been amplified when exposed to increased anesthetic (Wagner et al. 2014). Similar physiological stress may have been experienced by sham Muskellunge in the first month, due to increased MS-222 exposure (relative to tagged fish); this may have been amplified by electrosedation (prior to chemical anesthetization) and laparotomy. To this end, tag implantation and increased MS-222 exposure may have short-term, sublethal implications (i.e., predator avoidance) post-release. The reduced distance sham fish maintained between themselves and the object, one-week post-sedation, may have been a delayed reaction attributed to lingering effects of increased exposure to MS-222. With no difference in acclimation activity or flight response to sham fish, the short-term influence of tag presence on behaviour postsedation requires additional research.

In summary, small variation in growth rates at the end of this short-term study between treatment groups, negligible mortality, low body mass ratio and $100 \%$ transmitter retention observed in this study suggests that juvenile Muskellunge can successfully be implanted intracoelomically with mini-acoustic transmitters, though sedation methods and level of exposure, confounded by laparotomy, may influence short-term growth and behavioural responses. 


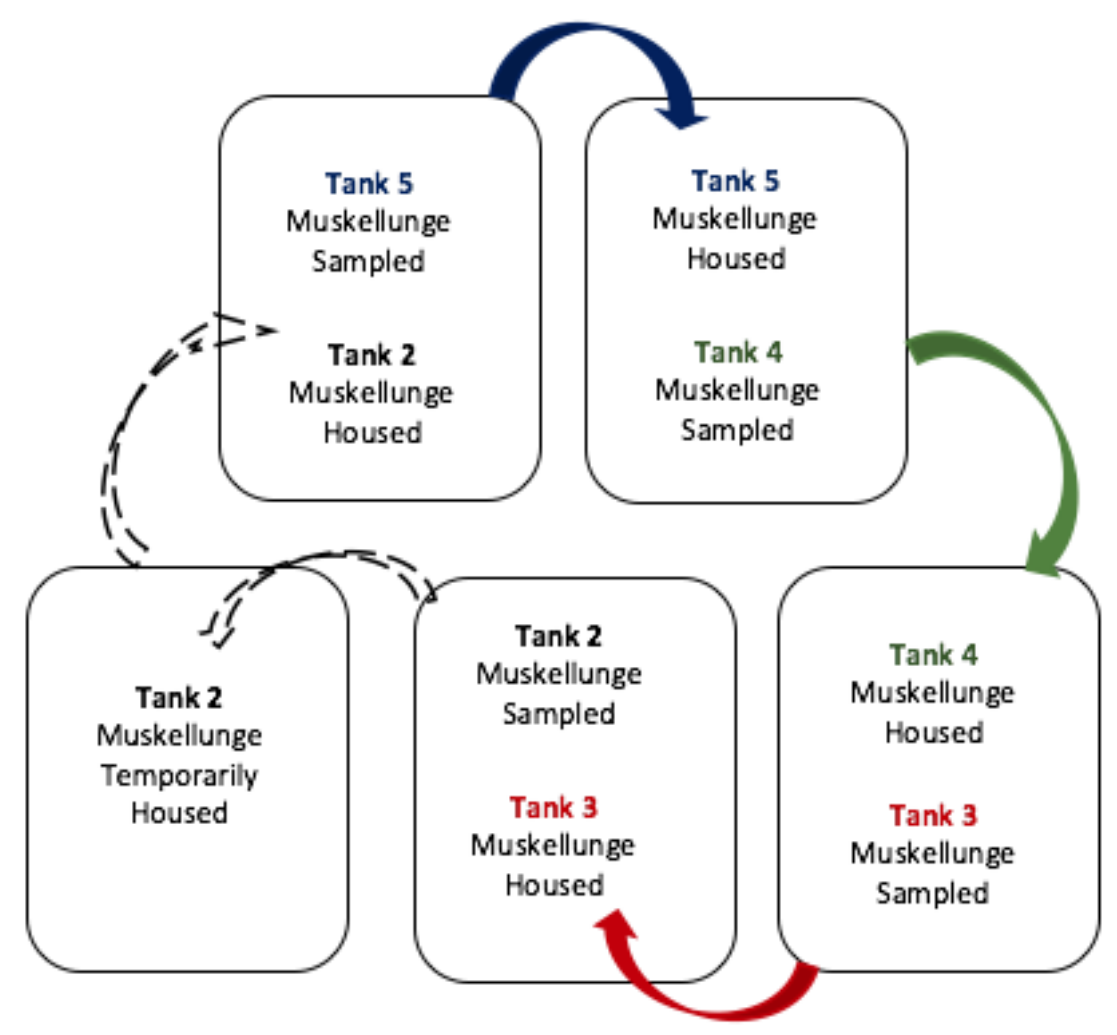

Figure 2.3. A diagram describing the order in which captive reared, age-0 Muskellunge were sampled and rotated through five 2.4 (1) x 1.2 (w) x 1.2 (h) m tanks at the Fleming College Muskellunge Hatchery. All fish were first sampled from Tank 2, and temporarily housed in Tank 1 . Fish from Tank 3 were sampled (weighed, measured, and photographed) and moved to Tank 2. This process continued with Tank 4 fish moved to Tank 3 (post-sampling), and Tank 5 fish to Tank 4. Once processing was complete after as specific sampling interval, all fish in Tank 1 were moved to Tank 2, as Tank 1 did not have the same dimensions as Tanks 2 through 5. 


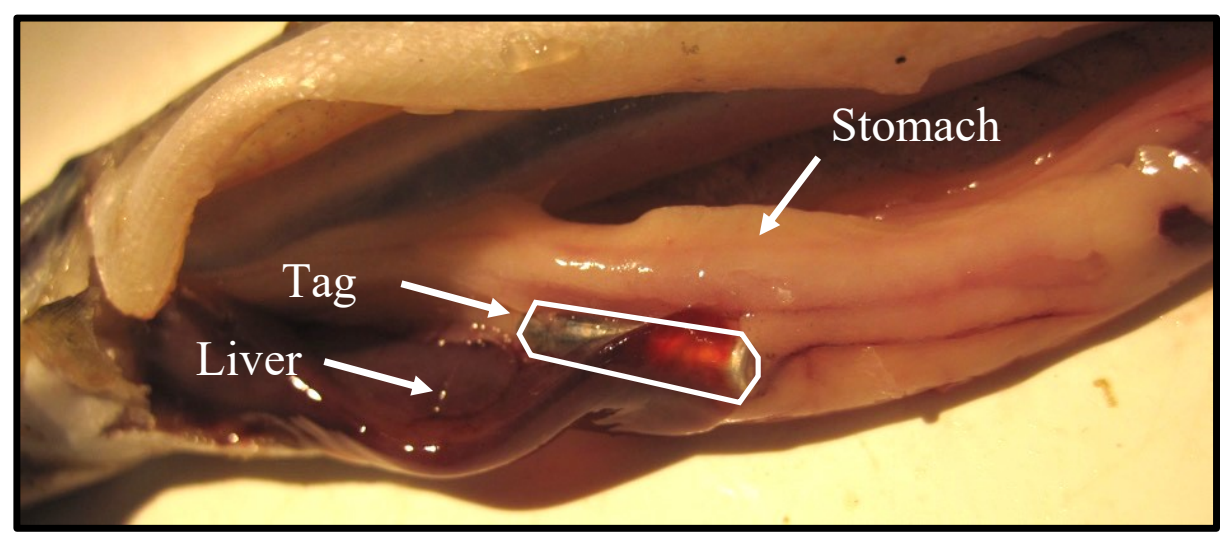

Figure 2.2. JSAT tag (white) location inside of a $250-\mathrm{mm}, 64.6$ gram (including tag) juvenile Muskellunge, 90-d post-implantation. This fish jumped from its tank and was found the morning of March 11, 2018. Necropsy was performed on March 16, 2018. The tag was found encapsulated between the stomach and the liver within the coelom, with no peritoneal infection. 

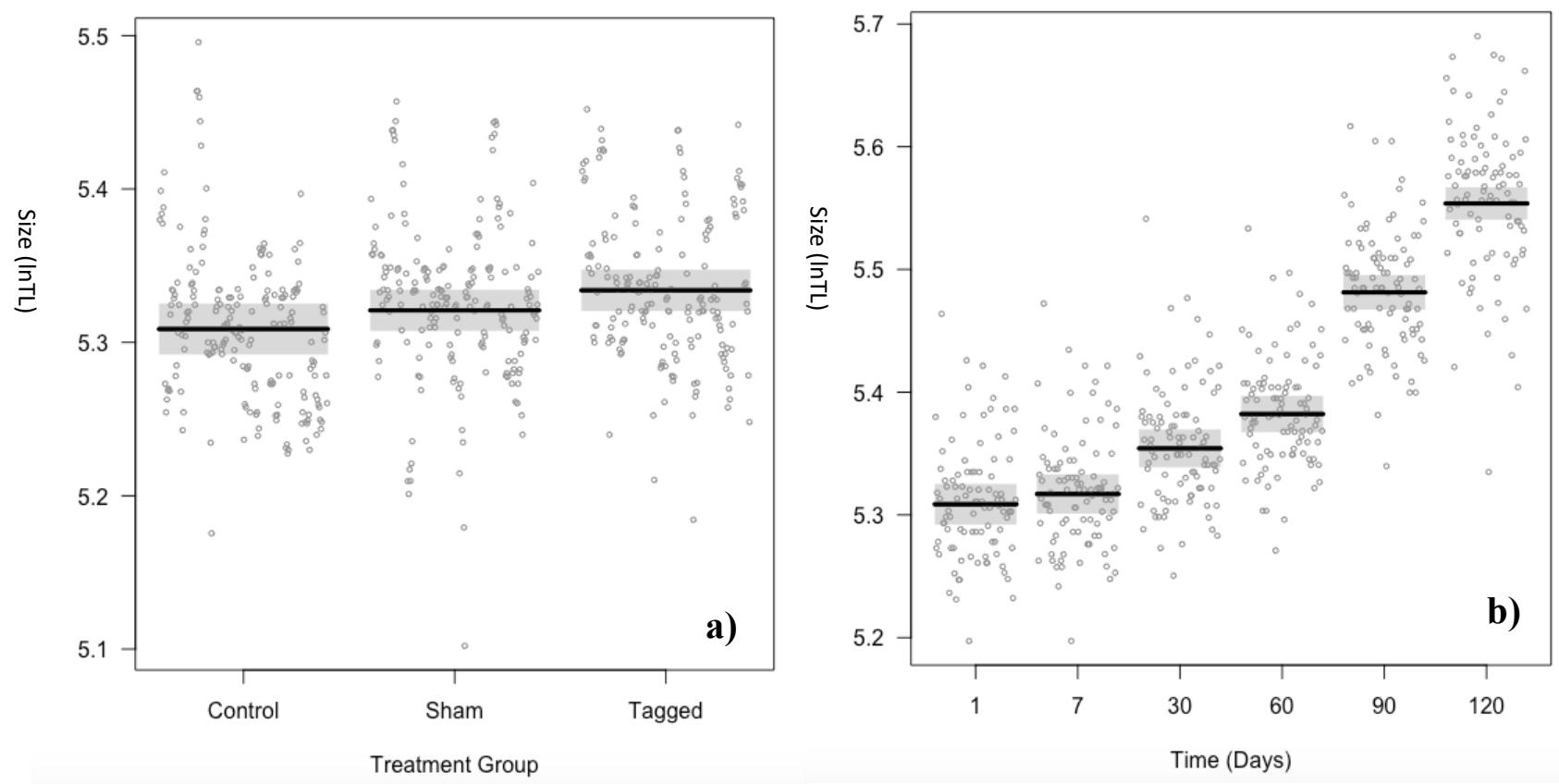

Figure 2.3. Presence of mini-acoustic transmitters had no effect on growth of age- 0 Muskellunge in a hatchery experiment. The average size as natural log total length $(\ln T L, \mathrm{~mm})$ of control, sham and tagged juvenile Muskellunge relative to treatment group 120-days post anesthesia, laparotomy, and surgical implantation of a mini acoustic tag (Treatment Group, a), and sampling interval in days (Time, b). Tagged fish were found to be significantly larger in average size at the start and end of the study, indicated by average length $(\ln T L)$ at the end of the study, relative to sham and control fish. 

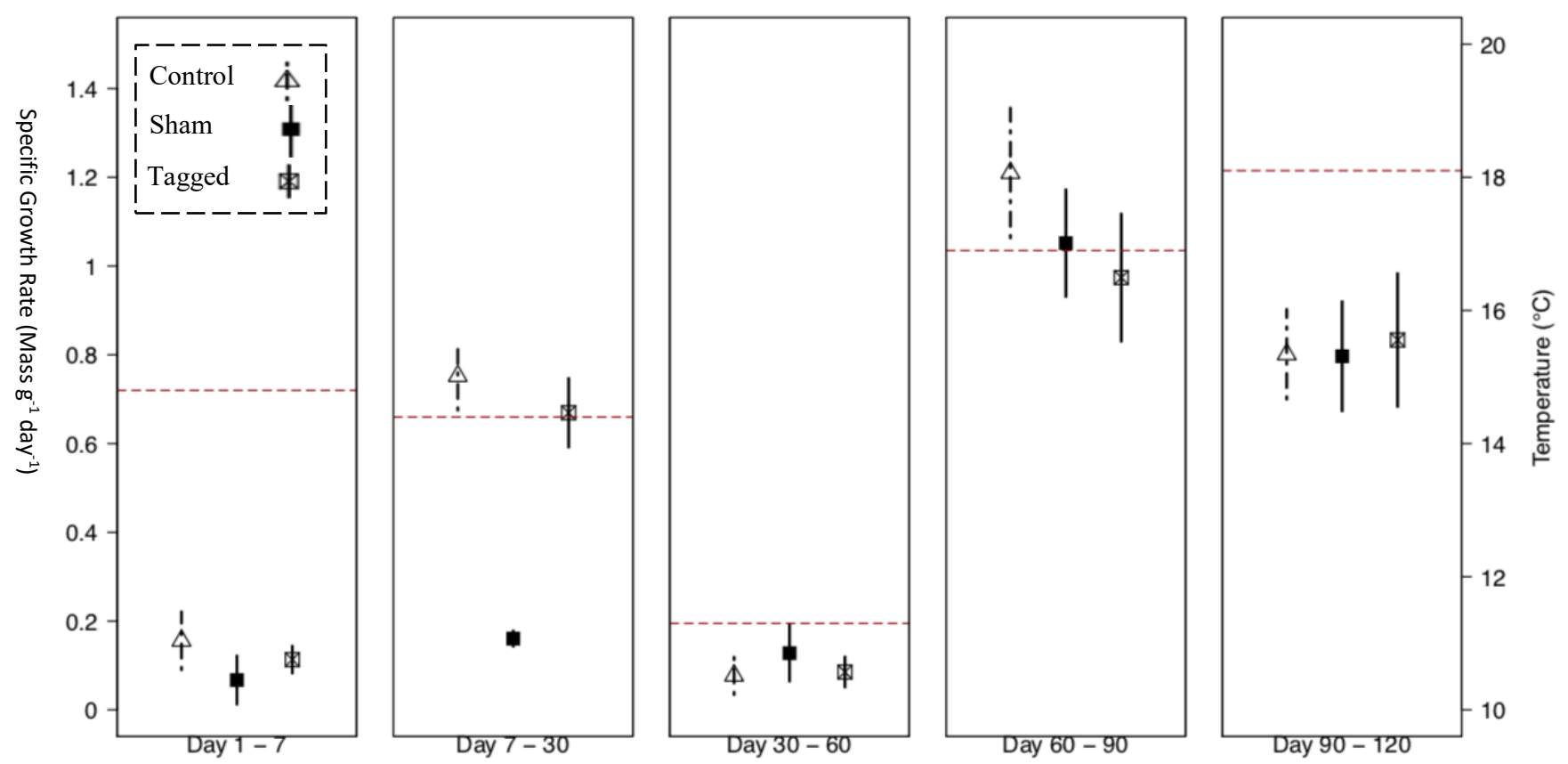

Figure 2.4. Specific (or relative) growth rates by weight (SGR, $\mathrm{g}^{-1} \mathrm{day}^{-1}$ ) of control, sham, and tagged age-0 Muskellunge over five sampling intervals. Error bars represent the SEs of treatment-specific means. Average water temperature for each sampling interval (horizontal dash line) is presented by the secondary Y axis. Sham fish had a significantly lower SGR between 7 and 30 days $(t=-5.67, p=$ $<0.001)$, as did tagged fish between 60 and 90 days $(t=-2.37, p=<0.018)$. Control fish had significantly higher SGR between 7 and 30 days $(t=8.87, p=<0.001), 60$ and 90 days $(t=9.07, p=$ $<0.001)$ and 90 to 120 days $(t=2.73, p=<0.001)$. 


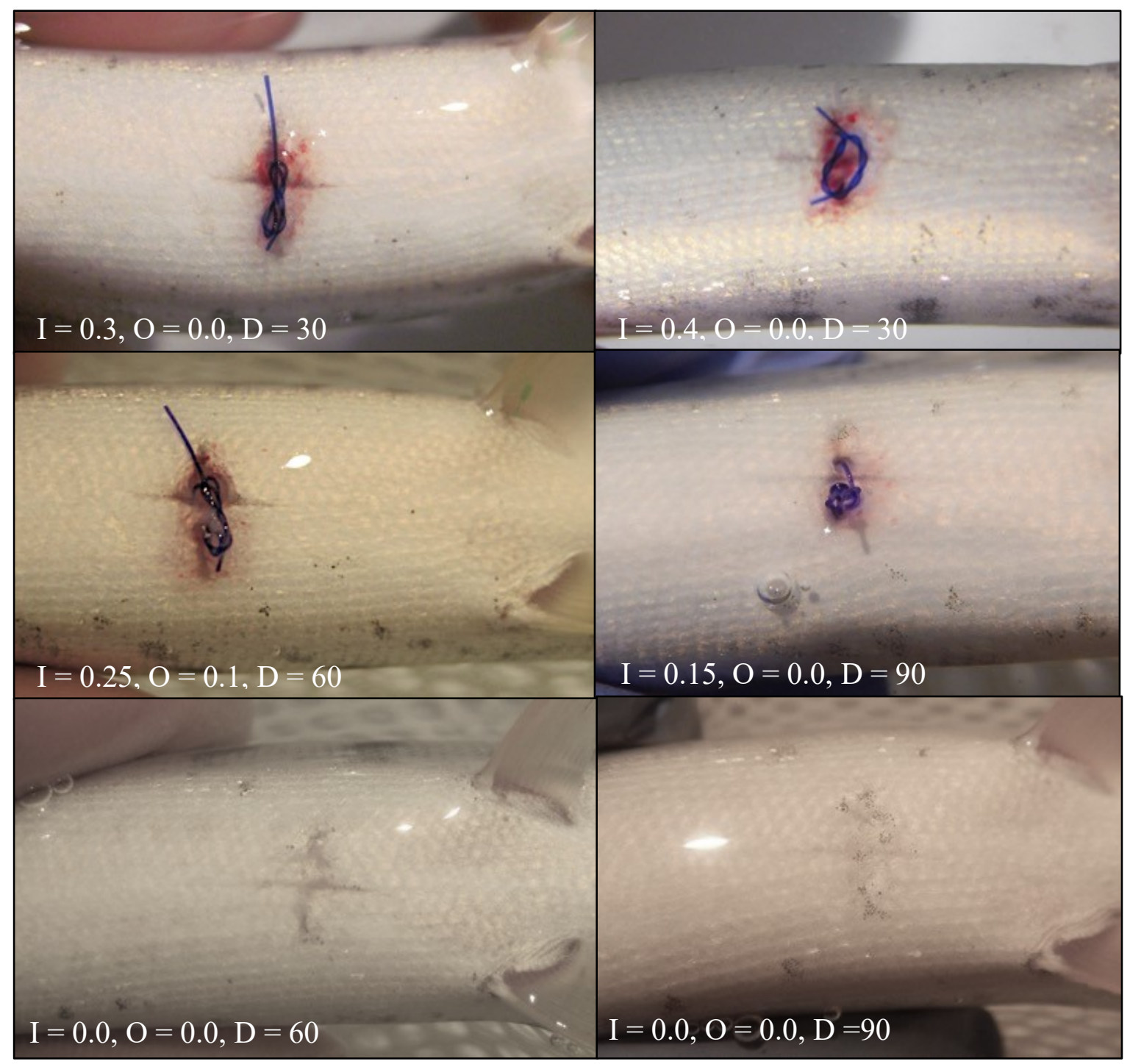

Figure 2.6. Representative photographs of six different juvenile Muskellunge, illustrating ranges of inflammation and wound openness. The key on each panel designates scores for inflammation (I) and wound openness (O) from 0 to 1, and days post-surgery (D). Score were based on six different percent categories (see Schoobyan et al. 2017 Table 1). 


\section{Reaction Score Post-Exposure to Moving Object}

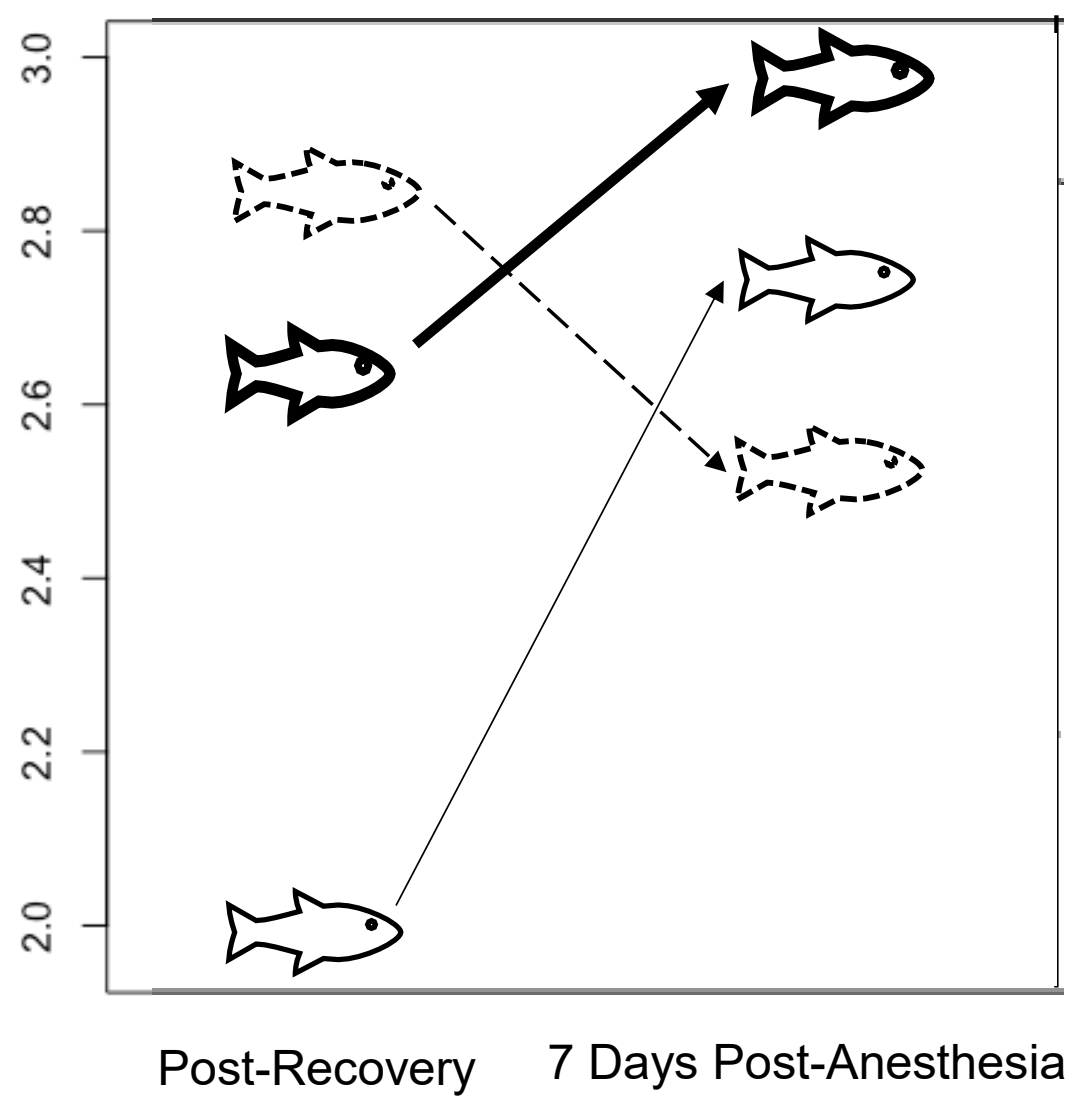

Figure 2.7. The average reaction post-exposure to the move object (movement relative to grid squares) by control (thick line), sham (dashed line) and tagged fish (thin line), post-recovery and seven days post-surgery. Tagged fish reacted significantly slower than sham or control fish postrecovery; their $95 \%$ confidence interval (with respect to their reaction score) did not cross zero. Moreover, tagged fish reacted significantly faster $\left(\operatorname{LR~}^{2}\right.$ $=7.8387, d f=2, p=0.02$ ) seven days after chemical anesthesia exposure compared to their initial reaction. 
Table 2.6. How juvenile Muskellunge were scored, post-anesthetic recovery. Individual fish were scored based on active movement during the five-minute acclimation interval in the aquarium, the flight initiation distance and reaction with respect to a moving object (aerator bubbler attached to a long rod), and the speed of the reaction response once the object was within two grid squares.

\begin{tabular}{llc} 
Activity & Response Description & Score \\
\hline $\begin{array}{l}\text { Acclimation } \\
\text { Period }\end{array}$ & Crossed $\geq 2$ grid squares during 5-minute acclimation interval & 2 \\
& Crossed < 2 grid squares during 5-minute acclimation interval & 1 \\
\hline $\begin{array}{l}\text { Flight Initiation } \\
\text { Reaction }\end{array}$ & Reacted (swam around tank) before object hit water & 4 \\
& Moved when object came within $\geq 2$ squares (far) & 3 \\
& Moved when object came within < 2 squares (close) & 2 \\
& Fish did not react or move & 1 \\
\hline $\begin{array}{l}\text { Reaction Post } \\
\text { Object Exposure }\end{array}$ & $\begin{array}{l}\text { Fast - Fish crossed tank in 1 second, once object was } \leq 2 \text { square away or } \\
\text { object had been in water less than 5 seconds } \\
\text { Moderate - Fish swam to maintain a minimum distance of 2 squares }\end{array}$ & 4 \\
& $\begin{array}{l}\text { Slow }- \text { Fish swam slowly as object pursed fish (less than 2 squares } \\
\text { distance) } \\
\text { None - Fish exhibited no speed through a swim response }\end{array}$ & 3
\end{tabular}


Table 2.2. Mean total length (TL) and weight (W) with standard deviations (SD) of juvenile Muskellunge by treatment group (Treat) over the six sampling intervals (Time), and the average water temperature between tanks over each sampling interval, and evaluation of the tag burden and effects of $0.2 \mathrm{~g} \mathrm{JSAT}$ acoustic tags on their growth (SGR) between November 2017 and March 2018 at the Fleming College Muskellunge hatchery. Significant values are bolded (e.g. SGR weight differences from sham and tagged fish relative to control fish) and starred (SGR of sham fish 7-30d, SGR of tagged fish 60-90-d; final total length of tagged fish relative to control fish).

\begin{tabular}{|c|c|c|c|c|c|c|c|c|}
\hline Treat & $\mathbf{N}$ & $\begin{array}{l}\text { Time } \\
\text { (Days) }\end{array}$ & $\begin{array}{c}\mathrm{TL} \pm \mathrm{SD} \\
(\mathrm{mm})\end{array}$ & $\mathrm{W} \pm \mathrm{SD}(\mathrm{g})$ & $\begin{array}{c}\text { Tag } \\
\text { Burden } \\
(\%)\end{array}$ & $\begin{array}{c}S G R \\
\ln w \pm S D \\
\left(\mathrm{~g}^{-1} \text { day- }^{-1}\right)\end{array}$ & $\begin{array}{c}\text { SGR } \\
\text { Intl } \pm \text { SD } \\
\left(\mathrm{mm}^{-1} \text { day }^{-1}\right)\end{array}$ & $\begin{array}{l}\text { Avg. } \\
\text { Temp } \\
\text { (oC) }\end{array}$ \\
\hline \multirow[t]{6}{*}{ Control } & 32 & 1 & $201 \pm 9.7$ & $29 \pm 5.4$ & - & - & - & - \\
\hline & 32 & 7 & $203 \pm 10.1$ & $31 \pm 6.0$ & - & $0.16 \pm 0.2$ & $0.16 \pm 0.2$ & - \\
\hline & 32 & 30 & $212 \pm 11.5$ & $37 \pm 6.8$ & - & $0.75 \pm 0.2$ & $0.37 \pm 0.2$ & 14.4 \\
\hline & 32 & 60 & $217 \pm 10.6$ & $38 \pm 6.8$ & - & $0.08 \pm 0.1$ & $0.18 \pm 0.1$ & 11.3 \\
\hline & 32 & 90 & $242 \pm 11.6$ & $55 \pm 10.4$ & - & $1.21 \pm 0.4$ & $0.80 \pm 0.2$ & 16.9 \\
\hline & 32 & 120 & $* 261 \pm 14.6$ & $71 \pm 15.5$ & - & $0.80 \pm 0.3$ & $0.64 \pm 0.2$ & 18.1 \\
\hline \multirow[t]{6}{*}{ Sham } & 32 & 1 & $206 \pm 10.4$ & $32 \pm 5.0$ & - & - & - & - \\
\hline & 32 & 7 & $207 \pm 9.6$ & $34 \pm 5.6$ & - & $0.07 \pm 0.2$ & $0.08 \pm 0.2$ & - \\
\hline & 32 & 30 & $215 \pm 10.4$ & $39 \pm 7.1$ & - & $0.66 \pm 0.4$ & $0.34 \pm 0.1$ & 14.4 \\
\hline & 32 & 60 & $221 \pm 10.5$ & $42 \pm 7.0$ & - & $0.13 \pm 0.2$ & $0.21 \pm 0.1$ & 11.3 \\
\hline & 32 & 90 & $245 \pm 13.1$ & $58 \pm 11.2$ & - & $1.05 \pm 0.3$ & $0.79 \pm 0.2$ & 16.9 \\
\hline & 32 & 120 & $264 \pm 17.4$ & $75 \pm 17.6$ & - & $0.80 \pm 0.3$ & $0.62 \pm 0.2$ & 18.1 \\
\hline \multirow[t]{6}{*}{ Tagged } & 32 & 1 & $208 \pm 10.0$ & $32 \pm 4.6$ & $0.6 \pm 0.08$ & - & - & - \\
\hline & 32 & 7 & $211 \pm 12.8$ & $33 \pm 5.6$ & $0.6 \pm 0.08$ & $0.11 \pm 0.1$ & $0.11 \pm 0.1$ & - \\
\hline & 32 & 30 & $217 \pm 10.2$ & $39 \pm 5.5$ & $0.5 \pm 0.07$ & $0.67 \pm 0.2$ & $0.31 \pm 0.1$ & 14.4 \\
\hline & 32 & 60 & $224 \pm 9.6$ & $42 \pm 6.8$ & $0.5 \pm 0.06$ & $0.08 \pm 0.1$ & $0.21 \pm 0.1$ & 11.3 \\
\hline & 30 & 90 & $246 \pm 11.3$ & $56 \pm 10.4$ & $0.4 \pm 0.07$ & $* 0.97 \pm 0.4$ & $0.71 \pm 0.2$ & 16.9 \\
\hline & 30 & 120 & $* 264 \pm 16.1$ & $72 \pm 18.2$ & $0.3 \pm 0.08$ & $0.83 \pm 0.4$ & $0.62 \pm 0.2$ & 18.1 \\
\hline
\end{tabular}


Table 2.3. Percent of juvenile Muskellunge from each treatment group that scored 4, 3, 2, or 1 (see Table 1) in response to a moving object in the behavioural experiment. The reactions of fish were scored immediately after their recovery from anesthesia (post-recovery), and seven-days after surgery. The number of fish (No. Fish) does not equal the original number assigned to each group $(n=32)$, as fish that did not have a matching score (post recovery or seven-days post-surgery) due to processing difficulties, or lack of video, were eliminated from the analysis. No significant differences were found between the percent of fish per reaction group over time.

\begin{tabular}{|c|c|c|c|c|c|c|c|c|c|}
\hline \multirow[b]{2}{*}{ Group } & \multicolumn{5}{|c|}{ Post-Recovery (\%) } & \multicolumn{4}{|c|}{ Post-Seven Days Post Surgery (\%) } \\
\hline & $\begin{array}{l}\text { No. } \\
\text { Fish }\end{array}$ & 4 & 3 & 2 & 1 & 4 & 3 & 2 & 1 \\
\hline Control & 31 & 6.5 & 51.6 & 22.6 & 19.4 & 9.7 & 71.0 & 9.7 & 9.7 \\
\hline Sham & 20 & 10 & 65 & 25 & 0 & 10 & 55 & 30 & 5 \\
\hline Tagged & 28 & 10.7 & 28.6 & 28.6 & 32.1 & 11 & 46 & 29 & 14 \\
\hline
\end{tabular}




\subsection{Supplementary}

Table S.2.1 Total length (TL) and weight (W) of all sham (Group "S"), tagged (Group “T”) and control fish (Group "C") studied in the Fleming College Muskellunge Hatchery mini-acoustic transmitter tagging study. TL and W are provided for day one (start) and six sampling intervals of $30,60,90$, and 120 days.

\begin{tabular}{|c|c|c|c|c|c|c|c|c|c|c|c|}
\hline Fish No. & Group & Start_TL & 30_TL & 60_TL & 90_TL & 120_TL & Start_W & 30_W & 60_W & 90_W & 120_W \\
\hline 1 & $S$ & 207 & 216 & 224 & 247 & 262 & 32 & 39.2 & 43.1 & 59.6 & 71.7 \\
\hline 2 & $\mathrm{~S}$ & 210 & 220 & 225 & 243 & 263 & 32 & 44.6 & 46 & 58.8 & 74.2 \\
\hline 3 & $S$ & 215 & 225 & 231 & 258 & 281 & 36 & 47.1 & 50.8 & 70.6 & 93 \\
\hline 4 & $S$ & 200 & 209 & 217 & 239 & 251 & 30.5 & 37.2 & 38.4 & 53.3 & 59.3 \\
\hline 5 & $S$ & 205 & 220 & 226 & 250 & 267 & 32.5 & 40.4 & 45 & 62.3 & 77.2 \\
\hline 6 & $S$ & 229 & 242 & 247 & 275 & 295 & 41.5 & 57.2 & 56.9 & 83 & 101 \\
\hline 7 & $S$ & 203 & 213 & 221 & 244 & 265 & 28.6 & 40.9 & 38.2 & 48.3 & 67.7 \\
\hline 8 & $S$ & 210 & 216 & 223 & 250 & 269 & 32.5 & 39.4 & 42 & 63.3 & 77.4 \\
\hline 9 & $S$ & 205 & 215 & 222 & 247 & 272 & 32.2 & 39.1 & 43 & 60 & 85.3 \\
\hline 10 & $S$ & 200 & 208 & 213 & 232 & 250 & 27.9 & 34.5 & 37.9 & 49.5 & 61.9 \\
\hline 11 & $S$ & 205 & 213 & 217 & 231 & 235 & 31.2 & 36.5 & 38.9 & 42.9 & 43 \\
\hline 12 & $S$ & 195 & 198 & 202 & 211 & 210 & 24 & 30.2 & 27.3 & 30.5 & 30 \\
\hline 13 & $S$ & 225 & 228 & 233 & 249 & 256 & 37.7 & 42.9 & 43.8 & 54.5 & 58 \\
\hline 14 & $S$ & 183 & 193 & 197 & 220 & 240 & 21.2 & 29.3 & 28.2 & 39.7 & 54 \\
\hline 15 & $S$ & 207 & 218 & 223 & 251 & 274 & 32.2 & 41.5 & 44.9 & 63 & 85.8 \\
\hline 16 & $S$ & 196 & 205 & 209 & 240 & 262 & 27.9 & 34 & 36.4 & 59.2 & 74 \\
\hline 17 & $S$ & 210 & 220 & 225 & 248 & 268 & 32.7 & 38.5 & 40.6 & 58 & 70.5 \\
\hline 18 & $S$ & 200 & 213 & 220 & 244 & 264 & 30.4 & 38.1 & 39.9 & 54.3 & 73.2 \\
\hline 19 & $S$ & 220 & 222 & 230 & 253 & 276 & 37.7 & 42.1 & 46.6 & 57.6 & 85 \\
\hline 20 & $S$ & 200 & 205 & 213 & 246 & 271 & 31 & 35 & 40.2 & 64.1 & 87.6 \\
\hline 21 & $S$ & 212 & 217 & 225 & 250 & 268 & 31.4 & 39.7 & 44.2 & 64.4 & 78.5 \\
\hline 22 & $S$ & 206 & 216 & 220 & 250 & 278 & 33.5 & 23.3 & 41.2 & 63.8 & 95.8 \\
\hline 23 & $S$ & 230 & 240 & 246 & 275 & 299.5 & 47.6 & 59.2 & 63.1 & 84.4 & 116.9 \\
\hline 24 & $S$ & 210 & 218 & 223 & 244 & 258 & 34.7 & 39.1 & 42 & 55.8 & 65.6 \\
\hline 25 & $S$ & 196 & 205 & 213 & 240 & 262 & 28 & 33.8 & 37 & 53.3 & 70 \\
\hline 26 & $S$ & 195 & 206 & 213 & 229 & 246 & 25.3 & 32.6 & 35.7 & 44 & 57.7 \\
\hline 27 & $S$ & 195 & 206 & 214 & 227 & 241 & 28.7 & 35.1 & 40.6 & 44.7 & 53.4 \\
\hline 28 & $S$ & 201 & 210 & 217 & 245 & 265 & 28.5 & 37 & 39.6 & 56 & 73.5 \\
\hline 29 & $S$ & 207 & 216 & 225 & 254 & 284 & 33.8 & 41.9 & 45.5 & 69.2 & 97.3 \\
\hline 30 & $S$ & 204 & 210 & 219 & 244 & 268 & 30.4 & 36.8 & 38.4 & 57.2 & 83 \\
\hline 31 & $S$ & 220 & 229 & 236 & 259 & 276 & 37.9 & 48.5 & 52.3 & 71.3 & 86.9 \\
\hline 32 & $S$ & 204 & 213 & 218 & 250 & 268 & 29.7 & w3 & 38 & 59.6 & 76.1 \\
\hline
\end{tabular}




\begin{tabular}{|c|c|c|c|c|c|c|c|c|c|c|c|}
\hline Fish No. & Group & Start_TL & 30_TL & 60_TL & 90_TL & 120_TL & Start_W & 30_W & 60_W & 90_W & 120_W \\
\hline 33 & $\mathrm{~T}$ & 230 & 238 & 244 & 258 & 271 & 40.3 & 46.9 & 48.3 & 58.5 & 72.5 \\
\hline 34 & $\mathrm{~T}$ & 224 & 231 & 236 & 249 & 261 & 37.6 & 48.2 & 46.2 & 53 & 67 \\
\hline 35 & $\mathrm{~T}$ & 205 & 210 & 215 & 227 & 228 & 29.7 & 32.5 & 33.8 & 37.7 & 36.3 \\
\hline 36 & $\mathrm{~T}$ & 195 & 203 & 210 & 239 & 261 & 26.2 & 31.8 & 34.9 & 53 & 71.3 \\
\hline 37 & $\mathrm{~T}$ & 206 & 214 & 221 & 243 & 269 & 30.7 & 37.1 & 40 & 55.7 & 78.7 \\
\hline 38 & $\mathrm{~T}$ & 215 & 227 & 232 & 258 & 276 & 33.2 & 43.6 & 44.6 & 63.6 & 79.9 \\
\hline 39 & $\mathrm{~T}$ & 203 & 214 & 224 & 244 & 265 & 31.6 & 38.6 & 43.2 & 55.4 & 74.8 \\
\hline 40 & $\mathrm{~T}$ & 209 & 215 & 218 & 227 & 234 & 32.5 & 37.2 & 37.6 & 39.6 & 43 \\
\hline 41 & $\mathrm{~T}$ & 208 & 219 & 226 & 253 & 275 & 33.3 & 41.8 & 45.6 & 68.2 & 89.9 \\
\hline 42 & $\mathrm{~T}$ & 197 & 207 & 215 & 229 & 252 & 25.7 & 30.6 & 33.4 & 40 & 55.5 \\
\hline 43 & $\mathrm{~T}$ & 206 & 214 & 220 & 239 & 265 & 33 & 41 & 43.3 & 60.6 & 80.9 \\
\hline 44 & $\mathrm{~T}$ & 196 & 205 & 214 & 238 & 253 & 26.1 & 32.5 & 36 & 50.3 & 60 \\
\hline 45 & $\mathrm{~T}$ & 209 & 217 & 220 & 237 & 254 & 32.3 & 37.1 & 38.3 & 49 & 59.9 \\
\hline 46 & $\mathrm{~T}$ & 199 & 210 & 216 & 241 & 267 & 28.9 & 35.9 & 37.8 & 55.9 & 77.3 \\
\hline 47 & $\mathrm{~T}$ & 208 & 217 & 225 & 243 & 262 & 31.5 & 38.2 & 42.3 & 51.4 & 67 \\
\hline 48 & $\mathrm{~T}$ & 219 & 229 & 233 & 252 & 271 & 37.6 & 43 & 44.9 & 58.1 & 75.4 \\
\hline 49 & $\mathrm{~T}$ & 197 & 206 & 214 & 243 & NA & 28.7 & 37.1 & 38.5 & 62.4 & NA \\
\hline 50 & $\mathrm{~T}$ & 207 & 218 & 223 & 243 & 260 & 28.7 & 36.8 & 37.2 & 49.1 & 61.4 \\
\hline 51 & $\mathrm{~T}$ & 224 & 233 & 240 & 268 & 298 & 42.3 & 49 & 53.9 & 78.4 & 114.8 \\
\hline 52 & $\mathrm{~T}$ & 212 & 222 & 228 & 249 & 273 & 31.8 & 39.5 & 41.2 & 43.3 & 78.9 \\
\hline 53 & $\mathrm{~T}$ & 201 & 212 & 218 & 246 & 269 & 31.8 & 38.3 & 41.7 & 64.1 & 83.8 \\
\hline 54 & $\mathrm{~T}$ & 226 & 241 & 246 & 270 & 290 & 42.3 & 54.6 & 54.3 & 72.2 & 98.1 \\
\hline 55 & $\mathrm{~T}$ & 215 & 220 & 225 & 238 & 241 & 31.8 & 36.9 & 38.8 & 44.3 & 43.5 \\
\hline 56 & $\mathrm{~T}$ & 201 & 210 & 219 & 255 & 278 & 30.3 & 37.9 & 43 & 71 & 91.1 \\
\hline 57 & $\mathrm{~T}$ & 203 & 216 & 226 & 253 & NA & 28.8 & 39.2 & 43.9 & 63.8 & NA \\
\hline 58 & $\mathrm{~T}$ & 200 & 207 & 214 & 234 & 255 & 27.9 & 42.5 & 36.8 & 49 & 66.3 \\
\hline 59 & $\mathrm{~T}$ & 192 & 202 & 211 & 237 & 259 & 24.2 & 30.3 & 34.7 & 48.6 & 63.8 \\
\hline 60 & $\mathrm{~T}$ & 220 & 228 & 234 & 265 & 295 & 36.9 & 43.1 & 45.6 & 73.5 & 110.9 \\
\hline 61 & $\mathrm{~T}$ & 224 & 232 & 239 & 261 & 279 & 38.7 & 44.3 & 48.3 & 64.8 & 80.3 \\
\hline 62 & $\mathrm{~T}$ & 208 & 215 & 220 & 233 & 243 & 29.9 & 35 & 34.2 & 42.6 & 48.4 \\
\hline 63 & $\mathrm{~T}$ & 206 & 214 & 222 & 247 & 260 & 32.2 & 40.1 & 41.5 & 56.5 & 70.1 \\
\hline 64 & $\mathrm{~T}$ & 206 & 213 & 218 & 240 & 254 & 31.7 & 35.8 & 37.1 & 51.8 & 60.9 \\
\hline
\end{tabular}




\begin{tabular}{|c|c|c|c|c|c|c|c|c|c|c|c|}
\hline Fish No. & Group & Start_TL & 30_TL & 60_TL & 90_TL & 120_TL & Start_W & 30_W & 60_W & 90_W & 120_W \\
\hline 65 & $\mathrm{C}$ & 195 & 200 & 206 & 224 & 242 & 26.2 & 29.8 & 33.1 & 44.1 & 54.2 \\
\hline 66 & C & 213 & 222 & 229 & 253 & 273 & 35.4 & 43.1 & 45.1 & 62.3 & 82.8 \\
\hline 67 & C & 206 & 215 & 223 & 249 & 271 & 32.3 & 39.6 & 44 & 63.1 & 83.5 \\
\hline 68 & $\mathrm{C}$ & 195 & 204 & 210 & 241 & 264 & 25.2 & 32.6 & 35.5 & 55.1 & 73.4 \\
\hline 69 & $\mathrm{C}$ & 191 & 200 & 207 & 233 & 259 & 23.8 & 29.3 & 32.7 & 49.4 & 71 \\
\hline 70 & $\mathrm{C}$ & 205 & 217 & 222 & 241 & 264 & 31.9 & 39.8 & 41.4 & 54.9 & 76.5 \\
\hline 71 & $\mathrm{C}$ & 200 & 212 & 216 & 241 & 259 & 28.7 & 36 & 36.9 & 55.1 & 70.4 \\
\hline 72 & $\mathrm{C}$ & 205 & 213 & 222 & 243 & 258 & 31.8 & 39.7 & 42.4 & 58.7 & 68.7 \\
\hline 73 & C & 198 & 211 & 217 & 244 & 265 & 29 & 36.4 & 40.3 & 65 & 85.2 \\
\hline 74 & C & 201 & 216 & 216 & 240 & 252 & 28.2 & 39.9 & 34.1 & 50.9 & 58.3 \\
\hline 75 & $\mathrm{C}$ & 188 & 201 & 212 & 234 & 252 & 24.4 & 37.8 & 35.3 & 48.2 & 60.8 \\
\hline 76 & $\mathrm{C}$ & 200 & 210 & 220 & 250 & 267 & 28.7 & 36.8 & 40.2 & 59.4 & 73.5 \\
\hline 77 & C & 208 & 216 & 223 & 244 & 268 & 31.9 & 36.1 & 40.1 & 57 & 79.5 \\
\hline 78 & C & 236 & 255 & 253 & 275 & 291 & 48.2 & 59 & 60.1 & 77.9 & 87.9 \\
\hline 79 & C & 211 & 225 & 232 & 258 & 283 & 37.2 & 48.1 & 52 & 74.4 & 99 \\
\hline 80 & C & 199 & 208 & 214 & 223 & 226 & 26.7 & 33.2 & 34.4 & 35.1 & 35 \\
\hline 81 & C & 199 & 209 & 215 & 243 & 262 & 28.8 & 35.5 & 39.2 & 63.3 & 75.3 \\
\hline 82 & C & 206 & 217 & 221 & 237 & 254 & 31.2 & 37 & 37.2 & 49.2 & 59.9 \\
\hline 83 & C & 217 & 228 & 233 & 260 & 286 & 40.3 & 51.2 & 52.4 & 76.3 & 107.3 \\
\hline 84 & C & 195 & 202 & 209 & 231 & 248 & 25.6 & 30.9 & 32.5 & 47.2 & 55.3 \\
\hline 85 & C & 204 & 217 & 223 & 245 & 264 & 29.7 & 37.1 & 40 & 54.7 & 68.5 \\
\hline 86 & C & 196 & 218 & 217 & 244 & 276 & 26.2 & 36 & 37.2 & 57.7 & 84.3 \\
\hline 87 & C & 194 & 198 & 206 & 237 & 257 & 25.3 & 30.4 & 33.1 & 54.6 & 74.6 \\
\hline 88 & C & 203 & 213 & 220 & 250 & 272 & 31 & 36.8 & 30.7 & 61.8 & 80.4 \\
\hline 89 & C & 207 & 221 & 224 & 254 & 282 & 31.3 & 43.4 & 41.1 & 66.6 & 90.4 \\
\hline 90 & C & 190 & 203 & 208 & 226 & 240 & 23.8 & 30.7 & 33.1 & 39.1 & 49.5 \\
\hline 91 & C & 190 & 200 & 201 & 234 & 256 & 23.7 & 29.4 & 31.5 & 52.3 & 67.8 \\
\hline 92 & C & 198 & 207 & 211 & 230 & 241 & 26.5 & 31.4 & 35.6 & 46.4 & 53.1 \\
\hline 93 & C & 193 & 201 & 205 & 225 & 243 & 23.9 & 30.1 & 31.1 & 41.8 & 54.7 \\
\hline 94 & C & 205 & 210 & 217 & 233 & 246 & 27.8 & 31.4 & 33.7 & 41 & 49.7 \\
\hline 95 & C & 187 & 195 & 201 & 233 & 260 & 22.6 & 28.2 & 31.6 & 51.2 & 73 \\
\hline 96 & C & 203 & 216 & 223 & 253 & 265 & 30.8 & 39.6 & 42.8 & 61.2 & 71 \\
\hline
\end{tabular}


Table S.2.2 Specific growth rates (sgr) for sham (Group "S"), tagged (Group "T") and control fish (Group "C") studied in the Fleming College Muskellunge Hatchery mini-acoustic transmitter tagging study for 10 sampling intervals. There was no significant difference in sgr over the full study period (sgr_1_120).

\begin{tabular}{|c|c|c|c|c|c|c|c|c|c|c|c|}
\hline Fish No. & Group & sgr_1_30 & sgr_1_60 & sgr_30_60 & sgr_1_90 & sgr_30_90 & sgr_60_90 & sgr_1_120 & sgr_30_120 & sgr_60_120 & sgr_90_120 \\
\hline 1 & $S$ & 0.164 & 0.496 & 0.158 & 0.691 & 0.698 & 1.080 & 0.672 & 0.671 & 0.848 & 0.616 \\
\hline 2 & $\mathrm{~S}$ & 0.202 & 0.605 & 0.052 & 0.676 & 0.461 & 0.818 & 0.701 & 0.566 & 0.797 & 0.775 \\
\hline 3 & $S$ & 0.198 & 0.574 & 0.126 & 0.748 & 0.675 & 1.097 & 0.791 & 0.756 & 1.008 & 0.919 \\
\hline 4 & $\mathrm{~S}$ & 0.148 & 0.384 & 0.053 & 0.620 & 0.599 & 1.093 & 0.554 & 0.518 & 0.724 & 0.356 \\
\hline 5 & $\mathrm{~S}$ & 0.265 & 0.542 & 0.180 & 0.723 & 0.722 & 1.084 & 0.721 & 0.720 & 0.900 & 0.715 \\
\hline 6 & $S$ & 0.240 & 0.526 & -0.009 & 0.770 & 0.620 & 1.258 & 0.741 & 0.632 & 0.956 & 0.654 \\
\hline 7 & $S$ & 0.188 & 0.482 & -0.114 & 0.582 & 0.277 & 0.782 & 0.718 & 0.560 & 0.954 & 1.126 \\
\hline 8 & $S$ & 0.143 & 0.427 & 0.107 & 0.741 & 0.790 & 1.367 & 0.723 & 0.750 & 1.019 & 0.670 \\
\hline 9 & $S$ & 0.144 & 0.482 & 0.158 & 0.692 & 0.714 & 1.110 & 0.812 & 0.867 & 1.142 & 1.173 \\
\hline 10 & $S$ & 0.171 & 0.511 & 0.157 & 0.637 & 0.602 & 0.890 & 0.664 & 0.650 & 0.818 & 0.745 \\
\hline 11 & $\mathrm{~S}$ & 0.124 & 0.368 & 0.106 & 0.354 & 0.269 & 0.326 & 0.267 & 0.182 & 0.167 & 0.008 \\
\hline 12 & $S$ & 0.066 & 0.215 & -0.168 & 0.266 & 0.016 & 0.369 & 0.186 & -0.007 & 0.157 & -0.055 \\
\hline 13 & $S$ & 0.076 & 0.250 & 0.035 & 0.409 & 0.399 & 0.729 & 0.359 & 0.335 & 0.468 & 0.207 \\
\hline 14 & $S$ & 0.231 & 0.476 & -0.064 & 0.697 & 0.506 & 1.140 & 0.779 & 0.679 & 1.083 & 1.025 \\
\hline 15 & $S$ & 0.183 & 0.554 & 0.131 & 0.746 & 0.696 & 1.129 & 0.817 & 0.807 & 1.079 & 1.030 \\
\hline 16 & $S$ & 0.107 & 0.443 & 0.114 & 0.836 & 0.924 & 1.621 & 0.813 & 0.864 & 1.182 & 0.744 \\
\hline 17 & $S$ & 0.161 & 0.361 & 0.089 & 0.637 & 0.683 & 1.189 & 0.640 & 0.672 & 0.920 & 0.651 \\
\hline 19 & $S$ & 0.160 & 0.353 & 0.169 & 0.471 & 0.522 & 0.706 & 0.677 & 0.781 & 1.002 & 1.297 \\
\hline 20 & $S$ & 0.064 & 0.433 & 0.231 & 0.807 & 1.008 & 1.555 & 0.866 & 1.019 & 1.298 & 1.041 \\
\hline 21 & $S$ & 0.205 & 0.570 & 0.179 & 0.798 & 0.806 & 1.255 & 0.764 & 0.757 & 0.957 & 0.660 \\
\hline 22 & $S$ & 0.143 & 0.345 & 0.950 & 0.716 & 1.679 & 1.458 & 0.876 & 1.571 & 1.406 & 1.355 \\
\hline 23 & $S$ & 0.147 & 0.470 & 0.106 & 0.636 & 0.591 & 0.969 & 0.749 & 0.756 & 1.028 & 1.086 \\
\hline 24 & $S$ & 0.121 & 0.318 & 0.119 & 0.528 & 0.593 & 0.947 & 0.531 & 0.575 & 0.743 & 0.539 \\
\hline 25 & $S$ & 0.151 & 0.465 & 0.151 & 0.715 & 0.759 & 1.217 & 0.764 & 0.809 & 1.063 & 0.909 \\
\hline 26 & $S$ & 0.172 & 0.574 & 0.151 & 0.615 & 0.500 & 0.697 & 0.687 & 0.634 & 0.800 & 0.904 \\
\hline 27 & $S$ & 0.172 & 0.578 & 0.243 & 0.492 & 0.403 & 0.321 & 0.517 & 0.466 & 0.457 & 0.593 \\
\hline 28 & $S$ & 0.169 & 0.548 & 0.113 & 0.750 & 0.691 & 1.155 & 0.789 & 0.763 & 1.031 & 0.906 \\
\hline 29 & $S$ & 0.185 & 0.495 & 0.137 & 0.796 & 0.836 & 1.398 & 0.881 & 0.936 & 1.267 & 1.136 \\
\hline 30 & $S$ & 0.084 & 0.389 & 0.071 & 0.702 & 0.735 & 1.328 & 0.837 & 0.904 & 1.285 & 1.241 \\
\hline 31 & $S$ & 0.194 & 0.537 & 0.126 & 0.702 & 0.642 & 1.033 & 0.692 & 0.648 & 0.846 & 0.660 \\
\hline 32 & $S$ & 0.164 & 0.411 & 0.156 & 0.774 & 0.906 & 1.500 & 0.784 & 0.876 & 1.157 & 0.815 \\
\hline
\end{tabular}




\begin{tabular}{|c|c|c|c|c|c|c|c|c|c|c|c|}
\hline Fish No. & Group & sgr_1_30 & sgr_1_60 & sgr_30_60 & sgr_1_90 & sgr_30_90 & sgr_60_90 & sgr_1_120 & sgr_30_120 & sgr_60_120 & sgr_90_120 \\
\hline 33 & $\mathrm{~T}$ & 0.506 & 0.302 & 0.049 & 0.414 & 0.368 & 0.639 & 0.489 & 0.484 & 0.677 & 0.715 \\
\hline 34 & $\mathrm{~T}$ & 0.828 & 0.343 & -0.071 & 0.381 & 0.158 & 0.458 & 0.481 & 0.366 & 0.620 & 0.781 \\
\hline 35 & $\mathrm{~T}$ & 0.300 & 0.216 & 0.065 & 0.265 & 0.247 & 0.364 & 0.167 & 0.123 & 0.119 & -0.126 \\
\hline 36 & $\mathrm{~T}$ & 0.646 & 0.478 & 0.155 & 0.783 & 0.851 & 1.393 & 0.834 & 0.897 & 1.191 & 0.989 \\
\hline 37 & $\mathrm{~T}$ & 0.631 & 0.441 & 0.125 & 0.662 & 0.677 & 1.104 & 0.784 & 0.836 & 1.128 & 1.152 \\
\hline 38 & $\mathrm{~T}$ & 0.908 & 0.492 & 0.038 & 0.722 & 0.629 & 1.183 & 0.732 & 0.673 & 0.972 & 0.761 \\
\hline 39 & $\mathrm{~T}$ & 0.667 & 0.521 & 0.188 & 0.624 & 0.602 & 0.829 & 0.718 & 0.735 & 0.915 & 1.001 \\
\hline 40 & $\mathrm{~T}$ & 0.450 & 0.243 & 0.018 & 0.220 & 0.104 & 0.173 & 0.233 & 0.161 & 0.224 & 0.275 \\
\hline 41 & $\mathrm{~T}$ & 0.758 & 0.524 & 0.145 & 0.797 & 0.816 & 1.342 & 0.828 & 0.851 & 1.131 & 0.921 \\
\hline 42 & $\mathrm{~T}$ & 0.582 & 0.437 & 0.146 & 0.492 & 0.446 & 0.601 & 0.642 & 0.662 & 0.846 & 1.092 \\
\hline 43 & $\mathrm{~T}$ & 0.724 & 0.453 & 0.091 & 0.675 & 0.651 & 1.120 & 0.747 & 0.755 & 1.042 & 0.963 \\
\hline 44 & $\mathrm{~T}$ & 0.731 & 0.536 & 0.170 & 0.729 & 0.728 & 1.115 & 0.694 & 0.681 & 0.851 & 0.588 \\
\hline 45 & $\mathrm{~T}$ & 0.462 & 0.284 & 0.053 & 0.463 & 0.464 & 0.821 & 0.515 & 0.532 & 0.745 & 0.670 \\
\hline 46 & $\mathrm{~T}$ & 0.723 & 0.447 & 0.086 & 0.733 & 0.738 & 1.304 & 0.820 & 0.852 & 1.192 & 1.080 \\
\hline 47 & $\mathrm{~T}$ & 0.643 & 0.491 & 0.170 & 0.544 & 0.495 & 0.650 & 0.629 & 0.624 & 0.767 & 0.884 \\
\hline 48 & $\mathrm{~T}$ & 0.447 & 0.296 & 0.072 & 0.484 & 0.502 & 0.859 & 0.580 & 0.624 & 0.864 & 0.869 \\
\hline 49 & $\mathrm{~T}$ & 0.856 & 0.490 & 0.062 & 0.863 & 0.867 & 1.610 & NA & NA & NA & NA \\
\hline 50 & $\mathrm{~T}$ & 0.829 & 0.432 & 0.018 & 0.597 & 0.481 & 0.925 & 0.634 & 0.569 & 0.835 & 0.745 \\
\hline 51 & $\mathrm{~T}$ & 0.490 & 0.404 & 0.159 & 0.686 & 0.783 & 1.249 & 0.832 & 0.946 & 1.260 & 1.271 \\
\hline 52 & $\mathrm{~T}$ & 0.723 & 0.432 & 0.070 & 0.343 & 0.153 & 0.166 & 0.757 & 0.769 & 1.083 & 2.000 \\
\hline 53 & $\mathrm{~T}$ & 0.620 & 0.452 & 0.142 & 0.779 & 0.858 & 1.433 & 0.807 & 0.870 & 1.163 & 0.893 \\
\hline 54 & $\mathrm{~T}$ & 0.851 & 0.416 & -0.009 & 0.594 & 0.466 & 0.950 & 0.701 & 0.651 & 0.986 & 1.022 \\
\hline 55 & $\mathrm{~T}$ & 0.496 & 0.332 & 0.084 & 0.368 & 0.305 & 0.442 & 0.261 & 0.183 & 0.191 & -0.061 \\
\hline 56 & $\mathrm{~T}$ & 0.746 & 0.583 & 0.210 & 0.946 & 1.046 & 1.672 & 0.917 & 0.974 & 1.251 & 0.831 \\
\hline 57 & $\mathrm{~T}$ & 1.028 & 0.703 & 0.189 & 0.884 & 0.812 & 1.246 & NA & NA & NA & NA \\
\hline 58 & $\mathrm{~T}$ & 1.403 & 0.461 & -0.240 & 0.626 & 0.237 & 0.954 & 0.721 & 0.494 & 0.981 & 1.008 \\
\hline 59 & $\mathrm{~T}$ & 0.749 & 0.601 & 0.226 & 0.775 & 0.787 & 1.123 & 0.808 & 0.827 & 1.015 & 0.907 \\
\hline 60 & $\mathrm{~T}$ & 0.518 & 0.353 & 0.094 & 0.766 & 0.890 & 1.591 & 0.917 & 1.050 & 1.481 & 1.371 \\
\hline 61 & $\mathrm{~T}$ & 0.450 & 0.369 & 0.144 & 0.573 & 0.634 & 0.980 & 0.608 & 0.661 & 0.847 & 0.715 \\
\hline 62 & $\mathrm{~T}$ & 0.525 & 0.224 & -0.039 & 0.393 & 0.328 & 0.732 & 0.401 & 0.360 & 0.579 & 0.425 \\
\hline 63 & $\mathrm{~T}$ & 0.731 & 0.423 & 0.057 & 0.625 & 0.571 & 1.028 & 0.648 & 0.621 & 0.874 & 0.719 \\
\hline 64 & $\mathrm{~T}$ & 0.405 & 0.262 & 0.059 & 0.546 & 0.616 & 1.113 & 0.544 & 0.590 & 0.826 & 0.539 \\
\hline
\end{tabular}




\begin{tabular}{|c|c|c|c|c|c|c|c|c|c|c|c|}
\hline Fish No. & Group & sgr_1_30 & sgr_1_60 & sgr_30_60 & sgr_1_90 & sgr_30_90 & sgr_60_90 & sgr_1_120 & sgr_30_120 & sgr_60_120 & sgr_90_120 \\
\hline 65 & C & 0.429 & 0.390 & 0.175 & 0.579 & 0.653 & 0.956 & 0.606 & 0.665 & 0.822 & 0.687 \\
\hline 66 & C & 0.656 & 0.404 & 0.076 & 0.628 & 0.614 & 1.077 & 0.708 & 0.725 & 1.013 & 0.948 \\
\hline 67 & C & 0.679 & 0.515 & 0.176 & 0.744 & 0.776 & 1.202 & 0.791 & 0.829 & 1.068 & 0.934 \\
\hline 68 & $\mathrm{C}$ & 0.858 & 0.571 & 0.142 & 0.869 & 0.875 & 1.465 & 0.891 & 0.902 & 1.211 & 0.956 \\
\hline 69 & C & 0.693 & 0.529 & 0.183 & 0.811 & 0.871 & 1.375 & 0.911 & 0.983 & 1.292 & 1.209 \\
\hline 70 & C & 0.738 & 0.434 & 0.066 & 0.603 & 0.536 & 0.941 & 0.729 & 0.726 & 1.023 & 1.106 \\
\hline 71 & C & 0.755 & 0.419 & 0.041 & 0.725 & 0.709 & 1.336 & 0.748 & 0.745 & 1.077 & 0.817 \\
\hline 72 & C & 0.740 & 0.479 & 0.110 & 0.681 & 0.652 & 1.084 & 0.642 & 0.609 & 0.804 & 0.524 \\
\hline 73 & $\mathrm{C}$ & 0.758 & 0.548 & 0.170 & 0.897 & 0.966 & 1.593 & 0.898 & 0.945 & 1.248 & 0.902 \\
\hline 74 & C & 1.157 & 0.317 & -0.262 & 0.656 & 0.406 & 1.335 & 0.605 & 0.421 & 0.894 & 0.452 \\
\hline 75 & $C$ & 1.459 & 0.615 & -0.114 & 0.756 & 0.405 & 1.038 & 0.761 & 0.528 & 0.906 & 0.774 \\
\hline 76 & C & 0.829 & 0.562 & 0.147 & 0.808 & 0.798 & 1.301 & 0.784 & 0.769 & 1.006 & 0.710 \\
\hline 77 & $C$ & 0.412 & 0.381 & 0.175 & 0.645 & 0.761 & 1.172 & 0.761 & 0.877 & 1.141 & 1.109 \\
\hline 78 & C & 0.674 & 0.368 & 0.031 & 0.533 & 0.463 & 0.865 & 0.501 & 0.443 & 0.634 & 0.403 \\
\hline 79 & $C$ & 0.857 & 0.558 & 0.130 & 0.770 & 0.727 & 1.194 & 0.816 & 0.802 & 1.073 & 0.952 \\
\hline 80 & $C$ & 0.726 & 0.422 & 0.059 & 0.304 & 0.093 & 0.067 & 0.226 & 0.059 & 0.029 & -0.010 \\
\hline 81 & C & 0.697 & 0.514 & 0.165 & 0.875 & 0.964 & 1.597 & 0.801 & 0.835 & 1.088 & 0.579 \\
\hline 82 & $C$ & 0.568 & 0.293 & 0.009 & 0.506 & 0.475 & 0.932 & 0.544 & 0.535 & 0.794 & 0.656 \\
\hline 83 & C & 0.798 & 0.438 & 0.039 & 0.709 & 0.665 & 1.253 & 0.816 & 0.822 & 1.195 & 1.137 \\
\hline 84 & $C$ & 0.627 & 0.398 & 0.084 & 0.680 & 0.706 & 1.244 & 0.642 & 0.647 & 0.886 & 0.528 \\
\hline 85 & C & 0.742 & 0.496 & 0.125 & 0.679 & 0.647 & 1.043 & 0.696 & 0.681 & 0.897 & 0.750 \\
\hline 86 & $C$ & 1.059 & 0.584 & 0.055 & 0.877 & 0.786 & 1.463 & 0.974 & 0.945 & 1.363 & 1.264 \\
\hline 87 & $C$ & 0.612 & 0.448 & 0.142 & 0.855 & 0.976 & 1.668 & 0.901 & 0.997 & 1.354 & 1.040 \\
\hline 88 & C & 0.572 & -0.016 & -0.302 & 0.767 & 0.864 & 2.332 & 0.794 & 0.868 & 1.605 & 0.877 \\
\hline 89 & $C$ & 1.089 & 0.454 & -0.091 & 0.839 & 0.714 & 1.609 & 0.884 & 0.815 & 1.314 & 1.018 \\
\hline 90 & C & 0.849 & 0.550 & 0.125 & 0.552 & 0.403 & 0.555 & 0.610 & 0.531 & 0.671 & 0.786 \\
\hline 91 & $C$ & 0.718 & 0.474 & 0.115 & 0.879 & 0.960 & 1.690 & 0.876 & 0.928 & 1.278 & 0.865 \\
\hline 92 & $C$ & 0.566 & 0.492 & 0.209 & 0.622 & 0.651 & 0.883 & 0.579 & 0.584 & 0.666 & 0.450 \\
\hline 93 & $C$ & 0.769 & 0.439 & 0.054 & 0.621 & 0.547 & 0.986 & 0.690 & 0.664 & 0.941 & 0.897 \\
\hline 94 & $C$ & 0.406 & 0.321 & 0.118 & 0.432 & 0.445 & 0.654 & 0.484 & 0.510 & 0.648 & 0.641 \\
\hline 95 & C & 0.738 & 0.559 & 0.190 & 0.909 & 0.994 & 1.609 & 0.977 & 1.057 & 1.396 & 1.182 \\
\hline 96 & $C$ & 0.838 & 0.548 & 0.130 & 0.763 & 0.726 & 1.192 & 0.696 & 0.649 & 0.844 & 0.495 \\
\hline
\end{tabular}


Table S.2.3 Fixed factors were compared against each other to test for correlation. Factors included the sampling period in days (time), treatment group (treat), the log natural total length $(\operatorname{lnTL})$ and weight $(\ln \mathrm{W})$ of each fish, the average temperature across tanks for each respective sampling period (temp), and the rearing tank a fish was housed during the time of sampling (tank). The final model (M4) did not include $\ln \mathrm{W}$ as it was collinear with $\ln$ TL. Time was collinear with temperature; however, time was included in the full model as a main effect and interaction.

\begin{tabular}{llll} 
Model & Factor & DF & VIF \\
\hline M1 & time & 4 & 2.439057 \\
& treat & 2 & 1.025702 \\
& InTL & 1 & 4.62346 \\
& InW & 1 & 4.166168 \\
& temp & 1 & 16.539776 \\
& tank & 1 & 2.090229 \\
\hline M2 & time & 4 & 2.033027 \\
& treat & 2 & 1.025635 \\
& InTL & 1 & 4.621708 \\
& InW & 1 & 4.15857 \\
& temp & 1 & 16.533774 \\
\hline M3 & treat & 2 & 1.008971 \\
& InTL & 1 & 1.018744 \\
& Inw & 1 & 4.198557 \\
& temp & 1 & 4.093027 \\
& tank & 1 & 1.28277 \\
\hline M4 & treat & 2 & 1.00277 \\
& InTL & 1 & 1.004112 \\
& temp & 1 & 1.285687 \\
& tank & 1 & 1.282055 \\
\hline \multirow{4}{*}{} & & & \\
& &
\end{tabular}


Table S.2.4 Two nested linear mixed effect models, which examined the effects of fish size, temporal factors, and treatment group on Esox masquinongy specific growth rates in a hatchery experiment, had the exact same AIC value. M2 (time included) was used for further analysis. Models accounted for autocorrelation using the ARM correlation function. Both models included a random effect for individual fish and parameters were standardized. SGR, or specific growth rate, is the response variable. "TM" is time in days post-processing, "TR" is the assigned treatment group of fish (tagged, sham, or control), "TK" is the tank a fish was sampled from (fish were rotated between tanks), "TP" is the temperature averaged all tanks over each sampling period (e.g. 7-to 30-d), and "lnTL" is the log natural total length.

\begin{tabular}{llll} 
Model & Formula & df & AIC \\
\hline M1 & $\mathrm{SGR} \sim \mathrm{TP}+\mathrm{TR}+\mathrm{TK}+\operatorname{InTL}+\mathrm{TR}: \mathrm{TM}+\mathrm{TR}: \operatorname{lnTL}$ & 26 & 18.15406 \\
$\mathrm{M} 2$ & $\mathrm{SGR} \sim \mathrm{TP}+\mathrm{TR}+\mathrm{TK}+\ln T L+\mathrm{TP}+\mathrm{TR}: \mathrm{TM}+\mathrm{TR}: \ln T \mathrm{~L}$ & 26 & 18.15406 \\
\hline
\end{tabular}


Table S.2.5 Time, temperature, tank, treatment, and fish size effects on Esox masquinongy specific growth rates (SGR) from the M2 nested linear mixed effect model. Main effects and interactions are compared to SGR (Intercept) of Control fish. Environmental parameters were standardized for comparison. Asterisks indicate a significant effect $(\mathrm{p}<0.05)$ on specific growth rates. Bolded values indicate those that are significant.

\begin{tabular}{llrrrl} 
Factor/Interaction & Standard Error & \multicolumn{1}{c}{ t value } & p value & Significant \\
\hline (Intercept) & 0.07015449 & 5.329483 & 0 & \\
time30 & $\mathbf{0 . 0 7 1 9 0 3 7 9}$ & $\mathbf{8 . 3 9 8 9 8 7}$ & $\mathbf{0}$ & $*$ \\
time60 & 0.27807149 & 0.954392 & 0.3404 & \\
time90 & $\mathbf{0 . 1 8 6 0 1 3 2 7}$ & $\mathbf{3 . 0 4 1 3 1 1}$ & $\mathbf{0 . 0 0 2 5}$ & $*$ \\
time120 & 0.28037931 & -0.327784 & 0.7432 & \\
sham & 0.08819845 & -0.726523 & 0.4679 & \\
tagged & 0.08550528 & -0.288635 & 0.773 & \\
tank3 & 0.02837011 & 0.76947 & 0.442 & \\
tank4 & 0.02719946 & -0.876093 & 0.3815 & \\
tank5 & $\mathbf{0 . 0 2 8 3 3 8 6 2}$ & $\mathbf{- 3 . 2 4 6 7 8 8}$ & $\mathbf{0 . 0 0 1 3}$ & $*$ \\
temperature & 0.18108627 & 1.594982 & 0.1115 & \\
Intl & $\mathbf{0 . 0 4 1 8 9 5 8 8}$ & $\mathbf{3 . 2 4 6 9 4 2}$ & $\mathbf{0 . 0 0 1 3}$ & $*$ \\
time30:sham & $\mathbf{0 . 0 9 0 6 6 9 8 2}$ & $\mathbf{- 5 . 8 4 2 9 5 4}$ & & $\mathbf{0}$ & $*$ \\
time60:sham & 0.09573712 & 1.122781 & 0.2622 & \\
time90:sham & 0.13056057 & -1.135345 & 0.2569 & \\
time120:sham & 0.16456165 & -0.156263 & 0.8759 & \\
time30:tagged & 0.08554125 & -1.079111 & 0.2812 & \\
time60:tagged & 0.09314405 & 0.015901 & 0.9873 & \\
time90:tagged & $\mathbf{0 . 1 2 8 8 1 8 5 5}$ & $\mathbf{- 2 . 4 0 7 5 0 9}$ & $\mathbf{0 . 0 1 6 5}$ & $*$ \\
time120:tagged & 0.16473483 & -0.369157 & 0.7122 & \\
sham:Intl & 0.05783128 & 0.867509 & 0.3862 & \\
tagged:Intl & 0.06080476 & 1.24869 & 0.2125 & \\
\hline
\end{tabular}

Eq S.2.1 Autocorrelation was observed, and AR, CAR, and ARM autocorrelation models were fitted. The ARMA model provided the best fit. As temperature was highly correlated, the AIC of three models using the ARM were compared using the following lme function:

$\mathrm{y}<-\operatorname{lme}($ response $\sim$ fixed factors + interactions, random $=\sim 1 \mid \mathrm{x}$, correlation $=\operatorname{corARMA}(\mathrm{p}=1, \mathrm{q}$ $=1$, form $=\sim 1 \mid \mathrm{x})$, data $=\mathrm{z}$, method="ML", control=list(lmeControl(opt = "optim"), maxIter $=10000$, msMaxIter $=10000$ ) 


\section{Chapter 3 - Spatiotemporal ecology of juvenile Muskellunge (Esox masquinongy) and}

Northern Pike (Esox lucius) in upper St. Lawrence River nursery bays over fall and winter seasons

\subsection{Abstract}

Knowledge of the spatial ecology of juvenile freshwater fish is often lacking, particularly during the winter period. A decline in self-sustaining populations of sympatric, congeneric predators - Muskellunge (Esox masquinongy) and Northern pike (Esox lucius) - in the upper St. Lawrence River prompted study of spatiotemporal patterns and habitat requirements associated with earlier life stages in fall and overwintering periods. Age-0 Muskellunge $(n=38)$ and Northern pike $(n=38)$ were tagged and passively monitored using acoustic telemetry in four nursery embayments between 2015 and 2017 in fall and winter months to elucidate basic ecology and inform restoration activities and population management. Presence, residency, space and habitat use, developed from kernel utilization densities, were assessed and modeled against key environmental (e.g. water temperature and levels) and biological (total length) parameters using mixed effect models to identify how biotic and abiotic factors may influence spatiotemporal patterns and habitat use. Deeper littoral regions with submergent aquatic vegetation (SAV) were used by both species, and complex interactions between temperature and water levels were found to influence spatiotemporal trends during this critical period. Future analyses may elucidate finescale use of restored or manipulated habitats in nearshore and deeper regions with canopy forming SAV and delineating fine-scale variation in depth use between these juveniles esocids during overwintering periods, in accordance with new water level management plans aimed at producing natural riverine cycles. 


\subsection{Introduction}

Freshwater fish generate many ecosystem services (Lynch et al. 2016), yet this group confronts a multitude of environmental stressors and anthropogenic pressures (i.e., dispersal barriers, development, pollution; Brunton 1995, Ricciardi and Rasmussen 1999, Dudgeon et al. 2006). For many freshwater species, little is known about their basic biology (see Cooke et al. 2016), despite the need for science-based management and habitat restoration (Lorenzen et al. 2016). Of particular importance is understanding how fish are distributed in space and time - their spatial ecology - a prerequisite to protecting critical habitats and the corridors that connect them (Bond and Lake 2003). Relationships between fish, their environment, and habitat use are fundamental to fish ecology as the environment influences growth, fecundity, and survival (Fry 1971). Owing to widespread anthropogenic habitat alterations and noted declines in fish populations, efforts to restore degraded fish habitats have increased (Cowx and Gerdeaux 2004). Yet, most of this work has focused on creation of spawning habitat rather than accounting for the habitat features required for all life stages. In particular, information on the ecology and seasonal habitat use of juvenile fish remains a significant research gap and has impeded habitat conservation and restoration activities.

Although occurring at naturally low densities as top predators (Cook and Solomon 1987), a substantial decline in the self-sustaining Muskellunge (Esox masquinongy) population of the upper St. Lawrence River have been recently reported (Farrell et al. 2017). In addition, population declines of their sympatric congener, Northern Pike (Esox lucius), have also been observed in the region (Smith et al. 2007), but abundances of Northern Pike greatly exceed those of Muskellunge in the region; young Muskellunge are often preyed on by their earlier spawning congener (Harvey 
2009). This has prompted additional study to better understand spatial ecology and habitat requirements of the earlier life stages of both species.

Summer nursery habitat requirements for age-0 Muskellunge in the upper St. Lawrence River are well understood and are generally described by the presence of low to moderate cover of submerged aquatic vegetation (SAV) (Werner et al. 1996, Farrell 1998, Farrell and Werner 1999, Murry and Farrell 2007, Kapuscinski and Farrell 2014, Farrell et al. 2014). Likewise, welloxygenated (Inskip 1982), deeper littoral areas with floating, emergent (Engstedt et al. 2018), and submerged aquatic vegetation (Cucherousset et al. 2009, Pierce et al. 2013) are preferred summer nurseries for age-0 Northern Pike (Grimm and Backx 1990). Most inferences about species-habitat relationships of juvenile esocids are restricted to seine or electrofishing surveys that provide a single point in time and space, typically for age-0 in the summer (July to August; e.g. Murry and Farrell 2007). Although this provides valuable information, these presence/absence surveys typically fail to account for seasonal movement patterns and habitat use, particularly into the fall and winter. For juvenile esocids in north temperate regions, little is known about habitat use and behaviour into late-fall and winter (Cunjak 1996), a period of time that imposes important selective pressure (i.e., survival) on fish populations during early life. Important to this understanding is how two congeneric predators that overlap in their early life histories and habitats exist in sympatry during the juvenile stage, a stage where juvenile Muskellunge can be easily preyed on by larger age- 0 Northern Pike. With such information, the conservation and restoration of core habitat(s) can provide for reduced predation risk of juvenile Muskellunge by their competitively superior early-life congener (e.g. Crane et al. 2015).

Knowledge of the spatial ecology of early life stages was historically hampered by technical limitations of telemetry equipment (e.g. large tag size, short battery life). Recent 
technological innovations, however, have made it possible to tag and track juvenile esocids over extended time periods. Thus, to better understand the ecology of esocids during a critical period of their early-life, the most recent telemetry technology was used to study the spatiotemporal trends associated with fall and overwintering behaviour and quantify core habitat features, and to determine the influence of environmental and biological variables on the presence, residency, and habitat use of age-0 Muskellunge and Northern Pike. Although maximizing edge habitat in littoral zones with moderate densities of SAV has been recommended to benefit multiple esocid life-stages (Crane et al. 2014), without a better understanding of habitat-by-species relationships, balancing the potential different habitat needs of sympatric Muskellunge and Northern Pike juveniles lacks precision.

\subsection{Methods}

\subsubsection{Study location}

This study took place in the Thousand Islands region of upper St. Lawrence River between Cape Vincent (43.30048 N, 79.80591 W) and Alexandria Bay, NY (43.30048 N, 79.80591 W). The upper St. Lawrence River is an oligotrophic system that is the effluence of eastern Lake Ontario and flows through the Eastern Great Lakes Lowland Forest (Thorp et al. 2005). Water levels in the upper St. Lawrence River are regulated by the International Joint Commission (IJC) at the Moses Saunders power dam that have artificially suppressed the magnitude and periodicity of water level fluctuations under plan-1958D (Farrell et al. 2010). The IJC has, however, implemented a new water level regulation regiment, plan-2014, to better reflect natural hydrology of the system.

The Thousand Islands region is characterized by its complex archipelago ( $>1,800$ islands), rocky shorelines, shoals, and extensive littoral community and coastal wetland embayments 
dominated by emergent and submergent vegetation (Farrell et al. 2010). The upper St. Lawrence River has also been the foci of a long-term monitoring program for esocids (Farrell et al. 1999; 2007; 2017) that has inventoried and evaluated critical early-life habitats of Muskellunge and Northern Pike. Like many coastal regions of the Great Lakes, those in the upper St. Lawrence River have experienced degradation of nearshore spawning and nursery habitats among many embayments (Carmignani \& Roy 2017) and would benefit from science-based restoration and protection of critical habitat. For this study, four embayments with a mix of open-water and vegetated nearshore coastal habitats were examined. These included Rose Bay $\left(44.185872{ }^{\circ} \mathrm{N}\right.$ $\left.76.225169^{\circ} \mathrm{E}\right)$, Buck Bay $\left(44.253241^{\circ} \mathrm{N}-76.136121^{\circ} \mathrm{E}\right)$, Flynn Bay $\left(44.25324^{\circ} \mathrm{N}-76.136121^{\circ} \mathrm{E}\right)$, and Grass Point. These sites were selected based on monitoring surveys that indicated an increase probability of catching sufficient numbers of age-0 Muskellunge and Northern Pike.

\subsubsection{Embayment Habitats}

Rose is a 9-hectare (ha) sheltered bay near Cape Vincent, NY (Fig. 1), and its mouth slopes steeply into the main channel. Buck (18-ha; Cooper 2016) is a narrow, shallow and sheltered bay that is adjacent to Flynn, a 74-ha system off Grindstone Island with a drowned river mouth tributary (Fig. 1; Farrell et al. 2014). Grass Point (47-ha), a New York State Park, was the least sheltered embayment that had a wide interface with the main channel (Fig. 1). Although exposed to the main channel, Grass Point exposure to prevailing westerly winds was limited by outcrops of islands and mainland shoreline that extends north into the river.

\subsubsection{Fish capture}

Age-0 Muskellunge and Northern Pike were captured using a standardized seining protocol where a $36.6 \mathrm{~m}$ seine net ( $6.4 \mathrm{~mm}$ mesh, stretch measure) with a $12.2 \mathrm{~m}$ bag was deployed in water depths less than $1.5 \mathrm{~m}$ for $18.3 \mathrm{~m}$; one full transect encompassed $449 \mathrm{~m}^{2}$ (Farrell and Werner 
1999). When age-0 Muskellunge and Northern Pike were caught by seine, they were transferred to a cooler with aerated water from the site of capture. Water temperature in the cooler was monitored and periodically exchanged to prevent thermal stress to fish. Muskellunge were captured in all four bays from September-11-2015 to September-15-2015 and September-06-2016 to October-06-2016. In 2015, Muskellunge caught in Rose and Buck were of wild and stocked origin (e.g. Farrell et al. 2017). All age-0 Northern Pike were of wild origin, and those used for telemetry were all caught in in Flynn Bay between September-26-2015 and September-28-2015 and on September-21-2016. One Muskellunge captured in Flynn Bay in 2015 was translocated to Buck Bay.

\subsubsection{Tags \& Surgical implantation}

Individuals were anesthetized in an aerated basin using a concentration of $75 \mathrm{mg} / \mathrm{L}$ tricaine methanesulfonate (MS-222). When loss of equilibrium was observed, anesthetized fish were weighed (nearest $0.1 \mathrm{~g}$ ), measured for total length (TL; nearest $1 \mathrm{~mm}$ ), and photographed. Fish were placed supine on the surgery table and received a maintenance dose of aerated anesthetic ( 75 $\mathrm{mg} / \mathrm{L}$ MS-222) through a silicone rubber hose placed in the fish's mouth so water gently flowed over gills. Persistent opercular movement of anesthetized fish was used to monitor their condition during surgery. Because of multiple surgeons, surgery time ranged from $<3$ minutes for all fish in 2015 to between 3.5 and 12 minutes in 2016. Muskellunge were anesthetized (total time, knock out and surgery) on average for 12-min. while Northern Pike average of 14-min. in 2016. Times were not recorded in 2015. A sterilized (betadine) mini-acoustic JSAT tags (either a Lotek Wireless, L-AMT-1.416, $0.28 \mathrm{~g}, 10.7 \times 5.4 \times 3.1 \mathrm{~mm}$ or PNNL JSAT, $0.20 \mathrm{~g}, 15.0$ × $3.4 \mathrm{~mm}$ ) was implanted into fish following the procedure described by Gallagher et al. (2018). The tags used in this study represent two of the smallest commercially available acoustic telemetry devices (i.e., L- 
AMT-1.416 and PNNL JSAT). Both tag types emitted a coded signal at a frequency of $416.7 \mathrm{kHz}$, with signal strengths of approximately 156 to $158 \mathrm{~dB}$ (re: $\mu \mathrm{PA} @ 1$ meter) using a BPSK (binomial phase shift key) 16-bit tag code. Following surgery, fish were allowed to recover in fresh, aerated water from the site of capture and release once fish regained full equilibrium.

\subsubsection{Receiver deployment}

In the fall of 2015, 38 receivers (Lotek WHS4250 $416.7 \mathrm{KHz}$, Newmarket, Ontario) were deployed in Rose, Buck, and Flynn Bays. A grid system in Rose and Buck bays was used to maximize residency and detection capacity with the assumption that fish remained in the shallow $(<1 \mathrm{~m})$ back portion of bays in the fall. A loose gate of receivers was positioned in deeper waters (1.5-3.0 m) of both bays to assess outward movement and residency as fall progressed to winter from October to December (Fig. 1). In Flynn, receivers were deployed to maximize coverage of the bay's shallow interior and deeper ( $>1$ meter) regions. In 2016, twenty-one receivers were deployed in the nearshore region of Rose and Grass Point and the mouth of Flynn in October to assess fall residency. In November, all 21 receivers were removed and downloaded. All 21 receivers (plus three more) were redeployed in the mouth or perimeter of Rose, Grass and Flynn until March 2017 (Fig. 1). In every instance that receivers were deployed, their location was recorded with a handheld GPS unit.

Receivers deployed in shallow waters were mounted to rebar using zip ties and electrical tape and buried in the substrate. The top of the receiver, which detected the signal, remained several inches above the substrate to prevent attenuation issues. Receivers deployed in waters $>2 \mathrm{~m}$ were secured between two sandbags filled with cobble-sized rocks and attached to twisted polypropylene rope that was buoy at the surface (Fig. S.1). Receivers set at depths $>3$ meters were rigged so that the receiver was near the substrate and the connected buoy was $2 \mathrm{~m}$ below the water's 
surface to ensure that water level fluctuations would prevent adverse contact with boats and that ice did not form around the buoy and move the receiver.

The effective range at which implanted fish could be detected (ratio of true to expected detections captured by receivers) was calculated by dividing the observed number of detections by the number expected per hour from sentinel tags $(n=180)$ and receiver beacon signals $(n=60)$. Both implanted and sentinel tags emit a series of bursts (herein known as a ping) with a digital ID every 20 seconds. Sentinel tags were placed 30-, 70-, and 120-meters from receivers in the nearshore region of Buck and Rose in 2015, to determine the furthest distance tagged fish would be detected $50 \%$ and $100 \%$ of the time. In 2016, sentinel tags were not deployed, therefore each receiver was also set to emit a ping (beacon signal) with similar power to real tags (Wigglesworth, pers. comm) every 60 seconds. Variation in pings/hour between signal sources (beacon vs. sentinel tag) was accounted for by multiplying observed beacon signals by three. Effective detection range

for both sentinel tags and beacon signals were $100 \%$ of signals received at 30 -meters and $50 \%$ of signals received at 75-meters.

\subsubsection{Environmental variable sources}

HOBO Pro v2 water temperature loggers were attached to receivers deployed in the interior of Rose and Buck in 2015, at Rose and Grass Point in 2016, and within the mouth of Flynn (2016). New loggers were deployed in deeper waters associated with the winter Rose array ( $>3$ meters), and waters $\sim 2$ meters deep in the Flynn and Grass Point arrays. Mean monthly water level data were sourced from the International Great Lakes Datum (Canadian Hydrographic Service 2017) from Port Weller, Toronto, Cobourg, and Kingston, Ontario, and Rochester and Oswego, New York stations. Water depths were documented in meters above sea level, as per IGLD 1985. Daily air temperature data, used as a proxy for water temperature in Buck and Flynn (2015) and Rose 
(2016/17), was sourced from Environment and Natural Resources Canada (2018) historical weather and climate data for October to December 2015 and October 2016 to March 2017. Hourly water temperatures (Rose 2015, Grass and Flynn 2016/17) which were condensed to daily values and compared against daily air temperatures values using Pearson's correlation coefficient, were not highly correlated $(<0.70)$. If they were highly correlated, water temperature from one bay (i.e. Grass) would have been used for another bay monitored within the same year (i.e. Rose).

\subsubsection{Analytical approach}

Detection data were filtered so that double detections and detections $<5 \mathrm{~min}$ apart at the same receiver were excluded. Detection data were then separated by year (2015 vs. 2016); October was excluded from the 2016 data set due to differences in array designs. Independent analyses were performed on the age-0 cohorts tagged for both species in 2015 and 2016/17, age-1 Muskellunge detected overwinter in Rose 2016/17, and age-1 Northern Pike detected in Flynn 2016/17. Differences in overall body size, represented by total length, was compared for each species between years using a one-way ANOVA, with year as a fixed factor.

\subsubsection{Diel data}

Detections over the full study period were categorized into four diel times: dawn (05000859), day (0900-1559), dusk (1600-2059), and night (2100-0459). Dusk and dawn were selected based on the earliest and latest hour that sunrise and sunset was observed in October. A generalized linear mixed model ( $g l m$, R package "lme4"; Bates et al. 2015) with a Poisson distribution and a least regression test ("LR") was used to analyze the total number of detections per diel period from sentinel tags, beacon signals, and tagged fish. Tagged data included the total number of detections per diel period from all receivers per embayment. Models included bay and year as fixed factors, with fish as the random factor. Pairwise comparisons were evaluated using a Tukey test ( $g l h t$, R 
package "multcomp"; Hothorn et al. 2008) when significance occurred.

\subsubsection{Monthly residency}

Abacus plots of acoustic detections were examined to visually assess spatial and temporal residency of fish in the arrays for the duration of each study period (three months 2015, six months 2016 to 2017; R package "glatos"; Holbrook et al. 2016). The presence/absence of a fish was identified on a monthly basis; a fish was considered present and assigned a value of one if it was detected $\geq 7$ days in a given month. If not, they were considered absent and given a value of zero for that month. A monthly residency index ranging from 0 to 1 (where values close to 1 indicated high residency in the array; Espinoza et al. 2014) was calculated for each fish classified as present by dividing the number of days a fish was detected within an array by the number of days the array was active during that month. To compare residency of fish detected from October 2016 to March 2017, monthly RI values were divided by the number of receivers active each month (e.g. seasonality) to ensure a reduction in detections was not due to the reduction in number of receivers, and to confirm a natural pattern rather than an artefact of the array.

\subsubsection{Space Use}

Space use was calculated based on center of activity (COA) locations and kernel utilization distribution (KUD) values. COA locations were calculated using method from Simpfendorfer et al. (2002), where mean fish positions, based on detections from all receivers within sequential twohour intervals, were calculated throughout the study period to reduce spatial and temporal autocorrelation (Rooney et al. 1998). KUD values (50\% core and 95\% extent) were then estimated for individual fish by using the kernelUD function (R package "adehabitatHR"; Calenge 2006). The kernelUD function included a smoothing parameter $(\mathrm{h}$, which controls the width of the kernel functions), a grid size (on which the KUD should be estimated, and its resolution) and an extent 
value (the extent of the grid used for the estimation). The UD (van Winkle, 1975) considers the space use described by bivariate probability density based on relocation coordinates (the COA locations) and the kernel method (Silverman 1986; Wand and Jones 1995), which averages the relocation values. The smoothing parameter was determined by calculating the " $h$ " value for each fish within an embayment (per year) and using the median value (Hollensead et al. 2016). The size of the grid was established by increasing grid values in increments of 250 (starting at 500) until the error message of "grid too small" no longer appeared, and extent values were increased starting at one. A consistent grid value of 1000 (appropriate across all bays and years), and extent value of four were used. Finally, variation in core space use and extent among individuals in the same embayment were assessed using linear models.

\subsubsection{Habitat features}

Habitat types within each bay were determined using an image classification of raster files representing each bay in ArcGIS (ArcMap 10.5.1; ESRI 2017) to compare embayments in a consistent manner. NY GIS Clearinghouse orthoimage raster files from 2015 of each embayment (NYS Information Technology Services 2018) were merged using the Mosaic Data Management tool, and clusters associated with physical habitat types (e.g. vegetation, exposed substrate, depth) were identified for each embayment mosaic map using the Iso unsupervised image classification tool (20 classes), in which the Iso Cluster and Maximum Likelihood Classification tools are combined and classify individual pixels based on the raster bands (red, green, blue) associated with the raster files. Habitat types were established by comparing clusters to vegetation survey data in published literature (Farrell et al. 2014) and an Ontario submerged aquatic vegetation (SAV) shapefile, which provided coarse resolution of exposed sand regions, low and high SAV (Shuchman et al. 2013). Mosaic maps for each bay were reclassified (Reclassify tool) based on 
like habitat features (see Fig. 1 legend) and converted into polygon features (Raster to Polygon tool). To calculate the percent of each habitat type within each fish's core range per month, monthly core use (50\% KUD) were first converted to ESRI shapefiles (writeOGR, R package "rgdal"; Bivand et al. 2017) then imported into file geodatabases (Feature Class to Geodatabase tool). Individual monthly core use ranges were intersected (each separately) to the habitat polygons, using the intersect tool. The percentage of each habitat type used within an individual's core space was divided by the total core area to calculate habitat proportions used.

\subsubsection{Mixed effect models}

A series of mixed effect models (R packages "nlme", Pinheiro et al. 2018; "lme4, Bates et al. 2015) were applied to explore the influence of water level, air and/or water temperature, and fish size (fixed factors which may elicit differences among response levels; Bolker et al. 2009) on residency, space and habitat use within deployed arrays for each species, per embayment, per year. Fixed factors were centred to simplify interpretation and facilitate comparison of their importance (Schielzeth 2010). Fish ID was a random factor to enable population-level prediction and account for the repeated-measures nature of the data (Bolker et al. 2009). Collinearity between fixed factors, were compared using Pearson correlation coefficients and variance inflation factors (vif, R package "car"; Fox and Weisburg 2011), and residual and auto-correlation plots evaluated models' goodness of fit (Bolker et al. 2009; Zuur 2010). If auto-correlation was present, models were fitted to account for spatial (e.g. corExp) or temporal (e.g. corAR1, corARMA) correlations, and heteroscedasticity. Akaike's information criterion (AICc) was calculated, and the models with the lowest AIC corrected for small sample sizes were selected (Burnham and Anderson 2004; see Supplementary Tables). Linear models (LME) for space use were analyzed using maximum likelihood, an "optim" lmeControl and a value of 10,000 for both maxIter and msMaxInter. 
Generalized models (GLMM) were fitted with a binomial error distribution using a logit link and an nAGQ value of seven (e.g., Bolker et al. 2009). The nAGQ (Adaptive Gauss-Hermite Quadrature) model is more accurate than Laplace estimations (Bolker et al. 2009) and increased the accuracy of the model's residency estimation (Pinheiro et al. 2006). Due to convergence failure, two separate optimisers were used: the "bobyqa" for Flynn, Buck, and Grass Point and "nloptwrap" for Rose Bay.

\subsection{Results}

\subsubsection{Descriptive}

Over the course of the study, nearly all age-0 fish tagged were detected (2015: 98\% Muskellunge and 100\% Northern Pike (Table 3.2, 3.3); 2016/17: 100\% Muskellunge and 98\% Northern Pike; Table 3.4), and consistent detections on multiple receivers indicated high survival in fall and overwintering periods. Total length) of age-0 Muskellunge was greater in 2016 (177 \pm $36.8-\mathrm{mm})$ than $2015(154 \pm 20.8-\mathrm{mm})$ but this difference was statistically indistinguishable $\left(F_{1,37}\right.$ $=3.7464, p=0.06)$. Similarly, Northern Pike did not differ in total length between $2015(234 \pm$ $55.2-\mathrm{mm})$ and $2016\left(227 \pm 38.3-\mathrm{mm} ; F_{1,37}=1.2429, p=0.27\right)$. One Muskellunge originally caught and tagged in Rose Bay in 2016 was subsequently recaptured four weeks later and had grown 78$\mathrm{mm}$ and gained 49.3-g in four weeks (Fig. S.3.13). Water depths fluctuated from $74.56 \mathrm{~m}$ (above sea level, October 2015) to $74.47 \mathrm{~m}$ (November 2015) to $74.74 \mathrm{~m}$ (December 2015) and increased from 74.48 to 75.00 meters (November 2016 and March 2017).

\subsubsection{Diel detections}

The temporal variation in detections of sentinel tags appeared to indicate an environmental influence on detection rate, rather than variation in fish movement among the diel periods. More detections were captured at night $(33 \% ; z=2.486, p=0.01)$ and day $(30 \% ; z=2.376, p=0.02)$ 
relative to the dusk and dawn diel periods. Fish detections followed a similar pattern to the sentinel tags between years; more detections occurred at night (30-40\%), while detections during the day (4-19\%), dusk (14-19\%) and dawn (15-32\%) were more evenly distributed.

\subsubsection{Detections, Residency \& Space Use}

\subsubsection{Muskellunge}

$\underline{\text { Rose Bay }}$

Twenty age-0 Muskellunge were initially tagged in Rose Bay in 2015, and all fish were frequently detected $(577 \pm 1,125$ [mean detection of all fish \pm SD], Fig. S.3.8). In contrast, of the five Muskellunge tagged in 2016, individuals were detected less frequently over winter (143 \pm 127), likely a product of differences in receiver array design and sample sizes between years.

In 2015, residency index was highest during early fall $(>0.50)$, and higher residency index was significantly correlated with warmer water temperatures $\left(>10^{\circ} \mathrm{C}\right)$ in both 2015 and $2016\left(\mathrm{x}^{2}=\right.$ 7.5242, $p=0.006$, 2015, Fig. 3.2a; $\mathrm{x}^{2}=7.5242, p=0.006$, 2016, Fig. 3.2d; Table S.2). Residency index was significantly higher with body size $\left(x^{2}=4.4903, p=0.03\right)$ in 2016 , but no effect was found in 2015 (Table S.21). Covariates had no effect on presence/absence in either season.

Four Muskellunge detected in 2015 exhibited significantly smaller $\left(F_{19,56}=3.3319, p=\right.$ 0.001) core spaces, relative to conspecifics (Fig. 3.4). Space use between individual fish was similar each month in 2015 (core, $0.04 \mathrm{~km}^{2} \pm 0.002 \mathrm{SE}$, extent $0.16 \mathrm{~km}^{2} \pm 0.004 \mathrm{SE}$; Table 3.1; Fig. 3.3a). In 2016, all fish detected ( $n=3$ ) shared the exact same core space use size of $0.02 \mathrm{~km}^{2}$, likely as a product of the array design, which drove small utilization distribution outputs.

Water temperature and water level were significant variables contributing to the fit of the data for core space. In 2015, Muskellunge had smaller core space use ranges between water temperatures of $9.5^{\circ} \mathrm{C}$ and $11.5^{\circ} \mathrm{C}\left(\mathrm{x}^{2}=4.59, p=0.03\right.$; Fig. $\left.3.2 \mathrm{~b}\right)$ and at lower water levels $\left(\mathrm{x}^{2}=\right.$ 
4.189, $p=0.04$; Fig. 3.2c). Over the 2016 winter season, Rose Muskellunge retracted their core space use when water levels increased $\left(x^{2}=5.07, p=0.024\right.$, Fig. 3.2e) and increased their extent size (95\% KUD) with warmer air temperatures $\left(x^{2}=14.363, p=<0.001\right.$, Fig. 3.2f).

\section{Buck, Flynn \& Grass Bays}

All eight Muskellunge tagged in Buck Bay were present during fall (100\% in October and

November), and residency index remained high each month. Fish were not often detected $(81 \pm$ 42, [mean detection of all fish $\pm \mathrm{SD}]$ ), however, all fish exhibited similar use of Buck Bay (Fig. 3.3a) with a core space use size of $<0.15 \mathrm{~km}^{2}$. Extent sizes averaged $0.50 \mathrm{~km}^{2} \pm 0.01 \mathrm{SE}$ (Table 3.1). Covariates had no effect on spatial responses among the factors examined.

The lone Muskellunge tagged and transported to Buck from Flynn was infrequently detected in Buck; however, it was detected in Flynn in 2016/17 for a brief period, demonstrating it migrated to its original site of capture. The sole Muskellunge tagged in Flynn in 2016/17 was also infrequently detected in October and over winter.

Grass Point Muskellunge tagged $(n=5)$ maintained a consistent presence within the embayment perimeter, as did residency index $(0.38 \pm 0.27 \mathrm{SD})$. Space use was consistent $(0.11$ $\mathrm{km}^{2} \pm 0.004 \mathrm{SE}$, core; $0.49 \mathrm{~km}^{2} \pm 0.01 \mathrm{SE}$, extent) among fish, though their individual use of the embayment perimeter where waters drop of varied extensively; space use did not overlap visually (Fig. 3.3b). No effects from biological or environmental variables on presence/absence, residency index, or space use were observed.

\subsubsection{Northern Pike}

All 24 age-0 Northern Pike tagged in 2015 were detected at some point, and 17 fish (788 \pm 812, [mean detection of 17 fish $\pm \mathrm{SD}$ ]) were considered present (Table 3.3). Of these 17 fish, three were found to have significantly larger core use areas $\left(F_{16,39}=4.2165, p<0.001\right.$; Fig. 3.4$)$ relative 
to conspecifics. Core use space for all fish $\left(0.06 \mathrm{~km}^{2} \pm 0.005 \mathrm{SE}\right)$ was often restricted to the embayment interior (Fig. 3.3a), while extent included both interior and mouth regions $\left(0.32 \mathrm{~km}^{2} \pm\right.$ $0.02 \mathrm{SE})$. Residency index was higher in the shallow interior of the bay $(>0.50)$ relative to the deeper water habitat of the embayment's mouth (0.05).

Of 15 age-0 Northern Pike tagged in 2016/17, all 15 were detected ( $80 \pm 102$, [mean detection of fish $\pm \mathrm{SD}]$ ), and $50 \%$ (seven) were considered present (Table 3.5). Core space $\left(0.18 \mathrm{~km}^{2} \pm 0.01\right)$ and extent $\left(0.62 \mathrm{~km}^{2} \pm 0.008\right)$ doubled relative to age- 0 fish monitored in 2015 , likely due to the change in array size. Residency index was low $(\sim 0.05)$ indicating that fish used other regions (nearshore or deep waters) more often than the mouth.

Water level significantly contributed to the fit of the data for residency index in 2015, as did air temperature for residency index and core space in 2016. Presence significantly increased as water levels rose, from $52 \%$ of fish to $96 \%$ of fish monitored $\left(x^{2}=6.7064, p=0.01\right.$; Fig. 3.5a), as did residency index $\left(x^{2}=26.3046, p=<0.001\right.$; Fig. 3.5b) in 2015. In 2016, space use (Fig. 3.5c, d) significantly increased with water temperature $\left(x^{2}=5.4234, p=0.020\right.$, core; $x^{2}=9.3907, p=$ 0.002 , extent).

3.4.4. Age -1 Fish

\subsubsection{Muskellunge}

Nineteen (95\%) of the age-0 Muskellunge tagged in the fall of 2015 in Rose were detected at some point $(31 \pm 20 \mathrm{SD}$, [mean detection of fish detected $\pm \mathrm{SD}$ ] $)$ as age-1 fish in the fall and winter of 2016 in their natal embayment. Of these 19 Muskellunge, four fish were consistently present (Table S.4) throughout the winter period of 2016/2017 (mean residency $0.48 \pm 0.12 \mathrm{SE}$ ). These four fish exhibited relatively small core use size $\left(0.02 \mathrm{~km}^{2}\right)$ and extent $\left(0.072 \mathrm{~km}^{2} \pm 0.008\right.$ SE). The likelihood of an age-1 Muskellunge being present in the array increased with total length 
at first capture $\left(\mathrm{x}^{2}=4.7012, p=0.03\right.$; Fig. S.3.14), but RI was low with warmer air temperature $\left(\mathrm{x}^{2}=5.2921, p=0.02\right.$, Fig. S.3.15). Space use was not influenced by covariates.

\subsubsection{Northern Pike}

Eighteen of the 24 Northern Pike originally tagged in 2015 as age- 0 fish were detected (75 \pm 67 SD) in the 2016/17 array in Flynn Bay as age-1 fish, and seven fish were present throughout the winter months (Table 3.5). Presence peaked in December (63\% of fish present) and declined in winter months (44\%). Mean residency index was high $(>0.55)$ for these seven fish, mean core space use $\left(<0.2 \mathrm{~km}^{2}\right)$ was concentrated on the western edge of the embayment mouth (Fig. 3.3b). Average extent included all receivers located in the grid pattern within the embayment mouth $(0.62$ $\pm 0.005 \mathrm{SE})$. No parameters were influenced by covariates.

\subsubsection{Habitat Features}

Flynn was the most diverse bay in terms of habitat including nine different habitat types that were classified. These included: established Typha, a mixture of SAV and emergent vegetation, SAV and floating vegetation, combination (50/50) of SAV and exposed substrates, newly developed Typha patches, exposed substrate, combination (25/75) SAV and exposed substrates, full (100\%) SAV and deep waters (>3-meter; Fig. 3.1). The least diverse system was Buck that included only three habitat categories (i.e., floating vegetation, SAV and emergent vegetation, and exposed substrate); the array overlapped all three categories. Rose and Grass Point shared habitat features (Fig. 3.1.), except for deep littoral waters with SAV and a small sediment plume observed along the shoreline that was unique to Rose (Fig. 3.1.).

Of the habitat features classified in each bay, the receiver array overlapped with four in Rose for the 2016/17 survey (i.e., deep waters, deeper littoral regions with SAV, and small proportions of both SAV intermixed with floating vegetation and exposed-shallow areas). In 
Flynn, the 2016/17 receiver array overlapped with seven of the nine habitat features (i.e., deeper waters, SAV, the combined [25/75] SAV and exposed region, exposed substrates, new Typha stands and submergent, emergent vegetative regions). The 2016/17 Grass Point fall survey overlapped with four of six features (i.e., deep waters, deeper littoral regions with SAV, regions with 50/50 exposed substrates and SAV amongst varying depths, and proportions of both SAV intermixed with floating vegetation), while the overwinter survey overlapped with all six features, which included shallow regions either exposed or with SAV.

\subsubsection{Muskellunge Habitat}

In fall and early winter of 2015 and 2016/17, age-0 Muskellunge in Rose were found to disproportionally favour one habitat type over others $\left(\mathrm{x}^{2}>1.41, p<0.001\right.$, for both years). Muskellunge frequented deep waters ( $>90 \%$ of habitat use within all core space areas) relative to other available habitats (Tukey's, $z=-103.9, p=<0.001$ ). Despite the availability of floating and SAV habitats, only $40-45 \%$ of core space use was of this habitat type in October and November of 2015 .

Buck Bay Muskellunge more frequently occupied shallow waters characterized by exposed substrates (55 - 85\% of habitat use within core space areas) and a mixture of SAV and emergents (30-40\%; $x^{2}=238.8137, p=<0.001 ;$ Fig. 3.6) than floating vegetation. Muskellunge in Grass Point appeared to occupy deeper waters (55-75\%) deeper littoral waters with SAV (20-80\%) more often relative to habitats characterized by a 50:50 ratio of exposed water/substrate and SAV cover $(<20 \%)$ and floating vegetation with SAV $(<10 \%)\left(x^{2}=52.9370, p=<0.001 ;\right.$ Fig. 3.6).

\subsubsection{Northern Pike Habitat}

Eight Northern Pike ( $T L=213$ to $275-\mathrm{mm}$ ) were nearly exclusively found in the vicinity of a receiver associated with $100 \%$ SAV cover and adjacent to habitat characterized by a $50: 50$ 
ratio of SAV cover and exposed substrates. Similar patterns were noted for all Northern Pike during both survey periods where fish disproportionately used different habitat types $\left(\mathrm{x}^{2}>458.59\right.$, $p<0.001$; Fig. 3.6). All 17 age-0 Northern Pike monitored preferentially occupied one habitat over others $\left(\mathrm{x}^{2}=252.7292, p=<0.001\right)$; shallow nearshore region of Flynn, characterized by $50 \% \mathrm{SAV}$ cover and exposed substrates, was preferred over exposed, shallow waters (Tukey test, $z=4.688$, $p=<0.001$; Fig. 3.6). In contrast, overwintering age-0 Northern Pike monitored in 2016/17 used significantly more exposed, shallow habitats (30 - 55\%) near the interior and southwest shore of Flynn Bay relative to deep water habitats (20 - 35\%) (Tukey test, $z=14.968, p=<0.001)$.

\subsubsection{Age -1 Habitat Use}

Age-1 Muskellunge detected in Rose in 2016/17 showed similar habitat use patterns observed during their first seasonal change; a greater proportion $(>95 \%)$ of all core space areas was comprised of deeper zones (>95\%), with little use of deeper littoral zones with SAV (3-4\%). Age-1 Northern Pike detected also showed similar patterns as their first year; individuals tended to use exposed zones (35-70\%), but also used deeper zones (25-45\%) within small patches of SAV. Though habitat features (exposed, shallow waters, partially exposed waters with SAV, and deep zones, in rank order) were used in significantly different proportions $\left(\mathrm{x}^{2}=252.7292, p=<0.001\right.$; Fig. 3.7) in 2016/17, the tendency for core use areas to include low proportions of available SAV within arrays either year may suggest core juvenile Northern Pike habitat is quantified by particular habitat use ratios beyond their first summer.

\subsection{Discussion}

This study is the first to use acoustic telemetry to examine spatial ecology of age-0 Muskellunge and Northern Pike. Results showed complex (and underestimated) space and habitat uses for both species, and influence of environmental covariates were dependent on embayment 
and the spatial variable examined. Muskellunge residency was positively related with warmer water and air temperatures, and core space use fluctuated pending water levels, while Northern Pike residency was positively related to warmer water temperatures and higher water levels, though these increases were dependent on the year fish were monitored. Fish used the entirety of their respective natal embayments as fall progressed to winter, contrasting Farrell et al. (2014), where age-1 Muskellunge and Northern Pike exhibited segregated space use of Flynn Bay based on radio-tracked movements. Overwinter, neither species nor age-class monitored were often present within embayment entrances, suggesting either continuous use of coastal wetlands and shallow shorelines, or deeper habitats at the edge of the embayment mouths over winter. As analytic tools may influence ecological interpretation, future exploration will evaluate age-0 Rose Muskellunge using network analysis to provide a more comprehensive picture of young Muskellunge movements (i.e., bidirectional movement through corridors; Lédée et al. 2015).

Segregation was noted in the habitat types most often used between age-0 Muskellunge (i.e., deep waters and deeper littoral zones) and Northern Pike (i.e., shallow, exposed zones around littoral patches) in early and late winter periods. This tendency towards segregation was observed by Farrell et al. (2014) between sympatric age-1 Muskellunge (stocked and wild) and Northern Pike (wild), radio-tracked in Flynn Bay in late fall. The contrasts noted in habitat use between age0 fish (present study) and age-1 fish (i.e., use of shallow, perimeter habitats by Muskellunge and deeper, offshore regions by Northern Pike; Farrell et al. 2014) may have been associated with how habitat uses were documented based on the telemetry tools employed or the monitoring year, but may have reflected habitat use in allopatric (present study) vs. sympatric (e.g., Farrell et al. 2014) scenarios. 
Both species tended to use regions that supported growth of submergent aquatic vegetation (SAV) in the fall and winter. This tendency was noted based on visual assessments of core space use, and documented use of different depth ranges (present study) and fine-scale water column depths in shared habitats (Farrell et al. 2014) may indicate that these congeneric predators occupy distinct realized environmental niches, similarly to Pterocles spp. (Benitez-Lopez et al. 2014). Juvenile Muskellunge and Northern Pike have a shared affinity for similar habitats (Murry and Farrell 2007), and as segregation was noted within nursery bays (site-specific), coexistence of juvenile Muskellunge and Northern Pike in any given embayment in the upper St. Lawrence River may result from a combination of macro- and micro-scale variables, rather than interspecific interactions. Monitoring both species within an embayment and manipulative habitat-use experiments are required to test this hypothesis.

Variation in residency based on water-levels may suggest that seasonal fluctuations (macro-habitat) in water levels and distributions of sensed SAV (micro-habitat). The upper St Lawrence River experienced drought-like conditions in 2016 and extreme flooding in 2017. As varying water levels may serve an important role in spatial overlap between species (Rosenfeld and Hatfield, 2006), future spatiotemporal analyses focused on the influence of variable water level cycles authorized by new IJC water level management in the upper St. Lawrence River (International Joint Commission 2014) may be worthwhile. Mimicking natural variation in water levels may accentuate segregation observed during spawning periods (Cooper et al. 2008) and juvenile space and habitat use (Farrell et al. 2014). Additionally, use of moderate- cover, fine-and broad-leafed SAV (e.g., Vallisineria; Rybicki and Carter 1986) is well-documented (Farrell et al. 1996, Farrell 1998, 2001, Kapuscinski and Farrell 2014), and use of different yet specific depths (one for each species) over a small depth gradient (i.e., one to three meters), as observed in 
sympatric juvenile skates (Raja spp.; Humphries et al. 2014) and age-1 Muskellunge and Northern Pike (Farrell et al. 2014), may play a key role in micro-habitat segregation the first winter so Muskellunge can effectively forage on preferred prey sources in these habitats (i.e., fusiformcyrpinds; Woodside 2009, Kapunscinski et al. 2012), and to avoid predation by the competitively superior Northern Pike. Understanding how macro-habitat (fluctuating water levels) and microhabitat use (regions that support growth of SAV) differs in their inaugural winter, and their use of vertical habitat in association with canopy-forming SAV may support the hypothesis of macroand micro-habitat use but also predict fine-scale core space use by each species to inform restorative actions (i.e., plantings) to improve nursery habitat for juvenile Muskellunge.

The lone age-0 Muskellunge transported to Buck from Flynn Bay in 2015 was briefly detected in the mouth of its natal embayment (i.e., Flynn) the winter of 2016. Spawning adults are known to exhibit strong site fidelity (e.g. LaPan et al. 1996); however, limited information on site fidelity for this earlier life stage is available. A complex corridor, made up of several islands, shoals, and deep channels exists between Buck and Flynn Bay; however, a continuous band of deeper growing SAV around this corridor may have been used by this Muskellunge to return to its natal embayment. Future spatiotemporal ecology studies which transplant juvenile Muskellunge to increase sample sizes may test the hypothesis that esocids establish their overwintering range near their natal embayment in their juvenile years. Supporting this hypothesis may elucidate an important ontogenetic change in space and habitat use by juvenile, sub-adult and adult esocids.

The importance of elevated water levels and temperatures for juvenile Northern Pike was found to extend beyond initial recruitment post-spawning (i.e., Hudon et al. 2010) in this study. Water temperature decreases with increasing depths, and this relationship is known to exert profound effects on early life survival and recruitment for fish, including Northern Pike (Hudon et 
al. 2010). Smith et al. (2007) noted year-class strength for Northern Pike in the upper St. Lawrence River was positively associated with high water levels and water temperatures in spawning and nursery areas in fall months, while Hudon et al. (2010) found ideal recruitment years for Northern Pike in the lower St. Lawrence River were characterized by high water levels and high $\left(>18.6^{\circ} \mathrm{C}\right)$ air temperature in June. Indeed, presence, residency and space use by age-0 Northern Pike in the first two autumn seasons in the present study corresponded with higher water levels and air temperatures, suggesting these conditions may act two-fold: good recruitment and good nursery habitat conditions in fall months. In addition, residency of age- 0 fish was strongly associated with a deeper littoral region in early fall known to contain dense pondweed (Potamogeton spp.) patches, as well as nearshore regions with high SAV cover. Farrell et al. (2014) documented frequent use

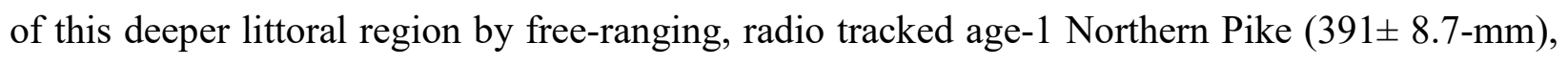
suggesting similar embayment-level habitat use throughout their juvenile stage.

Stocked and wild counterparts monitored in Rose and Buck Bays implied similar spatiotemporal behaviours between sources - a fundamental assumption (similar behaviours) of stocking - indicating restoration efforts targeting wild fish will likely benefit stocked conspecifics. Fifty percent more Muskellunge were caught and tagged at Rose in 2015 than 2016, likely due to stocking advanced fry prior to seine surveys in 2015. Success of stocked fingerlings within the upper St. Lawrence River must consider whether similar spatiotemporal patterns exist between stocked and wild fish (Farrell and Werner 1999). Farrell et al. (2014) postulated that the consistent habitat use by stocked age-1 Muskellunge in Flynn Bay resulted from their captive rearing environment; however, results showed overwhelmingly consistent habitat use between stocked and wild fish within Rose ( $>90 \%)$. Though stocked fish could not be differentiated from wild ones, detections from $95 \%$ of age- 0 fish as age- 1 fish in Rose Bay suggests high survival rates. 
The acoustic tags used in the initial season lasted substantially longer than anticipated, and permitted an evaluation of presence, residency, space and habitat uses of each Muskellunge and Northern Pike as age-1 individuals within two embayments. Specifications indicated a calculated lifespan of 87-days (L-AMT-1.416) and 131-days (L-AMT-1.421) with transmissions emitting at 20-second pings (Lotek, 2018); however, detections up to March 2017 suggest a lifespan of more than 570-days. More research is required into the lifespan of mini acoustic transmitters, to determine their validity in multi-year studies and the performance of an array with JSATS in various aquatic environments. For instance, juvenile esocids share an affinity for shallow, vegetated habitats, which create challenges for passive acoustic monitoring as transmitter signals are attenuated by dense vegetation (Cooke et al. 2013) and shallow water receivers can become exposed when water levels drop (i.e., $<1$ m nursery bays). To this end, biased detections rates (i.e., diel period) due to the environment in the present study may have influenced residency patterns, and thus my interpretation of how macro-scale variables (i.e., water levels) influence the length of time juveniles remain in their embayment and motives to stay rather than move out.

Future studies should focus efforts in deeper littoral waters and adjacent river shorelines, to better elucidate macro-habitat use and avoid fluctuating environmental conditions that restrict receiver placement, and test attenuation issues in shallow, heavily vegetated regions compared to deeper littoral zones. Further, studies may desire to explore the spatial ecology of age-0 Muskellunge and Northern Pike in the lower St. Lawrence River to determine model extrapolation and transferability within Lake St. Lawrence. Results of the present study identified a spatial process that correlates with water level and temperature; however, fine-scale, manipulative studies within the upper and lower river system may identify a causal process in space and habitat use between these juvenile esocids. 
Echoing Crane et al. (2015), protection and re-establishing moderate densities of SAV to maximize edge habitats may aid juveniles in meeting basic biological needs overwinter, though manipulative studies are required to test predictions associated with micro-habitat use relative to Northern Pike. Ontogeny is known to play a crucial role in habitat segregation and existence of sympatry between juveniles and adults (e.g. Rhnogobius spp; Sone et al. 2001, Guo et al. 2014), as subadult fish are rarely observed despite significant sampling effort (Farrell, pers. comm); this area of research is a critical, yet understudied link to elucidate movement patterns and critical habitat uses which may promote survivorship of esocids to adulthood. 


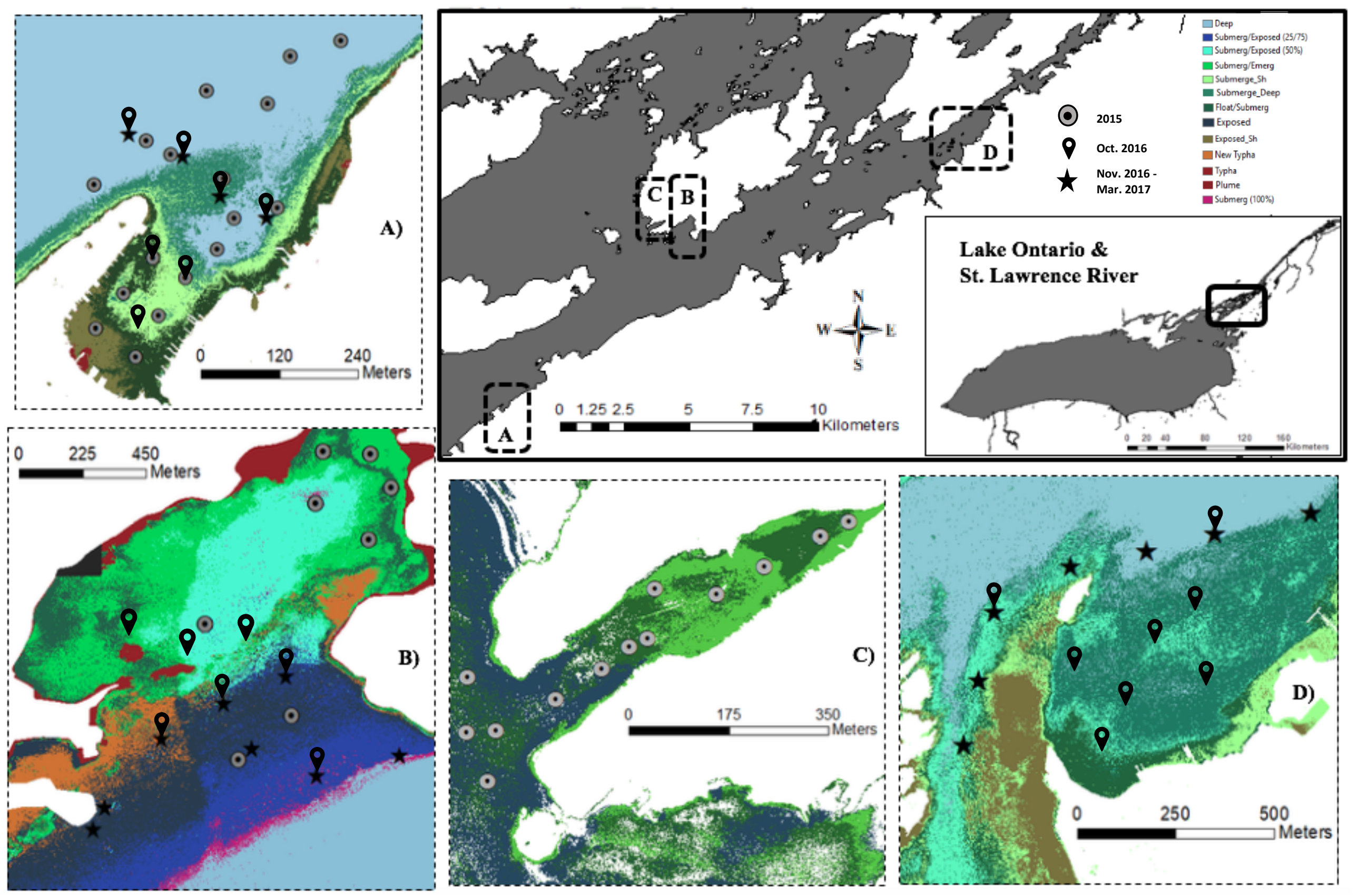


Figure 3.4. Map of the upper St. Lawrence River, and the study site, relative to Lake Ontario and the St. Lawrence River, where age-0 Muskellunge and Northern pike were captured, tagged, and tracked between 2015 and 2017. Embayment locations in which age-0 Muskellunge and Northern Pike were tagged and tracked are denoted by a dotted line indicating its location in the upper St. Lawrence River, with the associated letter. Embayments include A) Rose, B) Flynn, C) Buck and D) Grass Point Bays. The receivers deployed in 2015 are denoted by a grey circle with a black dot; October 2016 are denoted by a locator icon, from November 2016 to March 2017 by black stars. Colours denote the habitat features selected through the Iso unsupervised clustering analysis in ArcGIS. Deep zones are those $>3$ meters. Submerg/Exposed zones indicate regions with $25 \%$ or $50 \%$ exposed substrate. Submerge/Emerge zones include both SAV and emergent species in shallow waters, similarly to zones with both Floating and SAV. Exposed zones are exposed substrates in $>3$ meters of water, and Exposed_Sh are similar zones in shallow waters. Note that Typha is only present in Flynn, while the Plume is only observed in the nearshore of Rose. 


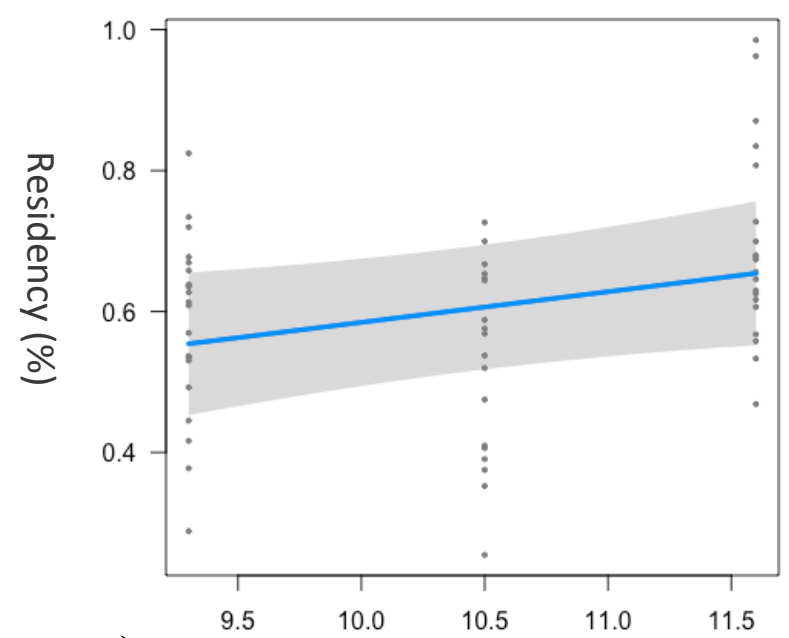

a)

Water Temperature $(\stackrel{\circ}{\circ})$

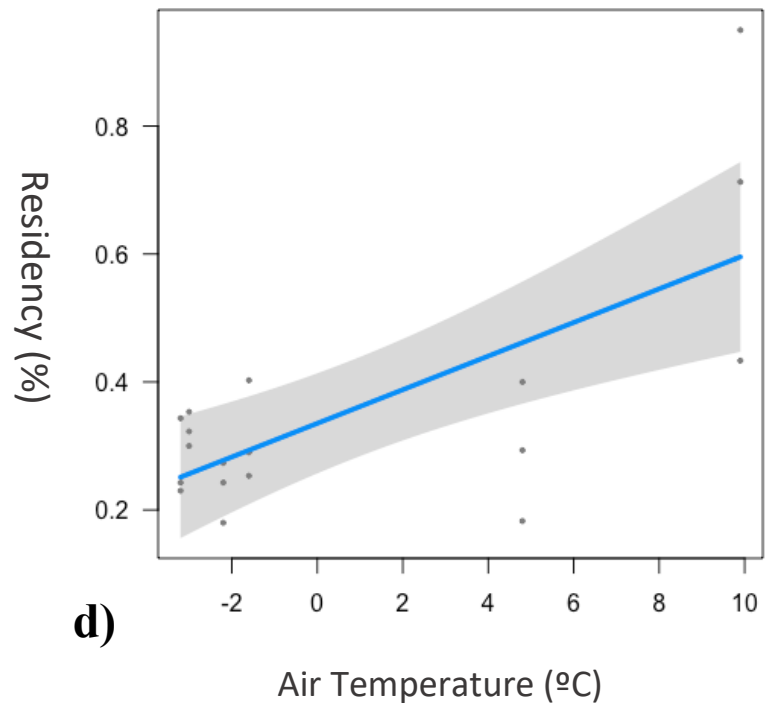

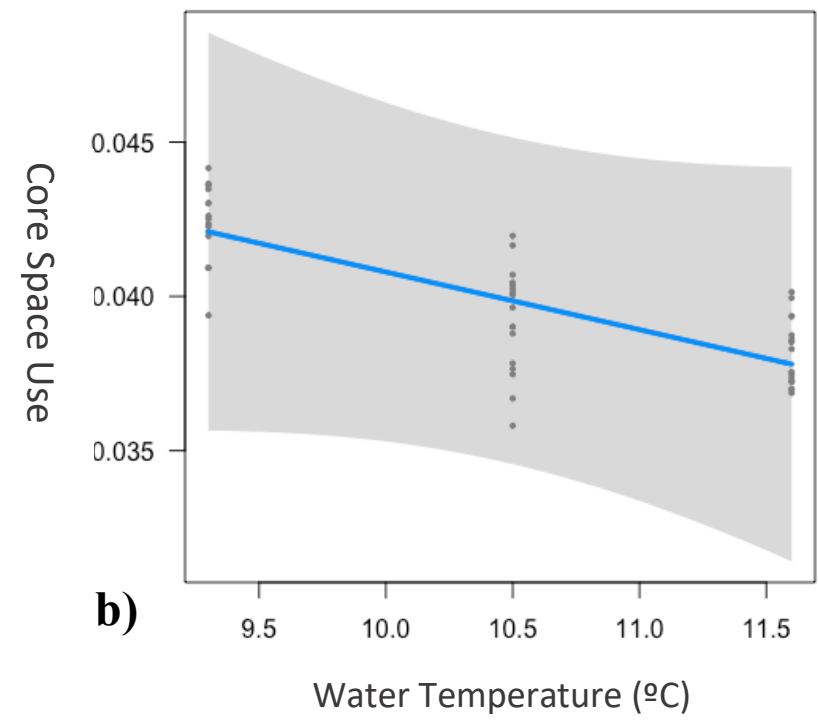

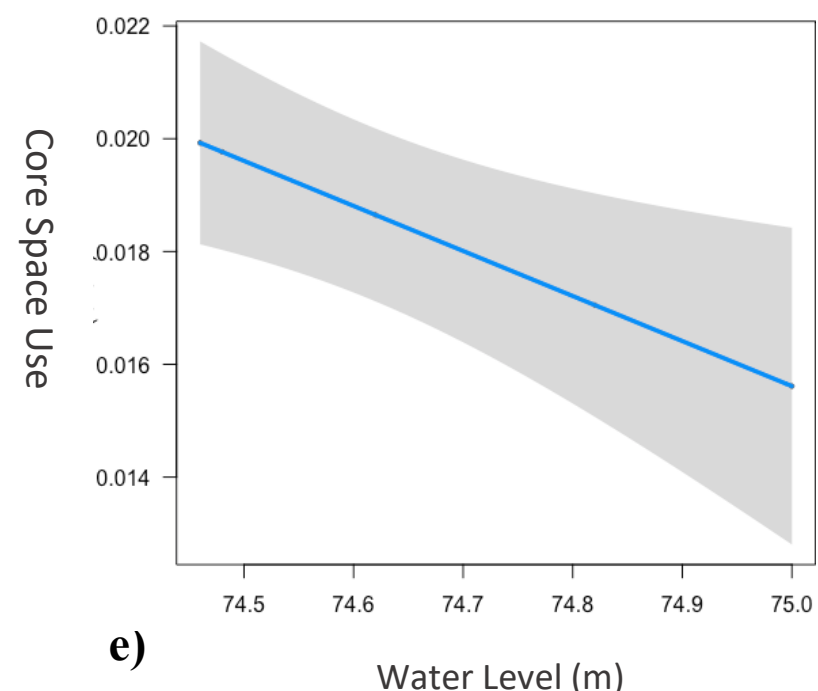

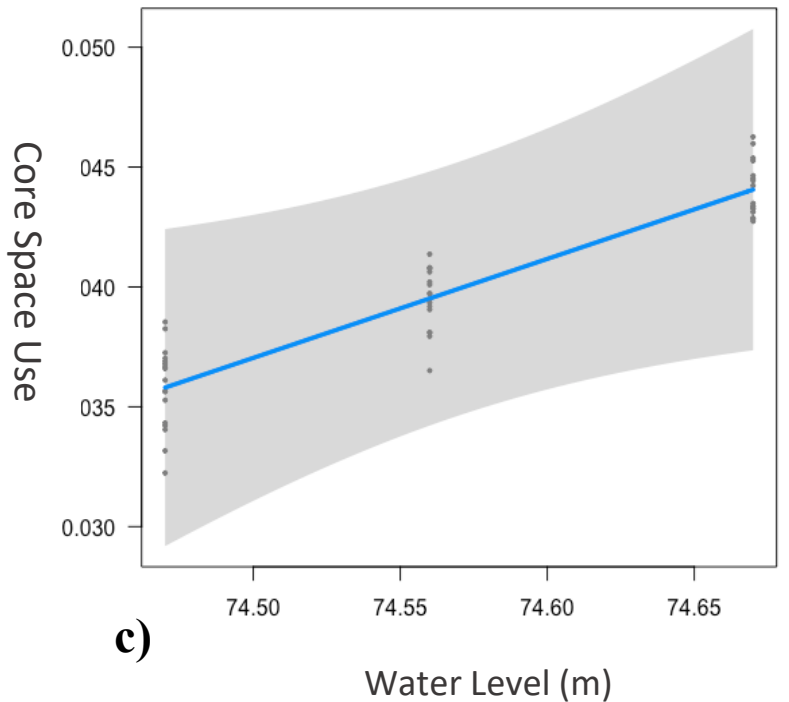

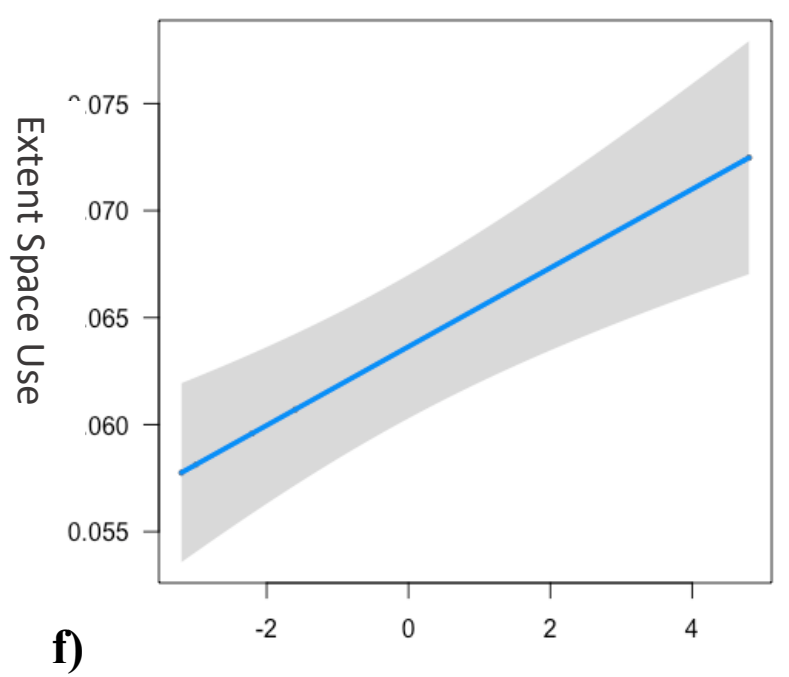

Air Temperature (으)

Figure 3.2. Significant relationships in residency (RI) and space use were observed for age-0 Muskellunge in Rose Bay in 2015 and $2016 / 17$ on a monthly basis. Each graph represents a separate statistical model. Dots represent individual RI and space use values at monthly water temperature and water levels; a) residency increased with warmer water temperatures in fall months, while b) core space use decreased with increased water temperatures and c) higher water levels. In 2016/17, d) residency increased with water temperatures, e) core space use became variable with high water levels, and f) extent increased with higher water temperatures. 


$$
\begin{aligned}
& 3 \\
& 200 \\
& 20
\end{aligned}
$$




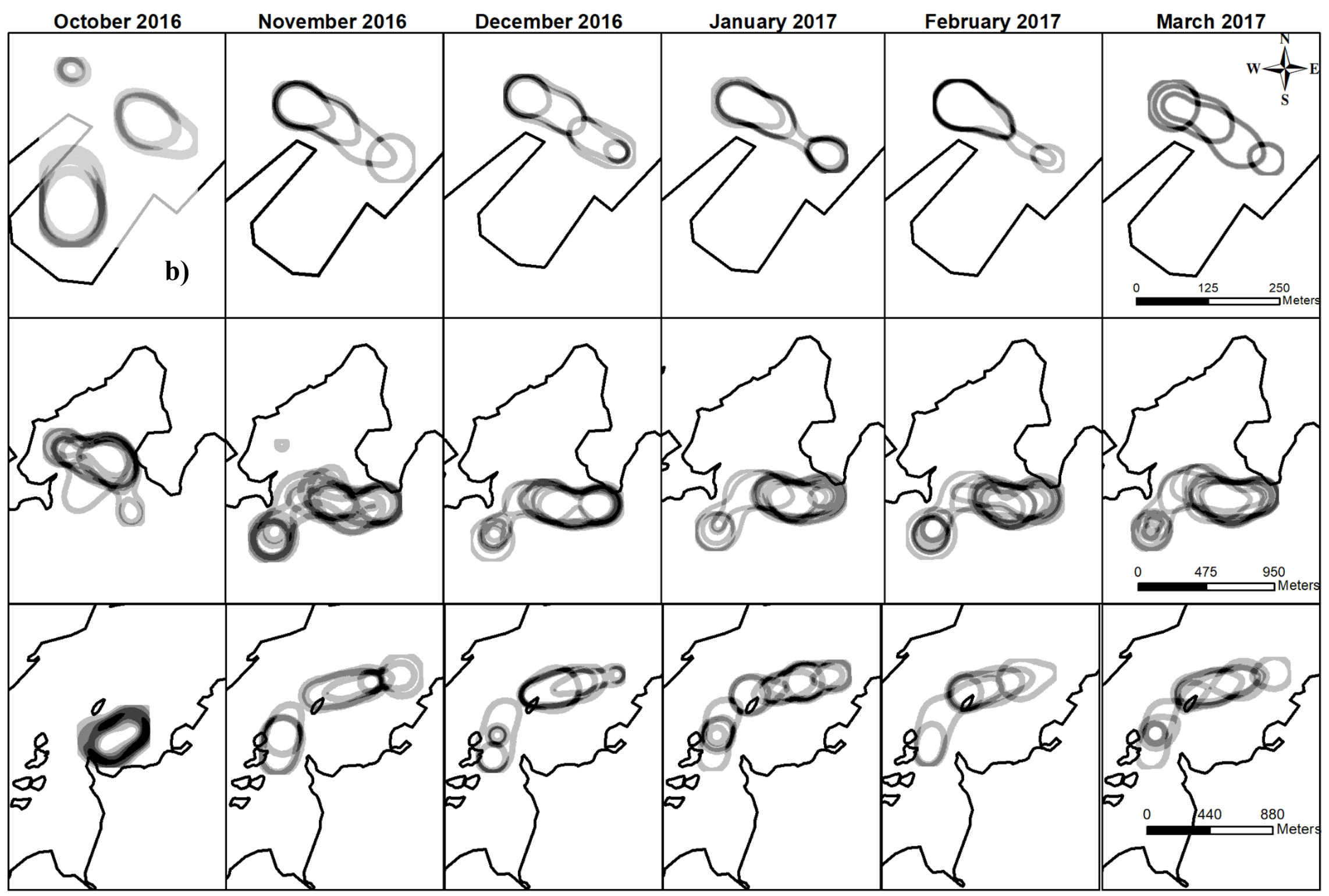

Figure 3.3. Core space use ( $\mathrm{km}^{2}-50 \%$ KUD) by age- 0 Muskellunge and Northern Pike in the upper St. Lawrence River in a) 2015 and b) 2016 and 2017. Darker circles denote areas heavily used by fish based on a monthly analysis for a) Rose (top), Flynn (middle) and Buck (bottom) and b) Rose (top), Flynn (middle) and Grass Point (bottom). 

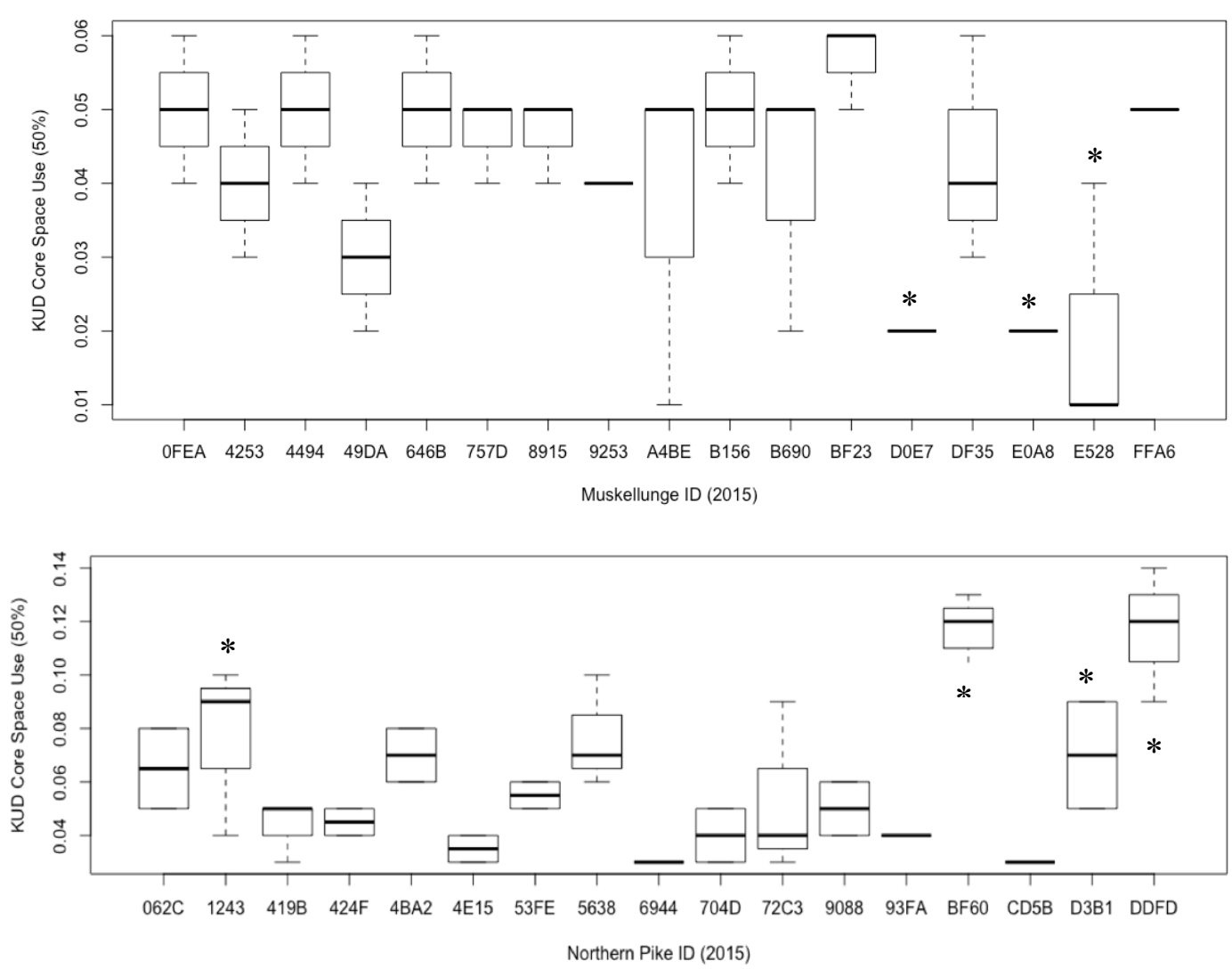

Figure 3.4. Significant differences in core use $\left(\mathrm{km}^{2}-50 \%\right.$ KUD) between muskellunge in Rose Bay, 2015 (top) and Northern pike in Flynn Bay, 2015 (bottom). Three muskellunge (BF60, D3B1 and DDF) had significantly larger core use areas, relative to conspecifics. Four Northern pike (49DA, D0E7, E0A8, and E528) had significantly smaller core use areas, relative to conspecifics. Total length did not influence core use size between fish. Fish with significant differences are denoted by a star, above or below their boxplot. 

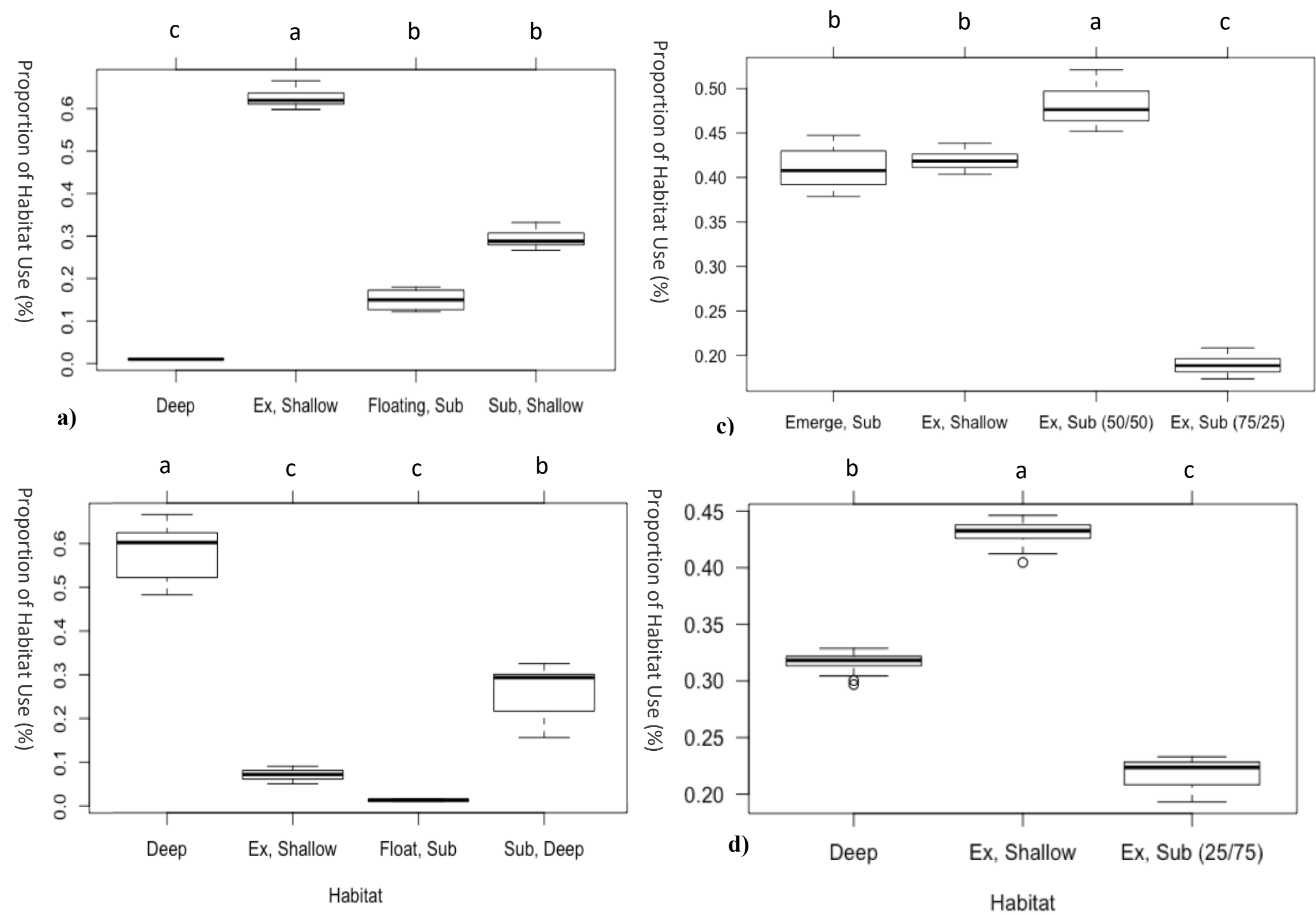

Figure 3.6. Boxplots indicating significant differences in proportional habitat use by age-0 Muskellunge in (a) Buck Bay in 2015 and (b) Grass Point Bay from 2016 to 2017), and for age-0 Northern Pike within (c) Flynn Bay in 2015 and (d) Flynn Bay from 2016 to 2017. Letters indicate how habitats are grouped with respect to their level of significance. Deeper regions were most used by Rose Muskellunge (>90\%) compared to Float, Sub. 

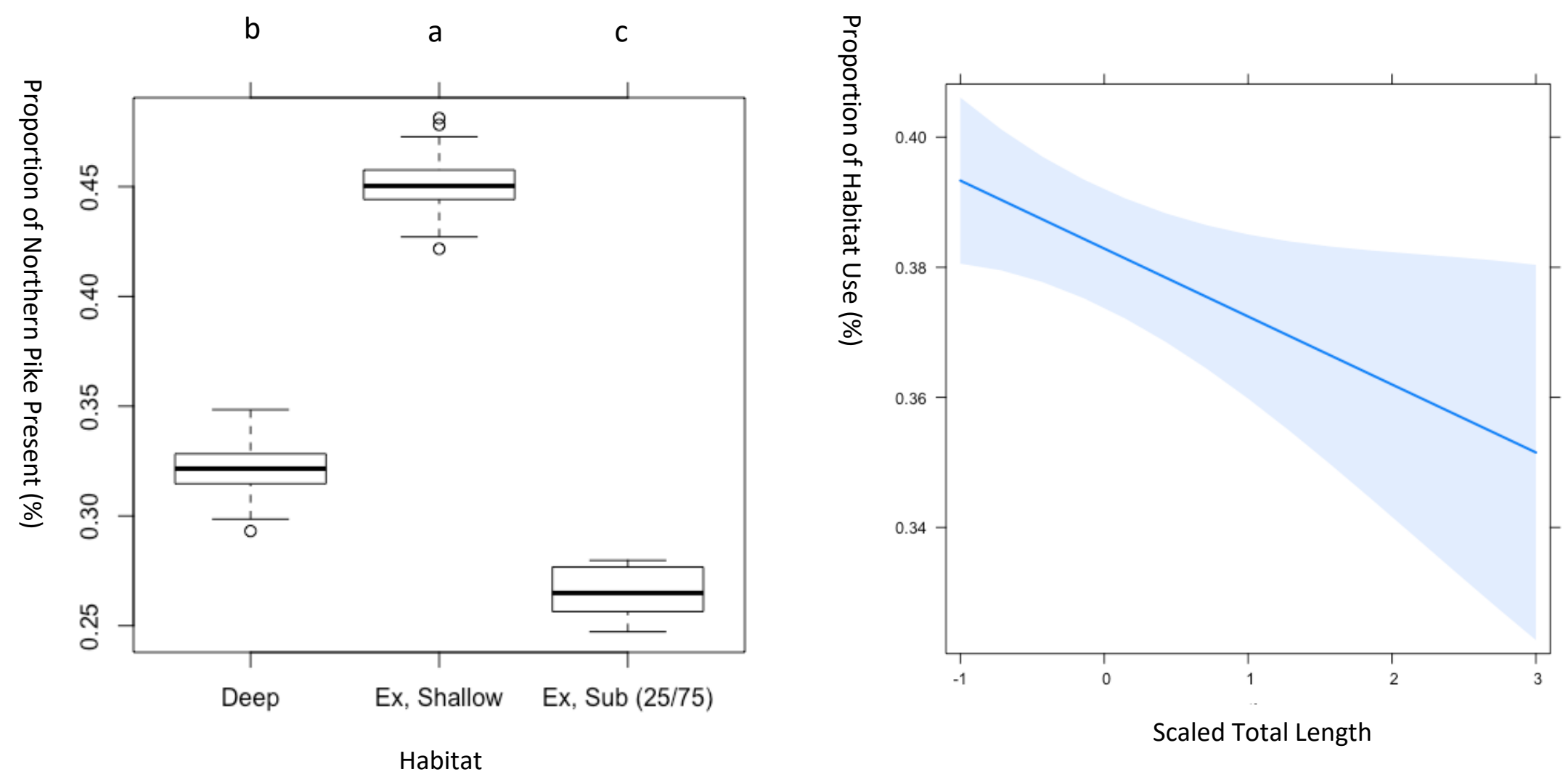

Figure 3.7. A) Boxplot indicating significant differences in proportional habitat use by age-1 Northern Pike from 2016 to 2017. Letters indicate how habitats are grouped with respect to their level of significance; B) Total length was found a significant predictor of proportional habitat use by age-1 Northern Pike; the lower the habitat use (e.g. deep zone, exposed with SAV), the larger the fish. 
Table 3.7. Detection and space use information for age-0 Muskellunge monitored in the upper St. Lawrence River over two different years. Fish captured in 2015 were tracked between October and December, and those in September 2016 from October 2016 to March 2017. Core use ( \pm SE) and Extent $( \pm \mathrm{SE}$ ) represent the mean 50\% and 95\% KUDs for each bay. Monthly residency Index was calculated using the consecutive number of days fish were detected by the number of days the array was active. The bracketed residency index values for fish monitored in $2016 / 17$ were divided by the number of receivers deployed each month, to ensure a reduction in detections was not due to the reduction in number of receivers from October to November through March, and to confirm a natural pattern rather than an artefact of the array.

\begin{tabular}{|c|c|c|c|c|c|c|c|c|c|c|c|c|}
\hline Year & Bay & $\begin{array}{l}\text { Size } \\
\text { (ha) }\end{array}$ & $\begin{array}{l}\text { No. } \\
\text { Fish }\end{array}$ & $\begin{array}{l}\text { Total } \\
\text { Length } \\
\pm \mathrm{SD} \\
(\mathrm{mm})\end{array}$ & $\begin{array}{l}\text { Weight } \\
\pm \text { SD } \\
\text { (g) }\end{array}$ & $\begin{array}{l}\text { Number } \\
\text { of } \\
\text { Detections }\end{array}$ & $\begin{array}{l}\text { Number of } \\
\text { Detections } \\
\pm \text { SD }\end{array}$ & $\begin{array}{l}\text { Core Use }\left(\mathbf{k m}^{2}\right) \\
\pm \mathrm{SE}\end{array}$ & $\begin{array}{l}\text { Extent }\left(\mathbf{k m}^{2}\right) \\
\pm \mathrm{SE}\end{array}$ & $\begin{array}{l}\text { Number of } \\
\text { Days Array } \\
\text { Active }\end{array}$ & $\begin{array}{l}\text { Consecutive } \\
\text { Days } \\
\text { Present }\end{array}$ & $\begin{array}{l}\text { Residency } \\
\text { Index } \\
\pm \text { SD }\end{array}$ \\
\hline \multirow[t]{3}{*}{2015} & Flynn & 74 & 15 & $234 \pm 55.2$ & $83 \pm 64.2$ & 18691 & $788 \pm 812$ & $0.06 \pm 0.005$ & $0.32 \pm 0.02$ & 71 & $0 \quad-70$ & $0.53 \pm 5.6$ \\
\hline & Rose & 9 & 20 & $151 \pm 19.4$ & $18 \pm 6.5$ & 45760 & $577 \pm 1125$ & $0.04 \pm 0.002$ & $0.16 \pm 0.004$ & 71 & $2-45$ & $0.64 \pm 5.4$ \\
\hline & Buck & 18 & 7 & $164 \pm 23.5$ & $19 \pm 7.8$ & 566 & $81 \pm 42$ & $0.13 \pm 0.005$ & $0.50 \pm 0.01$ & 70 & $2-18$ & $0.54 \pm 0.2$ \\
\hline \multirow[t]{3}{*}{2016} & Flynn & 74 & 16 & $227 \pm 38.3$ & $85 \pm 47.2$ & 1074 & $80 \pm 102$ & $0.18 \pm 0.01$ & $0.62 \pm 0.008$ & 178 & $9-165$ & $\begin{array}{l}0.49 \pm 0.21 \\
{[0.06 \pm 0.03]}\end{array}$ \\
\hline & Rose & 9 & 4 & $182 \pm 45.5$ & $35 \pm 28.5$ & 761 & $143 \pm 127$ & $0.02 \pm 0.008$ & $0.06 \pm 0.002$ & 180 & $31-86$ & $\begin{array}{l}0.40 \pm 0.21 \\
{[0.09 \pm 0.03]}\end{array}$ \\
\hline & Grass & 47 & 5 & $174 \pm 33.5$ & $32 \pm 11.9$ & 661 & $98 \pm 102$ & $0.11 \pm 0.004$ & $0.49 \pm 0.01$ & 170 & $\begin{array}{ll}0 & -12\end{array}$ & $\begin{array}{l}0.38 \pm 0.27 \\
{[0.05 \pm 0.04]}\end{array}$ \\
\hline
\end{tabular}


Table 3.8. Detection and biological data for individual age- 0 Muskellunge monitored in the upper St. Lawrence River from October to December 2015. The total number of detections are those of individual fish after filtering for double detections (receiver overlap) and removing detections within 5-minutes of each other. Residency Index (\%) was the number of days detected by array days. Fish greyed out were not used in residency, space or habitat use analyses, as they were detected $<7$ days in October or November (or $<2$ days in December), or less than two consecutive months. Muskellunge 875E was captured in Flynn and released in Buck Bay.

\begin{tabular}{|c|c|c|c|c|c|c|c|c|}
\hline $\begin{array}{l}\text { JSAT } \\
\text { TAG ID }\end{array}$ & $\begin{array}{l}\text { Total Length } \\
\pm \mathrm{SD}(\mathrm{mm})\end{array}$ & $\begin{array}{l}\text { Weight } \\
\pm \text { SD(g) }\end{array}$ & $\begin{array}{l}\text { Capture } \\
\text { Date }\end{array}$ & $\begin{array}{l}\text { Capture } \\
\text { Bay }\end{array}$ & $\begin{array}{c}\text { Total } \\
\text { Number of } \\
\text { Detections }\end{array}$ & $\begin{array}{l}\text { Total Days } \\
\text { Detected }\end{array}$ & $\begin{array}{c}\text { Cumulative } \\
\text { Days } \\
\text { Detected }\end{array}$ & $\begin{array}{c}\text { Residency } \\
\text { Index } \\
(\%)\end{array}$ \\
\hline F50E & 177 & 23.2 & 2015-09-11 & BUCK & 37 & 26 & 2 & 37 \\
\hline AEF1 & 158 & 17.1 & 2015-09-11 & BUCK & 102 & 40 & 18 & 57 \\
\hline C687 & 181 & 26.1 & $2015-09-12$ & BUCK & 95 & 42 & 6 & 60 \\
\hline 5859 & 167 & 19.4 & $2015-09-12$ & BUCK & 39 & 29 & 5 & 41 \\
\hline DF35 & 125 & 10.6 & 2015-09-16 & ROSE & 62 & 36 & 5 & 51 \\
\hline BD92 & 150 & 19.6 & 2015-09-16 & ROSE & 96 & 35 & 3 & 49 \\
\hline $646 B$ & 145 & 17.0 & $2015-09-16$ & ROSE & 95 & 41 & 4 & 58 \\
\hline OFEA & 140 & 17.1 & 2015-09-16 & ROSE & 375 & 70 & 25 & 99 \\
\hline 49DA & 122 & 8.6 & 2015-09-16 & ROSE & 711 & 49 & 27 & 69 \\
\hline A4BE & 160 & 25.4 & 2015-09-16 & ROSE & 3989 & 45 & 17 & 63 \\
\hline BF23 & 148 & 19.6 & 2015-09-16 & ROSE & 314 & 66 & 28 & 93 \\
\hline DA2A & 149 & 16.2 & 2015-09-16 & ROSE & 30 & 26 & 2 & 37 \\
\hline B690 & 126 & 12.0 & 2015-09-16 & ROSE & 503 & 42 & 9 & 59 \\
\hline 4494 & 134 & 13.9 & 2015-09-16 & ROSE & 71 & 42 & 6 & 59 \\
\hline 757D & 125 & 7.5 & 2015-09-16 & ROSE & 100 & 50 & 10 & 70 \\
\hline F3B8 & 195 & 27.8 & 2015-09-17 & BUCK & 104 & 45 & 6 & 64 \\
\hline E6CC & 127 & 7.27 & 2015-09-17 & BUCK & 43 & 30 & 2 & 43 \\
\hline $730 \mathrm{C}$ & 143 & 10.4 & 2015-09-17 & BUCK & 146 & 63 & 14 & 90 \\
\hline $875 E$ & 223 & 45.8 & $2015-09-18$ & *FLYNN & 123 & 44 & 8 & 63 \\
\hline
\end{tabular}




\begin{tabular}{lllllccccc}
64 E7 & 156 & 18.0 & $2015-09-19$ & ROSE & 111 & 34 & 4 & 48 \\
3915 & 158 & 17.9 & $2015-09-19$ & ROSE & 0 & 0 & 0 & 0 \\
D0E7 & 171 & 27.2 & $2015-09-19$ & ROSE & 16385 & 61 & 35 & 86 \\
FFA6 & 156 & 19.4 & $2015-09-19$ & ROSE & 155 & 64 & 32 & 90 \\
4253 & 185 & 31.1 & $2015-09-19$ & ROSE & 75 & 39 & 3 & 55 \\
B156 & 174 & 25.5 & $2015-09-19$ & ROSE & 42 & 33 & 4 & 43 \\
E0A8 & 170 & 21.7 & $2015-09-19$ & ROSE & 8339 & 69 & 24 & 37 \\
9253 & 179 & 26.7 & $2015-09-19$ & ROSE & 31 & 24 & 2 & 37 \\
E528 & 162 & 21.0 & $2015-09-19$ & ROSE & 12575 & 47 & 66 \\
\hline
\end{tabular}


Table 9.3. Detection and biological data for individual age-0 Northern pike monitored in the upper St. Lawrence River from October to December 2015. Total number of detections is the total number of detections collected from an individual fish, after filtering for double detections (receiver overlap) and removing detections within 5-minutes of each other. Residency Index (\%) was the number of days detected by array days. Fish grey out were not used in analyses (residency, space or habitat use) as they either died prior to tracking due to surgery or were detected $<7$ days in October or November (or $<2$ days in December), or less than two consecutive months. Fish 6944 and CD5B were detected solely in November.

\begin{tabular}{|c|c|c|c|c|c|c|c|c|}
\hline $\begin{array}{l}\text { JSAT } \\
\text { TAG ID }\end{array}$ & $\begin{array}{l}\text { Total Length } \\
\pm \mathrm{SD}(\mathrm{mm})\end{array}$ & $\begin{array}{l}\text { Weight } \\
\pm S D(g)\end{array}$ & $\begin{array}{l}\text { Capture } \\
\text { Date }\end{array}$ & $\begin{array}{c}\text { Capture } \\
\text { Bay }\end{array}$ & $\begin{array}{c}\text { Total } \\
\text { Number of } \\
\text { Detections }\end{array}$ & $\begin{array}{l}\text { Total Days } \\
\text { Detected }\end{array}$ & $\begin{array}{c}\text { Cumulative } \\
\text { Days } \\
\text { Detected }\end{array}$ & $\begin{array}{c}\text { Residency } \\
\text { Index } \\
(\%)\end{array}$ \\
\hline 4BA2 & 298 & 155 & $2015-09-26$ & FLYNN & 20 & 16 & 0 & 23 \\
\hline $6 B A 2$ & 301 & 145 & $2015-09-26$ & FLYNN & 336 & 22 & 3 & 31 \\
\hline BF60 & 380 & 290 & $2015-09-26$ & FLYNN & 120 & 62 & 15 & 87 \\
\hline 99EB & 146 & 18.5 & $2015-09-26$ & FLYNN & 14 & 13 & 0 & 18 \\
\hline DDFD & 171 & 26.8 & $2015-09-26$ & FLYNN & 295 & 71 & 70 & 100 \\
\hline 419B & 255 & 87 & $2015-09-26$ & FLYNN & 2982 & 63 & 17 & 89 \\
\hline AA29 & 247 & 85.0 & $2015-09-26$ & FLYNN & 23 & 11 & 29 & 15 \\
\hline 704D & 241 & 80.0 & $2015-09-26$ & FLYNN & 2005 & 55 & 24 & 77 \\
\hline *6944 & 356 & 235 & $2015-09-26$ & FLYNN & 300 & 28 & 4 & 39 \\
\hline 93FA & 222 & 59.3 & $2015-09-26$ & FLYNN & 2314 & 59 & 18 & 83 \\
\hline 1243 & 210 & 49.7 & $2015-09-28$ & FLYNN & 831 & 40 & 8 & 56 \\
\hline $424 \mathrm{~F}$ & 215 & 57.0 & $2015-09-28$ & FLYNN & 417 & 27 & 7 & 38 \\
\hline 9088 & 235 & 78.7 & $2015-09-28$ & FLYNN & 801 & 43 & 12 & 61 \\
\hline $53 \mathrm{FE}$ & 205 & 51.6 & $2015-09-28$ & FLYNN & 1271 & 46 & 8 & 65 \\
\hline $062 C$ & 200 & 43.5 & $2015-09-28$ & FLYNN & 83 & 29 & 12 & 41 \\
\hline
\end{tabular}




\begin{tabular}{lllllllll}
5638 & 172 & 27.0 & $2015-09-28$ & FLYNN & 857 & 58 & 18 & 82 \\
$72 C 3$ & 216 & 57.0 & $2015-09-28$ & FLYNN & 1451 & 58 & 24 & 82 \\
A6AE & 240 & 76.3 & $2015-09-28$ & FLYNN & 311 & 21 & 9 & 30 \\
CF7F & 247 & 93.4 & $2015-09-28$ & FLYNN & 521 & 53 & 8 & 75 \\
4E15 & 250 & 105 & $2015-09-28$ & FLYNN & 630 & 0 & 0 & 0 \\
D3B1 & 252 & 95.0 & $2015-09-28$ & FLYNN & 51 & 23 & 2 & 32 \\
$*$ CD5B & 213 & 56.0 & $2015-09-28$ & FLYNN & 1286 & 43 & 26 & 61 \\
C57F & 275 & 120 & $2015-09-28$ & FLYNN & 1744 & 33 & 19 & 46 \\
\hline
\end{tabular}


Table 3.10. Detection and biological data for individual age-0 Muskellunge tracked in their natal embayment from November 2016 to March 2017. Total number of detections is the total number of detections collected from an individual fish, after filtering for double detections (receiver overlap) and removing detections within 5-minutes of each other. Residency Index (\%) was the number of days detected by array days. Fish grey out were not used in analyses (residency, space or habitat use) as they were detected $<7$ days per month, or less than two consecutive months. Muskellunge A76D was first tagged as 933D on September 9, 2016.

\begin{tabular}{|c|c|c|c|c|c|c|c|c|c|}
\hline Species & $\begin{array}{c}\text { JSAT } \\
\text { TAG ID }\end{array}$ & $\begin{array}{l}\text { Total Length } \\
\pm \mathrm{SD}(\mathrm{mm})\end{array}$ & $\begin{array}{l}\text { Weight } \\
\pm S D(g)\end{array}$ & $\begin{array}{l}\text { Capture } \\
\text { Date }\end{array}$ & $\begin{array}{c}\text { Capture } \\
\text { Bay }\end{array}$ & $\begin{array}{l}\text { Total Number of } \\
\text { Detections } \\
\text { Nov to Mar }\end{array}$ & $\begin{array}{l}\text { Total Days } \\
\text { Detected }\end{array}$ & $\begin{array}{c}\text { Cumulative } \\
\text { Days } \\
\text { Detected }\end{array}$ & $\begin{array}{c}\text { Residency } \\
\text { Index } \\
(\%)\end{array}$ \\
\hline Musky & **933D & 156 & 18.0 & 2016-09-06 & ROSE & 70 & 6 & 0 & 4 \\
\hline Musky & 3605 & 168 & 25.5 & 2016-09-06 & ROSE & 59 & 46 & 2 & 31 \\
\hline Musky & 0274 & 118 & 11.9 & 2016-09-07 & GRASS & 78 & 55 & 3 & 12 \\
\hline Musky & 07DE & 196 & 41.5 & 2016-09-07 & GRASS & 374 & 144 & 21 & 96 \\
\hline Musky & $33 F 4$ & 176 & 32.1 & 2016-09-07 & GRASS & 73 & 45 & 4 & 30 \\
\hline Musky & $30 E C$ & 155 & 18.0 & 2016-09-12 & ROSE & 59 & 45 & 3 & 30 \\
\hline Musky & $790 D$ & 154 & 18.0 & 2016-09-21 & FLYNN & 19 & 20 & 1 & 13 \\
\hline Musky & AAD4 & 178 & 32.8 & 2016-09-29 & GRASS & 25 & 23 & 1 & 15 \\
\hline Musky & D14F & 203 & 40.4 & 2016-10-06 & GRASS & 61 & 48 & 3 & 32 \\
\hline Musky & $810 C$ & 250 & 78.5 & 2016-10-07 & ROSE & 84 & 67 & 5 & 45 \\
\hline Musky & $* * A 76 D$ & 234 & 67.5 & 2016-10-07 & ROSE & 46 & 11 & 0 & 7 \\
\hline
\end{tabular}


Table 3.5. Detection and biological data for individual age- 0 Northern Pike tracked in their natal embayment, November 2016 to March 2017. Number of detections is the total number of detections collected from an individual fish, after filtering for double detections (receiver overlap) and removing detections within 5-minutes of each other. Residency Index (\%) was the number of days detected by array days. Fish grey out were not used in analyses (residency, space or habitat use) as they were detected $<7$ days per month, or less than two consecutive months.

\begin{tabular}{|c|c|c|c|c|c|c|c|c|c|}
\hline Species & $\begin{array}{l}\text { JSAT } \\
\text { TAG ID }\end{array}$ & $\begin{array}{l}\text { Total Length } \\
\pm \mathrm{SD}(\mathrm{mm})\end{array}$ & $\begin{array}{l}\text { Weight } \\
\pm S D(g)\end{array}$ & $\begin{array}{l}\text { Capture } \\
\text { Date }\end{array}$ & $\begin{array}{c}\text { Capture } \\
\text { Bay }\end{array}$ & $\begin{array}{l}\text { Number of } \\
\text { Detections } \\
\text { Nov to Mar }\end{array}$ & $\begin{array}{l}\text { Total Days } \\
\text { Detected }\end{array}$ & $\begin{array}{c}\text { Cumulative } \\
\text { Days } \\
\text { Detected }\end{array}$ & $\begin{array}{c}\text { Residency } \\
\text { Index } \\
(\%)\end{array}$ \\
\hline N. Pike & $413 \mathrm{E}$ & 263 & 118.0 & 2016-09-21 & FLYNN & 77 & 64 & 7 & 43 \\
\hline N. Pike & $38 \mathrm{C} 3$ & 250 & 110.5 & $2016-09-21$ & FLYNN & 79 & 52 & 3 & 34 \\
\hline N. Pike & $4 \mathrm{D} 88$ & 310 & 202.8 & $2016-09-21$ & FLYNN & 61 & 50 & 3 & 33 \\
\hline N. Pike & †EC39 & 259 & 115.5 & 2016-09-21 & FLYNN & 38 & 35 & 4 & 23 \\
\hline N. Pike & tF603 & 254 & 105.6 & 2016-09-21 & FLYNN & 140 & 92 & 7 & 61 \\
\hline N. Pike & $91 \mathrm{FA}$ & 205 & 58.4 & 2016-09-21 & FLYNN & 22 & 21 & 0 & 14 \\
\hline N. Pike & 36B8 & 179 & 40.1 & $2016-09-21$ & FLYNN & 31 & 25 & 1 & 17 \\
\hline N. Pike & $5 \mathrm{~A} 49$ & 235 & 89.8 & $2016-09-21$ & FLYNN & 11 & 8 & 0 & 5 \\
\hline N. Pike & $69 B 5$ & 216 & 67.5 & 2016-09-21 & FLYNN & 7 & 7 & 0 & 5 \\
\hline N. Pike & $1 \mathrm{~A} 2 \mathrm{~B}$ & 219 & 66.8 & $2016-09-21$ & FLYNN & 29 & 27 & 1 & 18 \\
\hline N. Pike & 0351 & 183 & 38.0 & 2016-09-21 & FLYNN & 95 & 68 & 6 & 45 \\
\hline N. Pike & $92 \mathrm{~F} 2$ & 222 & 78.0 & 2016-09-21 & FLYNN & 18 & 16 & 1 & 11 \\
\hline N. Pike & 4317 & 195 & 43.8 & 2016-09-21 & FLYNN & 77 & 57 & 3 & 38 \\
\hline N. Pike & 0219 & 215 & 70.8 & 2016-09-21 & FLYNN & 358 & 139 & 31 & 93 \\
\hline N. Pike & $196 \mathrm{~A}$ & 197 & 47.8 & 2016-09-21 & FLYNN & 19 & 19 & 1 & 9 \\
\hline
\end{tabular}


Table 3.6. Detection and biological data for individual age-1 Muskellunge monitored in Rose Bay from November 2016 to March 2017. Number of detections is the total number after filtering for double detections (receiver overlap) and removing detections within 5minutes of each other. Residency Index (\%) was the number of days detected by array days. Fish grey out were not used in analyses (residency, space or habitat use) as they were detected $<7$ days per month, or less than two consecutive months.

\begin{tabular}{|c|c|c|c|c|c|c|c|c|}
\hline $\begin{array}{l}\text { JSAT } \\
\text { TAG ID }\end{array}$ & $\begin{array}{l}\text { Total Length } \\
\pm \mathrm{SD}(\mathrm{mm})\end{array}$ & $\begin{array}{l}\text { Weight } \\
\pm S D(g)\end{array}$ & $\begin{array}{l}\text { Capture } \\
\text { Date }\end{array}$ & $\begin{array}{l}\text { Capture } \\
\text { Bay }\end{array}$ & $\begin{array}{l}\text { Number of } \\
\text { Detections }\end{array}$ & $\begin{array}{l}\text { Days } \\
\text { Detected }\end{array}$ & $\begin{array}{c}\text { Cumulative Days } \\
\text { Detected }\end{array}$ & $\begin{array}{l}\text { Residency } \\
\text { Index (\%) }\end{array}$ \\
\hline DF35 & 125 & 10.6 & 2015-09-16 & ROSE & 27 & 16 & 2 & 11 \\
\hline BD92 & 150 & 19.6 & 2015-09-16 & ROSE & 14 & 11 & 0 & 7 \\
\hline $646 B$ & 145 & 17.0 & 2015-09-16 & ROSE & 29 & 17 & 2 & 11 \\
\hline OFEA & 140 & 17.1 & 2015-09-16 & ROSE & 232 & 113 & 13 & 75 \\
\hline 49DA & 122 & 8.6 & $2015-09-16$ & ROSE & 18 & 12 & 2 & 8 \\
\hline A4BE & 160 & 25.4 & 2015-09-16 & ROSE & 12 & 9 & 0 & 6 \\
\hline BF23 & 148 & 19.6 & $2015-09-16$ & ROSE & 77 & 49 & 3 & 33 \\
\hline $\mathrm{DA} 2 \mathrm{~A}$ & 149 & 16.2 & 2015-09-16 & ROSE & 14 & 11 & 2 & 7 \\
\hline B690 & 126 & 12.0 & 2015-09-16 & ROSE & 26 & 5 & 2 & 3 \\
\hline 4494 & 134 & 13.9 & $2015-09-16$ & ROSE & 41 & 26 & 2 & 17 \\
\hline 757D & 125 & 7.5 & 2015-09-16 & ROSE & 44 & 35 & 3 & 23 \\
\hline $64 \mathrm{E} 7$ & 156 & 18.0 & 2015-09-19 & ROSE & 63 & 38 & 2 & 25 \\
\hline 3915 & 158 & 17.9 & 2015-09-19 & ROSE & 0 & 0 & 0 & 0 \\
\hline D0E7 & 171 & 27.2 & 2015-09-19 & ROSE & 26 & 22 & 1 & 15 \\
\hline FFA6 & 156 & 19.4 & 2015-09-19 & ROSE & 74 & 46 & 6 & 31 \\
\hline 4253 & 185 & 31.1 & 2015-09-19 & ROSE & 22 & 17 & 2 & 11 \\
\hline B156 & 174 & 25.5 & 2015-09-19 & ROSE & 26 & 19 & 2 & 13 \\
\hline E0A8 & 170 & 21.7 & 2015-09-19 & ROSE & 29 & 23 & 2 & 15 \\
\hline 9253 & 179 & 26.7 & 2015-09-19 & ROSE & 15 & 14 & 1 & 9 \\
\hline E528 & 162 & 21.0 & 2015-09-19 & ROSE & 6 & 5 & 0 & 3 \\
\hline
\end{tabular}


Table 3.7. Detection and biological data for individual age-1 Northern Pike monitored in Flynn Bay. Number of detections is the total number after filtering for double detections (receiver overlap) and removing detections within 5-minutes of each other. Residency Index $(\%)$ was the number of days detected by array days. Fish grey out were not used in analyses (residency, space or habitat use) as they were detected $<7$ days per month, or less than two consecutive months. 


\begin{tabular}{|c|c|c|c|c|c|c|c|c|}
\hline $\begin{array}{l}\text { JSAT } \\
\text { TAG ID }\end{array}$ & $\begin{array}{l}\text { Total Length } \\
\pm S D(\mathrm{~mm})\end{array}$ & $\begin{array}{l}\text { Weight } \\
\pm S D(g)\end{array}$ & $\begin{array}{l}\text { Capture } \\
\text { Date }\end{array}$ & $\begin{array}{c}\text { Capture } \\
\text { Bay }\end{array}$ & $\begin{array}{l}\text { Number of } \\
\text { Detections }\end{array}$ & $\begin{array}{c}\text { Days } \\
\text { Detected }\end{array}$ & $\begin{array}{l}\text { Cumulative } \\
\text { Days } \\
\text { Detected }\end{array}$ & $\begin{array}{l}\text { Residency } \\
\text { Index (\%) }\end{array}$ \\
\hline 4BA2 & 298 & 155 & 2015-09-26 & FLYNN & 43 & 39 & 1 & 26 \\
\hline $6 \mathrm{BA2}$ & 301 & 145 & 2015-09-26 & FLYNN & 13 & 13 & 1 & 9 \\
\hline BF60 & 380 & 290 & $2015-09-26$ & FLYNN & 275 & 143 & 13 & 95 \\
\hline 99EB & 146 & 18.5 & 2015-09-26 & FLYNN & 38 & 33 & 2 & 22 \\
\hline DDFD & 171 & 26.8 & 2015-09-26 & FLYNN & 663 & 180 & 59 & 100 \\
\hline $419 B$ & 255 & 87 & $2015-09-26$ & FLYNN & 92 & 70 & 6 & 47 \\
\hline AA29 & 247 & 85 & 2015-09-26 & FLYNN & 6 & 6 & 0 & 4 \\
\hline $704 \mathrm{D}$ & 241 & 80 & 2015-09-26 & FLYNN & 25 & 25 & 2 & 17 \\
\hline 6944 & 356 & 235 & 2015-09-26 & FLYNN & 40 & 37 & 2 & 25 \\
\hline $93 F A$ & 222 & 59.3 & 2015-09-26 & FLYNN & 122 & 88 & 6 & 59 \\
\hline 1243 & 210 & 49.7 & $2015-09-28$ & FLYNN & 56 & 46 & 2 & 31 \\
\hline $424 \mathrm{~F}$ & 215 & 57 & $2015-09-28$ & FLYNN & 32 & 30 & 3 & 20 \\
\hline 9088 & 235 & 78.7 & $2015-09-28$ & FLYNN & 47 & 43 & 2 & 29 \\
\hline 53FE & 205 & 51.6 & $2015-09-28$ & FLYNN & 94 & 74 & 8 & 49 \\
\hline $062 C$ & 200 & 43.5 & $2015-09-28$ & FLYNN & 54 & 47 & 6 & 31 \\
\hline 5638 & 172 & 27 & $2015-09-28$ & FLYNN & 198 & 117 & 10 & 78 \\
\hline $72 \mathrm{C} 3$ & 216 & 57 & $2015-09-28$ & FLYNN & 75 & 64 & 4 & 43 \\
\hline A6AE & 240 & 76.3 & $2015-09-28$ & FLYNN & 12 & 12 & 0 & 8 \\
\hline CF7F & 247 & 93.4 & $2015-09-28$ & FLYNN & 151 & 99 & 4 & 66 \\
\hline 4E15 & 250 & 105 & 2015-09-28 & FLYNN & 13 & 13 & 1 & 9 \\
\hline D3B1 & 252 & 95 & $2015-09-28$ & FLYNN & 67 & 55 & 3 & 37 \\
\hline CD5B & 213 & 56 & $2015-09-28$ & FLYNN & 17 & 16 & 2 & 11 \\
\hline C57F & 275 & 120 & 2015-09-28 & FLYNN & 34 & 30 & 1 & 20 \\
\hline$* 875 \mathrm{E}$ & 223 & 45.8 & 2015-09-18 & ${ }^{*}$ FLYNN & 43 & 38 & 3 & 25 \\
\hline
\end{tabular}




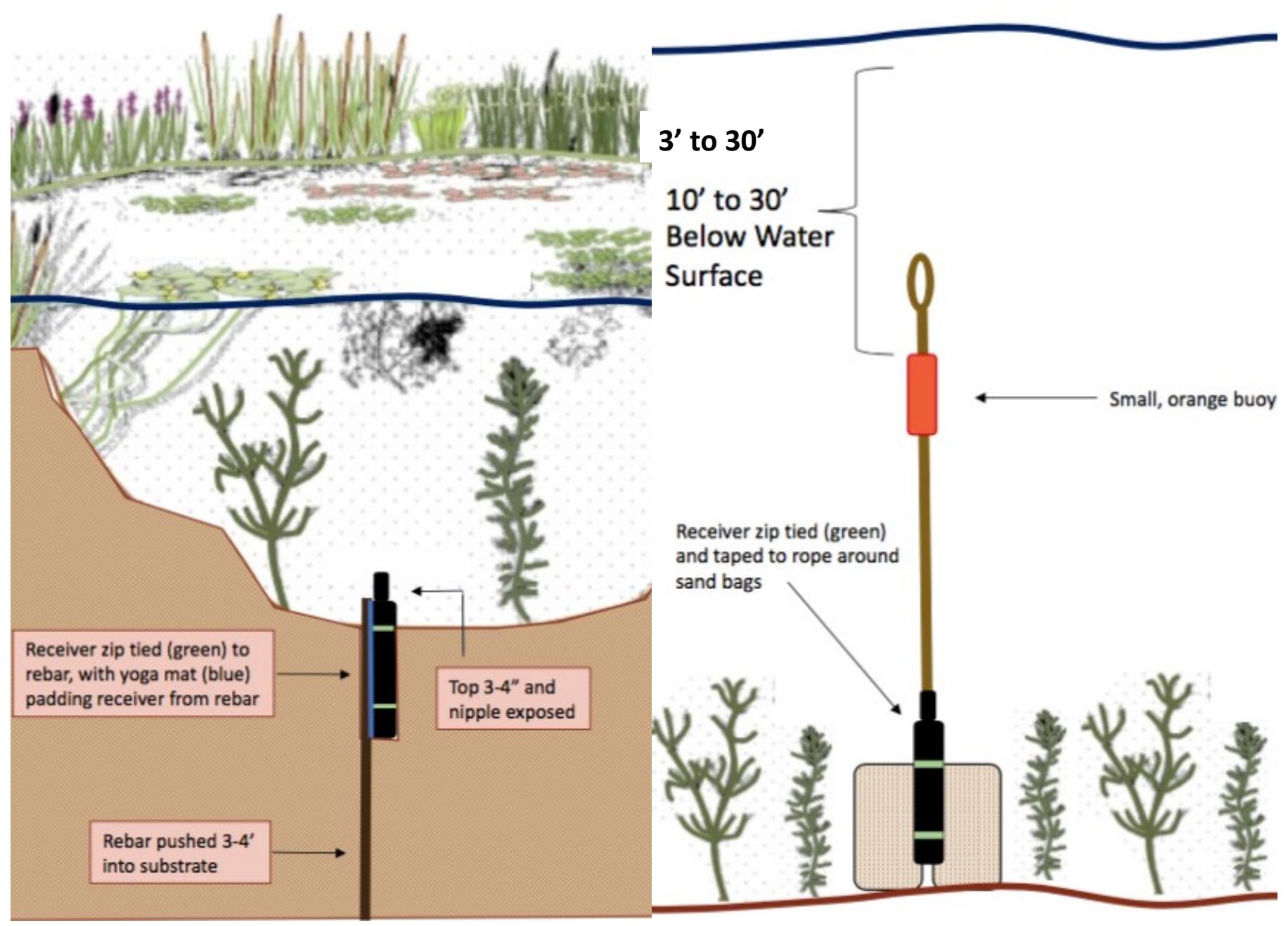

Figure S.3.1. Deployment methods for Lotek WSH4250 receivers in upper St. Lawrence River wetland nursery embayments for passive acoustic monitoring of juvenile Muskellunge and Northern Pike. Shallow $(<2$ meters) deployment (left) involved attaching the receiver to rebar and placing the unit into the substrate. Deeper deployment (right) involved attaching the receiver to a cobble-filled bag and buoy system. Buoys were submerged underwater by a minimum of 3 feet (1-meter). 


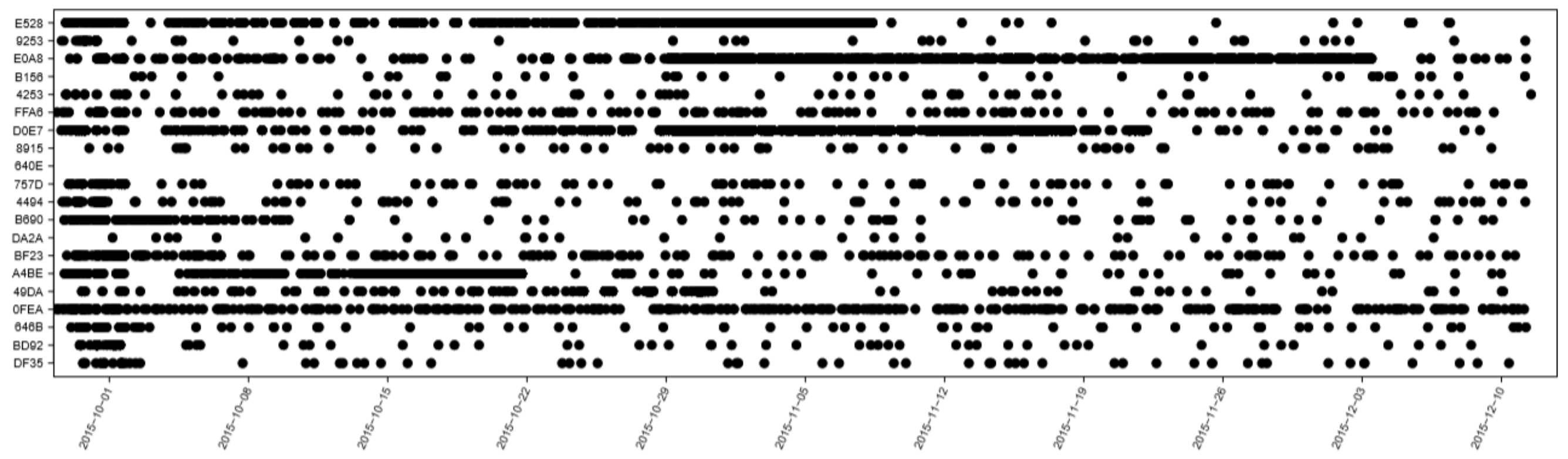

Figure S.3.2. Detections of individual age-0 Muskellunge $(n=24)$ in Rose Bay from October 1 to December 10, 2015. This array covered the entirety of the natal Muskellunge embayment. The X axis indicates an individual week starting on October 1, 2015. 


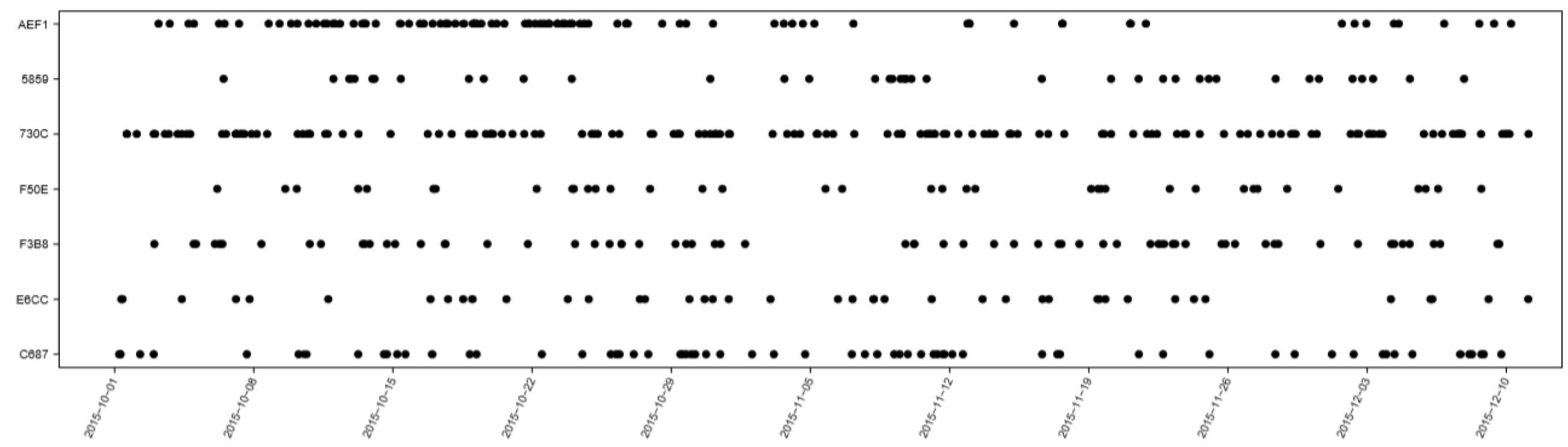

Figure S.3.3. Detections of individual age-0 Muskellunge $(n=7)$ in Buck Bay from October 1 to December 10, 2015. This array covered the entirety of the natal Muskellunge embayment. The X axis indicates an individual week starting on October 1, 2015. 


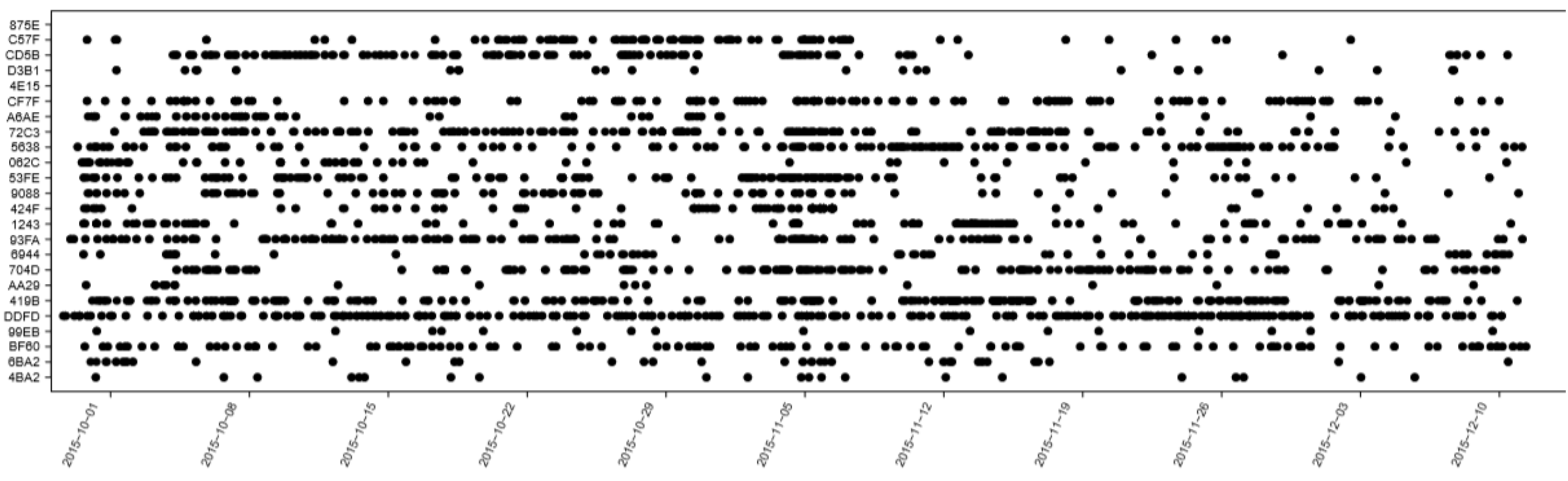

Figure S.3.4. Detections of individual age-0 Northern Pike $(n=24)$ in Buck Bay from October 1 to December 10, 2015. Arrays were deployed within the nearshore interior and the embayment mouth; therefore, detections could have occurred at either location. The X axis indicates an individual week starting on October 1, 2015. 

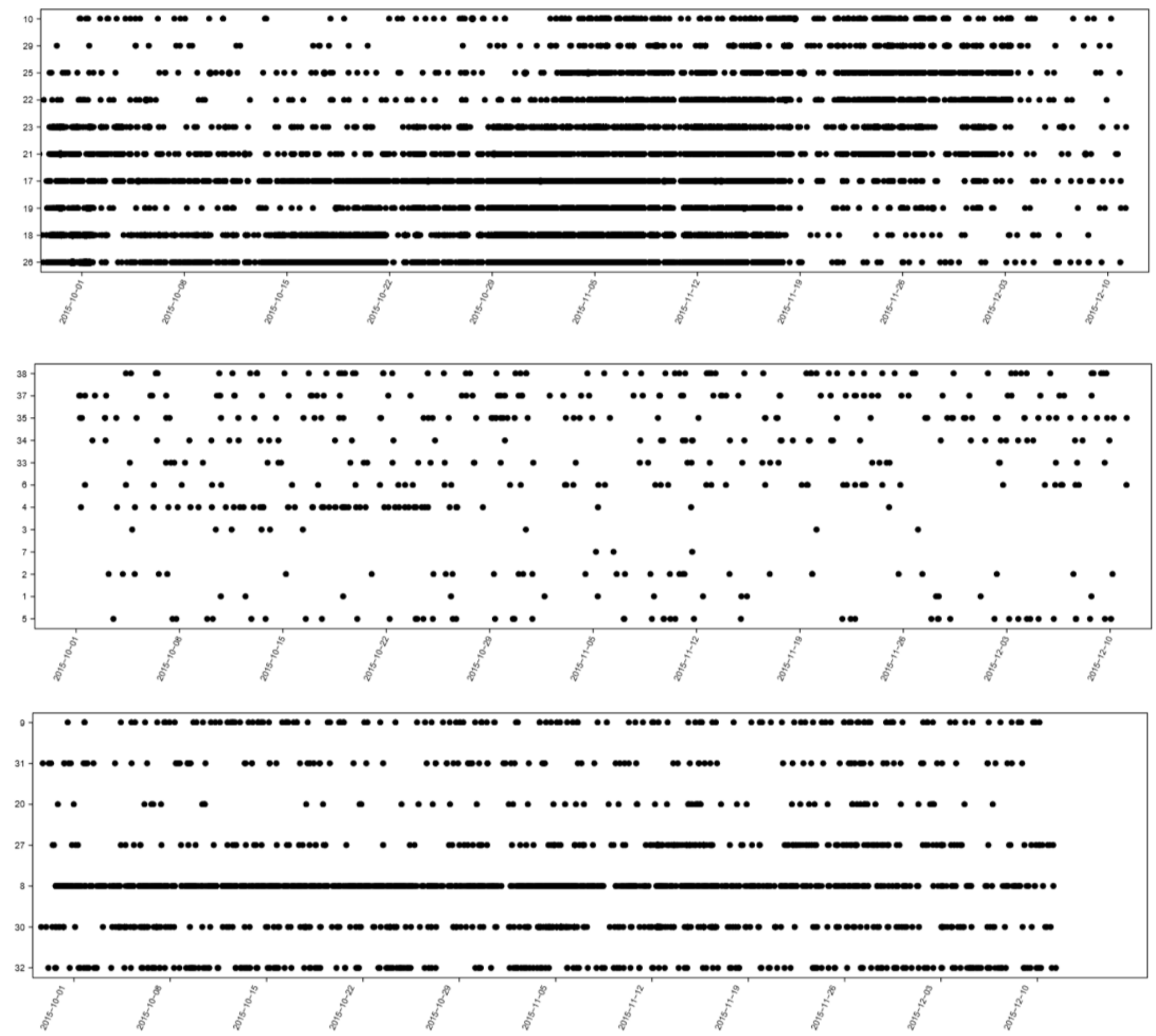

Figure S.3.5. Abacus plots indicating detections by all age- 0 Muskellunge ( $n=20$, Rose, top; $n=7$, Buck, middle) and age-0 Northern Pike ( $\mathrm{n}=15$, Flynn, bottom) from October 1 to December 10, 2015. Y axis indicates fish moving out of their embayment; receiver numbers start in the nearshore (bottom) and move to deeper waters (top). The $\mathrm{X}$ axis indicates an individual week starting on October 1, 2015. 

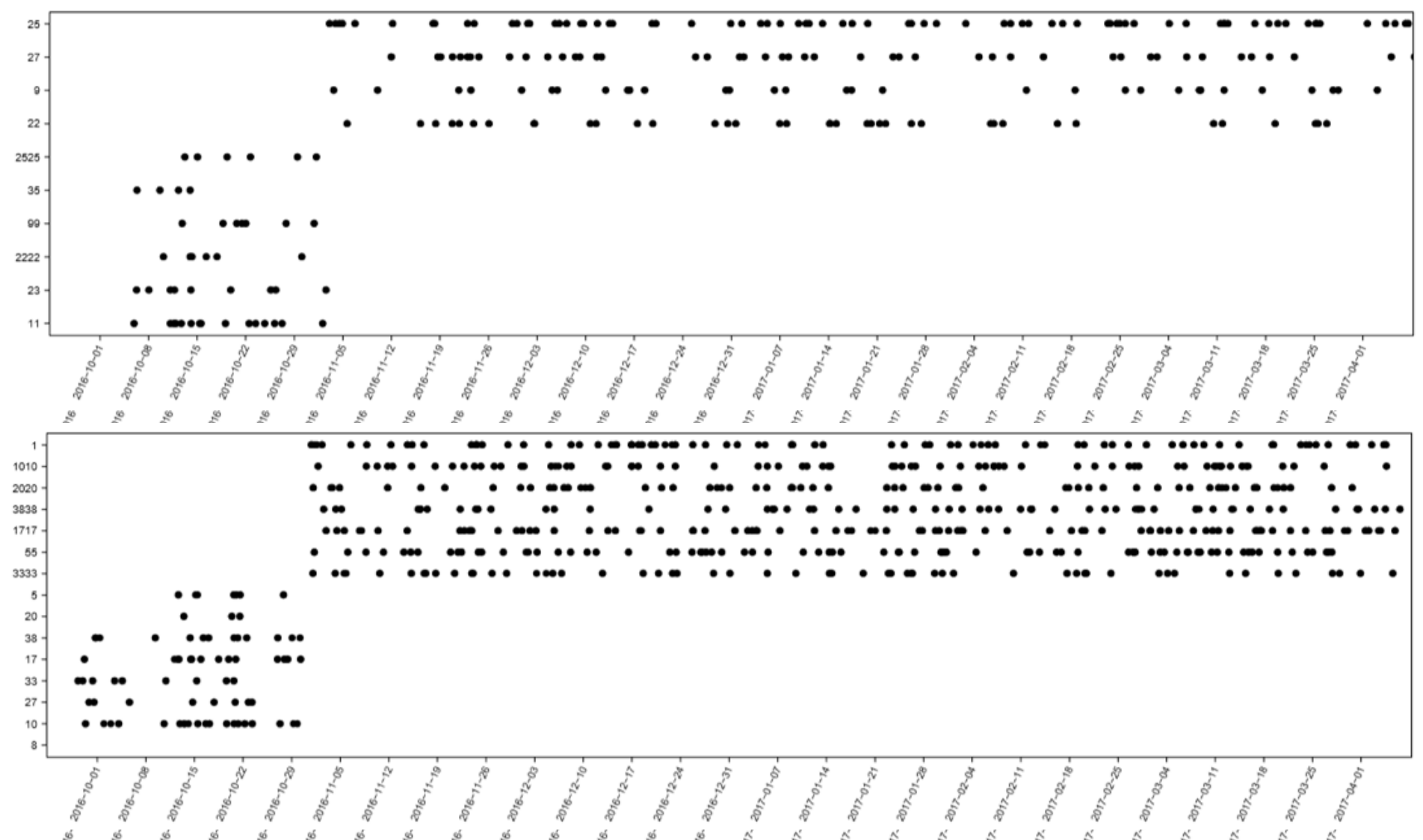
की

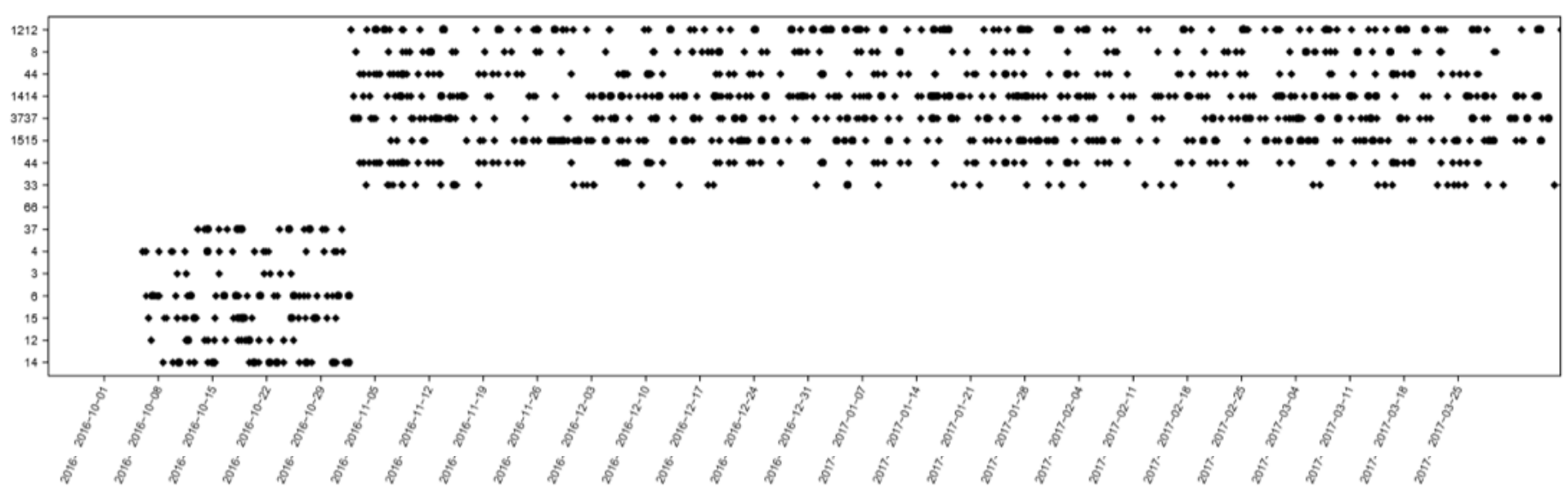

Figure S.3.6. Abacus plots indicating detections by all age- 0 Muskellunge $(n=4$, Rose, top; $n=5$, Grass, middle) and age-0 Northern Pike ( $\mathrm{n}=15$, Flynn, bottom) from October 1, 2016 to March 30, 2017. Y axis indicates fish moving out of their embayment; receiver numbers start in the nearshore (bottom) and move to deeper waters (top). The $\mathrm{X}$ axis indicates an individual week starting on October 1, 2015. The $\mathrm{X}$ axis indicates an individual week starting on October 1, 2016. Note the lack of detections in nearshore regions due to receiver deployment in deeper locations overwinter (starting November 1, 2016). 
Musky 5859, TL (mm)167

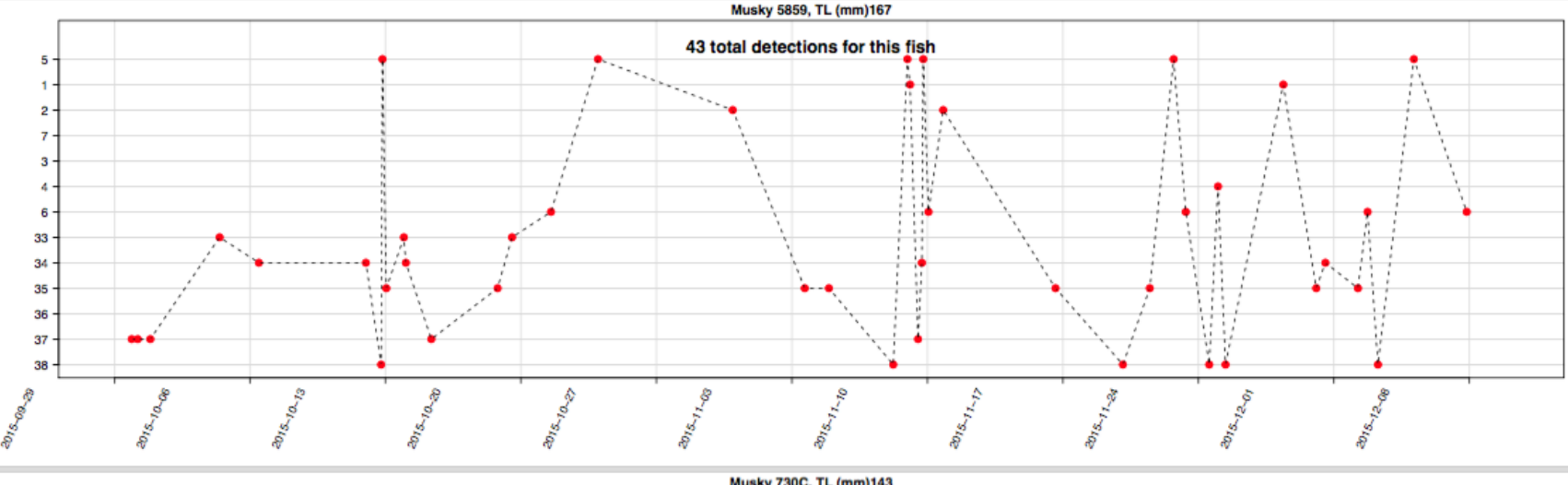

Musky 730C, TL (mm)143

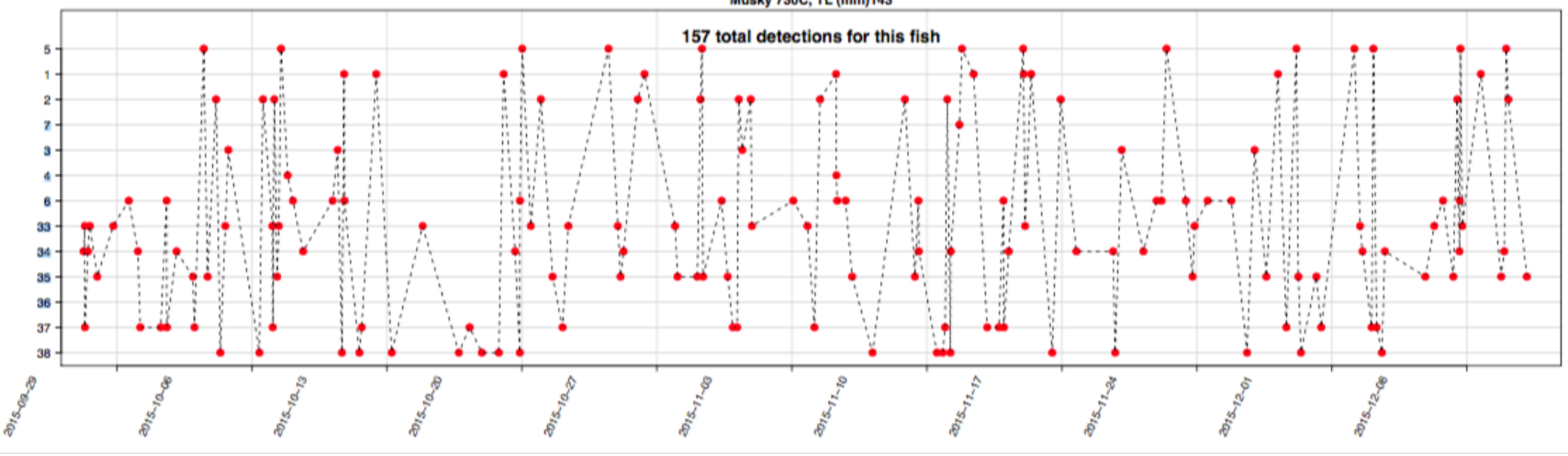

Musky AEF1, $\pi$ (mm)15e

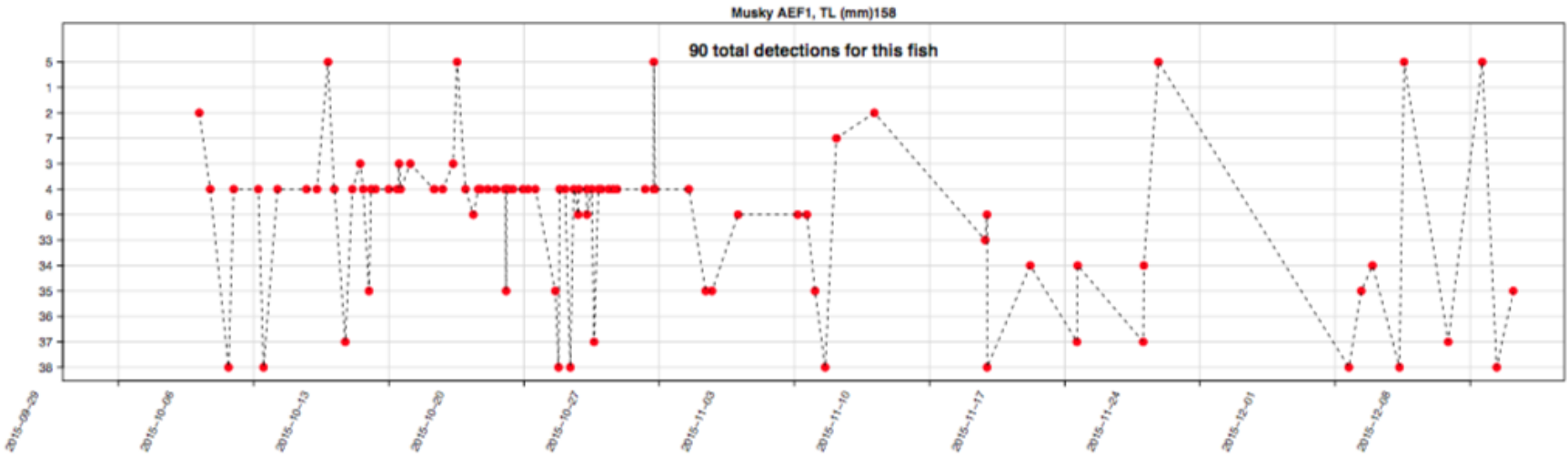

MUsky F5OE, TL (mm)177

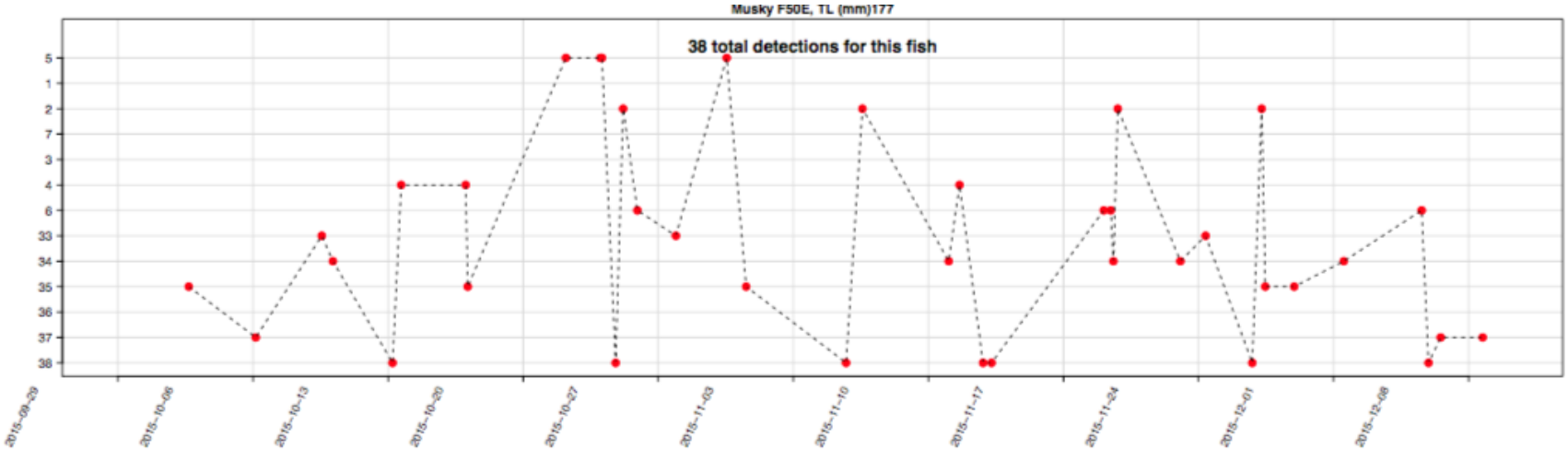



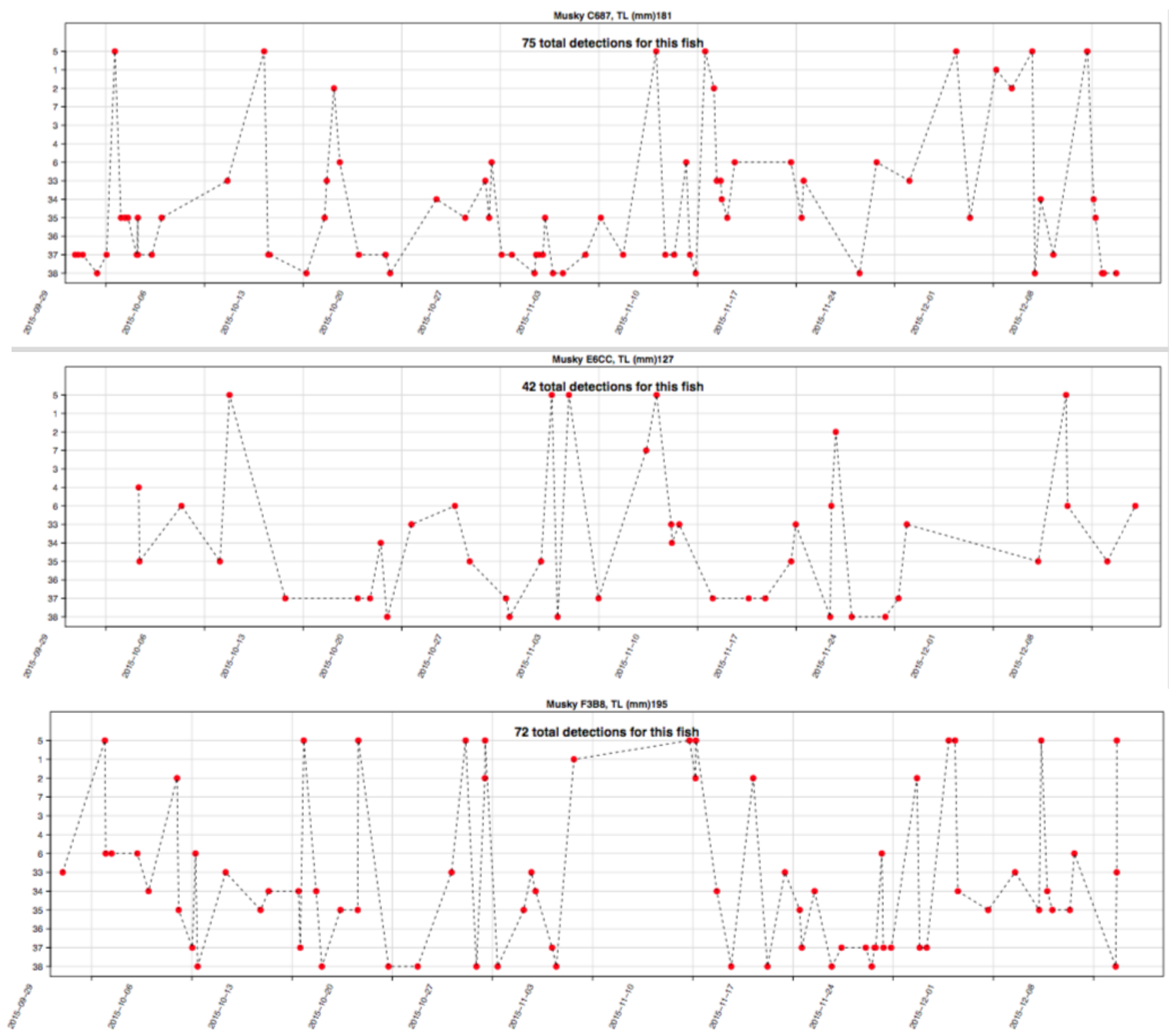

Figure S.3.7. Abacus plots for individual age-0 Muskellunge in Buck Bay $(n=7)$ from October 1 to December 10, 2015. Points indicate when fish were detected, and lines movement patterns between receivers from nearshore ( $\mathrm{Y}$ axis bottom) and deeper waters ( $\mathrm{Y}$ axis top) in the fall and early winter. Time is depicted by weeks starting with October 1, 2015 (X axis). 
Musky OFEA, TL (mm)140
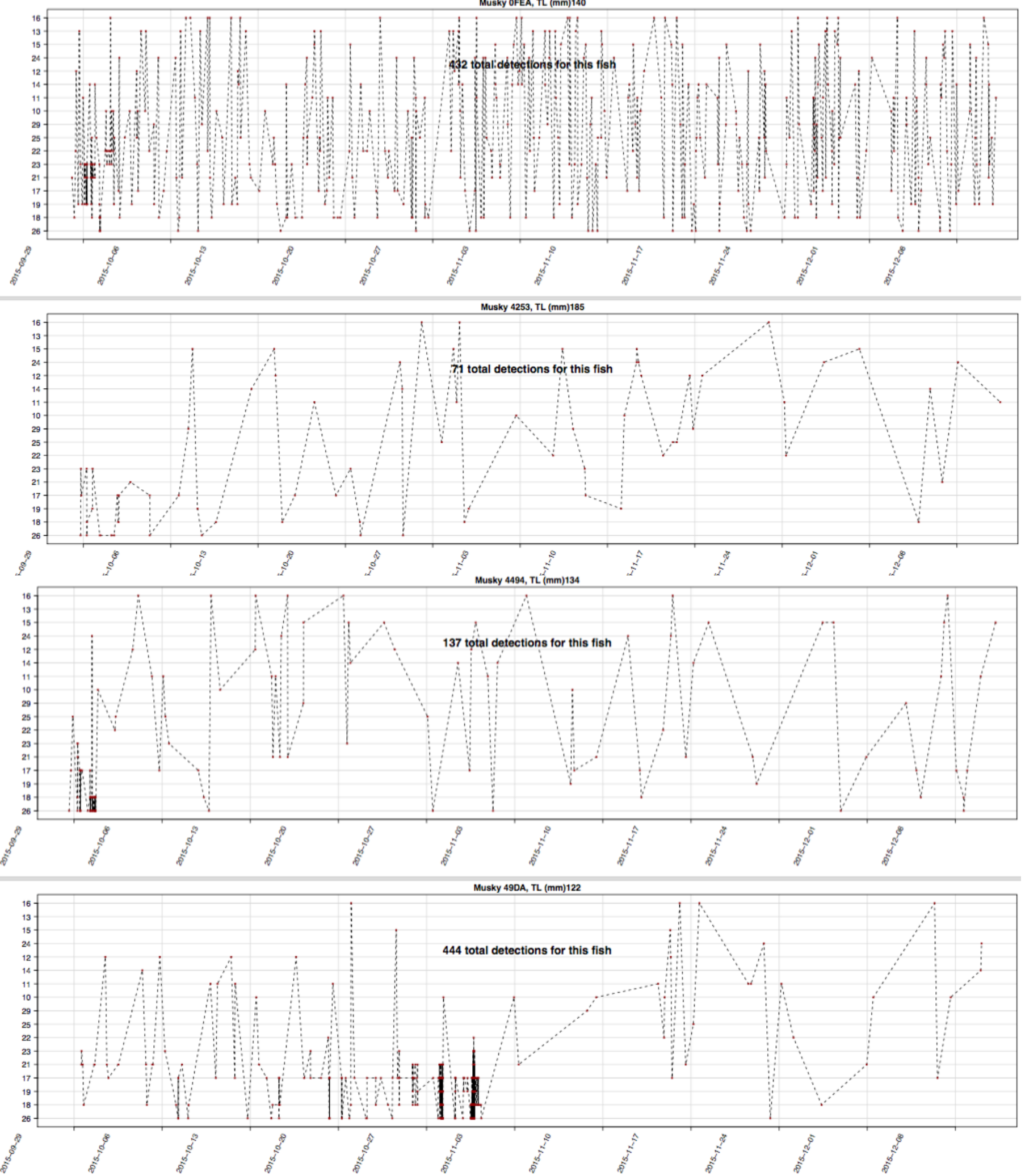
Musky 8915, TL (mm)158
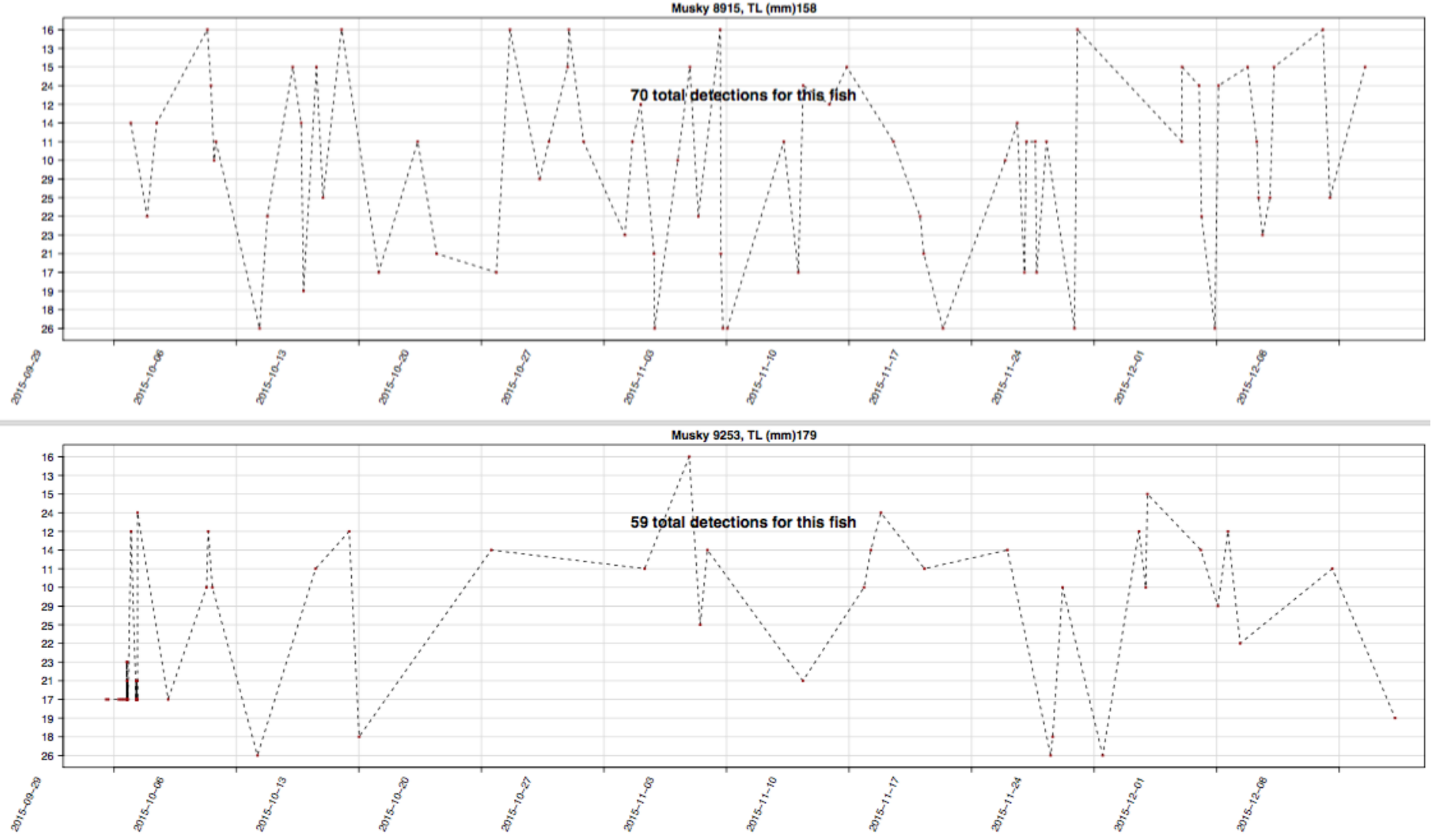

Musky 646B, TL (mm)145
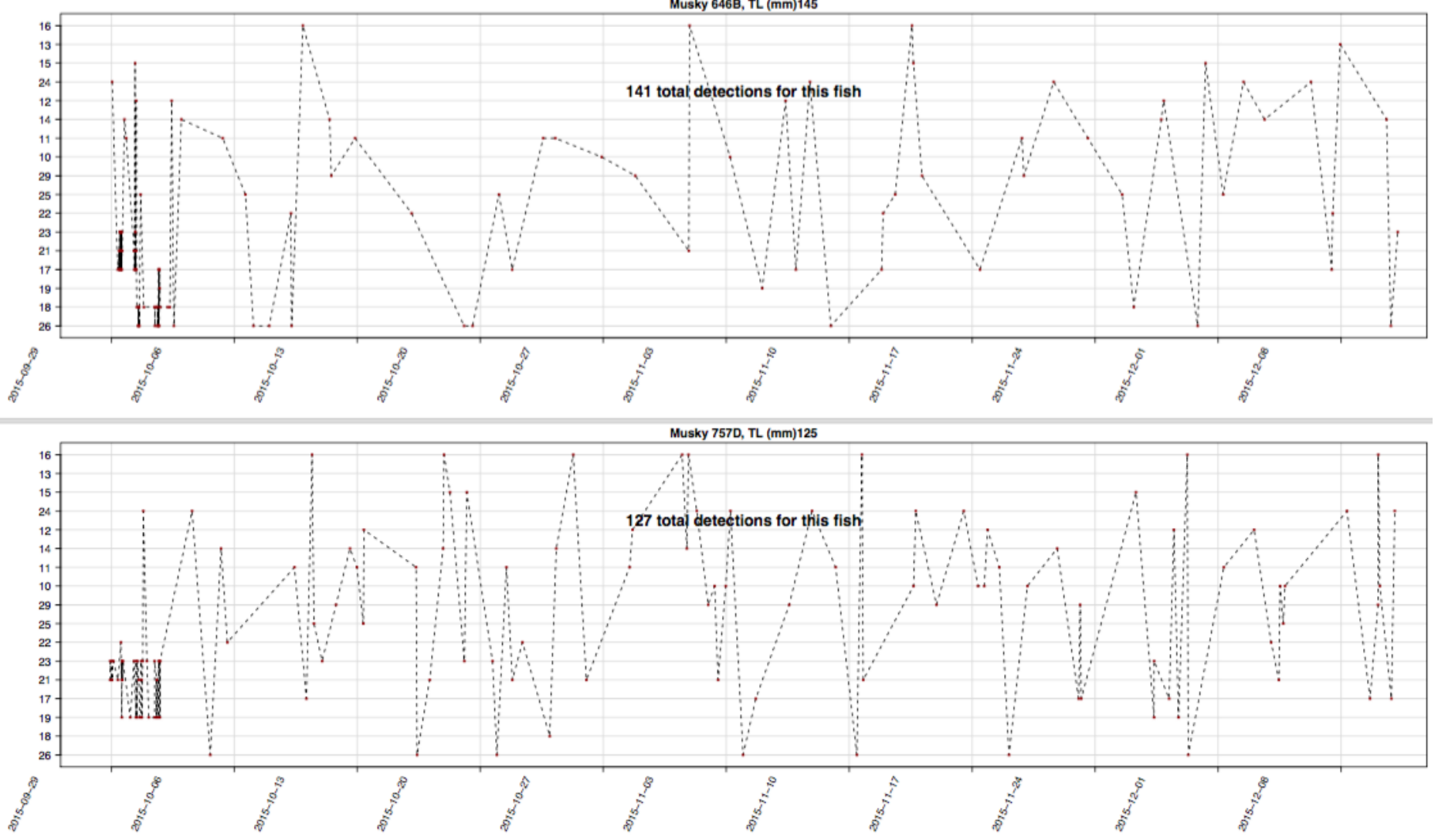

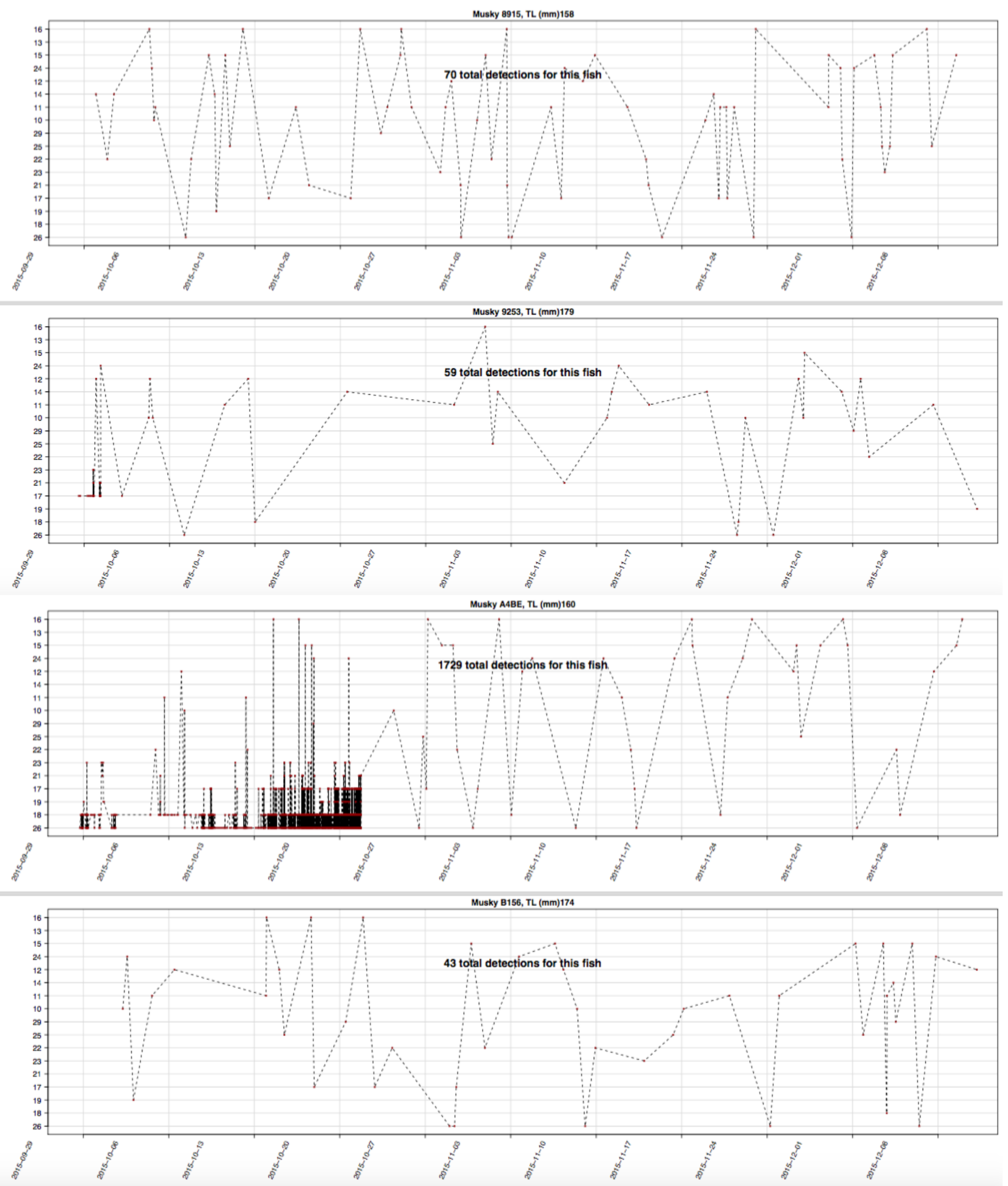
Musky B690, TL (mm)126
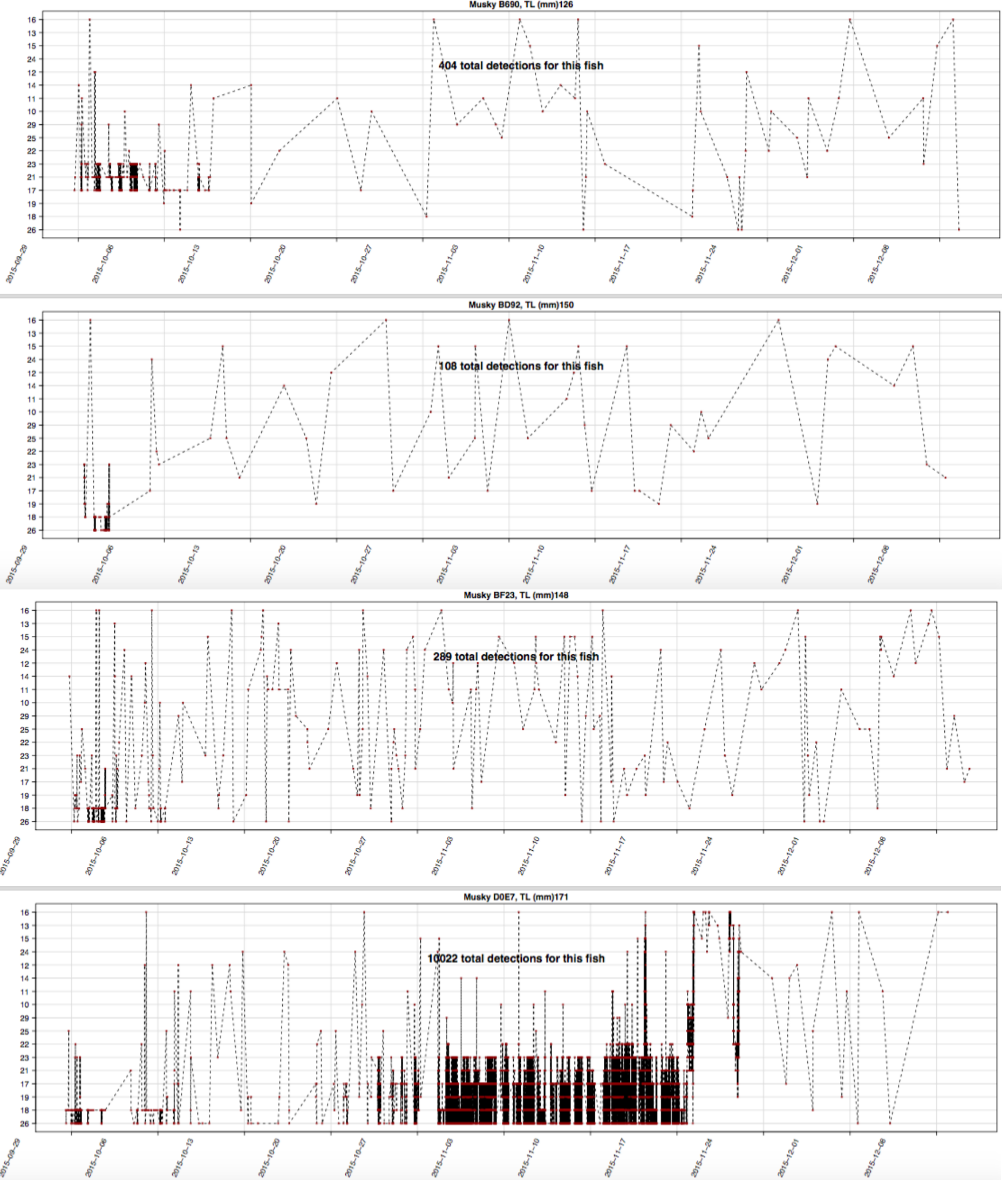
Musky DA2A, TL (mm)149
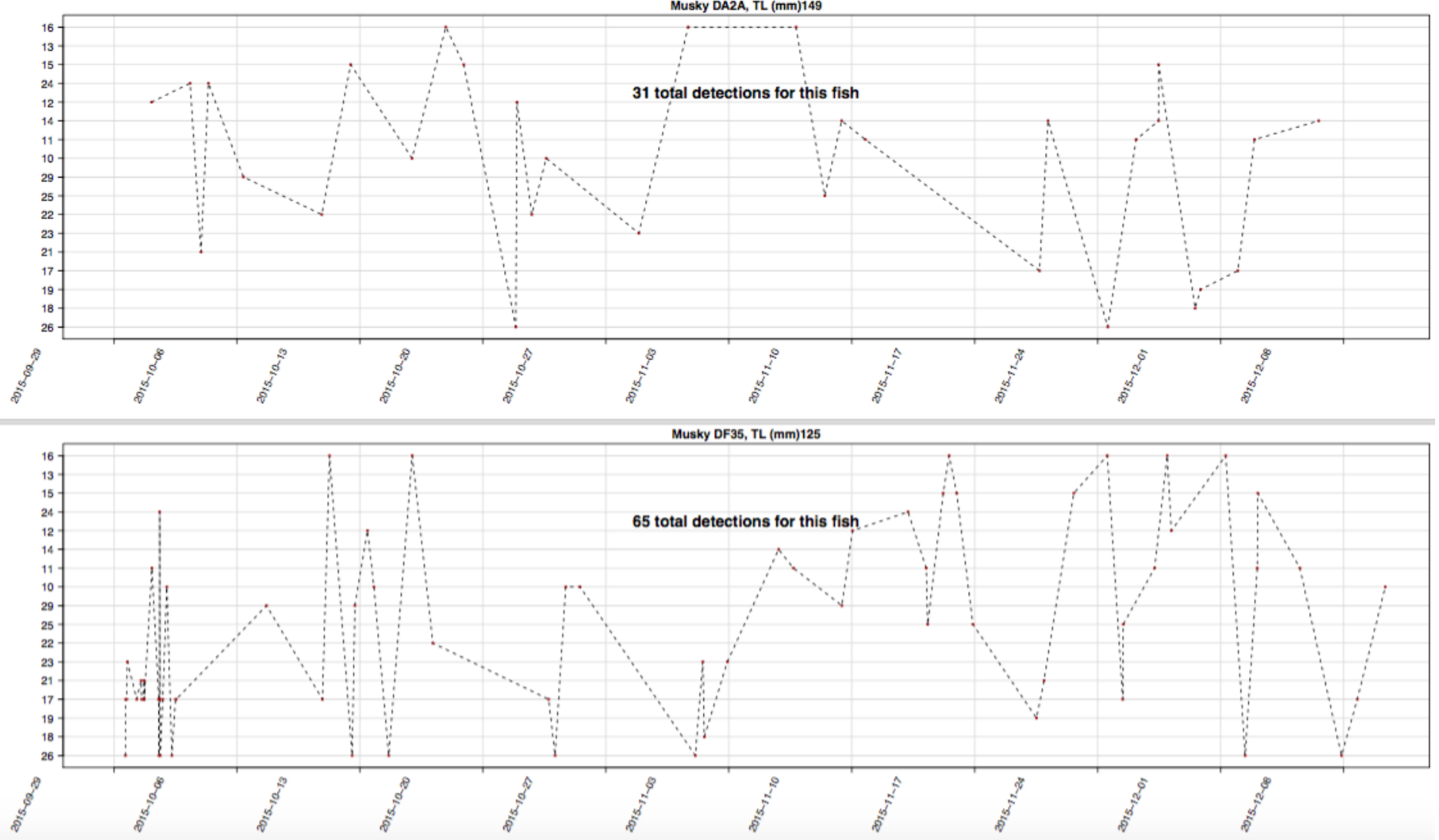

Musky EOAB, TL (mm)170
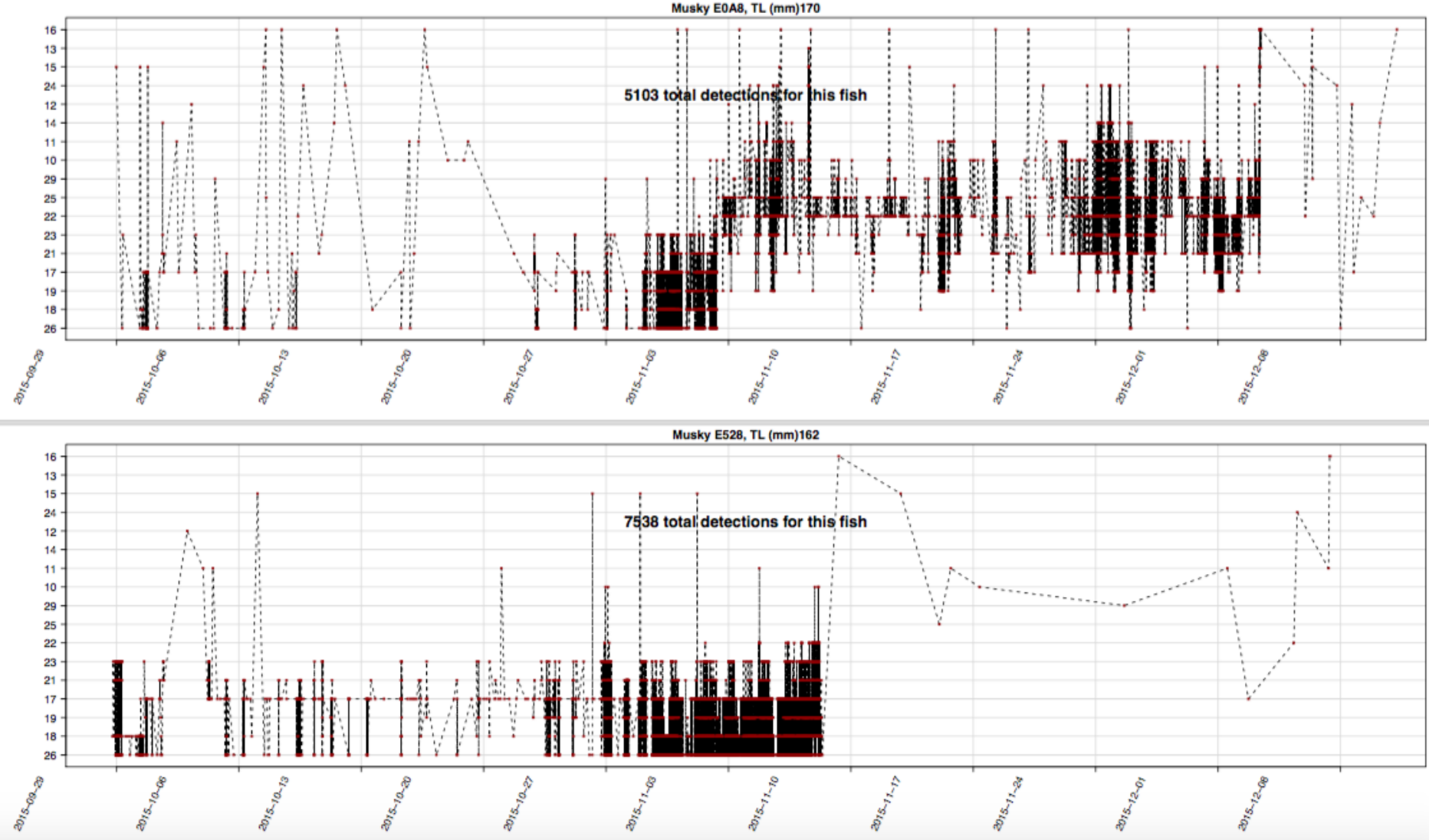
Figure S.3.8. Abacus plots for individual age-0 Muskellunge in Rose Bay $(\mathrm{n}=20)$ from October 1 to December 10, 2015. Points indicate when fish were detected, and lines movement patterns between receivers from nearshore ( $\mathrm{Y}$ axis bottom) and deeper waters ( $\mathrm{Y}$ axis top) in the fall and early winter. Time is depicted by weeks starting with October 1, 2015 (X axis).
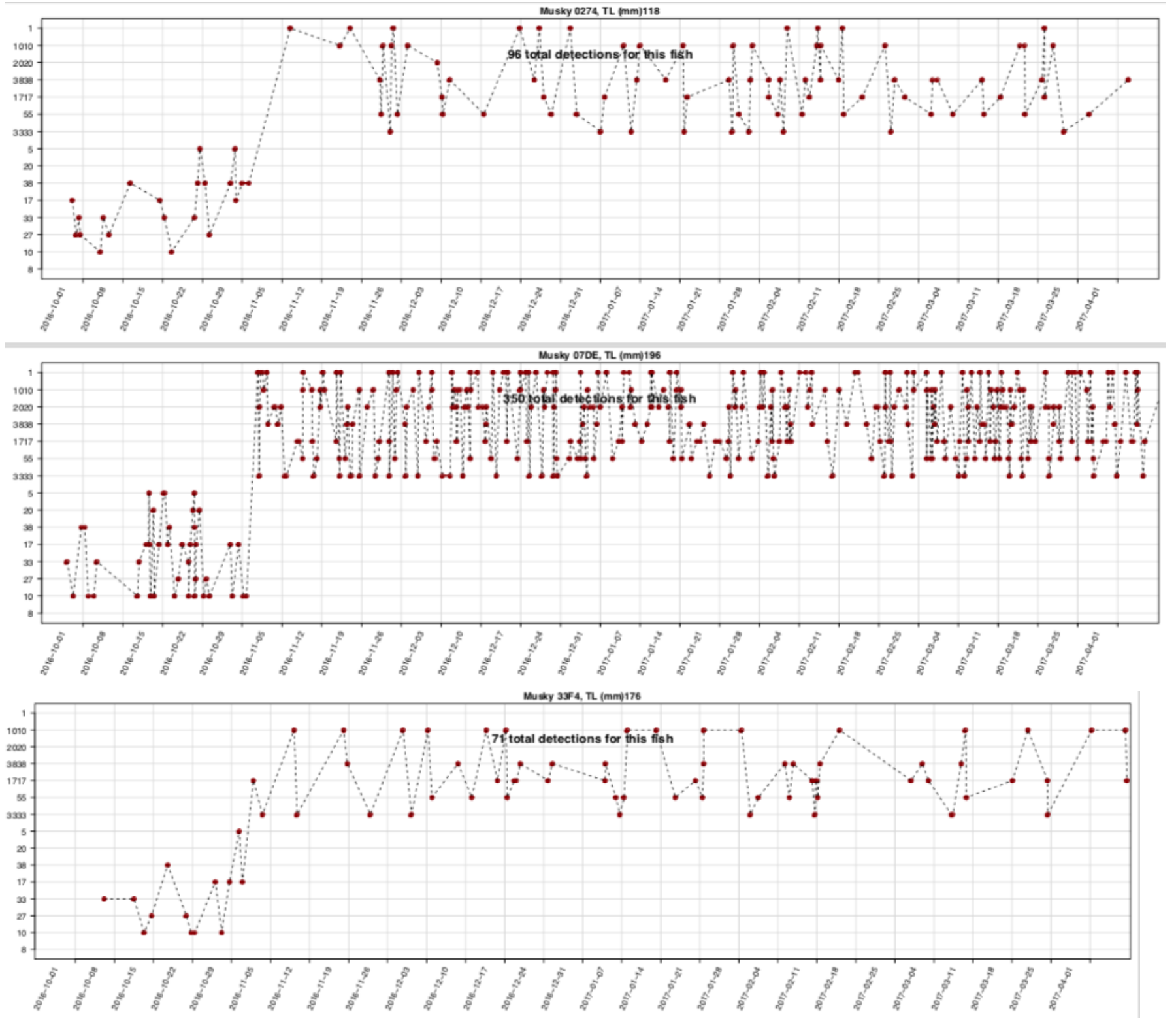

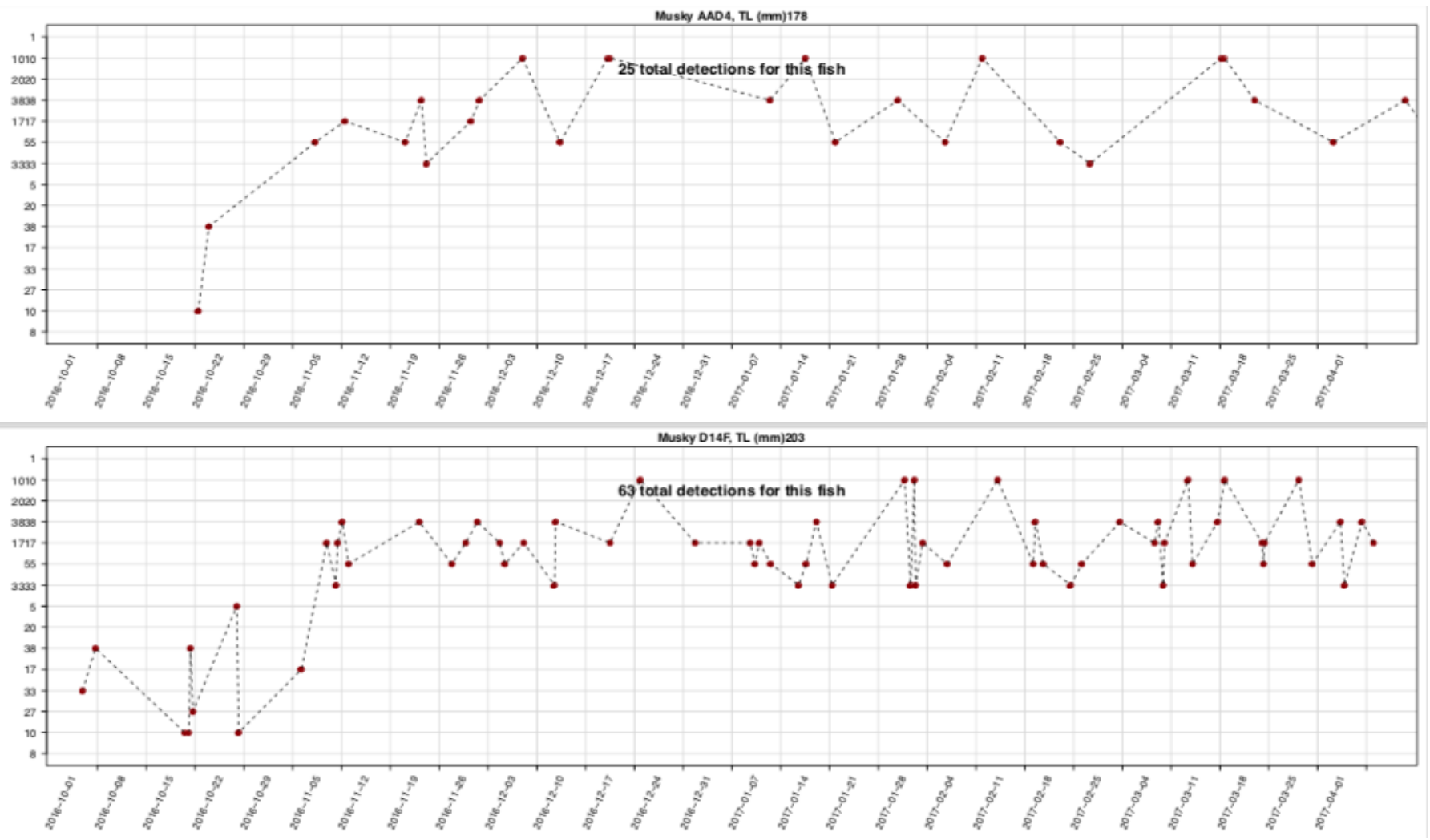

Figure S.3.9. Abacus plots for individual age-0 Muskellunge in Grass Point Bay $(n=5)$ from October 1 2016 to March 31, 2017. Points indicate when fish were detected, and lines movement patterns between receivers from nearshore ( $\mathrm{Y}$ axis bottom) and deeper waters ( $\mathrm{Y}$ axis top) in the fall and winter. Time is depicted by weeks starting with October 1, 2016 (X axis). 

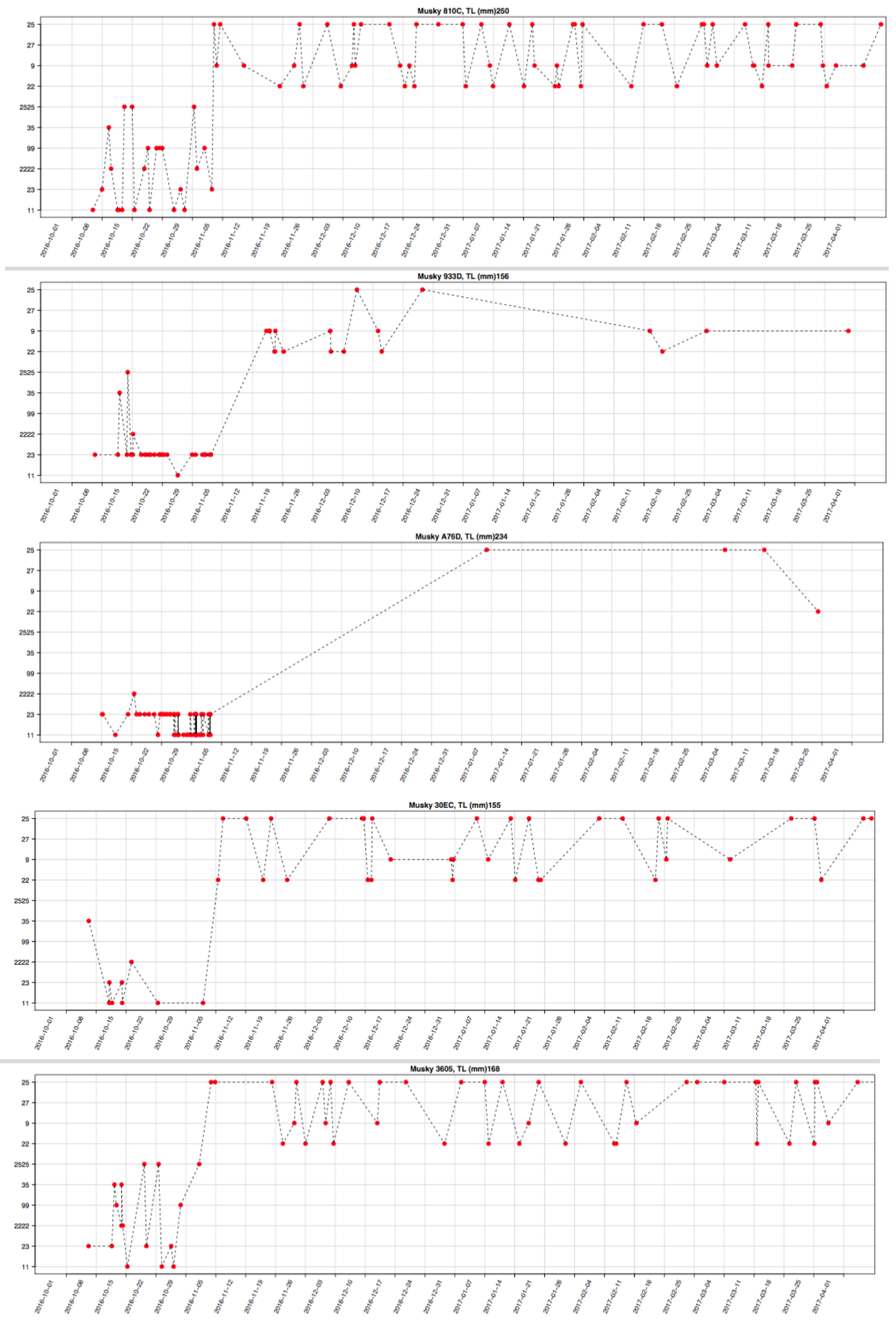
Figure S.3.10. Abacus plots for individual age-0 Muskellunge in Rose Bay $(n=5)$ from October 1, 2016 to March 31, 2017. Points indicate when fish were detected, and lines movement patterns between receivers from nearshore ( $\mathrm{Y}$ axis bottom) and deeper waters ( $\mathrm{Y}$ axis top) in the fall and winter. Time is depicted by weeks starting with October 1, 2016 (X axis).
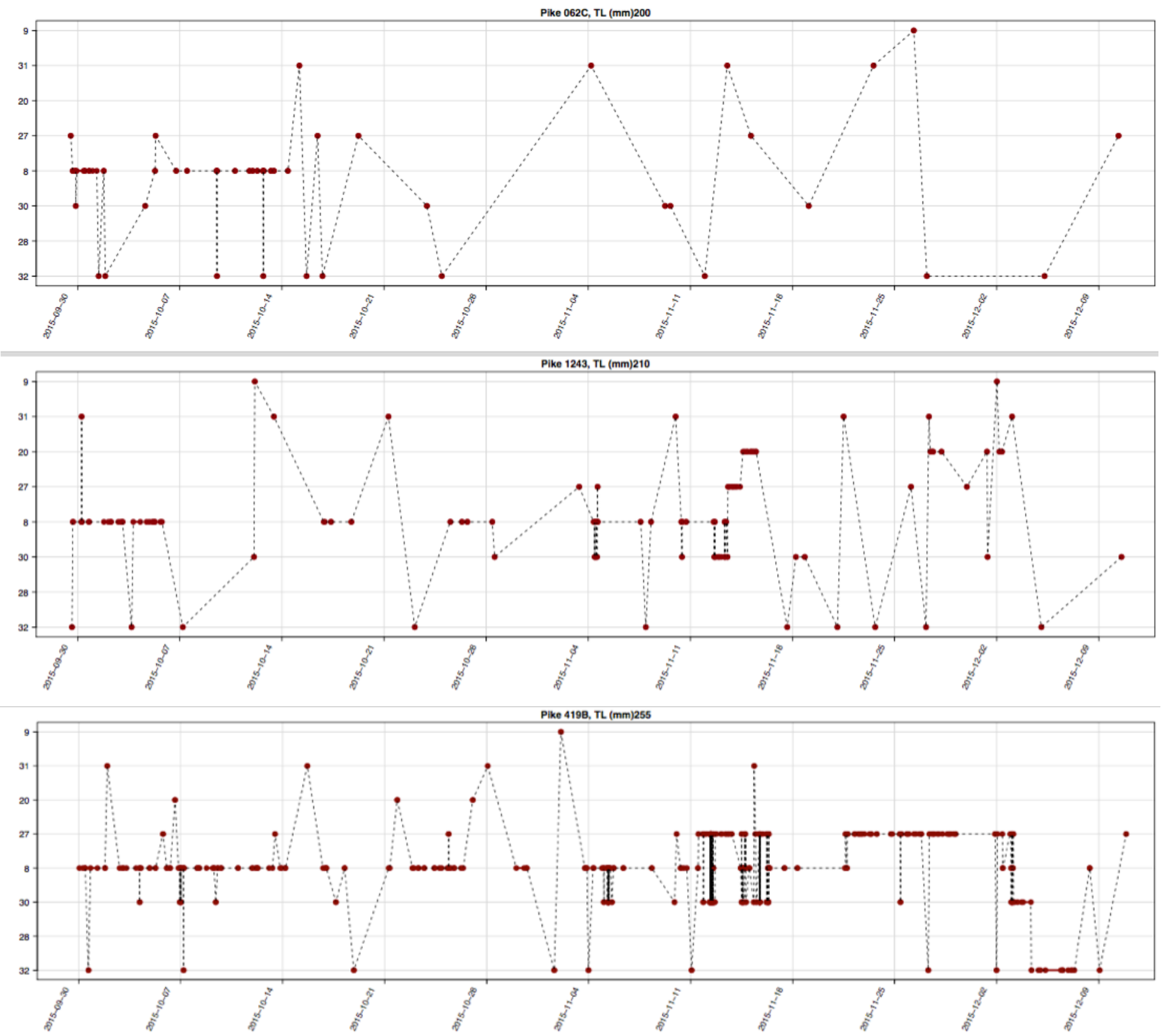

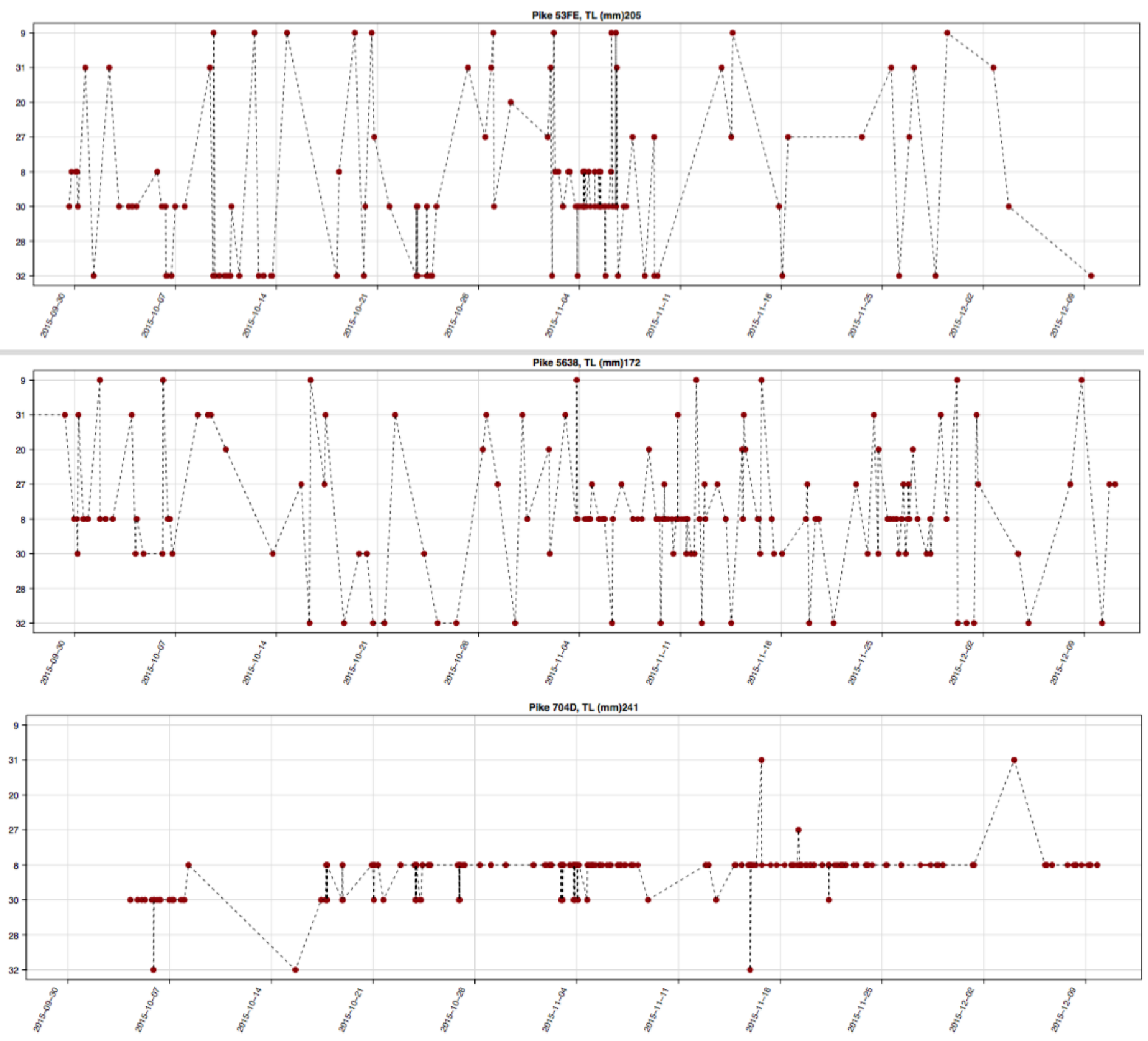

Pike 72C3, TL (mm)216

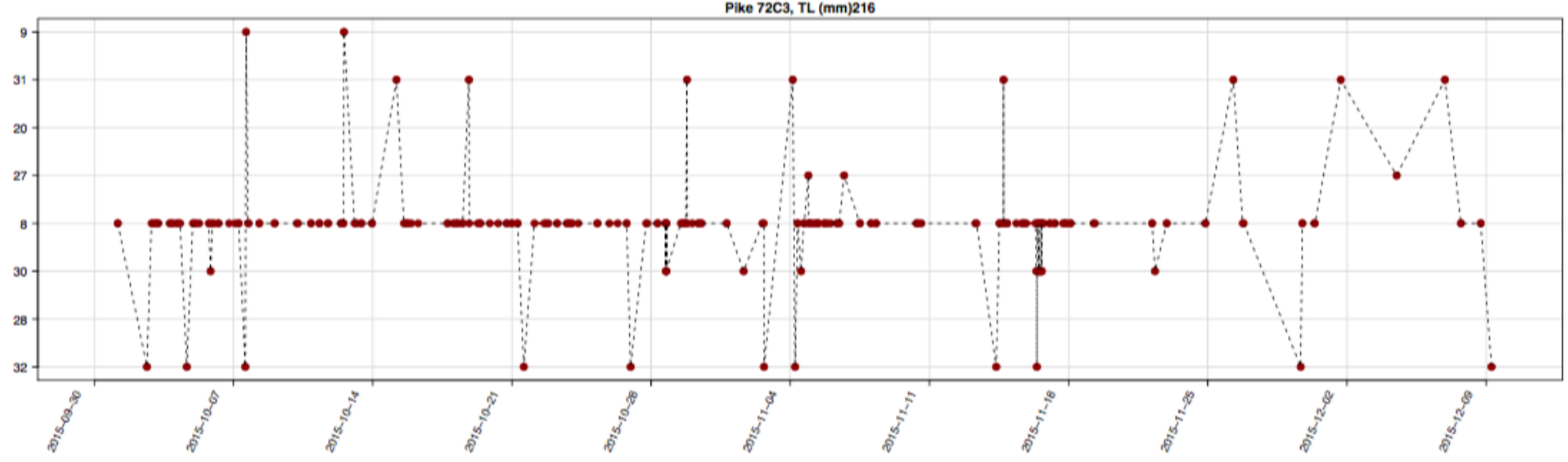


Pike 9088, TL (mm)235
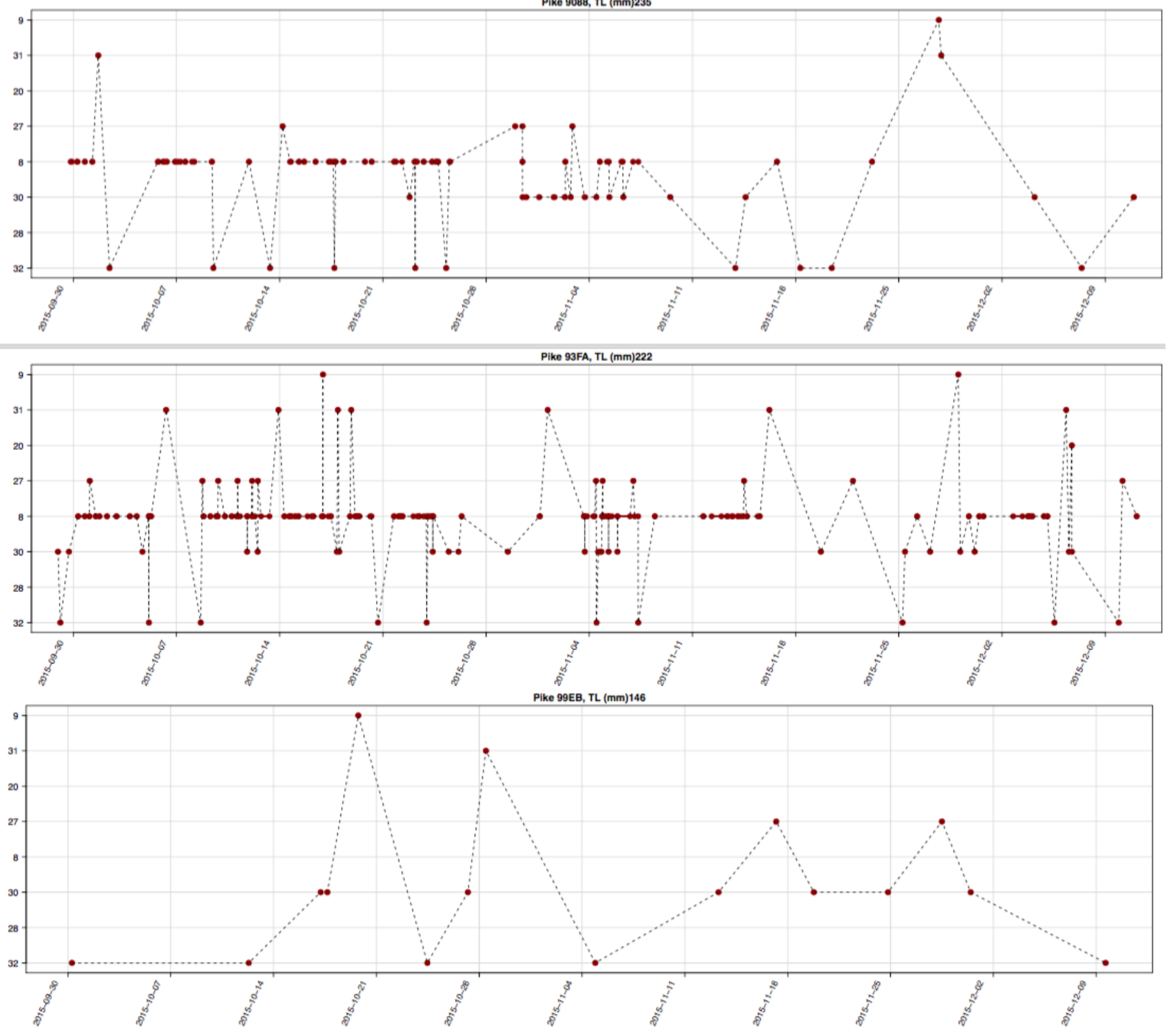

Pike A6AE, TL (mm)240

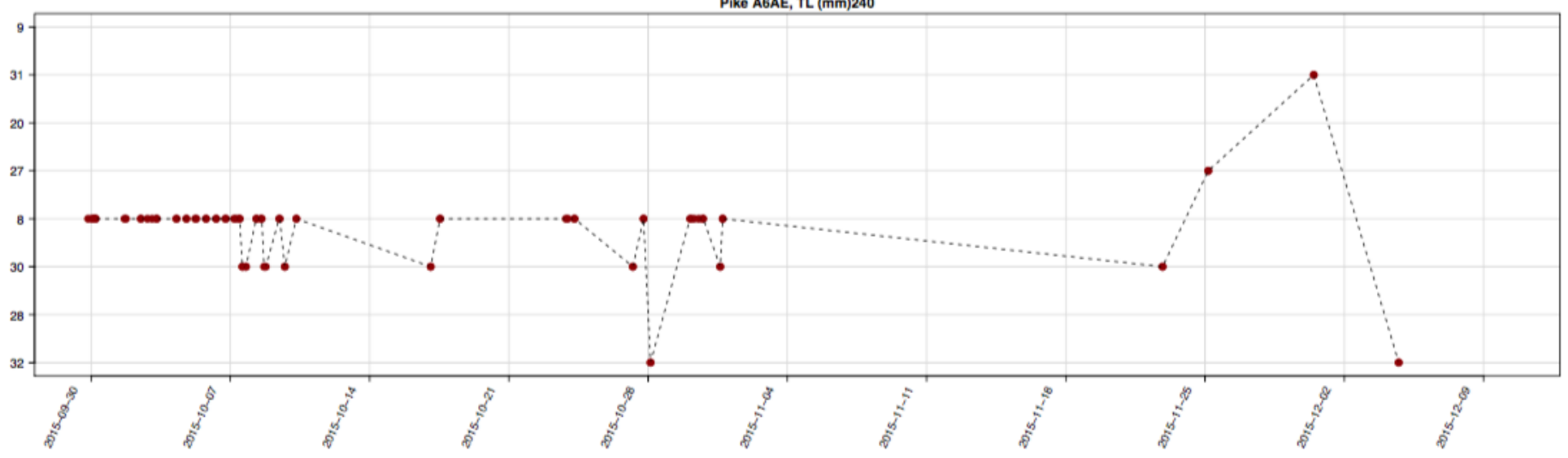



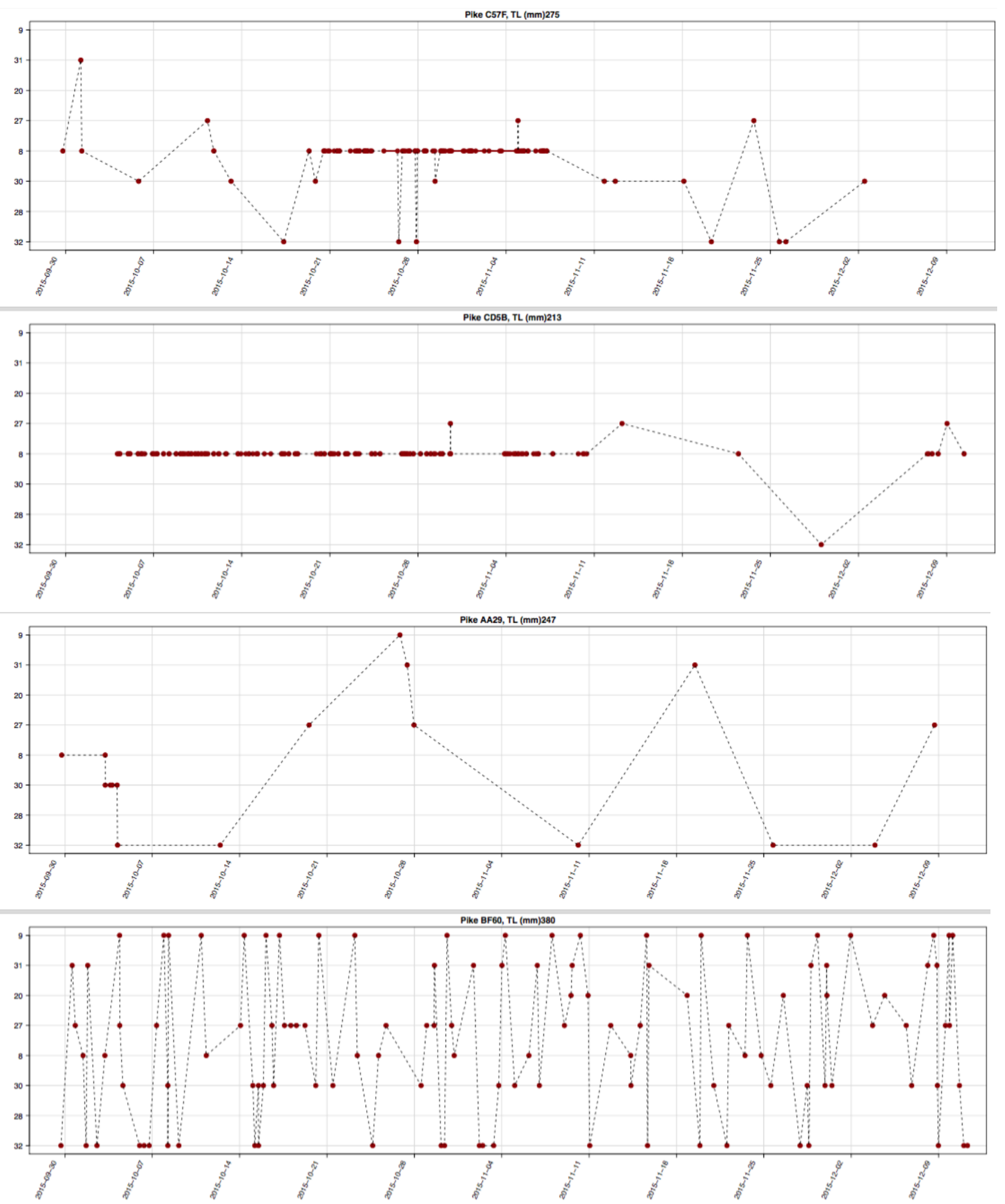

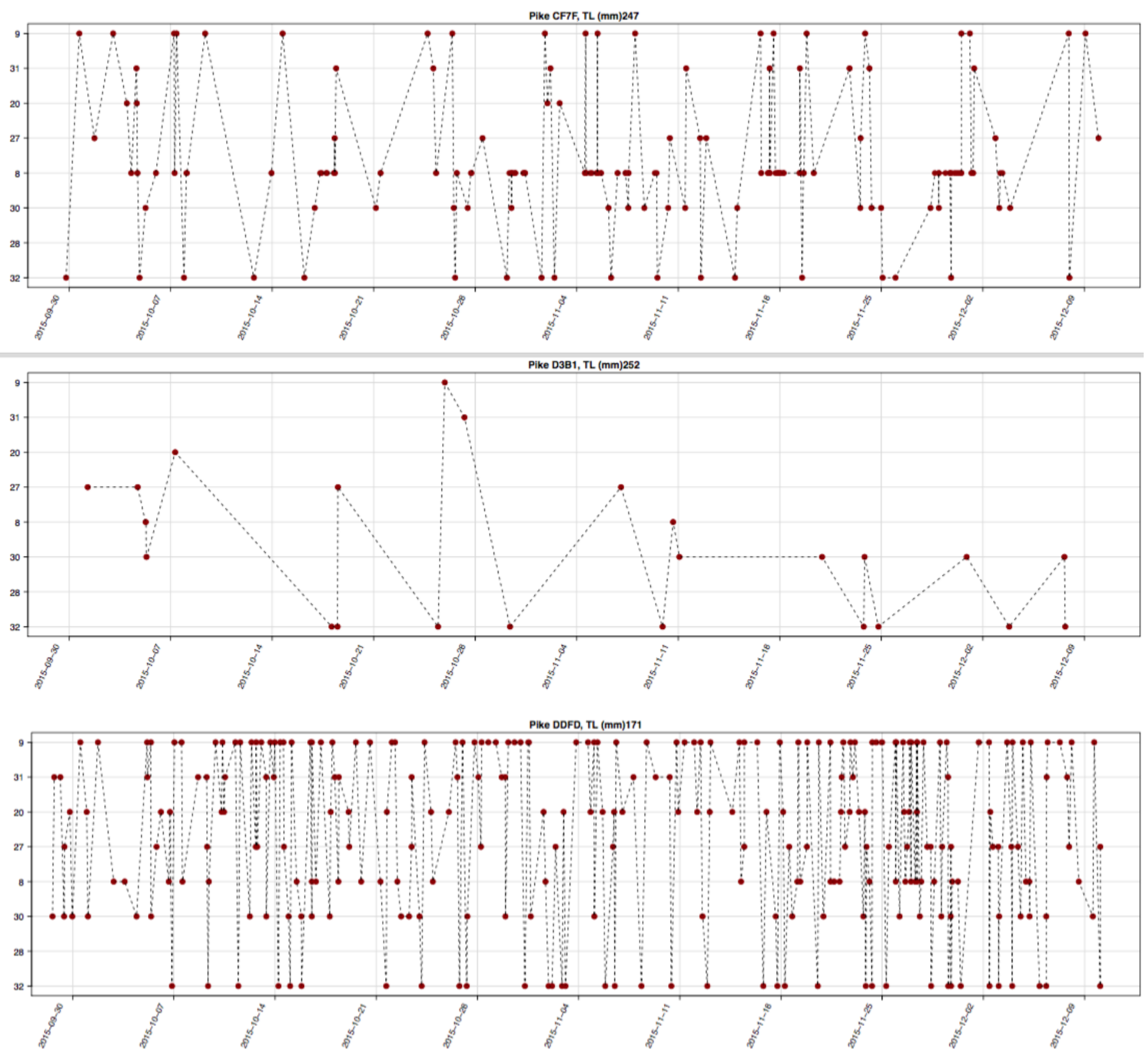

Figure S.3.11. Abacus plots for individual age-0 Northern Pike in Flynn Bay $(n=22)$ from October 1 to December 10, 2016. Points indicate when fish were detected, and lines movement patterns between receivers from nearshore ( $\mathrm{Y}$ axis bottom) and deeper waters ( $\mathrm{Y}$ axis top) in the fall and early winter. Time is depicted by weeks starting with October 1, 2015 (X axis). 
Pike 0219, TL (mm) 215

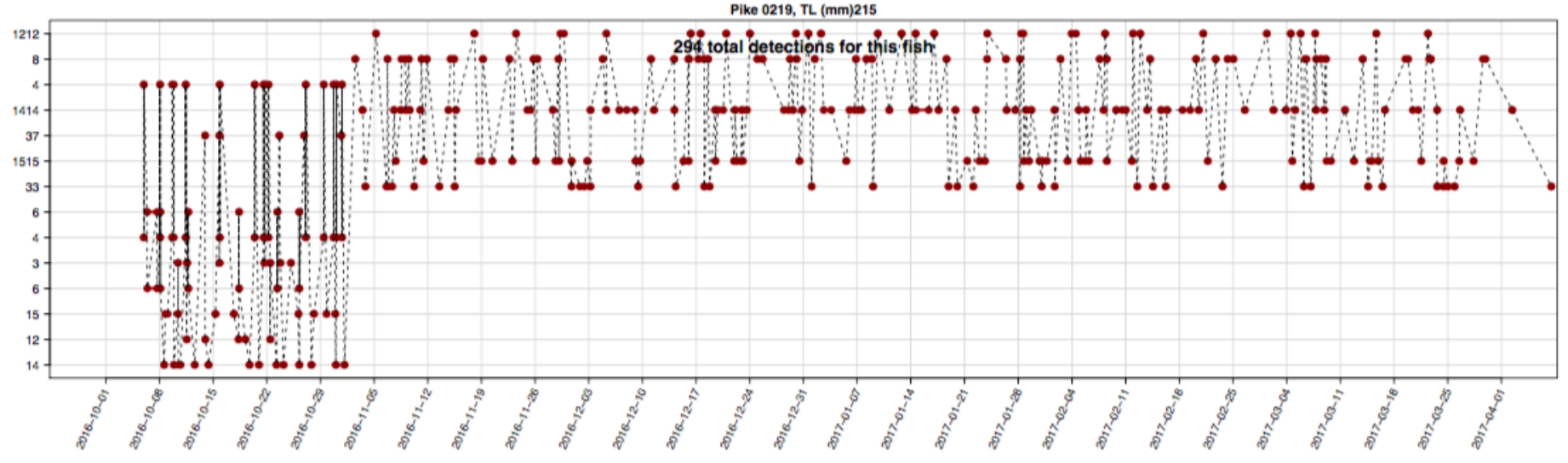

Pike 1A2B, TL (mm)219
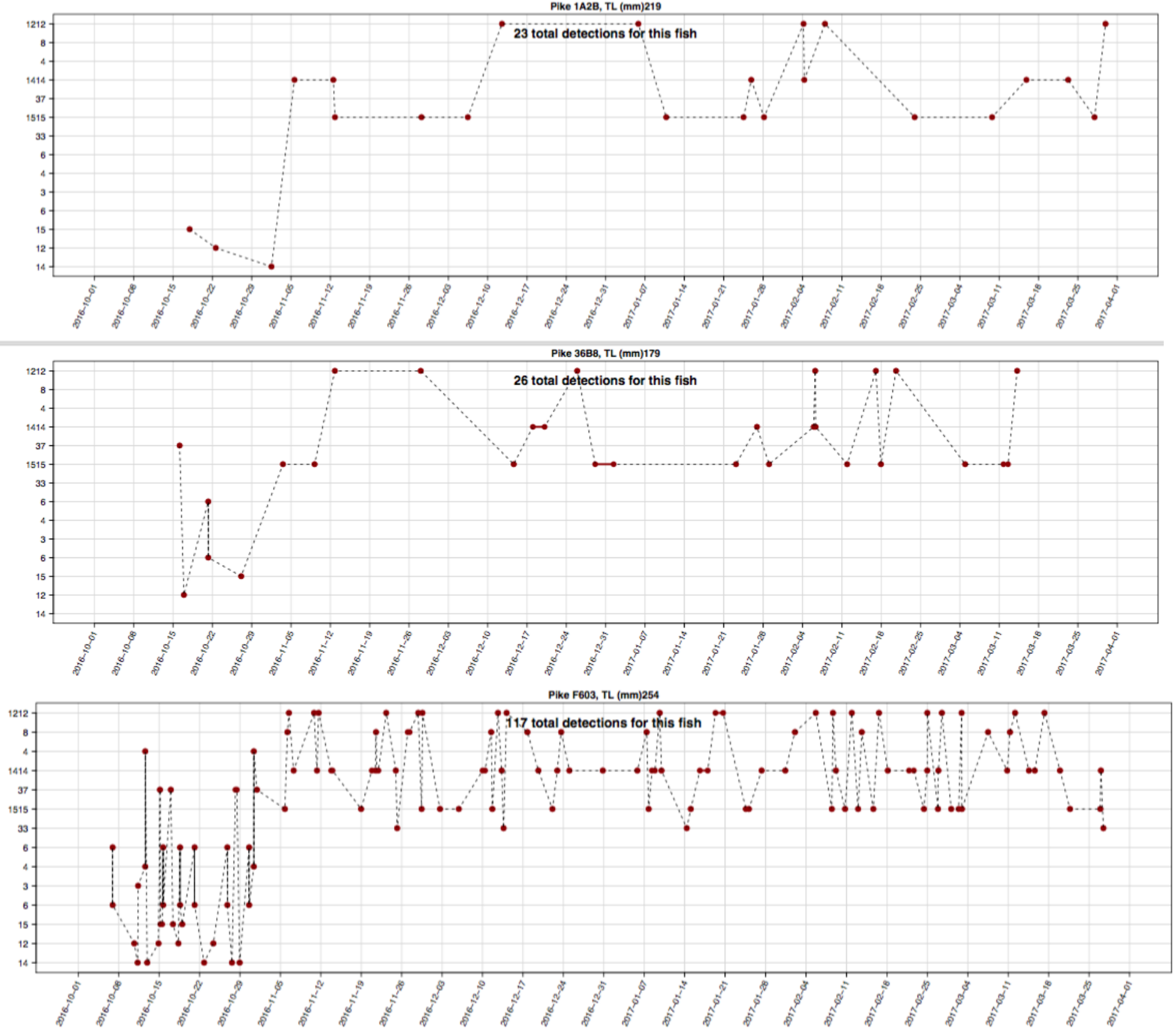
Pike 4317, TL (mm)195
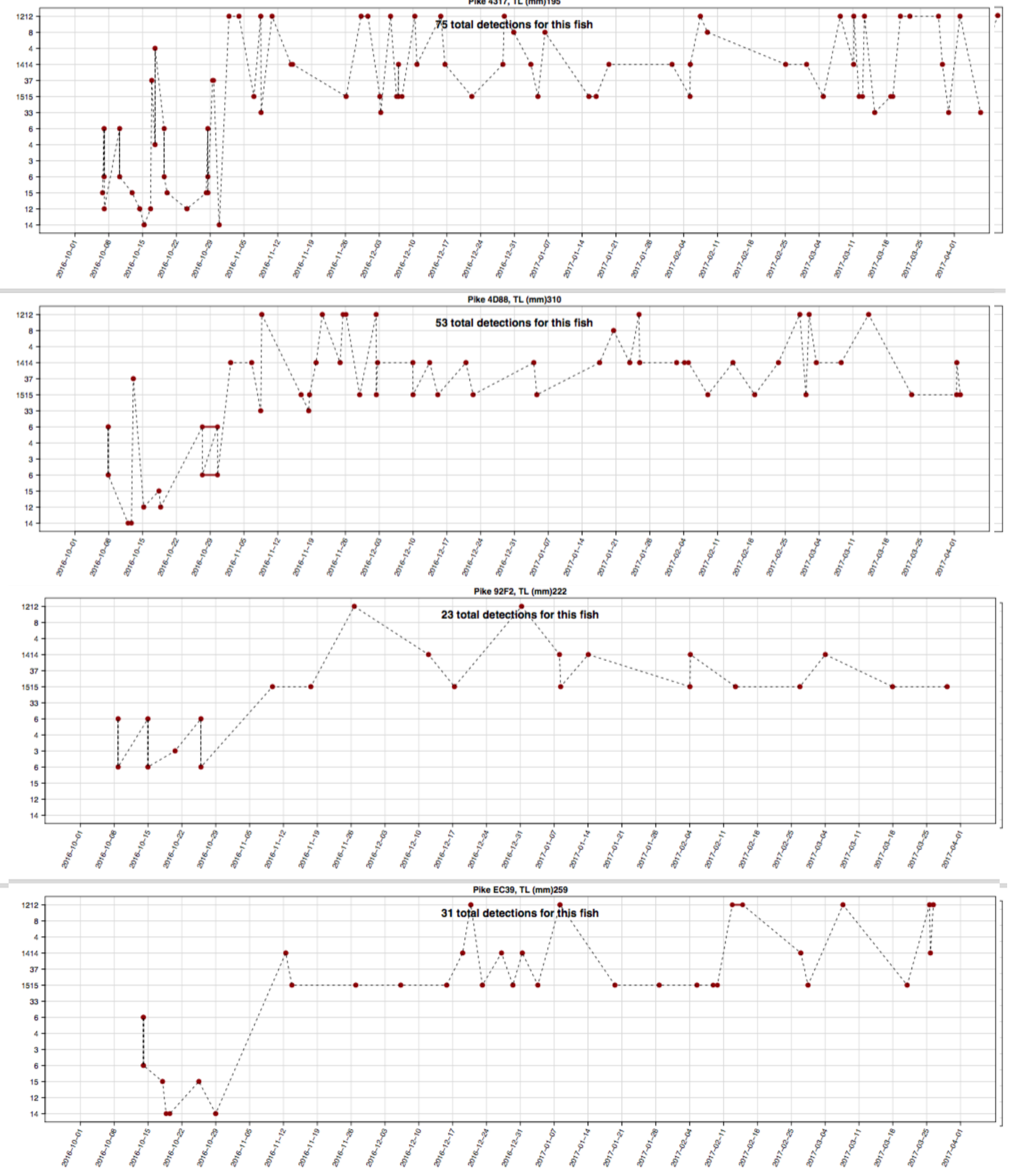
Pike 5A49, TL (mm)235

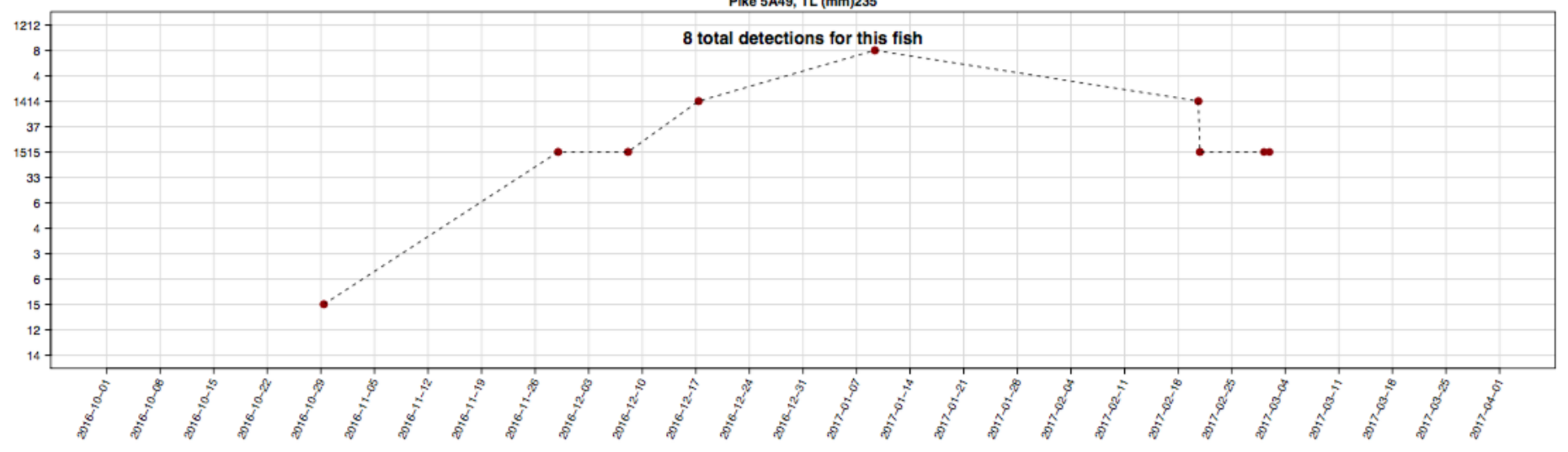

Pike 6985, TL (mm)216

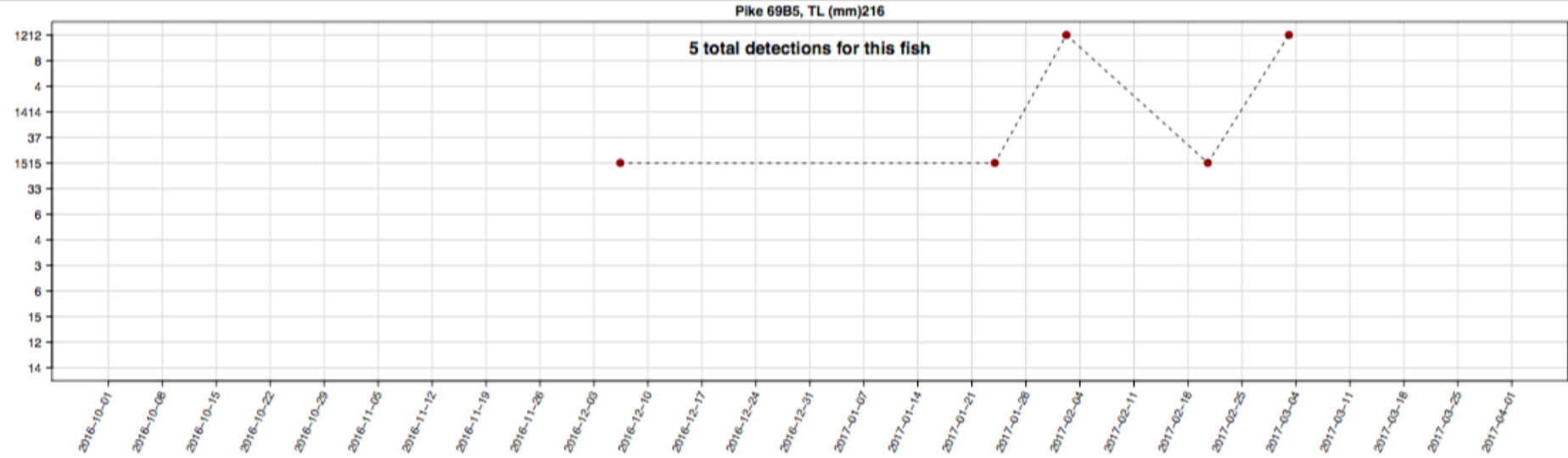

Pike 790D, TL (mm)NA

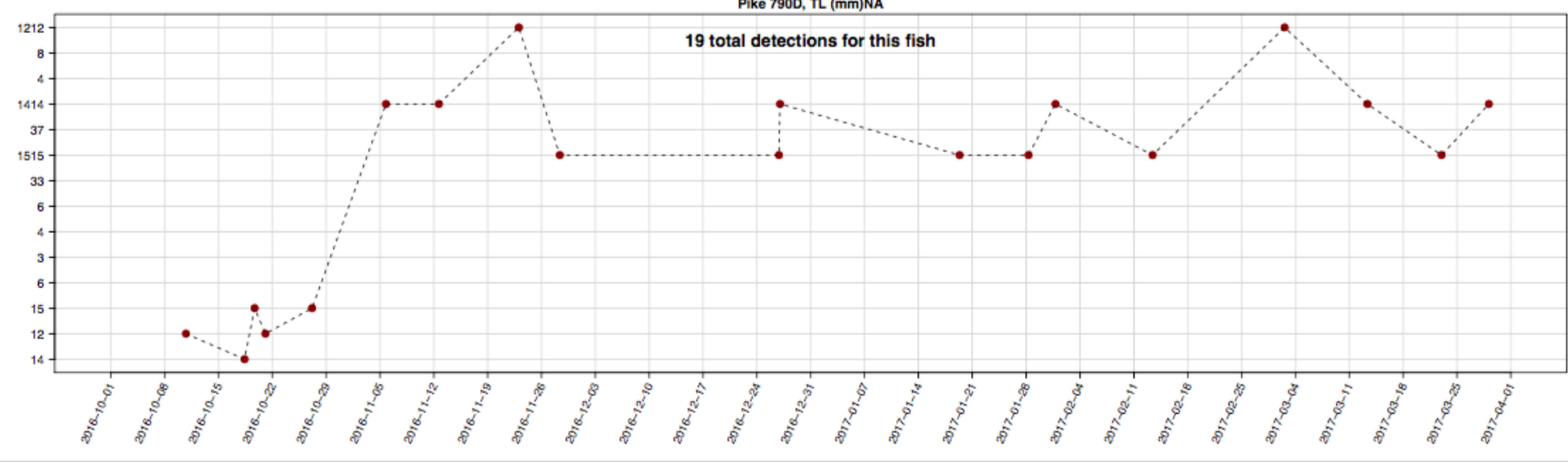

Pike 91FA, TL (mm)205

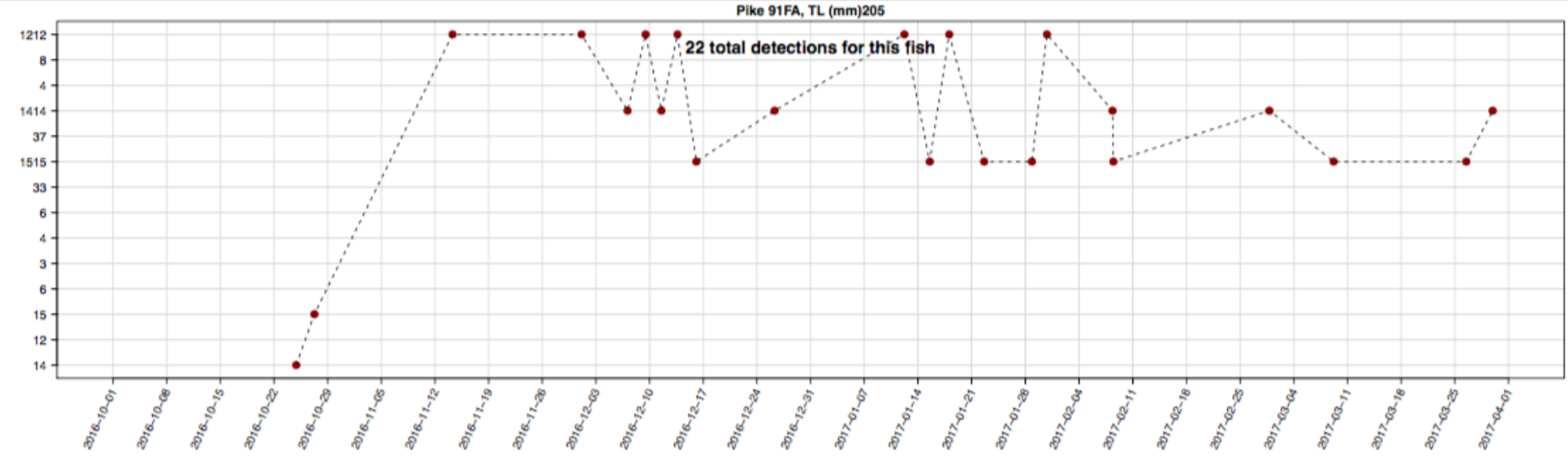


Figure S.3.12. Abacus plots for individual age-0 Northern Pike in Flynn Bay $(n=20)$ from October 1 , 2016 to March 31, 2017. Points indicate when fish were detected, and lines movement patterns between receivers from nearshore ( $\mathrm{Y}$ axis bottom) and deeper waters ( $\mathrm{Y}$ axis top) in the fall and winter. Time is depicted by weeks starting with October 1, 2016 (X axis). 


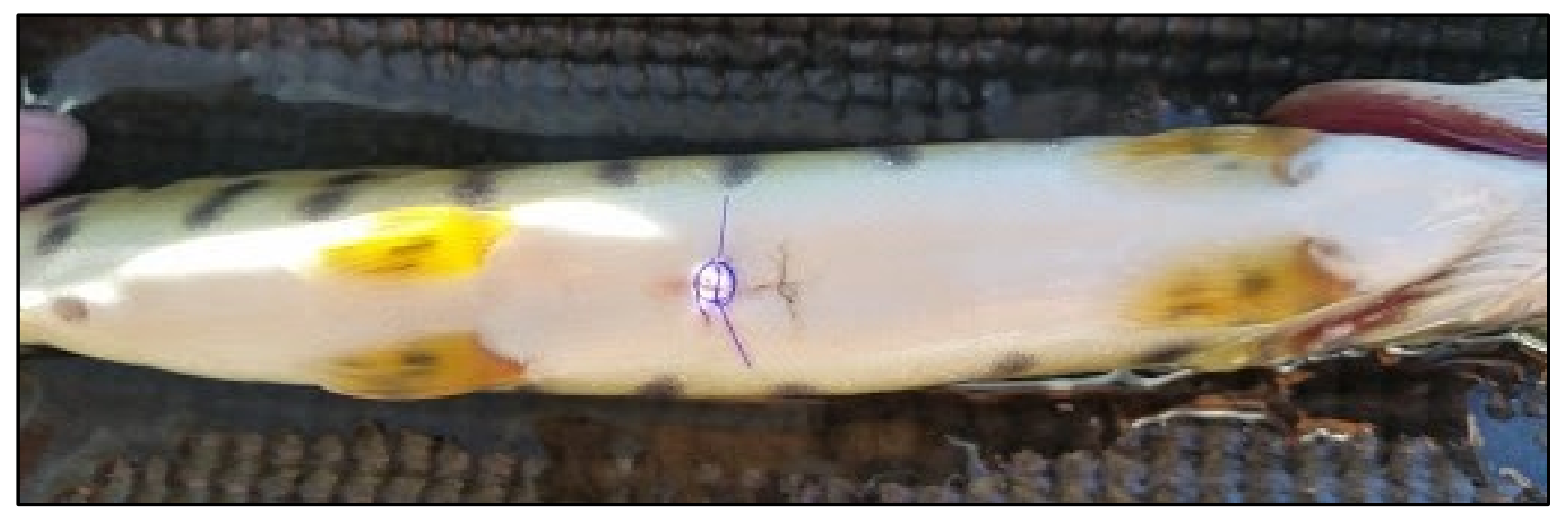

Figure S.3.13. A recaptured Muskellunge (tagged 933D on September 6, 2016) from Rose Bay retagged $\mathrm{A} 76 \mathrm{D}$ on October 7, 2016. This fish was recaptured near its initial tagging location. It grew 78-mm and 49.3-g in four weeks. Note the former surgery is nearly healed and only one dissolvable suture is retained. 


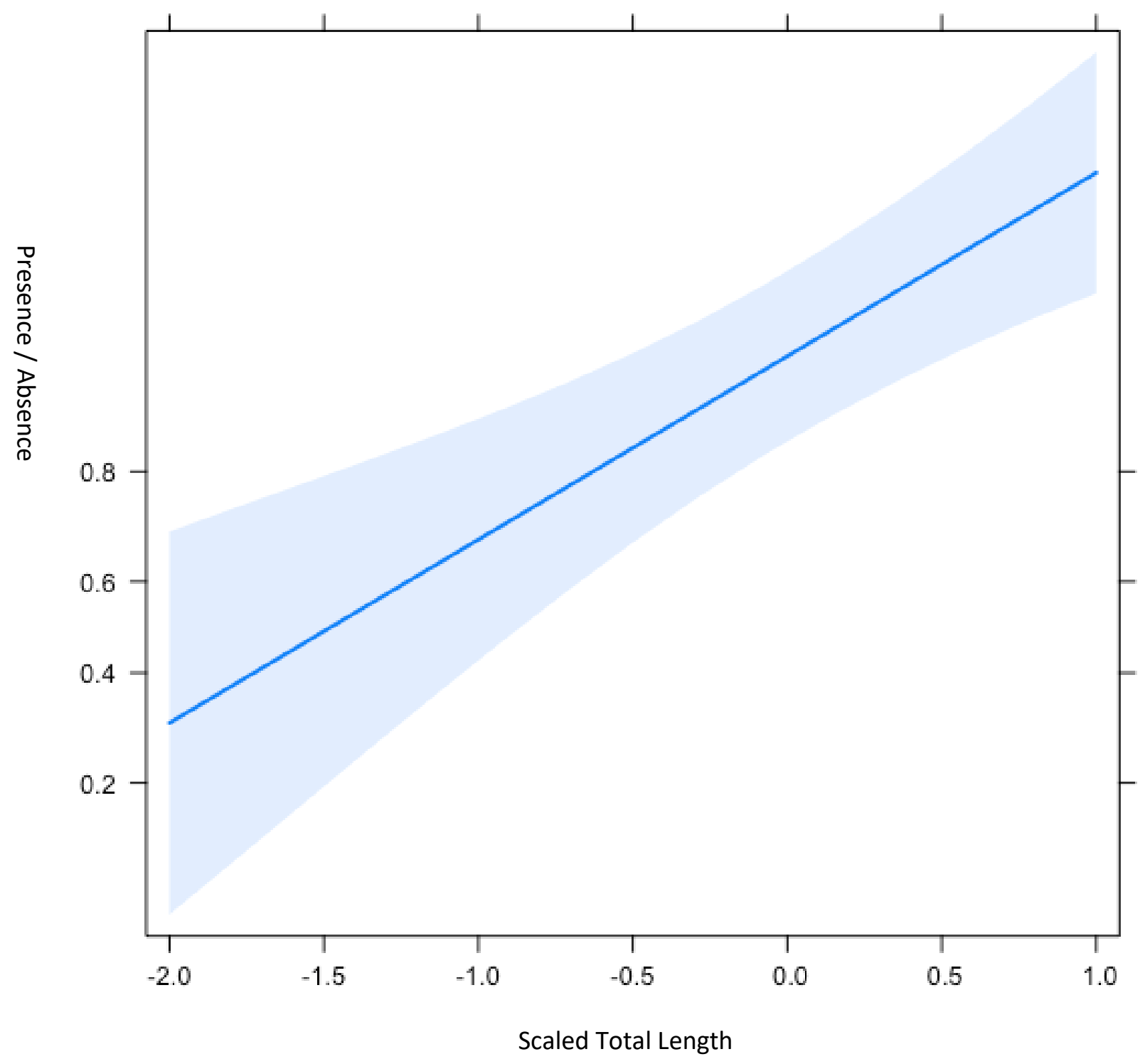

Figure S.3.14. Interaction plot indicating that the likelihood of an age-1 Muskellunge in Rose Bay being present in the array from October 2016 to March 2017 increased with the initial total length of a fish when captured as a young-of-year. 


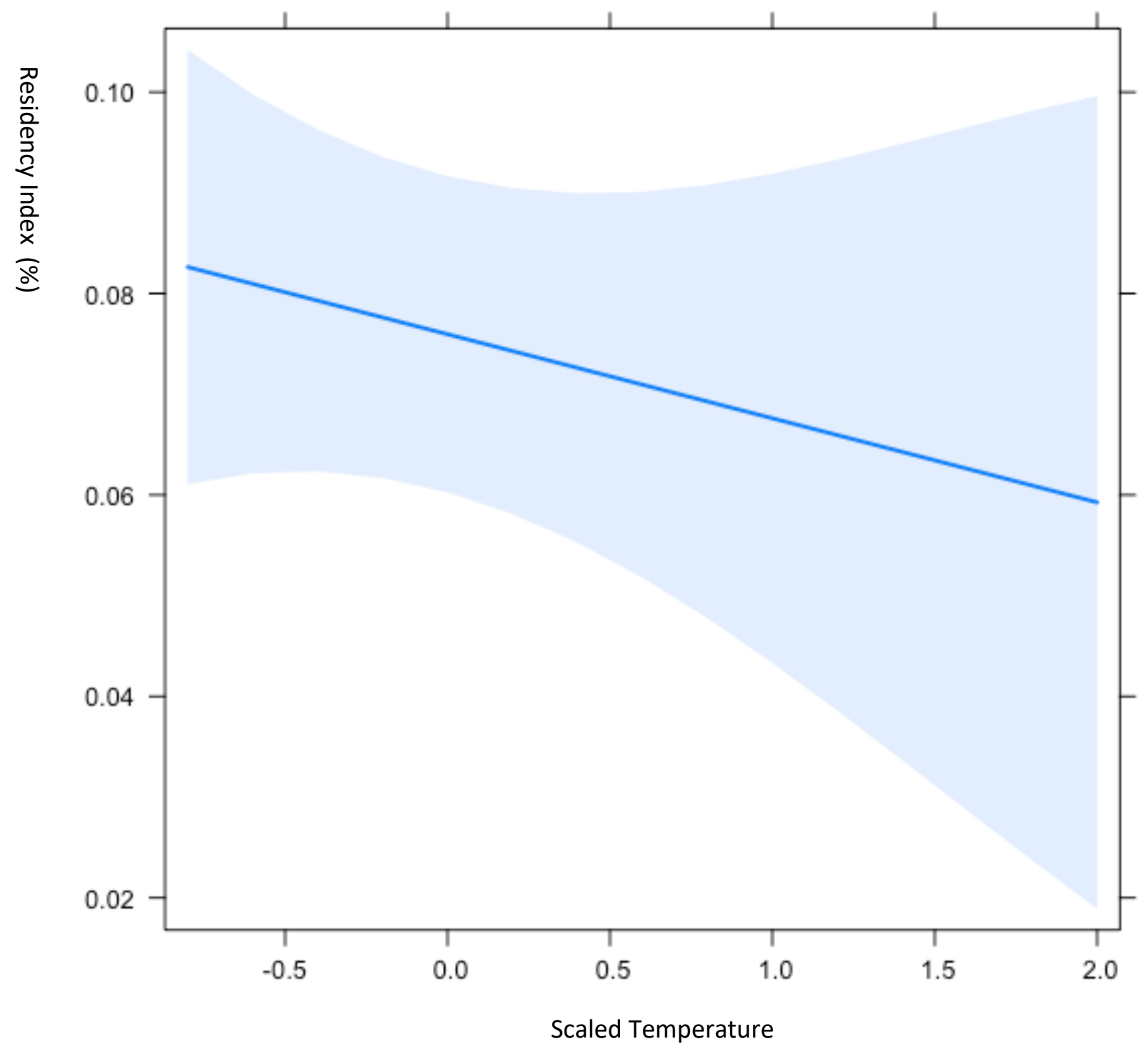

Figure S.3.15. Interaction plot indicating that the likelihood of an age-1 Muskellunge in Rose Bay residing in the array from October 2016 to March 2017 decreased as air temperatures increased. 

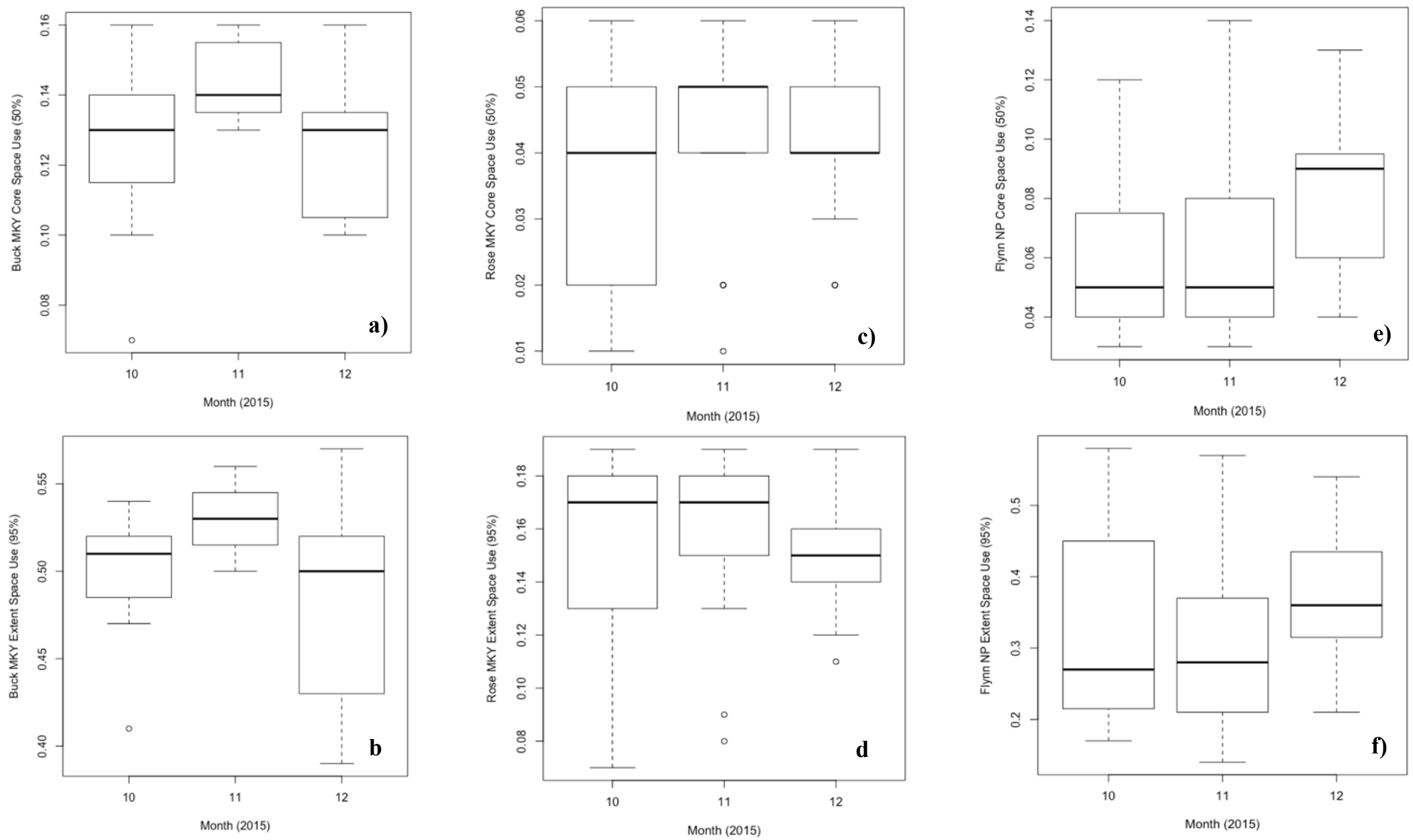

Fig. S.3.16. Space use for age- 0 Buck Muskellunge (a, core; b, extent), age-0 Rose muskellunge (c, core; d, extent), and age-0 Flynn Northern pike (e, core; f, extent) by month in 2015; month is indicated by numbers (10 - October, 11 - November, 12 - December). 

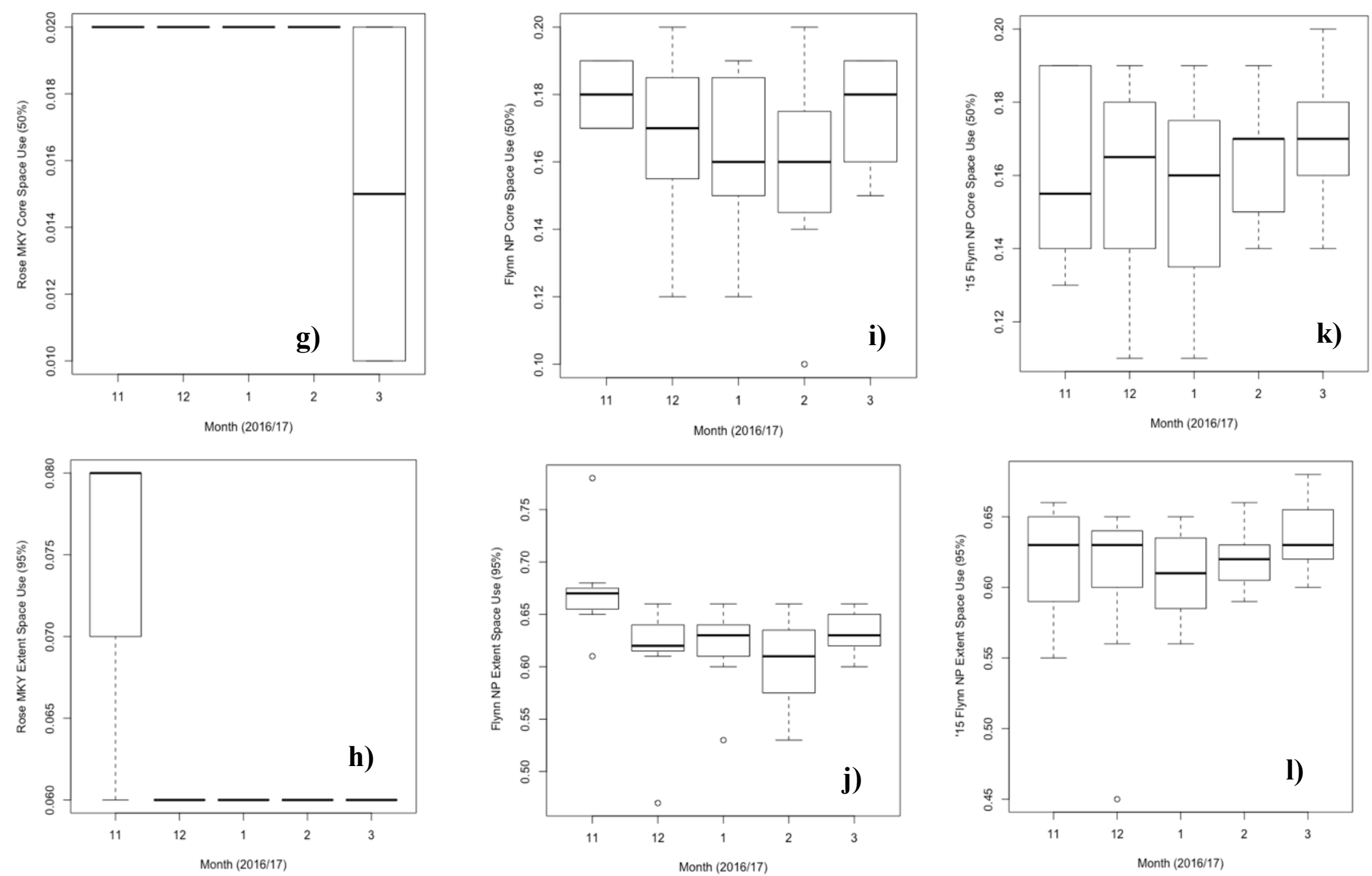

Fig. S.17. Space use for age-0 Rose Bay muskellunge (g, core; h, extent), age-0 Flynn Bay Northern pike (i, core; $j$, extent), and age-1 Flynn Bay Northern pike (k, core; 1, extent) by month in 2016/17. Month is indicated by numbers (11 - November, 12 - December, 1 January, 2 - February, 3 - March). 
Table S.3.1 Biological and monthly detection data for individual age-0 Muskellunge and Northern Pike monitored in their natal embayments from October to December 2015. Total detections for an individual fish were documented after filtering for double detections (receiver overlap) and removing detections within 5-minutes of each other. 875E is the lone Muskellunge monitored in captured in Flynn Bay and monitored in Buck Bay. 


\begin{tabular}{|c|c|c|c|c|c|}
\hline $\begin{array}{l}\text { JSAT } \\
\text { TAG ID }\end{array}$ & $\begin{array}{l}\text { Total Length } \\
\pm \text { SD (mm) }\end{array}$ & Bay & $\begin{array}{r}\text { Total Detections } \\
\text { October }\end{array}$ & $\begin{array}{r}\text { Total } \\
\text { Detections } \\
\text { November }\end{array}$ & $\begin{array}{r}\text { Total } \\
\text { Detections } \\
\text { December }\end{array}$ \\
\hline OFEA & 140 & ROSE & 153 & 169 & 53 \\
\hline 4253 & 185 & ROSE & 47 & 23 & 5 \\
\hline 4494 & 122 & ROSE & 37 & 22 & 12 \\
\hline 49DA & 122 & ROSE & 673 & 22 & 6 \\
\hline $646 B$ & 145 & ROSE & 62 & 23 & 10 \\
\hline $64 \mathrm{E7}$ & 156 & ROSE & 83 & 24 & 4 \\
\hline 757D & 125 & ROSE & 50 & 36 & 14 \\
\hline 8915 & 158 & ROSE & 30 & 28 & 10 \\
\hline 9253 & 179 & ROSE & 10 & 16 & 5 \\
\hline A4BE & 160 & ROSE & 3960 & 23 & 6 \\
\hline B156 & 174 & ROSE & 19 & 12 & 11 \\
\hline B690 & 126 & ROSE & 467 & 30 & 6 \\
\hline BD92 & 150 & ROSE & 72 & 20 & 4 \\
\hline BF23 & 148 & ROSE & 247 & 51 & 16 \\
\hline D0E7 & 171 & ROSE & 3621 & 12758 & 6 \\
\hline $\mathrm{DA} 2 \mathrm{~A}$ & 149 & ROSE & 15 & 12 & 3 \\
\hline DF35 & 125 & ROSE & 30 & 24 & 8 \\
\hline E0A8 & 170 & ROSE & 2262 & 5378 & 699 \\
\hline E528 & 162 & ROSE & 4150 & 8418 & 7 \\
\hline FFA6 & 156 & ROSE & 80 & 56 & 19 \\
\hline 5859 & 167 & BUCK & 13 & 21 & 5 \\
\hline $730 \mathrm{C}$ & 143 & BUCK & 66 & 57 & 23 \\
\hline AEF1 & 158 & BUCK & 78 & 15 & 9 \\
\hline C687 & 181 & BUCK & 48 & 34 & 13 \\
\hline $\mathrm{E} 6 \mathrm{CC}$ & 127 & BUCK & 20 & 18 & 5 \\
\hline F3B8 & 195 & BUCK & 30 & 64 & 10 \\
\hline F50E & 177 & BUCK & 16 & 16 & 5 \\
\hline 062C & 200 & FLYNN & 70 & 11 & 2 \\
\hline 1243 & 210 & FLYNN & 419 & 382 & 30 \\
\hline $419 B$ & 255 & FLYNN & 1110 & 1224 & 648 \\
\hline $424 \mathrm{~F}$ & 215 & FLYNN & 165 & 248 & 4 \\
\hline 4BA2 & 298 & FLYNN & 7 & 10 & 3 \\
\hline 4E15 & 250 & FLYNN & 234 & 391 & 5 \\
\hline 53FE & 205 & FLYNN & 362 & 906 & 3 \\
\hline 5638 & 172 & FLYNN & 79 & 764 & 14 \\
\hline 6944 & 356 & FLYNN & 138 & 71 & 91 \\
\hline $6 \mathrm{BA} 2$ & 301 & FLYNN & 15 & 319 & 2 \\
\hline
\end{tabular}




\begin{tabular}{lrlrrr}
$704 D$ & 241 & FLYNN & 281 & 1351 & 373 \\
$72 C 3$ & 216 & FLYNN & 894 & 545 & 12 \\
$* 875 E$ & 223 & FLYNN & 10 & 12 & 6 \\
9088 & 235 & FLYNN & 508 & 290 & 3 \\
$93 F A$ & 222 & FLYNN & 900 & 1257 & 157 \\
$99 E B$ & 146 & FLYNN & 6 & 7 & 1 \\
A6AE & 240 & FLYNN & 307 & 3 & 1 \\
AA29 & 247 & FLYNN & 18 & 3 & 2 \\
BF60 & 380 & FLYNN & 54 & 49 & 17 \\
C57F & 275 & FLYNN & 964 & 779 & 1 \\
CD5B & 213 & FLYNN & 781 & 478 & 27 \\
CF7F & 247 & FLYNN & 166 & 318 & 37 \\
D3B1 & 252 & FLYNN & 35 & 12 & 4 \\
DDFD & 171 & FLYNN & 120 & 137 & 38 \\
\hline
\end{tabular}


Table S.3.2 Biological and monthly detection data for individual age-0 Muskellunge and age-0 Northern pike monitored in their natal embayments from October 2016 to March 2017. Total detections collected from an individual fish, after filtering for double detections (receiver overlap) and removing detections within 5-minutes of each other, for each month, respectively.

\begin{tabular}{|c|c|c|c|c|c|c|c|c|c|c|}
\hline Species & $\begin{array}{c}\text { JSAT } \\
\text { TAG ID }\end{array}$ & $\begin{array}{c}\text { Total } \\
\text { Length } \\
\pm \text { SD } \\
(\mathrm{mm})\end{array}$ & $\begin{array}{l}\text { Weight } \\
\pm S D(g)\end{array}$ & $\begin{array}{c}\text { Capture } \\
\text { Bay }\end{array}$ & $\begin{array}{r}\text { Total } \\
\text { Detections } \\
\text { October }\end{array}$ & $\begin{array}{r}\text { Total } \\
\text { Detections } \\
\text { November }\end{array}$ & $\begin{array}{r}\text { Total } \\
\text { Detections } \\
\text { December }\end{array}$ & $\begin{array}{r}\text { Total } \\
\text { Detections } \\
\text { January }\end{array}$ & $\begin{array}{r}\text { Total } \\
\text { Detections } \\
\text { February }\end{array}$ & $\begin{array}{r}\text { Total } \\
\text { Detections } \\
\text { March }\end{array}$ \\
\hline Musky & 933D & 156 & 18.0 & ROSE & 39 & 38 & 25 & 0 & 4 & 2 \\
\hline Musky & 3605 & 168 & 25.5 & ROSE & 15 & 15 & 10 & 11 & 9 & 10 \\
\hline Musky & 0274 & 118 & 11.9 & GRASS & 18 & 9 & 9 & 18 & 17 & 9 \\
\hline Musky & 07DE & 196 & 41.5 & GRASS & 41 & 4 & 49 & 37 & 38 & 52 \\
\hline Musky & $33 F 4$ & 176 & 32.1 & GRASS & 13 & 9 & 10 & 11 & 8 & 10 \\
\hline Musky & $30 \mathrm{EC}$ & 155 & 18.0 & ROSE & 9 & 8 & 11 & 10 & 8 & 10 \\
\hline Musky & 790D & 154 & 18.0 & FLYNN & 5 & 5 & 3 & 4 & 1 & 6 \\
\hline Musky & AAD4 & 178 & 32.8 & GRASS & 3 & 6 & 2 & 3 & 2 & 3 \\
\hline Musky & D14F & 203 & 40.4 & GRASS & 7 & 7 & 6 & 9 & 4 & 13 \\
\hline Musky & $810 \mathrm{C}$ & 250 & 78.5 & ROSE & 22 & 13 & 19 & 21 & 12 & 16 \\
\hline Musky & ${ }^{* *}$ A76D & 234 & 67.5 & ROSE & 321 & 377 & 2 & 1 & 1 & 5 \\
\hline N. Pike & $413 \mathrm{E}$ & 263 & 118.0 & FLYNN & 13 & 11 & 19 & 18 & 9 & 20 \\
\hline N. Pike & $38 \mathrm{C} 3$ & 250 & 110.5 & FLYNN & 16 & 12 & 9 & 17 & 10 & 15 \\
\hline N. Pike & $4 \mathrm{D} 88$ & 310 & 202.8 & FLYNN & 10 & 15 & 11 & 11 & 12 & 12 \\
\hline N. Pike & †EC39 & 259 & 115.5 & FLYNN & 6 & 4 & 9 & 5 & 11 & 9 \\
\hline N. Pike & tF60E & 254 & 105.6 & FLYNN & 27 & 32 & 28 & 26 & 25 & 29 \\
\hline N. Pike & 91FA & 205 & 58.4 & FLYNN & 2 & 1 & 7 & 6 & 4 & 4 \\
\hline N. Pike & 36B8 & 179 & 40.1 & FLYNN & 4 & 4 & 7 & 6 & 9 & 5 \\
\hline N. Pike & $5 A 49$ & 235 & 89.8 & FLYNN & 1 & 2 & 3 & 1 & 2 & 2 \\
\hline
\end{tabular}




\begin{tabular}{lrrrlrrrrr} 
N. Pike & $69 \mathrm{~B} 5$ & 216 & 67.5 & FLYNN & 0 & 1 & 1 & 1 & 3 \\
N. Pike & 1A2B & 219 & 66.8 & FLYNN & 2 & 6 & 4 & 7 & 6 \\
N. Pike & 0351 & 183 & 38.0 & FLYNN & 14 & 15 & 19 & 22 & 21 \\
N. Pike & $92 \mathrm{~F} 2$ & 222 & 78.0 & FLYNN & 4 & 4 & 3 & 3 & 4 \\
N. Pike & 4317 & 195 & 43.8 & FLYNN & 19 & 17 & 21 & 9 & 10 \\
N. Pike & 0219 & 215 & 70.8 & FLYNN & 63 & 81 & 74 & 78 & 55 \\
N. Pike & $169 \mathrm{~A}$ & 197 & 47.8 & FLYNN & 1 & 5 & 3 & 3 & 3 \\
\hline
\end{tabular}


Table S.3.3 Collinearity data (VIF) for presence/absence (PA), residency index (RI) and space use (SU) "Models" for age-0 Muskellunge in Rose Bay based on "Year" (2015 - 15, 2016/17 - 1617).

\begin{tabular}{|c|c|c|c|}
\hline Year & Model & Factor & VIF \\
\hline \multirow[t]{3}{*}{15} & PA & cTL & 1 \\
\hline & & cTEMP & 1.386425 \\
\hline & & cLEVEL & 1.386425 \\
\hline \multirow[t]{3}{*}{1617} & PA & cTL & 1 \\
\hline & & cTEMP & 1.503419 \\
\hline & & cLEVEL & 1.503419 \\
\hline \multirow[t]{3}{*}{15} & $\mathrm{RI}$ & cTL & 1.004039 \\
\hline & & cTEMP & 1.403956 \\
\hline & & cLEVEL & 1.40422 \\
\hline \multirow[t]{3}{*}{1617} & $\mathrm{RI}$ & cTL & 1 \\
\hline & & cTEMP & 1.588863 \\
\hline & & cLEVEL & 1.588863 \\
\hline \multirow[t]{3}{*}{15} & SU & cTL & 1 \\
\hline & & cTEMP & 1.588863 \\
\hline & & cLEVEL & 1.588863 \\
\hline \multirow[t]{3}{*}{1617} & SU & cTL & 1.036146 \\
\hline & & cTEMP & 1.495974 \\
\hline & & cLEVEL & 1.480366 \\
\hline \multirow[t]{3}{*}{15} & $\mathrm{HAB}$ & cTL & 1 \\
\hline & & cTEMP & 1.44 \\
\hline & & cLEVEL & 1.44 \\
\hline \multirow[t]{3}{*}{1617} & $\mathrm{HAB}$ & cTL & 1 \\
\hline & & cTEMP & 1.49 \\
\hline & & cLEVEL & 1.49 \\
\hline
\end{tabular}


Table S.3.4 Model comparisons for age-0 Muskellunge in Rose Bay for presence/absence (PA), residency index (RI) and space use (SU) variables based on "Year" as 2015 (15) or 2016/17 (1617). "Formula" dictates the factors used in each model, the "AIC" value indicates which was lower, and the "p Value" shows whether the alternate model was significantly different. Formulas in bold indicate the alternative model was significantly different from the null model.

\begin{tabular}{|c|c|c|c|c|c|c|}
\hline Year & Function & Variable & Formula & df & AIC & p Value \\
\hline \multirow[t]{2}{*}{15} & GLMER & PA & $\mathrm{PA} \sim \mathrm{cTEMP}+\mathrm{cTL}+(1 \mid \mathrm{FISH})$ & 4 & 50.82 & \\
\hline & & & $\mathrm{PA} \sim 1+(1 \mid \mathrm{FISH})$ & 1 & 47.23 & 0.5288 \\
\hline \multirow[t]{3}{*}{1617} & GLMER & PA & $\mathrm{PA} \sim \mathrm{cTEMP}+\mathrm{cTL}+(1 \mid \mathrm{FISH})$ & 4 & 23.20 & $<0.001$ \\
\hline & & & $\mathrm{PA} \sim \mathrm{cLEVEL}+\mathrm{cTL}+(1 \mid \mathrm{FISH})$ & 4 & 29.21 & \\
\hline & & & $\mathrm{PA} \sim 1+(1 \mid \mathrm{FISH})$ & 2 & 33.77 & \\
\hline \multirow[t]{2}{*}{15} & LMER & $\mathrm{RI}$ & RES cLEVEL + cTEMP + cTL + (1| FISH) & 6 & -14.28 & 0.01 \\
\hline & & & $\mathrm{RES} \sim 1+(1 \mid \mathrm{FISH})$ & 3 & -9.44 & \\
\hline \multirow[t]{2}{*}{1617} & LMER & $\mathrm{RI}$ & RES cLEVEL + cTEMP + cTL + (1| FISH) & 6 & -9.43 & 0.002 \\
\hline & & & $\mathrm{RES} \sim 1+(1 \mid \mathrm{FISH})$ & 3 & -0.72 & \\
\hline \multirow[t]{4}{*}{15} & LME & SU & KUD_50 cTEMP + cLEVEL + cTL , 1| FISH/MONTH & 7 & -326.48 & 0.1 \\
\hline & & & KUD_50 1, 1| FISH/MONTH & 4 & -326.41 & \\
\hline & & & KUD_95 cTEMP + cLEVEL + cTL, 1| FISH/MONTH & 7 & -228.65 & \\
\hline & & & KUD_95 1, 1| FISH/MONTH & 4 & -231.20 & 0.32 \\
\hline \multirow[t]{4}{*}{1617} & LME & SU & KUD_50 cTEMP + cLEVEL + cTL, 1| FISH/MONTH & 7 & -99.33 & \\
\hline & & & KUD_50 1, 1| FISH/MONTH & 4 & -99.26 & 0.11 \\
\hline & & & KUD_95 cTEMP + cLEVEL + cTL , 1| FISH/MONTH & 7 & -80.69 & 0.01 \\
\hline & & & KUD_95 1, 1| FISH/MONTH & 4 & -75.52 & \\
\hline \multirow[t]{2}{*}{15} & LMER & $\mathrm{HAB}$ & HAB HABITAT + cLEVEL + cTL + (1| FISH) & 6 & -325.10 & $<0.001$ \\
\hline & & & $\mathrm{HAB} \sim 1+(1 \mid \mathrm{FISH})$ & 3 & -45.40 & \\
\hline \multirow[t]{2}{*}{1617} & LMER & $\mathrm{HAB}$ & HAB HABITAT + cLEVEL + cTL + (1| FISH) & 6 & 567.45 & \\
\hline & & & $\mathrm{HAB} \sim 1+(1 \mid \mathrm{FISH})$ & 3 & 148.95 & 0.001 \\
\hline
\end{tabular}


Table S.3.5. Model output for age-0 Muskellunge in Rose Bay for presence/absence (PA), residency index (RI) and space use (SU) models. "Factor" highlights the variable used in the model, " $\mathrm{X}$ " " the Chi Square value from the Anova () model, and the "P Value" indicates significant differences between the factor to the dependent model variable. Bolded factors indicate those that significantly influenced the dependent model factor.

\begin{tabular}{|c|c|c|c|c|}
\hline Year & Model & Factor & $x^{2}$ & P Value \\
\hline \multirow[t]{3}{*}{15} & PA & (Intercept) & 24.8209 & $6.29 \mathrm{E}-07$ \\
\hline & & $\mathrm{ctl}$ & 0.3891 & 0.5327 \\
\hline & & ctemp & 0.01 & 0.9202 \\
\hline \multirow[t]{3}{*}{1617} & PA & (Intercept) & 0.5149 & 0.473 \\
\hline & & $\mathrm{ctl}$ & 0.0439 & 0.834 \\
\hline & & ctemp & 0.5898 & 0.443 \\
\hline \multirow[t]{4}{*}{15} & RI & (Intercept) & 171.835 & $<2.2 \mathrm{e}-16$ \\
\hline & & $\mathrm{ctl}$ & 0.0596 & 0.807 \\
\hline & & ctemp & 7.5242 & 0.006 \\
\hline & & clevel & 0.0206 & 0.886 \\
\hline \multirow[t]{4}{*}{1617} & RI & (Intercept) & 124.09 & $<2.2 \mathrm{e}-16$ \\
\hline & & ctemp & 9.7294 & 0.002 \\
\hline & & clevel & 0.1753 & 0.675 \\
\hline & & ctl & 4.4903 & 0.034 \\
\hline \multirow[t]{8}{*}{15} & SU_50 & (Intercept) & 236.4473 & $<2 \mathrm{e}-16$ \\
\hline & & $\mathrm{ctl}$ & 1.4306 & 0.231 \\
\hline & & ctemp & 4.5914 & 0.032 \\
\hline & & clevel & 4.1875 & 0.041 \\
\hline & SU_95 & (Intercept) & 1338.5754 & $<2 \mathrm{e}-16$ \\
\hline & & $\mathrm{ctl}$ & 2.4806 & 0.115 \\
\hline & & ctemp & 0.8263 & 0.363 \\
\hline & & clevel & 0.0052 & 0.943 \\
\hline \multirow[t]{6}{*}{1617} & SU_50 & (Intercept) & 945.7814 & $<2 \mathrm{e}-16$ \\
\hline & & ctl & 2.0598 & 0.151 \\
\hline & & ctemp & 0.0431 & 0.836 \\
\hline & & clevel & 5.07 & 0.024 \\
\hline & SU_95 & (Intercept) & 2198.0766 & $<2.2 \mathrm{e}-16$ \\
\hline & & $\mathrm{ctl}$ & 0.5115 & 0.474 \\
\hline
\end{tabular}




\begin{tabular}{lllll} 
& & ctemp & $\mathbf{1 4 . 3 6 3 3}$ & $\mathbf{0 . 0 0 0}$ \\
& clevel & 0.1888 & 0.664 \\
\hline 15 & HAB & (Intercept) & $2.96 \mathrm{E}+05$ & $<2 \mathrm{e}-16$ \\
& & habitat & $\mathbf{9 . 2 8 E}+03$ & $<2 \mathrm{e}-16$ \\
& ctl & $4.80 \mathrm{E}-03$ & 0.945 \\
& & clevel & $2.24 \mathrm{E}-01$ & 0.636 \\
\hline \multirow{2}{*}{1617} & HAB & (Intercept) & $2.13 \mathrm{E}+05$ & $<2.2 \mathrm{e}-16$ \\
& & habitat & $\mathbf{1 . 4 0 E + 0 5}$ & $<2.2 \mathrm{e}-16$ \\
& & ctl & $\mathbf{2 . 7 4 E + 0 0}$ & $\mathbf{0 . 0 9 8}$ \\
& & ctemp & $1.34 \mathrm{E}+00$ & 0.247 \\
& & clevel & $5.95 \mathrm{E}-02$ & 0.807 \\
\hline
\end{tabular}


Table S.3.6. Collinearity data (VIF) for presence/absence (PA), residency index (RI) and space use (SU) "Models" for age-0 Northern Pike in Flynn Bay based on "Year" (2015 - 15, 2016/17 - 1617). Air temperature was used as a proxy for water temperature in 2015 , and collinearity values indicated correlation (VIF >5), water level was the sole environmental variable kept in the statistical formula.

\begin{tabular}{|c|c|c|c|}
\hline Year & Model & Factor & VIF \\
\hline \multirow[t]{3}{*}{15} & $\mathrm{PA}$ & cTL & 1 \\
\hline & & cTEMP & 67.82 \\
\hline & & cLEVEL & 67.82 \\
\hline \multirow[t]{2}{*}{15.2} & & cTL & 1 \\
\hline & & cLEVEL & 1 \\
\hline \multirow[t]{3}{*}{1617} & PA & cTL & 1 \\
\hline & & cTEMP & 1.24 \\
\hline & & cLEVEL & 1.24 \\
\hline \multirow[t]{5}{*}{15} & $\mathrm{RI} / \mathrm{SU}$ & cTL & 1 \\
\hline & & cTEMP & 67.82 \\
\hline & & cLEVEL & 67.82 \\
\hline & & cTL & 1 \\
\hline & & cLEVEL & 1 \\
\hline \multirow[t]{3}{*}{1617} & $\mathrm{RI}$ & cTL & 1 \\
\hline & & cTEMP & 1.24 \\
\hline & & cLEVEL & 1.24 \\
\hline \multirow[t]{3}{*}{1617} & SU & cTL & 1.04 \\
\hline & & cTEMP & 1.50 \\
\hline & & cLEVEL & 1.48 \\
\hline \multirow[t]{5}{*}{15} & HAB & cTL & 1.02 \\
\hline & & cTEMP & 15.23 \\
\hline & & cLEVEL & 15.23 \\
\hline & & cTL & 1 \\
\hline & & cLEVEL & 1 \\
\hline \multirow[t]{3}{*}{1617} & $\mathrm{HAB}$ & cTL & 1.04 \\
\hline & & cTEMP & 1.50 \\
\hline & & cLEVEL & 1.48 \\
\hline
\end{tabular}


Table S.3.7. Model comparisons for age-0 Northern Pike in Flynn Bay for presence/absence (PA), residency index (RI) and space use (SU) variables based on "Year" as 2015 (15) or 2016/17 (1617). "Formula" dictates the factors used in each model, the "AIC" value indicates which was lower, and the " $p$ Value" shows whether the alternate model was significantly different. Formulas in bold indicate the alternative model was significantly different from the null model.

\begin{tabular}{|c|c|c|c|c|c|c|}
\hline Year & Function & Model & Formula & df & AIC & p Value \\
\hline \multirow[t]{3}{*}{15} & GLMER & PA & $\mathrm{PA} \sim \mathrm{cTEMP}+\mathrm{cTL}+(1 \mid \mathrm{FISH})$ & 4 & 61.70 & $<0.001$ \\
\hline & & & $\mathrm{PA} \sim \mathrm{cLEVEL}+\mathrm{cTL}+(1 \mid \mathrm{FISH})$ & 4 & 62.94 & \\
\hline & & & $\mathrm{PA} \sim 1+(1 \mid \mathrm{FISH})$ & 2 & 77.69 & \\
\hline \multirow[t]{2}{*}{1617} & GLMER & PA & $\mathrm{PA} \sim \mathrm{cTEMP}+\mathrm{cLEVEL}+\mathrm{cTL}+(1 \mid \mathrm{FISH})$ & 5 & 87.67 & \\
\hline & & & $\mathrm{PA} \sim 1+(1 \mid \mathrm{FISH})$ & 2 & 88.14 & 0.09 \\
\hline \multirow[t]{2}{*}{15} & LMER & $\mathbf{R} \mathbf{I}$ & RES cLEVEL + cTL + (1| FISH) & 4 & -20.48 & $<0.001$ \\
\hline & & & RES $1+(1 \mid \mathrm{FISH})$ & 2 & -2.934 & \\
\hline \multirow[t]{2}{*}{1617} & LMER & $\mathbf{R I}$ & RES cLEVEL + cTEMP + cTL + (1| FISH) & 6 & -233.24 & $<0.002$ \\
\hline & & & RES $1+(1 \mid \mathrm{FISH})$ & 3 & -229.78 & \\
\hline \multirow[t]{4}{*}{15} & LME & SU & KUD_50 cLEVEL + cTL, 1| FISH/MONTH & 6 & -164.00 & \\
\hline & & & KUD_50 1, 1| FISH/MONTH & 4 & -163.58 & 0.27 \\
\hline & & & KUD_95 cLEVEL + cTL, 1| FISH/MONTH & 6 & -52.52 & \\
\hline & & & KUD_95 1, 1| FISH/MONTH & 4 & -56.34 & 0.91 \\
\hline \multirow[t]{4}{*}{1617} & LME & SU & KUD_50 cTEMP + cLEVEL + cTL, 1| FISH/MONTH & 7 & -158.00 & \\
\hline & & & KUD_50 1, 1| FISH/MONTH & 4 & -156.58 & 0.06 \\
\hline & & & KUD_95 cTEMP + cLEVEL + cTL, 1| FISH/MONTH & 7 & -104.95 & 0.01 \\
\hline & & & KUD_95 1, 1| FISH/MONTH & 4 & -100.96 & \\
\hline \multirow[t]{2}{*}{15} & LMER & HAB & HAB HABITAT + cLEVEL + cTL + (1| FISH) & 8 & -271.23 & $<0.001$ \\
\hline & & & $\mathrm{HAB} \sim 1+(1 \mid \mathrm{FISH})$ & 3 & -124.70 & \\
\hline \multirow[t]{2}{*}{1617} & LMER & HAB & HAB HABITAT + cLEVEL + cTL + (1| FISH) & 9 & -425.93 & $<0.001$ \\
\hline & & & $\mathrm{HAB} \sim 1+(1 \mid \mathrm{FISH})$ & 3 & -226.02 & \\
\hline
\end{tabular}


Table S.3.8. Model output for age-0 Northern Pike in Flynn Bay for presence/absence (PA), residency index (RI) and space use (SU) models. "Factor" highlights the variable used in the model, "ChiSqu" the value from the Anova() model, and the "P Value" indicates significant differences between the factor to the dependent model variable. Bolded factors indicate those that significantly influenced the dependent model factor. 


\begin{tabular}{|c|c|c|c|c|}
\hline Year & Model & Factor & $x^{2}$ & $P$ Value \\
\hline \multirow[t]{3}{*}{15} & PA & (Intercept) & 7.4589 & 0.006312 \\
\hline & & $c t l$ & 6.8881 & 0.853228 \\
\hline & & clevel & 0.0342 & 0.008677 \\
\hline \multirow[t]{4}{*}{1617} & PA & (Intercept) & 0.226 & 0.635 \\
\hline & & $c t l$ & 2.44 & 0.118 \\
\hline & & clevel & 1.9534 & 0.162 \\
\hline & & ctemp & 2.4595 & 0.117 \\
\hline \multirow[t]{3}{*}{15} & $\mathrm{RI}$ & (Intercept) & 104.592 & $<2 \mathrm{e}-16$ \\
\hline & & clevel & 26.3046 & $<0.001$ \\
\hline & & $\mathrm{ctl}$ & 0.1358 & 0.713 \\
\hline \multirow[t]{4}{*}{1617} & $\mathrm{RI}$ & (Intercept) & 33.1815 & $8.395 e-09$ \\
\hline & & ctl & 0.5979 & 0.439 \\
\hline & & ctemp & 9.0821 & 0.002 \\
\hline & & clevel & 0.4860 & 0.486 \\
\hline \multirow[t]{6}{*}{15} & SU_50 & (Intercept) & 96.4609 & $<2 \mathrm{e}-16$ \\
\hline & & ctl & 0.0953 & 0.758 \\
\hline & & clevel & 2.5901 & 0.108 \\
\hline & SU_95 & (Intercept) & 133.5557 & $<2 \mathrm{e}-16$ \\
\hline & & $\mathrm{ctl}$ & 0.0688 & 0.793 \\
\hline & & clevel & 0.1088 & 0.742 \\
\hline \multirow[t]{8}{*}{1617} & SU_50 & (Intercept) & 1461.2612 & $<2 \mathrm{e}-16$ \\
\hline & & $\mathrm{ctl}$ & 2.7552 & 0.097 \\
\hline & & ctemp & 5.4234 & 0.020 \\
\hline & & clevel & 0.3354 & 0.563 \\
\hline & SU_95 & (Intercept) & 7035.7926 & $<2.2 \mathrm{e}-16$ \\
\hline & & $\mathrm{ctl}$ & 1.5117 & 0.219 \\
\hline & & ctemp & 9.3907 & 0.002 \\
\hline & & clevel & 0.2602 & 0.610 \\
\hline \multirow[t]{4}{*}{15} & $\mathrm{HAB}$ & (Intercept) & 1106.982 & $<2 \mathrm{e}-16$ \\
\hline & & habitat & 514.7326 & $<2 \mathrm{e}-16$ \\
\hline & & clevel & 4.7068 & 0.03004 \\
\hline & & $\mathrm{ctl}$ & 0.082 & 0.77459 \\
\hline \multirow[t]{4}{*}{1617} & $\mathrm{HAB}$ & (Intercept) & 243.0656 & $<2.2 \mathrm{e}-16$ \\
\hline & & habitat & 182.8703 & $<2.2 \mathrm{e}-16$ \\
\hline & & ctl & 0.0013 & 0.098 \\
\hline & & ctemp & 0.1343 & 0.247 \\
\hline
\end{tabular}


Table S.3.9. Model comparisons for age-0 Muskellunge in Buck Bay for presence/absence (PA), residency index (RI) and space use (SU) variables in 2015. "Formula" dictates the factors used in each model, the "AIC" value indicates which was lower, and the "p Value" shows whether the alternate model was significantly different. Formulas in bold indicate the alternative model was significantly different from the null model. Collinearity was the same for all models: 1 for cTL and 5.08 for each cLEVEL and cTEMP. As air temperature was used as a proxy for water temperature, cTEMP was dropped from the formula

\begin{tabular}{|c|c|c|c|c|c|}
\hline Function & Model & Formula & df & AIC & p Value \\
\hline \multirow[t]{2}{*}{ GLMER } & PA & $\mathrm{PA} \sim \mathrm{cLEVEL}+\mathrm{cTL}+(1 \mid \mathrm{FISH})$ & 3 & 16.593 & 0.003 \\
\hline & & $\mathrm{PA} \sim 1+(1 \mid \mathrm{FISH})$ & 2 & 24.45033 & \\
\hline \multirow[t]{2}{*}{ LMER } & $\mathrm{RI}$ & $\mathrm{PA} \sim \mathrm{cLEVEL}+\mathrm{cTL}+(1 \mid \mathrm{FISH})$ & 6 & -11.538 & 0.7 \\
\hline & & $\mathrm{PA} \sim 1+(1 \mid \mathrm{FISH})$ & 3 & -6.948 & \\
\hline \multirow[t]{4}{*}{ LME } & SU & KUD_50 cLEVEL + cTL, 1| FISH/MONTH & 6 & -87.34628 & \\
\hline & & KUD_50 1, 1| FISH/MONTH & 4 & -90.33165 & 0.6 \\
\hline & & KUD_95 cLEVEL + cTL, 1| FISH/MONTH & 6 & -55.06325 & 0.8 \\
\hline & & KUD_95 1, 1| FISH/MONTH & 4 & -58.61949 & \\
\hline \multirow[t]{2}{*}{ LMER } & $\mathrm{HAB}$ & HAB HABITAT + cLEVEL + cTL + (1| FISH) & 9 & -76.987 & $<0.001$ \\
\hline & & $\mathrm{HAB} \sim 1+(1 \mid \mathrm{FISH})$ & 3 & -0.24 & \\
\hline
\end{tabular}


Table S.3.10. Model output for age-0 Muskellunge in Buck Bay for presence/absence (PA), residency index (RI) and space use (SU) models in 2015. "Factor" highlights the variable used in the model, "ChiSqu" the value from the Anova() model, and the "P Value" indicates significant differences between the factor to the dependent model variable. No biological or environmental variables influenced spatial ecology in Buck Bay.

\begin{tabular}{llll} 
Model & Factor & $\mathbf{X}^{\mathbf{2}}$ & P Value \\
\hline PA & (Intercept) & & \\
& ctl & 0.8162 & 0.3663 \\
& clevel & 0 & 0.9974 \\
\hline RI & (Intercept) & 56.0807 & 0.000 \\
& clevel & 1.3015 & 0.254 \\
& ctl & 0.0517 & 0.820 \\
\hline SU_50 & (Intercept) & 697.3808 & $<2 \mathrm{e}-16$ \\
& ctl & 0.1358 & 0.713 \\
& clevel & 0.9037 & 0.342 \\
\hline SU_95 & (Intercept) & 2202.1689 & $<2 \mathrm{e}-16$ \\
& ctl & 0.2184 & 0.640 \\
& clevel & 0.2301 & 0.632 \\
\hline HAB & (Intercept) & 0.0711 & 0.7898 \\
& habitat & $\mathbf{2 2 9 . 1 4 8 1}$ & $<2 \mathrm{e}-16$ \\
& clevel & 0.2919 & 0.589 \\
& Ctemp & 0.1403 & 0.708 \\
& ctl & 0.2654 & 0.6064 \\
\hline
\end{tabular}


Table S.3.11. Model comparisons for age-0 Muskellunge in Grass Point Bay for presence/absence (PA), residency index (RI) and space use (SU) models between 2016 and 2017. "Formula" dictates the factors used in each model, the "AIC" value indicates which was lower, and the "p Value" shows whether the alternate model was significantly different. Formulas in bold indicate the alternative model was significantly different from the null model. Collinearity was the same for all models: 1 for cTL and 2 for each cLEVEL and cTEMP.

\begin{tabular}{|c|c|c|c|c|c|}
\hline Function & Model & Formula & df & AIC & p Value \\
\hline \multirow[t]{2}{*}{ GLMER } & PA & $\mathrm{PA} \sim \mathrm{cTEMP}+\mathrm{cLEVEL}+\mathrm{cTL}+(1 \mid \mathrm{FISH})$ & 5 & 26.659 & \\
\hline & & $\mathrm{PA} \sim 1+(1 \mid \mathrm{FISH})$ & 2 & 22.722 & 0.56 \\
\hline \multirow[t]{2}{*}{ LMER } & $\mathrm{RI}$ & RES $\sim$ cLEVEL + cTEMP + cTL + (1| FISH) & 6 & -33.185 & \\
\hline & & $\mathrm{RES} \sim 1+(1 \mid \mathrm{FISH})$ & 3 & -39.028 & 1 \\
\hline \multirow[t]{5}{*}{ LME } & SU & KUD_50 cTEMP + cLEVEL + cTL , 1| FISH/MONTH & 6 & -92.60082 & \\
\hline & & KUD_50 MONTH, 1 | FISH & 7 & -94.27143 & 0.06 \\
\hline & & KUD_50 1+(1| FISH) & 4 & -92.71965 & \\
\hline & & KUD_95 cTEMP + cLEVEL + cTL , 1| FISH/MONTH & 6 & -55.77731 & 0.42 \\
\hline & & KUD_95 1, 1| FISH/MONTH & 4 & -58.06800 & \\
\hline
\end{tabular}


Table S.3.12. Model output for age-0 Muskellunge in Grass Point Bay for presence/absence (PA), residency index (RI) and space use (SU) models for 2016 and 2017. "Factor" highlights the variable used in the model, "ChiSqu" the value from Anova models, and the "P Value" indicates significant differences between the factor to the dependent model variable. No biological or environmental variables influenced spatial ecology in Buck Bay.

\begin{tabular}{llrrr} 
Model & Factor & $\mathbf{X}^{2}$ & DF & \multicolumn{2}{c}{ P Value } \\
\hline PA & (Intercept) & 0.6744 & 1 & 0.412 \\
& ctl & 0.7329 & 1 & 0.392 \\
& clevel & 0.425 & 1 & 0.514 \\
& ctemp & 0.8479 & 1 & 0.357 \\
\hline RI & (Intercept) & 7.1342 & 1 & 0.007 \\
& ctemp & 0.2968 & 1 & 0.586 \\
& clevel & 2.9113 & 1 & 0.088 \\
& ctl & 0.0994 & 1 & 0.752 \\
\hline SU_50 & (Intercept) & 187.8358 & 1 & $<2 \mathrm{e}-16$ \\
& ctl & 0.0181 & 1 & 0.893 \\
& clevel & 0.2254 & 1 & 0.635 \\
& ctemp & 0.8094 & 1 & 0.368 \\
\hline SU_95 & (Intercept) & 649.2671 & 1 & $<2 \mathrm{e}-16$ \\
& ctl & 0.5354 & 1 & 0.464 \\
& clevel & 0.2847 & 1 & 0.593 \\
& ctemp & 0.0016 & 1 & 0.986 \\
\hline
\end{tabular}


Table S.3.13. Model comparisons for age-1 Northern Pike detected in Flynn Bay for presence/absence (PA), residency index (RI) and space use (SU) models between 2016 and 2017. "Formula" dictates the factors used in each model, the "AIC" value indicates which was lower, and the "p Value" shows whether the alternate model was significantly different. Formulas in bold indicate the alternative model was significantly different from the null model. Collinearity was the same for PA, RI and SU models: 1 for cTL and 2 for each cLEVEL and cTEMP. Collinearity for the habitat model was 1.308 (cLEVEL), 1.026 (cTL), and 1.34 (cTEMP).

\begin{tabular}{|c|c|c|c|c|c|}
\hline Function & Model & Formula & df & AIC & p Value \\
\hline \multirow[t]{2}{*}{ GLMER } & PA & $\mathrm{PA} \sim \mathrm{cTEMP}+\mathrm{cLEVEL}+\mathrm{cTL}+(1 \mid \mathrm{FISH})$ & 5 & 26.659 & \\
\hline & & $\mathrm{PA} \sim 1+(1 \mid \mathrm{FISH})$ & 2 & 22.722 & 0.56 \\
\hline \multirow[t]{2}{*}{ LMER } & $\mathrm{RI}$ & RES cLEVEL + cTEMP + cTL + (1| FISH) & 6 & -472.59 & \\
\hline & & RES 1 + (1| FISH) & 3 & -477.50 & 0.77 \\
\hline \multirow[t]{4}{*}{ LME } & SU & KUD_50 cTEMP + cLEVEL + cTL , 1| FISH/MONTH & 7 & -252.95 & 0.15 \\
\hline & & KUD_50 $1+(1 \mid \mathrm{FISH})$ & 4 & -252.34 & \\
\hline & & KUD_95 cTEMP + cLEVEL + cTL , 1| FISH/MONTH & 7 & -207.21 & 0.18 \\
\hline & & KUD_95 1, 1| FISH/MONTH & 4 & -213.34 & \\
\hline \multirow[t]{2}{*}{ LMER } & $\mathrm{HAB}$ & HAB HABITAT + cLEVEL + cTEMP + cTL + (1| FISH) & 8 & -350.54 & $<0.001$ \\
\hline & & $\mathrm{HAB} \sim 1+(1 \mid \mathrm{FISH})$ & 3 & -228.26 & \\
\hline
\end{tabular}


Table S.3.14. Model output for age-1 Northern Pike presence/absence (PA), residency index (RI) and space use (SU) models for 2016 and 2017. "Factor" highlights the variable used in the model, "ChiSqu" the value from Anova models, and the "P Value" indicates significant differences between the factor to the dependent model variable. Though cLEVEL was found a significant covariate to core space use, there was no difference between the null and alternate model.

\begin{tabular}{llrrr} 
Model & Factor & $\mathbf{X}^{2}$ & DF & \multicolumn{2}{c}{ P Value } \\
\hline PA & (Intercept) & 0.6744 & 1 & 0.412 \\
& ctl & 0.7329 & 1 & 0.392 \\
& clevel & 0.425 & 1 & 0.514 \\
& ctemp & 0.8479 & 1 & 0.357 \\
\hline RI & (Intercept) & 58.9521 & 1 & $<2 \mathrm{e}-16$ \\
& ctemp & 0.7672 & 1 & 0.381 \\
& clevel & 0.0008 & 1 & 0.977 \\
& ctl & 0.1028 & 1 & 0.787 \\
\hline \multirow{2}{*}{ SU_50 } & (Intercept) & 1305.8762 & 1 & $<\mathrm{e}-16$ \\
& ctemp & 2.4608 & 1 & 0.116 \\
& clevel & $\mathbf{6 . 1 0 7 8}$ & $\mathbf{1}$ & $\mathbf{0 . 0 1 3}$ \\
& ctl & 1.6436 & 1 & 0.200 \\
\hline & (Intercept) & 37.5081 & 1 & $<2 \mathrm{e}-16$ \\
& ctl & 0.2351 & 1 & 0.628 \\
& ctemp & 0.3366 & 1 & 0.562 \\
& clevel & 0.0976 & 1 & 0.755 \\
\hline HAB & (Intercept) & 2056.4869 & 1 & $<2 \mathrm{e}-16$ \\
& habitat & $\mathbf{2 5 2 . 7 2 9 2}$ & $\mathbf{2}$ & $<2 \mathrm{e}-16$ \\
& ctl & 0.1986 & 1 & 0.6559 \\
& ctemp & 0.6172 & 1 & 0.4321 \\
& clevel & $\mathbf{3 . 9 5 9 6}$ & $\mathbf{1}$ & $\mathbf{0 . 0 4 6 6}$ \\
\hline & & & &
\end{tabular}


Table S.3.15. Collinearity data (VIF) for presence/absence (PA), residency index (RI) and space use (SU) "Models" for age-1 Muskellunge in Rose Bay from October 2016 to March 2017. Habitat use was not modeled, as all fish used the same proportion of habitat features.

\begin{tabular}{llr} 
Model & Factor & \multicolumn{1}{l}{ VIF } \\
\hline PA & cTL & 1 \\
& cTEMP & 1.381751 \\
& cLEVEL & 1.381751 \\
\hline RI & cTL & 1 \\
& cTEMP & 1.381751 \\
& cLEVEL & 1.381751 \\
\hline SU_95 & cTL & 1 \\
& cTEMP & 1.503419 \\
& cLEVEL & 1.503419 \\
\hline
\end{tabular}


Table S.3.16. Model comparisons for age-1 Muskellunge detected in Rose Bay for presence/absence (PA), residency index (RI) and space use (SU) models between 2016 and 2017. "Formula" dictates the factors used in each model, the "AIC" value indicates which was lower, and the "p Value" shows whether the alternate model was significantly different. Formulas in bold indicate the alternative model was significantly different from the null model. Models were not performed on habitat use; all fish used the deep zone $>95 \%$ of the time.

\begin{tabular}{|c|c|c|c|c|c|}
\hline Function & Model & Formula & df & AIC & p Value \\
\hline \multirow[t]{2}{*}{ GLMER } & PA & PA cTEMP + cLEVEL + cTL + (1| FISH) & 5 & 37.478 & 0.01 \\
\hline & & $\mathrm{PA} \sim 1+(1 \mid \mathrm{FISH})$ & 2 & 37.234 & \\
\hline \multirow[t]{2}{*}{ LMER } & RI & $\mathrm{RES} \sim \mathrm{cLEVEL}+\mathrm{cTEMP}+\mathrm{cTL}+(1 \mid \mathrm{FISH})$ & 6 & -155.91 & \\
\hline & & $\mathrm{RES} \sim 1+(1 \mid \mathrm{FISH})$ & 3 & -156.65 & 0.15 \\
\hline \multirow[t]{2}{*}{ LME } & SU & KUD_95 cTEMP + cLEVEL + cTL , 1| FISH/MONTH & 7 & -128.54 & \\
\hline & & KUD_95 1+ (1| FISH) & 4 & -131.05 & 0.32 \\
\hline
\end{tabular}


Table S.3.17. Model output for age-1 Muskellunge presence/absence (PA), residency index (RI) and space use (SU) models from October 2016 to March 2017. "Factor" highlights the variable used in the model, "ChiSqu" the value from Anova models, and the "P Value" indicates significant differences between the factor to the dependent model variable. KUD_50 was 0.02 for all fish, therefore, no analysis was completed on this parameter. Models were not performed on habitat use; all fish used the deep zone $>95 \%$ of the time.

\begin{tabular}{lllll} 
Model & Factor & $\mathbf{X}^{\mathbf{2}}$ & $\mathbf{D F}$ & P Value \\
\hline PA & (Intercept) & 6.3791 & 1 & 0.012 \\
& ctl & $\mathbf{4 . 7 0 1 2}$ & $\mathbf{1}$ & $\mathbf{0 . 0 3 0}$ \\
& clevel & 2.2198 & 1 & 0.136 \\
& ctemp & 0.1874 & 1 & 0.665 \\
\hline RI & (Intercept) & 58.9521 & 1 & $<0.001$ \\
& ctemp & $\mathbf{0 . 7 6 7 2}$ & $\mathbf{1}$ & $\mathbf{0 . 0 2 1}$ \\
& clevel & 0.0008 & 1 & 0.240 \\
& ctl & 0.1028 & 1 & 0.839 \\
\hline SU_95 & (Intercept) & 2205.8749 & 1 & $<2 \mathrm{e}-16$ \\
& ctl & 1.3926 & 1 & 0.2380 \\
& ctemp & 0.0274 & 1 & 0.8686 \\
& clevel & 1.8538 & 1 & 0.1733 \\
\hline
\end{tabular}


Table S.3.18. Model output for age-1 Muskellunge presence/absence (PA), residency index (RI) and space use (SU) models from October 2016 to March 2017. "Factor" highlights the variable used in the model, "ChiSqu" the value from Anova models, and the "P Value" indicates significant differences between the factor to the dependent model variable. KUD_50 was 0.02 for all fish, therefore, no analysis was completed on this parameter.

\begin{tabular}{|c|c|c|c|c|c|c|c|c|}
\hline Species + Bay & Cohort & Model + Year & Parameter & Comparison & Estimate & St. Error & Z Value & P Value \\
\hline \multirow{3}{*}{ Northern Pike + Flynn } & \multirow{3}{*}{ Age-1 } & \multirow{3}{*}{$\mathrm{RI}+2015$} & \multirow{3}{*}{$\begin{array}{l}\text { Water Level } \\
\text { (meters) }\end{array}$} & $74.56-74.47$ & 0.14208 & 0.03947 & 3.600 & $<0.001$ \\
\hline & & & & $74.67-74.47$ & 0.20750 & 0.03947 & 5.258 & $<0.001$ \\
\hline & & & & $74.67-74.56$ & 0.06542 & 0.03947 & 1.658 & 0.22 \\
\hline \multirow{3}{*}{ Muskellunge + Rose } & \multirow{3}{*}{ Age-0 } & \multirow{3}{*}{$\mathrm{RI}+2015$} & \multirow{3}{*}{$\begin{array}{l}\text { Water } \\
\text { Temperature }\end{array}$} & $10.5-9.3$ & -0.06562 & 0.04929 & -1.331 & 0.378 \\
\hline & & & & $11.6-9.3$ & 0.10272 & 0.04696 & 2.188 & 0.073 \\
\hline & & & & $11.6-10.5$ & 0.16834 & 0.04948 & 3.403 & 0.002 \\
\hline \multirow{15}{*}{ Muskellunge + Rose } & \multirow{15}{*}{ Age-0 } & \multirow{15}{*}{$\mathrm{RI}+2016 / 17$} & \multirow{15}{*}{$\begin{array}{l}\text { Water } \\
\text { Temperature }\end{array}$} & $(-3.0)-(-3.2)$ & 0.05333 & 0.10536 & 0.506 & 1 \\
\hline & & & & $(-2.2)-(-3.2)$ & 0.04000 & 0.10536 & -0.380 & 1 \\
\hline & & & & $(-1.6)-(-3.2)$ & 0.04333 & 0.10536 & 0.411 & 1 \\
\hline & & & & $4.8-(-3.2)$ & 0.02000 & 0.10536 & 0.190 & 1 \\
\hline & & & & $9.9-(-3.2)$ & 0.42667 & 0.10536 & 4.050 & $<0.001$ \\
\hline & & & & $(-2.2)-(-3.0)$ & -0.09333 & 0.10536 & -0.886 & 0.95 \\
\hline & & & & $(-1.6)-(-3.0)$ & -0.01000 & 0.10536 & -0.095 & 1 \\
\hline & & & & $4.8-(-3.0)$ & -0.03333 & 0.10536 & -0.316 & 1 \\
\hline & & & & $9.9-(-3.0)$ & 0.37333 & 0.10536 & 3.543 & 0.005 \\
\hline & & & & $(-1.6)-(-2.2)$ & 0.08333 & 0.10536 & 0.791 & 0.97 \\
\hline & & & & $4.8-(-2.2)$ & 0.06000 & 0.10536 & 0.569 & 1 \\
\hline & & & & $9.9-(-2.2)$ & 0.46667 & 0.10536 & 4.429 & $<0.001$ \\
\hline & & & & $4.8-(-1.6)$ & -0.02333 & 0.10536 & -0.221 & 1 \\
\hline & & & & $9.9-(-1.6)$ & 0.38333 & 0.10536 & 3.638 & 0.003 \\
\hline & & & & $9.9-4.8$ & 0.40667 & 0.10536 & 3.860 & 0.002 \\
\hline
\end{tabular}




\section{Chapter 4. General Discussion}

My thesis sought to validate the use of mini-acoustic for age-0 Muskellunge by measuring biologically relevant endpoints, and to improve our basic understanding of age- 0 Muskellunge and Northern Pike spatial ecology to inform habitat restoration, spatial research studies, and water level management in the upper St. Lawrence River. In Chapter 2, captive reared, age-0 Muskellunge were subject to three treatments - tagged (sedated, laparotomy, mini-acoustic transmitter implantation), sham (sedated and laparotomy), and control (solely measured) - and their survival, tag retention, tag burden, incision healing, growth rates and flight initiation response post chemical anesthesia were assessed at specified sampling intervals over a four-month period. Chapter 3 focused on evaluating spatial ecology (i.e. presence, residency, space use) and habitat use of wild and stocked age-0 Muskellunge and free ranging age-0 Northern Pike overwinter and how environmental (e.g. water temperature and level) and biological (e.g. body size) parameters may influence spatial ecology based on passive-acoustic telemetry monitoring.

Research on the spatial ecology of earlier Muskellunge and Northern Pike life stages have primarily targeted summer, natal habitat uses (e.g. Leblanc et al. 2014, Farrell et al. 2014) and movement and dispersal of stocked fish in riverine systems (e.g. Wagner and Wahl 2011, Owensby et al. 2017). My thesis generated data which verified that mini-acoustic transmitter implantation is appropriate to conduct spatiotemporal studies on juvenile Muskellunge and in-situ results which supported the importance of environmental parameters on the fall and overwinter spatial ecology for age-0 Muskellunge and Northern Pike. Indeed, results elucidated that environmental parameters may drive fine-scale habitat segregation between the two species and provided a foundation on which future studies may tests hypotheses related to habitat restoration initiatives and riverine management associated with water level regulation. 
Although variation in array design between the seasons in which fish were tracked inherently limited the ability to compare spatiotemporal patterns, each design permitted comparisons in overall habitat feature use in relation to embayment geomorphology. Furthermore, age-0 Muskellunge are elusive, and due to declining stocks, sample sizes of Muskellunge tagged varied year-to-year, resulting in a low catch per unit effort and few fish to monitor. Future studies are encouraged to use a consistent array design to better compare, and to elucidate patterns associated with movement through network analyses using the current dataset on Rose Bay Muskellunge and Flynn Bay Northern Pike monitored in 2015. Despite design and sampling challenges, this research generated useful information associated with the winter phenology of juvenile Muskellunge and Northern Pike in a large riverine system near the northeastern extent of their sympatric range.

\subsection{Findings and Implications}

\subsubsection{Intracoelomic tagging and surgical process}

In Chapter 2, I assessed whether the surgical process and presence of acoustic tags associated with passive telemetry monitoring influenced short-term biology and behaviour. Specifically, I aimed to quantify several endpoints after fish underwent sedation, laparotomy, and intracoelomic implantation of mini-acoustic transmitters. My overall findings strongly suggest that the implantation process (e.g. laparotomy, suturing, presence of intracoelomic tag) do not impose issues on the short-term growth and survival of juvenile Muskellunge, though chemical sedation may cause lingering behavioural effects which could increase predation risk in their natural environment. All fish survived the surgical process and no fish died due to complications with tag presence (e.g. infection, starvation); the two mortalities in the study were due to tank escapement. Tag retention was $100 \%$ for all fish, and necropsies of the two tagged fish that escaped indicated tags did not move post-insertion, and rapid healing (30- to 60 -days) of the incision wounds likely attributed to tag retention. Tag burden was low $(<1 \%)$ at the start 
of the study, and without negative influence of process or tag on the growth of fish after four-months, burden progressively decreased.

Short-term healing rates between the free-ranging recapture and those Muskellunge retained in captivity were similar at 30-days post-surgery; however, captive reared Muskellunge implanted with an acoustic tag experienced significant increase in dehiscense (dermal rupture) after 60-days, concurrent with the lowest average water temperatures. Incisions of free-ranging Walleye (Sander vitreus), captured and tagged over five years in Lake Erie and Lake Huron between March and April, fully closed 62-days post-surgery (Schoonyan et al. 2017). To this end, increasing water temperatures in late spring (May, June) and higher water temperatures retained from summer in early fall (October) likely expedited wound closure and ejection of absorbable sutures (e.g. Walsh et al. 2000) in free-ranging fish. Indeed, no inflammation or dermal rupture were observed in the age-0 Muskellunge recaptured 30-days after its initial processing in the upper St. Lawrence River (Fig. S.13), and suture absorption had begun. Such rapid healing post-surgery in free-ranging fishes (e.g. Walsh et al. 2000, Schoonyan et al. 2017) was evident in both our free-ranging and hatchery reared juvenile Muskellunge, as wounds healed shortly after the 60-day period. Though control fish grew longer and heavier than sham and tagged fish the first week, as groups which underwent laparotomy may have allocated more energy to initiate wound closure to than somatic growth, specific growth rates of all treatment groups were similar after 120-days indicating no physical limitations (e.g. foraging capacity, somatic growth) associated with tag presence over this short-term period.

Reaction of fish to the moving object after initial exposure indicated that both tagged and sham fish experienced inhibited responses at different time scales. Tagged fish experienced a significantly inhibited response relative to sham and control fish immediately after chemical sedation, compared to sham fish's inhibited response seven-days beyond surgery. I postulate the inhibited response and reduced 
growth rates of sham fish between 7- and 30-days post-surgery may be associated with greater exposure to MS-222 and may be linked to decreased blood levels of $\mathrm{Na}^{+}, \mathrm{Ca}^{2+}$, and $\mathrm{K}^{+}$previously observed with increased MS-222 exposure in juvenile Chinook Salmon (Wagner et al. 2014). As blood plasma samples were not collected, this cannot be confirmed. The inhibited response by tagged fish suggests the potential for sublethal effects (e.g. predation) immediately post-recovery, signifying the need for interdisciplinary studies to link short-term behaviour, post-tag implantation, with physiology. Moreover, my results reiterate the importance of allowing fish to recover and testing for RAMP metrics (e.g., Raby et al. 2012) prior to release. MS-222 induced knock out times for hatchery fish were substantially reduced (2-minutes vs. 5-minutes) relative to their wild congeners in the upper St. Lawrence River, likely due to prior narcosis by electrosedation for the hatchery fish.

Validating the effects of surgical procedures, tag presence, and anesthetic exposure is necessary to reduce harm associated with processing and manipulating fish for spatiotemporal or mark recapture studies. It offers insight on how to adapt surgical procedures (i.e. electro-sedation) and whether telemetry tools (e.g. mini-acoustic transmitters) are appropriate to monitor juvenile Muskellunge in real-time.

\subsubsection{In-situ spatial ecology}

In Chapter 3, I explored the spatial ecology of juvenile Muskellunge and Northern Pike within their natal embayments during fall and winter periods. Specifically, I modeled presence/absence, residency, space and habitat use variables against environmental (water/air temperature and water levels) and biological (total length) parameters. My overall findings suggested that both environmental parameters measured play a complex yet critical role in the spatiotemporal patterns of juvenile esocids. There was no evidence of mortality throughout the fall and early winter in 2015 , or full $2016 / 17$ overwintering period based on detections, though lack of detection by several age-1 Muskellunge in Rose may suggest predation in late winter of 2016. 
Habitat use results suggest that, in fall and early winter periods, age-0 Northern Pike actively used nearshore habitats, close to deep littoral zones (i.e. similarly to age-1 Northern Pike, Farrell et al. 2014), as did age-0 Muskellunge, despite variation in Muskellunge embayment size, shape, and slope of the bay transitioning to deeper channel depths. As fish from either species seldom used their embayment mouths during flood events, I postulate they actively used shallow, littoral regions at high water levels. These regions are likely inhabitable in winter months when water levels recede due to river regulation; however, they may have fit the bill as appropriate winter habitat during a flood event - deeper, sandy littoral zones (relative to summer months) with a diversity of vegetation - negating the need to emigrate.

Due to the influence of environmental variables on spatial parameters, studying the impacts of the new IJC Plan 2014 on spatiotemporal patterns of juvenile (age-0-5) Muskellunge and Northern Pike is likely a worthwhile endeavour. Refining habitat use profiles is a key step to evaluated and measure essential habitat features within restored bays and may inform management considerations on the impact of altered water level regulation. Further, it may demonstrate future risk and efficacy of restoration and enhancement efforts (Langton et al. 1996). Research that targets overwintering habitat use in deeper (1.5 - 3 meters), littoral and limnetic regions as Plan 2014 commences may support and refine how these habitats are used with respect to more natural water level cycles. Moreover, results may either negate or encourage the need for restoration activities.

In a broader context, this study is the first to use acoustic telemetry to assess age-0 Muskellunge and Northern Pike spatiotemporal ecology in relation to fall and winter phenology in their northeastern range. This work is now part of a growing body of literature explicitly tailored to consider spatiotemporal patterns of juvenile fish to identify core habitat for riverine management and habitat restoration purposes. Such studies may further inform policy and provide science-based evidence for legislative protection (e.g. SARA critical habitat designation). 


\section{2: Future Research Opportunities}

This thesis validates the use of telemetry tools to study juvenile Muskellunge and frames the story of how age-0 Muskellunge and Northern Pike may be using their natal embayments overwinter. Such insights may advise animal care protocols regarding juvenile esocids and inform future research objectives targeting spatial ecology and behavioural interactions between these species across earlier stages. Finally, changes in winter phenology due to climate change may substantially alter habitat use and interactions between these congeneric predators.

Based on the results from Chapter 2, further investigation should establish the best immobilization method to surgically implant acoustic tags in juvenile esocids. Despite the fact that no fish died as a result of predation after varying MS-222 exposure times in the field study, delayed reactions to moving objects post varying exposure times to MS-222 suggest that alternate methods should be considered. Successful narcosis (immobilization for $<15$ minutes without physical damage) using 60 to 90-V pulsed DC was noted for age-0 Northern Pike (130-190 mm; Walker et al. 1994), juvenile hybrid Striped Bass (female Morone chrysops $\times$ male M. saxatilis; Trushenski and Bowker 2012), and other small fish species (i.e. Bluegill Lepomis macrochirus; Rous et al. 2015). A complementary study on stocked juvenile Muskellunge, tagged for spatiotemporal analysis or mark recapture programs, should use electro-sedation and quantify physiological and behavioural limitations relative to chemical anesthesia.

As environmental parameters were found to influence spatial ecology of juvenile esocids in Chapter 3, I propose a future study which determines overlap of core space use in deep, littoral microhabitats within and beyond natal embayments (e.g. along the St. Lawrence River shoreline) and compares this overlap to fine-scale variations in water level. Variation in micro-habitat use based on depth and vegetation may elucidate how these congeneric predators overlap in earlier life stages, prior 
to ontogenetic segregation, and the importance of these zones with respect to the nursery-role hypothesis (Beck et al. 2001). Continued, long-term monitoring may assess changes in sub-adult population estimates with respect to water level regulation to determine whether habitat restoration efforts are required to stimulate recruitment to sub-adulthood (Beck et al. 2001). Moreover, elucidating juvenile winter home ranges and the age and conditions under which their summer and winter ranges become established may fill knowledge gaps with respect to Muskellunge and Northern Pike natural history.

A longer-term study is further proposed to assess the spatial ecology of Muskellunge across life stages, from juvenile to adult. An expanded array, similar to those associated with Great Lakes Acoustic Telemetry Networking projects (Krueger et al. 2017), deployed from the point of outflow from Lake Ontario at Cape Vincent to Collins Landing, may elucidate successive movement patterns in association with ontogenetic change (juvenile to adult) and identify mechanisms that lead to the development of core summer and winter ranges in the Thousand Islands region. Such data may elucidate changes in reproductive strategies (e.g. Shuter et al. 2012) due to different extremes in winter conditions. Adverse environmental conditions are well-known to shape the physiological and behavioural strategies of fish (Shuter et al. 2012), and climatic changes (e.g. warming water temperatures) may impose spatiotemporal boundaries for Northern Pike (cool-water fish). A changing aquatic environment may further influence the energetic capacity of Muskellunge and, due to increased foraging efficiency (Shuter et al. 2012), alter how they distribute themselves with respect to winter habitat conditions and presence of Northern Pike during juvenile, sub-adult, and adult stages. Understanding the fundamental interactions between environmental parameters, space and habitat use, and movement patterns for each life stage may permit the development of a robust life-history based management framework (e.g. Nislow and Armstrong 2011); a key constituent needed to develop and implement stage-specific research objectives related to water level regulation and habitat restoration for esocids in the St. Lawrence River system. 


\section{References}

Acolas, M.L., Roussel, J.M., Lebel, J.M. \& Bagliniere, J.L. 2007. Laboratory experiment on survival, growth and tag retention following PIT injection into the body cavity of juvenile brown trout (Salmo trutta). Fisheries Research 86: 280-284.

Arlinghaus, R., Lorenzen, K., Johnson, B.M, Cooke, S.J. \& Cowx, I.G. 2016. Management of freshwater fisheries: addressing habitat, people and fishes. Freshwater Fisheries Ecology, Chapter 6.3, 557579.

Augustyn, E. 2017. Larval Northern Pike (Esox lucius) Ecology in Natural and Restored Coastal Wetlands of the Upper St. Lawrence River. Master's thesis, State University of New York College of Environmental Science and Forestry, Syracuse, New York.

Bates, D., Maechler, M., Bolker, B. \& Walker, S. 2015. Fitting Linear Mixed-Effects Models Using lme4. Journal of Statistical Software 67(1), 1-48.

Bivand, R., Keitt, T. \& Rowlingson, B. 2017. rgdal: Bindings for the 'Geospatial' Data Abstraction Library. R package version 1.2-16. https:/CRAN.R-project.org/package=rgdal

Bolker, B.M., Brooks, M.E., Clark, C.J., Geange, S.W., Poulsen, J.R., Stevens, M.H. \& White, J.S.S. 2009. Generalized linear mixed models: a practical guide for ecology and evolution. Trends in Ecology and Evolution 24: 127-35.

Bond, N. R. \& Lake, P. S. 2003. Characterizing fish-habitat associations in streams as the first step in ecological restoration. Austral Ecology 28(6), 611-621.

Beck, M.W., Heck, K.L., Able, K.W., Childers, D.L., Eggleston, D.B., Gillanders, B.M., Halpern, B., Hays, C.G., Hoshino, K., Minello, T.J., Orth, R.J., Sheridan, P.F. \& Weinstein, M.R. 2001. The identification, conservation, and management of estuarine and marine nurseries for fish and invertebrates. Bioscience 51: 633-641. 
Benitez-Lopez, A., Vinuela, J., Suarez, F., Hervas, I. \& Garcia, J.T. 2014. Niche-habitat mechanisms and biotic interactions explain the coexistence and abundance of congeneric sandgrouse species. Oecologia 176: 193-206.

Bruton, M. N. 1995. Have fishes had their chips? The dilemma of threatened fishes. Environmental Biology of Fishes 43(1), 1-27.

Burnham, K.P. \& Anderson, D.R.2004. Multimodel inference - understanding AIC and BIC in model selection. Sociological Method Research 33: 261-304.

Canadian Hydrograph Service Canada. 2017. Historical monthly mean water levels from coordinated network for each of the Great Lakes, Lake Ontario. http://www.tides.gc.ca/C\&A/network_means-eng.html

Calenge, C. 2006. The package adehabitat for the R software: a tool for the analysis of space and habitat use by animals. Ecological Modelling 197, 516-519.

Carmignani, J.R. \& Roy, A.H. 2017. Ecological impacts of winter water level drawdowns on lake littoral zones: a review. Aquatic Sciences 79: 803-824.

Carter, K.M., Woodley, C.M. \& Brown, R.S. 2011. A review of tricaine methanesulfonate for anesthesia of fish. Reviews in Fish Biology and Fisheries 21, 51-59.

Christensen, R. H. B. 2018. Ordinal - Regression Models for Ordinal Data. R package version 2018.

Colesante, R.R. \& Bubnack, J. 1992. Fingerling Muskellunge production in an intensive-extensive culture system in New York State. The Progressive Fish Culturalist 54(4), 243-246.

Cook, M.F. \& Solomon, R.C. 1987. Habitat Suitability Index Models: Muskellunge. Biological Report 82(10.148), Fish and Wildlife Service, U.S. Department of the Interior. 
Cooke, S.J., Graeb, B.D.S., Suski, C.D. \& Ostrand, K.G. 2003. Effects of suture material on incision healing, growth and survival of juvenile largemouth bass implanted with miniature radio tags: case study of a novice and experienced fish surgeon. Journal of Fish Biology 62: 1366-80.

Cooke, S.J., Woodley, C.M., Brad Eppard, M., Brown, R.S. \& Nielsen, J.L. 2011. Advancing the surgical implantation of electronic tags in fish: a gap analysis and research agenda based on a review of trends in intracoelomic tagging effects studies. Reviews in Fish Biology and Fisheries 21: $127-$ 151.

Cooke, S.J., Midwood, J.D., Thiem, J.D., Klimley, P., Lucas, M.C., Thorstad, E.B., Eiler, J., Holbrook, C. \& Ebner, B.C. 2013. Tracking animals in freshwater with electronic tags: past, present and future. Animal Biotelemetry 1: 5-5.

Cooke, S.J., Martins, E.G., Struthers, D.P., Gutowsky, L.F.G., Power, M., Doka, S.E., Dettmers, J.M., Crook, D.A., Lucas, M.C., Holbrook, C.M. \& Krueger, C.C. 2016. A moving targetincorporating knowledge of the spatial ecology of fish into the assessment and management of freshwater fish populations. Environmental Monitoring and Assessment 188: 1-18.

Cooper, J.E., Mead, J.V., Farrell, J.M. \& Werner, R.G. 2008. Potential effects of spawning habitat changes on the segregation of northern pike (Esox lucius) and muskellunge (E. masquinongy) in the Upper St. Lawrence River. Hydrobiologia 601: 41-53.

Cooper, J.E. 2016. Zooplankton density and diet composition of fish larvae in three bays in the upper St. Lawrence River. Chapter Four, Doctoral thesis, State University of New York College of Environmental Science and Forestry, Syracuse, New York.

Cowx, I. G. \& Gerdeaux, D. 2004. The effects of fisheries management practises on freshwater ecosystems. Fisheries Management and Ecology 11(3-4), 145-151. 
Crane, D.P., Miller, L.M., Diana, J.S., Casselman, J.M., Farrell, J.M., Kapuscinski, K.L. \& Nohner, J.K. 2015. Muskellunge and Northern Pike Ecology and Management: Important Issues and Research Needs. Fisheries 40: 258-267.

Crossman, E. J. 1986. The noble Muskellunge: a review. Pages 1-13 in G. E. Hall, editor. Managing muskies. American Fisheries Society, Special Publication 15, Bethesda, Maryland.

Cucherousset, J., Paillisoon, J.M., Cuzol, A. \& Roussel, J.M. 2009. Spatial behaviour of young-of-year northern pike (Esox lucius L.) in a temporality flooded nursery area. Ecology of Freshwater Fish 18: 314-322.

Cunjak, R.A. 1996. Winter habitat of selected stream fishes and potential impacts from land-use activity. Canadian Journal of Fisheries and Aquatic Sciences 53: 267-282.

Dahlgren, C.P., Kellison, G.T., Adams, A.J., Gillanders, B.M., Kendall, M.S., Layman, C.A., Ley, J.A., Nagelkerken, I. \& Serafy, J.E. 2006. Marine nurseries and effective juvenile habitats: concepts and applications. Marine Ecology Progress Series 312: 291-295.

DeBoom, C.S. \& Wahl, D.H. 2013. Effects of Coarse Woody Habitat Complexity on Predator Prey Interactions of Four Freshwater Fish Species. Transactions of the American Fisheries Society 142: 1602-1614.

Deters, K. A., Brown, R.S., Boyd, J.W., \& Seaburg, A.G. 2010. Optimal suturing technique and number of sutures for surgical implantation of acoustic transmitters in juvenile salmonids. Prepared for U.S. Army Corps of Engineers by Pacific Northwest National Laboratory, Richland, Washington.

Diana, J. S., Mackay, W.C. \& Ehrman, M. 1977. Movements and habitat preference of Northern Pike (Esox lucius) in Lac Ste. Anne, Alberta. Transactions of the American Fisheries Society 106: $560-565$. 
Dombeck, M.P. 1979. Movement and behaviour of the Muskellunge determined by radio telemetry. Wisconsin Department of Natural Resources. Technical Bulletin No. 113.

Donaldson, M.R., Hinch, S.G., Suski, C.D., Fisk, A.T., Heupel, M.R. \& Cooke, S.J. 2014. Making connections in aquatic ecosystems with acoustic telemetry monitoring. Frontiers in Ecology and the Environment 12: 565-573.

Dudgeon, D., A.H. Arthington, M.O. Gessner, Z-I. Kawabata, D.J. Knowler, C. Leveque, R.J. Naiman, A-H. Prieur-Richard, D. Soto, M.L.J. Stiassny, \& C.A. Sullivan. Freshwater biodiversity: importance, threats, status and conservation challenges. Biological Reviews, 81(2): 163-182.

Engstedt, O., Nilsson, J. \& Larsson. 2018. Chapter 10: Habitat restoration a sustainable key to management IN Skov, C. \& Anders Nilsson P. Biology and Ecology of Pike. CRC Press.

Environment and Natural Resource Canada. 2018. Weather, climate and hazard: past weather and climate, Kingston.

Espinoza, M., Cappo, M., Heupel, M.R., Tobin, A.J., \& Simpfendorfer, C.A. 2014. Quantifying shark distribution patterns and species-habitat associations: implications of marine park zoning. PLoS One 9:e106885.

ESRI. 2017. ArcMap 10.5.1. Redlands, California. http://www.esri.com.

Farrell, J.M., Werner, R.G., LaPan, S.R. \& Claypoole, K.A. 1996. Egg distribution and spawning habitat of northern pike and muskellunge in a St Lawrence River Marsh, New York. Transactions of the American Fisheries Society 125: 127-131.

Farrell, J.M. 1998. Population ecology of sympatric age-0 northern pike and muskellunge in the St. Lawrence River. Dissertation/Thesis: ProQuest Dissertations Publishing. 
Farrell, J.M. \& Werner, R.G. 1999. Distribution, Abundance, and Survival of Age-0 Muskellunge in Upper St. Lawrence River Nursery Bays. North American Journal of Fisheries Management 19: 309-320.

Farrell, J.M., Klindt, R.M., Casselman, J.M., LaPan, S.R., Werner, R.G. \& Schiavone, A. 2007. Development, implementation, and evaluation of an international muskellunge management strategy for the upper St Lawrence River. Environmental Biology of Fishes 79: 111-123.

Farrell, J.M., Holeck, K.T., Mills, E.L., Hoffman, C.E. \& Patil, V.J. 2010. Recent ecological trends in lower trophic levels of the international section of the St. Lawrence River: a comparison of the 1970s to the 2000s. Hydrobiologia 647: 21-33.

Farrell, J.M., Kapuscinski, K.L. \& Underwood, H.B. 2014. Fine scale habitat use by age-1 stocked Muskellunge and wild Northern Pike in an upper St. Lawrence River bay. Journal of Great Lakes Research 40: 148-153.

Farrell, J.M., R.G. Getchell, K.L. Kapuscinski, \& LaPan, S.R. 2017. Long-term Trends of St. Lawrence River Muskellunge: Effects of Viral Hemorrhagic Septicemia and Round Goby Proliferation Creates Uncertainty for Population Sustainability. American Fisheries Society Symposium 85: 275-301.

Fox, J. \& Weisberg, S. 2011. An $\{$ R $\}$ Companion to Applied Regression, Second Edition. Thousand Oaks CA: Sage. URL: http://socserv.socsci.mcmaster.ca/jfox/Books/Companion

Fry, F.E.J. 1971. The effect of environmental factors on the physiology of fish. Fish Physiology 1-98. Gallagher, A.J., Szekeres, P., Cooke, S.J., \& Farrell, J.M. 2018. Tracking age-0 Northern Pike and Muskellunge: monitoring behaviour and habitat use during fall and out-migration from nursery sites. Pages 167-170 IN Kapuncinski, K.L., Simonson, T.D., Crane, D.P., Kerr, S.J., Diana, J.S., \& Farrell, J.M, editors. Muskellunge management: fifty years of cooperation among anglers, 
scientists, and fisheries biologists. American Fisheries Society, Symposium 85, Bethesda, Maryland.

Gries, G. \& Letcher, B.H. 2002. Tag retention and survival of age-0 Atlantic salmon following surgical implantation with passive integrated transponder tags. North American Journal of Fisheries Management 22: 219-222.

Grimm, M.P. \& Backx, J. 1990. The restoration of shallow eutrophic lakes, and the role of Northern Pike, aquatic vegetation and nutrient concentration. Hydrobiologia 200: 557-566.

Guo, Z., Liu, J., Lek, S., Li, Z., Zhu, F., Tang, J. \& Cucherousset, J. 2014. Trophic niche differences between two congeneric goby species: evidence for ontogenetic diet shift and habitat use. Aquatic Biology 20: 23-33.

Hanson, D.A. \& Margenau, T.L. 1992. Movement, Habitat Selection, Behavior, and Survival of Stocked Muskellunge. North American Journal of Fisheries Management 12: 474-483.

Harvey, B. 2009. A biological synopsis of northern pike (Esox lucius). Canadian Manuscript Report of Fisheries and Aquatic Sciences. 2885: v $+31 \mathrm{p}$.

Holbrook, C., Hayden,T. \& Binder T. 2016. glatos: A packagr for the Great Lakes Acoustic Telemetry Observation System. R package version 0.2.3. https://gitlab.oceantrack.org/GreatLakes/glatos

Hollensead, L.D., Grubbs, R.D., Carlson, J.K. \& Bethea, D.M. 2016. Analysis of fine-scale daily movement patterns of juvenile Pristis pectinata within a nursery habitat. Aquatic ConservationMarine and Freshwater Ecosystems 26: 492-505.

Hothorn, T., Bretz, F. \& and Westfall, P. 2008. Simultaneous Inference in General Parametric Models. Biometrical Journal 50(3), 346-363. 
Hudon, C., Armellin, A., Gagnon, P. \& Patoine, A. 2010. Variations in water temperatures and levels in the St. Lawrence River (Quebec, Canada) and potential implications for three common fish species. Hydrobiologia 647: 145-161.

Hühn, D., Klefoth, T., Pagel, T., Zajicek, P. \& Arlinghaus, R. 2014. Impacts of External and SurgeryBased Tagging Techniques on Small Northern Pike Under Field Conditions. North American Journal of Fisheries Management 34, 322-334.

Humphries, N.E., Simpson, S.J., Wearmouth, V.J. \& Sims, D.W. 2016. Two's company, three's a crowd: fine-scale habitat partitioning by depth among sympatric species of marine mesopredator. Marine Ecology Progress Series 561: 173-187.

Hussey, N.E., Kessel, S.T., Aarestrup, K., Cooke, S.J., Cowley, P.D., Fisk, A.T., Harcourt, R.G., Holland, K.N., Iverson, S.J., Kocik, J.F., Flemming, J.E.M. \& Whoriskey, F.G. 2015. Aquatic animal telemetry: A panoramic window into the underwater world. Science 348.

Huusko, A., Greenberg, L., Stickler, M., Linnansaari, T., Nykanen, M., Vehanen, T., Koljonen, S., Louhi, P., \& Alfredson, K. Life in the ice land: the winter ecology of stream salmonids. River Research and Applications 23(5): 469-491.

Inskip, P.D. 1982. Habitat suitability index models: Northern Pike. U.S. Department of the Interior Fish and Wildlife Service. FWS/OBS-82/10.7 40 pp.

International Joint Commission. 2014. Lake Ontario St. Lawrence River Plan 201: Protecting against extreme water levels, restoring wetlands and preparing for climate change. < http://www.ijc.org/en /Plan2014/Report>.

Jackson, D.A., Peres-Neto, P.R. \& Olden, J.D. 2001. What controls who is where in freshwater fish communities - the roles of biotic, abiotic, and spatial factors. Canadian Journal of Fisheries and Aquatic Sciences 58: 157-170. 
Jepsen, N., Schreck, C.B., Clements, S. \& Thorstad, E.B. 2004. A brief discussion on the $2 \%$ tag/bodymass rule of thumb. In: Spedicato, M.T., Lembo, G., Marmulla, G., eds. Aquatic telemetry: advances and applications: proceedings of the fifth conference on fish telemetry held in Europe. Rome: FAO/COISPA, pp. 255-259.

Kapuscinski, K.L., Farrell, J.M. \& Murry, B.A. 2012. Feeding Strategies and Diets of Young-of-theYear Muskellunge from Two Large River Ecosystems. North American Journal of Fisheries Management 32: 635-647.

Kapuscinski, K.L. \& Farrell, J.M. 2014. Habitat factors influencing fish assemblages at muskellunge nursery sites. Journal of Great Lakes Research 40: 135-147.

Kelso, J.R.M., \& Hartig, J.H. 1995. Methods of modifying habitat to benefit the Great Lakes ecosystem. Canadian Institute of Science and Technical Information, National Research Council Canada.

Klinard, N.V, Halfyard, E.A., Fisk, A.T., Stewart, T.J., \& Johnson, T.B. (2018). Effects of Surgically Implanted Acoustic Tags on Body Condition, Growth, and Survival in a Small Laterally Compressed Forage Fish. Transactions of the American Fisheries Society, DOI: 10.1002/tafs. 10064 .

Koppelman, J. B., \& Philipp D.P. 1986. Genetic applications in Muskellunge management. Pages 111121 in G. E. Hall, editor. Managing muskies. American Fisheries Society, Special Publication 15, Bethesda, Maryland.

Krueger, C., Holbrook, C.M., Binder, T.R., Vandergoot, C., Hayden T.A., Hondrop, D.W., Nate, N., Paige, K., Riley, S.C., Fish, A.T. \& Cooke. S.J. Acoustic Telemetry Observation System: challenges encountered and overcome in the Laurentian Great Lakes. Canadian Journal of Fisheries and Aquatic Sciences, DOI: 10.1139/cjfas-2017-0406. 
Lacroix, G.L., Knox, D. \& McCurdy, P. 2004. Effects of implanted dummy acoustic transmitters on juvenile Atlantic salmon. Transactions of the American Fisheries Society 133: 211-220.

LaPan, S.R., Schiavone, A. \& Werner, R.G. 1996. Spawning and post-spawning movements of the St. Lawrence River muskellunge (Esox masquinongy) IN Kerr, S.J., \& Olver, C.H, editors. Managing Muskies in the 90's. Workshop proceedings. OMNR, Southern Region Science and Technology Transfer Unit WP-007, pp 73-82.

Leblanc, J.P., Weller, J.D. \& Chow-Fraser, P. 2014. Thirty-year update: Changes in biological characteristics of degraded muskellunge nursery habitat in southern Georgian Bay, Lake Huron, Canada. Journal of Great Lakes Research 40: 870-878.

Lédée, E.J.I., Heupel, M.R., Tobin, A.J., Knip, D.M. \& Simpfendorfer, C.A. 2015. A comparison between traditional kernel-based methods and network analysis: an example from two nearshore shark species. Animal Behaviour 103: 17-28.

Lenth, R.V. 2016. Least-Squares Means: The R Package 1smeans. Journal of Statistical Software, 69(1), $1-33$.

Lucas, M.C. \& Baras, E. 2000. Methods for studying spatial behaviour of freshwater fishes in the natural environment. Fish and Fisheries 1: 283-316.

Lynch, A.J., Cooke, S.J., Deines, A.M., Bower, S.D., Bunnell, D.B., Cowx, I.G., Nguyen, V.M., Nohner, J., Phouthavong, K., Riley, B., Rogers, M.W., Taylor, W.W., Woelmer, W., Youn, S.J. \& Beard, T.D., Jr. 2016. The social, economic, and environmental importance of inland fish and fisheries. Environmental Reviews 24: 115-121.

McMichael, G.A., Eppard, M.B., Carlson, T.J., Carter, J.A., Ebberts, B.D., Brown, R.S., Weiland, M., Ploskey, G.R., Harnish, R.A. \& Deng, Z.D. 2010. The Juvenile Salmon Acoustic Telemetry System: A New Tool. Fisheries 35: 9-22. 
Midwood, J.D., Kerr, S.J., Levick, P. \& Cooke, S.J. 2015. Conference report: muskellunge science and management: progress through partnerships. Environmental Biology of Fishes 98: 2031-2035.

Murry, B.A. \& Farrell, J.M. 2007. Quantification of native muskellunge nursery habitat: influence of body size, fish community composition, and vegetation structure. Environmental Biology of Fishes 79: 37-47.

NYS Information Technology Services. 2016. Orthoimagery: Jefferson County. NYS GIS Clearinghouse. $<$ http://gis.ny.gov/gateway/mg/>.

Owensby, D.P., Rice, J.A. \& Aday, D.D. 2017. Mortality, Dispersal, and Habitat Use of Stocked Juvenile Muskellunge in Two Western North Carolina Rivers. North American Journal of Fisheries Management 37: 108-121.

Panther, J.L., Brown, R.S., Gaulke, G.L., Deters, K.A., Woodley, C.M. \& Eppard, M.B. 2011. Influence of Incision Location on Transmitter Loss, Healing, Survival, Growth, and Suture Retention of Juvenile Chinook Salmon. Transactions of the American Fisheries Society 140: 1492-1503.

Pierce, R.B., Carlson, A.J., Carlson, B.M., Hudson, D. \& Staples, D.F. 2013. Depths and Thermal Habitat Used by Large versus Small Northern Pike in Three Minnesota Lakes. Transactions of the American Fisheries Society 142: 1629-1639.

Pinheiro, J.C. \& Chao, E.C. 2006. Efficient Laplacian and adaptive Gaussian quadrature algorithms for multilevel generalized linear mixed models. Journal of Computational Graphic Statistics 15: 5881.

Pinheiro, J., Bates, D., DebRoy, S., Sarkar, D., \& R Core Team. 2018. nlme: Linear and Nonlinear Mixed Effects Models. R package version 3.1-137. 
Raby, G. D., Donaldson, M. R., Hinch, S. G., Patterson, D. a., Lotto, A. G., Robichaud, D., \& Cooke, S. J. 2012. Validation of reflex indicators for measuring vitality and predicting the delayed mortality of wild coho salmon bycatch released from fishing gears. Journal of Applied Ecology, 49(1), 9098.

Ricciardi, A. \& Rasmussen, J. B. (1999). Extinction rates of North American freshwater fauna. Conservation Biology 13(5), 1220-1222.

Richard, A., O'Rourke, J., Caudron, A. \& Cattaneo, F. 2013. Effects of passive integrated transponder tagging methods on survival, tag retention and growth of age-0 brown trout. Fisheries Research 145: $37-42$.

Ricker, W.E. 1975. Computation and interpretation of bio- logical statistics of populations. Bulletin of Fisheries Research Board of Canada 191. 382 pp.

Rooney, S.M., Wolfe, A. \& Hayden, T.J. 1998. Autocorrelated data in telemetry studies: time to independence and the problem of behavioural effects. Mammal Review 28: 89-98.

Rosenfeld, J. 2003. Assessing the Habitat Requirements of Stream Fishes: An Overview and Evaluation of Different Approaches. Transactions of the American Fisheries Society 132: 953-968.

Rous, A.M, Forrest, A., McKittrick, E.H, Letterio, G., Roszel, J., Wright, T. \& Cooke, S.J. 2015. Orientation and Position of Fish Affects Recovery Time from Electrosedation, Transactions of the American Fisheries Society 144:4, 820-828.

RStudio Team (2016). RStudio: Integrated Development for R. RStudio, Inc., Boston, MA URL http://www.rstudio.com/.

Rybicki, N.B. \& Carter, V. 1986. Effect of sediment depth and sediment type on the survival of Vallisneria americana Michx grown from tubers. Aquatic Botany 24: 233-240. 
Scott, W.B. and E.J. Crossman, 1998. Freshwater fishes of Canada. Oakville, Ontario, Canada: Galt House Publications. 966 p.

Schielzeth, H. 2010. Simple means to improve the interpretability of regression coefficients. Methods in Ecology and Evolution 1: 103-13.

Schoonyan, A., Kraus, R., Faust, M., Vandergoot, C., Cooke, S., Cook, H., Hayden, T. \& Krueger, C. 2017. Estimating incision healing rate for surgically implanted acoustic transmitters from recaptured fish. Figshare.

Shuchman, R.A., Sayers, M.J. \& Brooks, C.N. 2013. Mapping and monitoring the extent of submerged aquatic vegetation in the Laurentian Great Lakes with multi-scale satellite remote sensing. Journal of Great Lakes Research 39: 78-89.

Shuter, B.J., Finstad, A.G., Helland, I.P., Zweimuller, I. \& Holker, F. 2012. The role of winter phenology in shaping the ecology of freshwater fish and their sensitives to climate change. Aquatic Sciences, 74: 637-657.

Silva, T.S.F., Costa, M.P.F., Melack, J.M. \& Novo, E. 2008. Remote sensing of aquatic vegetation: theory and applications. Environmental Monitoring and Assessment 140: 131-145.

Silverman, B.W. 1986. Density estimation for statistics and data analysis. Monographs on Statistics and Applied Probability, London: Chapman and Hall.

Simpfendorfer, C.A., Heupel, M.R., \& Hueter, R.E. 2002. Estimation of short-term centers of activity from an array of omnidirectional hydrophones and its use in studying animal movements. Canadian Journal of Fisheries and Aquatic Sciences 59: 23-32.

Simpfendorfer, C.A., Wiley, T.R. \& Yeiser, B.G. 2010. Improving conservation planning for an endangered sawfish using data from acoustic telemetry. Biological Conservation 143: 14601469. 
Skalski, J.R., Lady, J., Townsend, R., Giorgi, A.E., Stevenson, J.R., Peven, C.M. \& McDonald, R.D. 2001. Estimating in-river survival of migrating salmonid smolts using radiotelemetry. Canadian Journal of Fisheries and Aquatic Sciences 58: 1987-1997.

Smith, B.M., Farrell, J.M., Underwood, B. \& Smith, S.J. 2007. Year-class formation of upper St. Lawrence River Northern pike. North American Journal of Fisheries Management 2: 481-491.

Sone, S., Inoue, M. \& Yanagisawa, Y. 2001. Habitat use and diet of two stream gobies of the genus Rhinogobius in south-western Shikoku, Japan. Ecological Research 16: 205-219.

Sunrise Sunset. 2018. Clayton New York sunrise and sunset. https://sunrise-sunset.org/us/clayton-ny

Tiffan, K.F., Perry, R.W., Connor, W.P., Mullins, F.L., Rabe, C.D. \& Nelson, D.D. 2015. Survival, Growth, and Tag Retention in Age-0 Chinook Salmon Implanted with 8-, 9-, and 12-mm PIT Tags. North American Journal of Fisheries Management 35: 845-852.

Thorp, J.H., Lamberti, G.A., \& Casper, A.F. 2005. Chapter 21: St. Lawrence River basin. Rivers of Northern America Academic Press, 983-1028.

Thorstad, E.B., Rikardsen, A.H., Alp, A. \& Okland, F. 2013. The Use of Electronic Tags in Fish Research - An Overview of Fish Telemetry Methods. Turkish Journal of Fisheries and Aquatic Sciences 13: 881-896.

Trushenski JT, Bowker JD. 2012. Effect of voltage and exposure time on fish response to electrosedation. Journal of Fish and Wildlife Management 3(2):276-287; e1944-687X.

Turnquist; K. N., Wesley L., Farrell, J.M., Hanchin, P.A., Kapuscinski; K.L., Miller, L.M, Scribner, K.T., Wilson, C.C., \& Sloss, B.L. 2017. Genetic structure of muskellunge in the Great Lakes region and the effects of supplementation on genetic integrity of wild populations. Journal of Great Lakes Research 43(6): 1141-1152. 
Van Winkle, W. 1975. Comparison of several probabilistic home-range models. Journal of Wildlife Management 39(1): 118-123.

Walsh, M.G., Bjorgo, K.A. \& Isely, J.J. 2000. Effects of implantation method and temperature on mortality and loss of simulated transmitters in hybrid striped bass. Transactions of the American Fisheries Society 129: 539-544.

Wand, M.P. \& Jones, M.C. 1995. Kernel Smoothing. Chapman and Hall, London.

Wagner, C.P., Jennings, M.J., Kampa, J.M. \& Wahl, D.H. 2007. Survival, growth, and tag retention in age-0 Muskellunge implanted with passive integrated transponders. North American Journal of Fisheries Management 27: 873-877.

Wagner, C.P. \& Wahl, D.H. 2011. Movement, home range and habitat selection of stocked juvenile muskellunge, Esox masquinongy, in Forbes Lake, Illinois: exploring the effects of latitudinal origin: latitudinal influence on muskellunge management. Fisheries Management and Ecology 18: 482-496.

Wagner, K.A., Woodley, C.M., Seaburg, A.G., Skalski, J.R. \& Eppard, M.B. 2014. Physiological Stress Responses to Prolonged Exposure to MS-222 and Surgical Implantation in Juvenile Chinook Salmon. North American Journal of Fisheries Management 34: 863-873.

Walsh, M.G., Bjorgo, K.A \& Isely, J.J. 2000. Effects of implantation method and temperature on mortality and loss of simulated transmitters in hybrid striped bass. Transactions of the American Fisheries Society 2: 539-544.

Ward, T. D., J. W. Brownscombe, L. F. G. Gutowsky, R. Ballagh, N. Sakich, D. McLean, G. Quesnel, S. Gambhir, C. M. O’Connor, and S. J. Cooke. 2017. Electric fish handling gloves provide effective immobilization and do not impede reflex recovery of adult largemouth bass. North American Journal of Fisheries Management 37: 652-659. 
Wilson, C.C., Liskauskas, A.P. \& Wozney, K.M., 2016. Pronounced genetic structure and site fidelity among native muskellunge populations in Lake Huron and Georgian Bay. Transactions of the American Fisheries Society 145: 1290-1302.

Winter, J. M. 1983. Underwater biotelemetry. Pages 371-395 in L. A. Nielsen and D. L. Johnson, editors. Fisheries techniques. American Fisheries Society, Bethesda, Maryland.

Wolter, P.T., Johnston, C.A. \& Niemi, G.J. 2005a. Mapping submergent aquatic vegetation in the US Great Lakes using Quickbird satellite data. International Journal of Remote Sensing 26: 52555274.

Woodside, K. 2009. Development and application of models predicting young of year Muskellunge presence and abundance from nursery features. Master's thesis, State University of New York College of Environmental Science and Forestry, Syracuse, New York.

Younk, J.A., Cook, M. F., Goeman, T.J., \& Spencer, P.D. 1996. Seasonal habitat use and movement of Muskellunge in the Mississippi River. Minnesota Department of Natural Resources. Investigational Report 449.

Younk, J.A., Herwig, B.R. \& Pittman, B.J. 2010. Short- and Long-Term Evaluation of Passive Integrated Transponder and Visible Implant Elastomer Tag Performance in Muskellunge. North American Journal of Fisheries Management 30: 281-288.

Zuur, A.F., Ieno, E.N., \& Elphick, C.S. 2010. A protocol for data exploration to avoid common statistical problems. Methods in Ecology and Evolution 1: 3-14. 